\title{
Manuela Spindler
}

\section{International Relations}

A Self-Study Guide to Theory

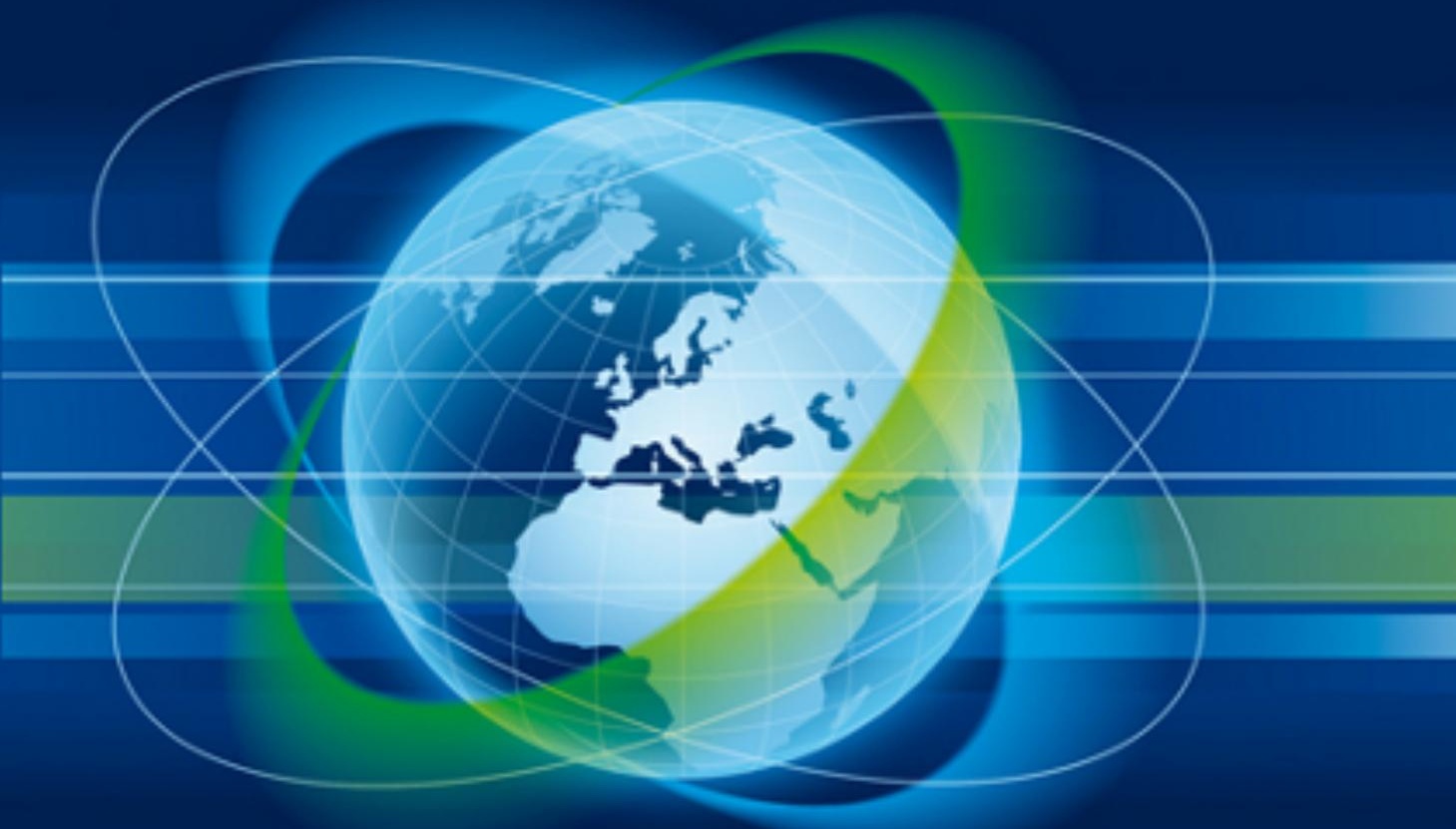

Barbara Budrich Publishers 


\section{Manuela Spindler International Relations}


Manuela Spindler

\section{International Relations}

A Self-Study Guide to Theory

Barbara Budrich Publishers

Opladen • Berlin • Toronto 2013 
An electronic version of this book is freely available, thanks to the support of libraries working with Knowledge Unlatched. KU is a collaborative initiative designed to make high quality books Open Access for the public good. The Open Access ISBN for this book is 978-3-86649-550-0. More information about the initiative and links to the Open Access version can be found at www.knowledgeunlatched.org

(C) 2013 This work is licensed under the Creative Commons Attribution-ShareAlike 4.0. (CCBY-SA 4.0)

It permits use, duplication, adaptation, distribution and reproduction in any medium or format, as long as you share under the same license,

give appropriate credit to the original author(s) and the source, provide a link to the Creative Commons license and indicate if changes were made.

To view a copy of this license, visit https://creativecommons.org/licenses/by-sa/4.0/

(C) 2013 Dieses Werk ist beim Verlag Barbara Budrich GmbH erschienen und steht unter der Creative Commons Lizenz Attribution-ShareAlike 4.0 International (CC BY-SA 4.0): https://creativecommons.org/licenses/by-sa/4.0/

Diese Lizenz erlaubt die Verbreitung, Speicherung, Vervielfältigung und Bearbeitung bei Verwendung der gleichen CC-BY-SA 4.0-Lizenz und unter Angabe der UrheberInnen, Rechte, Änderungen und verwendeten Lizenz.

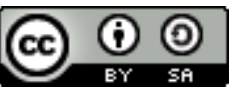

This book is available as a free download from www.barbara-budrich.net (https://doi.org/10.3224/84740005). A paperback version is available at a charge.

The page numbers of the open access edition correspond with the paperback edition.

$\begin{array}{ll}\text { ISBN } & 978-3-8474-0005-9 \text { (paperback) } \\ \text { eISBN } & 978-3-86649-550-0 \text { (PDF) } \\ \text { DOI } & 10.3224 / 84740005\end{array}$

Verlag Barbara Budrich GmbH

Stauffenbergstr. 7. D-51379 Leverkusen Opladen, Germany

86 Delma Drive. Toronto, ON M8W 4P6 Canada

www.barbara-budrich.net

A CIP catalogue record for this book is available from

Die Deutsche Bibliothek (The German Library) (http://dnb.d-nb.de)

Jacket illustration by disegno, Wuppertal, Germany - www.disenjo.de

Typesetting: R + S, Redaktion + Satz Beate Glaubitz, Leverkusen, Germany 


\section{Manuela Spindler}

\section{International Relations \\ A Self-Study Guide to Theory}

\section{Preface}

The book is written for active learners - those keen on cutting their own path through the complex and at times hardly comprehensible world of THEORY in International Relations. Learning and studying is an active process that requires a great deal of self-organization. To aid this process as much as possible, this book employs the didactical and methodical concept of integrating teaching and self-study. It will do so by offering a structured concept for learning about theories of International Relations, the application of which will be demonstrated in the book. The intention behind this concept is to enable students to subsequently apply the concept themselves when learning about theory and theories of International Relations. In an attempt to be as learner-oriented as possible, the book will offer advice and guidance on studying IR theory by integrating self-study instructions throughout the text. The book also requires readiness to look at phenomena from different perspectives, to critically question teaching and learning contents and to actively engage in critical debates and share knowledge. In order to meet these learning challenges adequately, readers should expect to set aside at least twice as much time for self-study as they will spend reading the book.

The criteria for structured learning about IR theory will be derived from an extensive discussion of the questions and problems of philosophy of science (Part 1 of the book). This is because the learning objective of the book is NOT to learn about particular theories of IR (such as Neo-Institutionalist or New Liberal Theory) as is the case in most of the textbooks on IR theories, but to learn about THEORY itself. Theory of IR refers to the scientific study of IR and covers all of the following subtopics: the role and status of theory in the academic discipline of IR; the understanding of IR as a science and what a "scientific" theory is; the different assumptions upon which theory 
building in IR is based; the different types of theoretical constructions and models of explanations found at the heart of particular theories; and the different approaches taken on how theory and the practice of international relations are linked to each other.

The criteria for the structured learning process will be applied in Part 2 of the book during the presentation of five selected theories of International Relations. The concept is based on "learning through example" - that is, the five theories have been chosen because, when applying the criteria developed in Part 1 of the book, each single theory serves as an example for something deeply important to learn about THEORY of IR more generally. The presentation of those five theories will be based on the concept of a reference author. Each will be presented using the coherent body of theoretical work done by a single accepted representative of the theoretical strand and structured according the criteria derived from Part 1. The concept of a reference author has also been successfully applied in a textbook introducing eighteen theories of IR (Schieder/Spindler 2010 and Schieder/Spindler 2013, forthcoming). Readers interested in learning more about particular theories of IR might find it helpful to read not only this book on THEORY but to also combine it with the textbook by Schieder/Spindler (2013) and other works that provide more specific introductions to the large number of individual IR theories. You will find the titles in the reference section at the end of the book.

In short, the focus of this book is not on the five theories themselves but rather on what they stand for in terms of philosophy of science. Most important are the insights that their analysis through the philosophical lenses can provide for our understanding of the role and function of theory more generally.

By the end of the book, the learning method should have enabled students to apply the philosophy of science criteria - the guide to a structured learning process - to any specific theory of their interest as well as to their own theoretical work. They should also be able to engage in a critical discussion on the topic of International Relations as a science.

The two parts of the book are divided into nine learning units altogether four in Part 1 and five in Part 2. Each learning unit usually consists of three to seven learning steps, including a summary of key aspects, a range of review questions and, in general, two to four self-study instructions integrated into the text. At the end of each unit are recommendations for required and supplementary reading.

The book is written in a communicative style that aims to replicate "a conversation". For the more auditory learners among you, an audio CD based on the book will be released soon. 
In each unit, there will be several summaries in the text as well as key aspects listed at the end. However, when reading, please also be aware of and concentrate on the words and phrases in italic type and bold print that highlight particularly relevant issues and terms.

It is the very nature of the book to present "thought in progress". In line with the learner-oriented concept introduced above, the book will not finish with a conclusion or any fixed "outcome". As a result of the integrated selfstudy parts, your learning progress will be geared to your own individual pace and will depend greatly on how you linked and applied what you have learned to additional readings. Instead of providing a conclusion, the book will finish by formulating a range of questions on IR as a science that are meant to stimulate and invite you to actively engage in further discussion. For this purpose, the book is linked to a course on iversity (iversity.org) where you will find additional information and useful links as well as opportunities to share your knowledge and to engage in discussions in a range of working groups on different aspects of IR theory. For admission to the course, please send an email with a short statement about your interests to SpindlerIRTheory-Book@yahoo.de.

Last but not least, I would like to give thanks to a range of people for their support of the book project. My first and special thanks goes to Alexandra Skinner (alexandraskinner.edit@gmail.com) for making the text a much more readable book through her careful and thoughtful language editing. Beyond that, I am indebted to the students of my IR Theory and Philosophy of Science classes at the University of Erfurt and the Brandt School of Public Policy as well as to the $\mathrm{PhD}$ candidates attending my courses on MacroTheoretical Approaches to International Relations at the Graduate School of Global Politics at the Free University of Berlin for their test-reading of selected chapters of Part 2 of the book. Among the latter group, my special thanks goes to Jost Wübbeke for his detailed and helpful comments on Part 1 and to Daniel Cardoso, Philani Mthembu and Miguel Verde for their comments on Unit 9.

Responsibility for mistakes and misrepresentations is mine alone and I am happy to receive any comments and advice that will help to make this a better book.

Berlin, March 2013 



\section{Contents}

Preface

Part I: International Relations' Theory

1. History of theoretical thought on inter-state relations and the formation of "International Relations" as an academic discipline ...

2. International Relations as science ................................................. 36

3. World views and the idea of science in the history of European philosophy

4. Didactics and method

Part II: Theories of International Relations: Five Approaches

5. Neorealist theory

6. Neoinstitutionalist theory

7. New liberal theory

8. World-systems analysis

9. Social constructivist theory 

Part I:

International Relations' Theory 



\section{History of theoretical thought on inter-state relations and the formation of "International Relations" as an academic discipline}

Learning steps

Introduction

Step 1:

International Relations from an historical perspective: Interstate theory and discipline formation

1.1 A social and political "need" for a theory of interstate relations ........... 15

Greek Antiquity .................................................................................... 17

The European Middle Ages ................................................................... 17

The Modern Age .............................................................................. 18

Summary ........................................................................... 20

1.2. The "birth" of the discipline in 1919: Institutionalization and

International Relations as Science ......................................................... 21

Institutionalization of IR as an academic discipline ............................... 22

International Relations as science ............................................................ 23

Step 2:

The core subject of International Relations and International

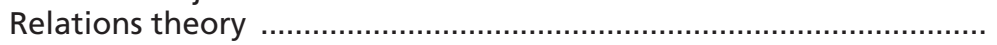

2.1. The modern sovereign state and international relations in the modern states system

2.2. Politics "inside" the modern state: the allocation of societal values as the core function of the state

2.3. Politics "outside" the modern state: the politics of international relations

2.4. Summary and conclusion ................................................................ 30

Step 3:

Check your understanding: key aspects and review questions

Step 4:

Self-study and consolidation 


\section{Introduction}

Systematic and methodical reflections about international relations and therefore "theory" and "methods" are core criteria to be applied when discussing the "birth" of an academic discipline. However, tracing the formation of the discipline "International Relations" back in history is not an easy undertaking, as a great deal of controversy exists over the actual "birthday" of International Relations as an academic discipline.

This controversy has much to do with the status of "theory" within the discipline. Does an academic discipline start once there is historical evidence of theoretical reflections on the core subject? Do we need additional criteria to think of a new discipline, such as the existence of departments or some sort of "infrastructure" where theoretical reflection, research and academic teaching take place?

Academic discipline formation in the field of International Relations cannot be meaningfully discussed without some deeper knowledge of the history of political thought on interstate relations. Step 1 of this unit will introduce readers to the history of International Relations theory. This will not merely take the form of a descriptive account of the history of thought on interstate relations. Rather, the process of tracing back the history of ideas on international relations will be guided by the thesis that any theoretical reflections strongly depend on and are part of real-world (international) politics. The history of International Relations theory is closely tied to the history of the European states system. It is crucial for our understanding of IR theory to know when and why theoretical reflections on interstate relations emerged in history. Therefore, Step 1 will introduce a specific account of the history of IR theory. It will be complemented by a perspective on the discipline's formation after World War I, or in other words, a focus on its institutional development with the first departments and chairs of International Relations and the new understanding of International Relations as a "science", requiring a scientific study of interstate relations.

Step 2 will make a suggestion to students as to how to discuss the core subject of International Relations conceptually. Conclusions will be drawn for further discussions of the role and function of theory in International Relations.

These three aspects of the first learning unit - a basic understanding of the discipline's development and its core subject, together with an initial understanding of how the core subject is studied - are essential preconditions for enlarging upon the scientific study of IR and scientific IR theory in the next step (Part 1, Unit 2). 
Before we start to learn more about the academic discipline of International Relations, we have to reach a consensus on how to use the terminology at the core of our first learning unit (and throughout the book) in order to avoid any misunderstanding.

The term International Relations (IR as the abbreviation, in capital letters) refers to the academic discipline. Sometimes the discipline is called International Politics, International Studies, World Politics or Global Politics.

International relations or international politics (lower case) is the term used for the core subject of the academic discipline. That is, international relations/international politics are the "real world-processes" and thus the subject to study by IR as an academic discipline (or international politics, world politics or global politics, if you prefer). For the scholarship that analyzes those "real-world-processes" you will sometimes also find the abbreviation SIR in textbooks, that is, scholarship or the study of international relations.

Throughout the book, you will find the conventional term "International Relations" referring to the academic discipline. For the theory within this academic discipline (International Relations theory), the abbreviation "IR theory" is used.

\section{Step 1: \\ International Relations from an historical perspective: Interstate theory and discipline formation}

\subsection{A social and political "need" for a theory of interstate relations}

The thesis of a strong linkage between real-world (international) political relations and the systematic theoretical reflection on interstate relations will be at the heart of the specific account of the history of IR theory. It is derived from a central argument in the writings of Andreas Osiander (1994, 1996, 2008), a German political scientist and historian. He provides a "needsoriented" view of International Relations theory that is worth discussing in more detail for the purpose of our first learning unit.

At the core of Osiander's writing about the history of thought in International Relations lies the basic argument that political thought is always "needsoriented". It is the concerns that are of primary importance to society that cause a "need" for theoretical reflection (Osiander 1996: 43). Interstate relations (that is, relations between states, hence inter-state) became such a prima- 
ry concern to society and therefore only "caused" a need for theoretical reflection as a result of the advent of two conditions in history. The first condition consists of the existence of a more or less stable system of states in which states interact. Without states and a state system there would be no reflection about interstate relations. Second, the system of states has to be "integrated". The more a system of states becomes "integrated", the more likely it is that theoretical reflection takes place (Osiander 1996: 43). This is basically a statement about the social and political relevance of interstate relations: once inter-state relations become highly relevant for societies, systematic theoretical reflection about those interstate relations will occur. The social and political relevance is the defining feature of what Osiander calls "interstate interdependence". Only when the mutual economic and military dependency of states becomes socially and politically relevant, or in other words, when it affects the functioning or even the survival of the societies, will those interstate relations become the object of theoretical inquiry on a larger scale. The higher the level of interdependence and the more a state system is "integrated", the more theoretical reflection there will be on interstate relations.

Theoretical reflection on interstate relations therefore took place historically on a larger scale once such an "integrated" system of states with the defining feature of interstate interdependence came into being. This change did not occur before the industrial revolution, and Osiander convincingly develops a line of argument that traces the development of political thought on interstate relations back in history up to that "threshold", beyond which theory formation occurred on a larger scale. With the advent of industrialization, the mutual dependence of states became so significant to the state and to society as a whole that a real "need" developed for a theory of interstate relations. More precisely, the history of the European states system can be discussed as a history of rising levels of interdependence, with interstate relations becoming more and more relevant to societies. It is this history that brought about theories of international relations.

It is worthwhile to take the argument further by briefly discussing the historical developments behind it in more detail, starting with antiquity (the states system of city-states in ancient Greece and of the large-scale Roman empire), and moving through the European Middle Ages with the feudal state, the Italian states system, eighteenth century Europe and the nineteenth century with its industrialization, nationalism and increasingly integrated world economy. The next sections will draw on Osiander 1996. Please note that the text written by Osiander will be part of the required reading. It will give you the chance to explore the line of argument in depth after reading the introductory text contained in this unit. 


\section{Greek Antiquity}

In antiquity, states were integrated into federations of city states or into largescale empires.

The Greek states system of ancient Greece (500-100 BC) was a system of city states (such as Athens or Sparta; the city-state was also referred to as polis). According to Osiander, this system was not stable enough, economic exchange between the states was not relevant enough, and wars - despite their destruction of city-states - did not threaten the existence of Greek society as a whole. Osiander argues that there was thus no need for a theory of interstate relations. For this reason, and in contrast to many textbooks, he denies that Thucydides (History of the Peloponnesian War, written around $431 \mathrm{BC}$ ) is the "father" of a theory of interstate relations (Osiander 1996: 46, on Thucydides and IR theory see Doyle 1990). Osiander reasons that he does not see any large scale theoretical writing on interstate relations of the Greek city states in that time and thus considers the single text to be a pragmatic text in the context of a particular historical moment (a similar argument is developed by Czempiel 1965).

With regard to the Roman Empire (200 BC- AD 500), the large-scale empire is seen as the dominant form of social organization of the states system at this time. In the context of imperial expansion in particular, no stable interstate relations existed. Here again, cross-border relations held only a limited significance for the Roman Empire. There was therefore no need to reflect upon interstate relations on a large scale.

\section{The European Middle Ages}

The empire remained the dominant pattern of political organization in Christian Europe after the fall of the Roman Empire, with the successor of the Roman Empire in Europe being the Medieval (Roman Catholic) empire, known as Christendom, based at Rome in Western Europe and, in Eastern Europe and the near East, the Byzantine (Orthodox) empire with Constantinople at the center. These empires composed the two parts of the European medieval Christian world (500-1500).

Within the empires, the medieval European state existed with its central feature, the feudal tenure system. This decentralized system had a high regard for power, was economically particular and locally organized, and had no central control of large territories. The emperor and the monarchs were political decision makers who entrusted power to vassals. Power and authority were organized on both a religious and a political basis by the Pope and the Emperor respectively. The medieval state was organized through personal 
ties. Through the medieval tenure system, power was distributed to a number of hierarchically organized actors. The authority and capacity to engage in wars was not monopolized by the state. Consequently, there could be no thoughts of autonomous independent politic units in the European Middle Ages, a prerequisite for a theory of interstate relations. With regard to external relations, the Middle Ages were an era of empire with relations between those empires only at the margins (Osiander 1996: 47).

\section{The Modern Age}

In the early modern age came the first attempts to formulate a theory of interstate relations, based on the experience of the Italian system of states. The writings of Niccolò Machiavelli (Il Principe, 1513 and the Discorsi, about 1518) discussed the internal and external dimension of the state's ability to cope with threats, indicating a strong awareness of the importance of foreign relations of states for society. However, according to Osiander (1996: 48), this was still a theory of the state which only featured some reflections on foreign relations.

Please note that you will read a short text, the "Recommendations for the Prince" by Machiavelli, as part of the required reading at the end of this introductory unit. It will give you an impression of the quality and style of this early writing on interstate relations.

The historical development in the modern age can be summarized as a general process towards the formation of the centralist territorial sovereign state. It is a process of centralizing and consolidating power within the state. This development makes the distinction between the domestic and the interstate sphere increasingly clear: there is "inside" and "outside" the state. A general agreement exists that this modern state is a "product" of the Thirty Years War (1618-48) and the Peace of Westphalia, which ended the war and established the principle of the sovereign state. From the middle of the $17^{\text {th }}$ century onwards, the modern state was considered the only legitimate political system in Europe, composed of a separate (state) territory, (state) governments and (state) citizens. The centralist state's monopoly on legitimate violence is thus the outcome of a historical process in early modern Europe, a process of the consolidation of sovereign territorial states with a monopoly on the means of warfare.

From a theoretical perspective, this process has been reflected in attempts in political theory to politically legitimize the new central powers. Thomas Hobbes' Leviathan (1651) provided the starting point. In his writing, he drew an analogy of relations among "sovereigns" to relations among individuals prior to the establishment of society. He called this condition a "state of war" 
and considered it to be the core problem of politics. The idea that the basic condition of the interstate system is a "state of war" became influential for International Relations theory at a later stage (Realism). Please note that a short text fragment of Hobbes' Leviathan is part of the required reading, allowing you to form an impression of those early thoughts on the nature of the interstate system. However, in addition to political theory, there have been other important contributions which have helped develop the idea of "sovereignty" as a concept of international law. Examples include Hugo Grotius' Mare Liberum (1609), discussing the sea as "international waters".

From the mid- $17^{\text {th }}$ century through the $18^{\text {th }}$ and $19^{\text {th }}$ centuries, the history of the European states system is not only a history of the central sovereign state (inside) but also a history of intensifying interstate relations (outside the state). An increasing exchange of ideas and diplomatic contacts between the European states were preconditions for establishing the post-Napoleonic European balance of power system at the Congress of Vienna (1815), agreed upon by the great powers (the Concert of Europe). The balance of power system lasted more or less for most of the period 1815-1914.

"Inside" the modern state, relationships between state and society obtained a new quality in the $19^{\text {th }}$ century with the advent of nationalism and the nation state. The rise of nationalism was part of the process of centralizing and consolidating the power of the state. Economic relations within societies became increasingly integrated (national economies), as did the external economic relations. Economic theory of the $18^{\text {th }}$ and $19^{\text {th }}$ century, such as Adam Smith's An Enquiry into the Nature and Causes of the Wealth of Nations (1776) and David Ricardo's On the Principles of Political Economy and Taxation (1817), reflected theoretically on the gains in welfare through an international division of labor and the integration of national markets. Increasing integration of the national economies through an intensification of trade, transport and communication, along with interdependence in the sphere of national security, became central features of the European states system.

A mutual dependence in issues of economic and security meant that external relations of the state also became increasingly relevant for societies. The danger of interstate war was perceived as a threat to the existence and well-being of national societies and thus became a central concern for those societies.

It therefore comes as no surprise that the international peace movement is a product of the $19^{\text {th }}$ century and emerged along with industrialization. Peace Societies appeared immediately after the Napoleonic Wars in England and the US (1815-1816). Members called themselves "friends of peace" (Cooper 1984: 76). These early peace societies are the first examples of private citizen 
groups formed in order to lobby and influence foreign policy. The American and the British Peace Societies were soon followed by the Parisian and the Genevan Peace Societies. The 1860s saw a significant increase in new peace societies in Europe (Cooper 1984: 91). Together these societies formed an international peace movement, setting up a headquarters in Berne after 1891 (the Bureau International de la Paix) to coordinate the movements in more than 20 nations until 1914. Peace movements are "associations of private citizens, usually drawn from several social classes, who form societies that work to influence or protect against expansionist foreign and military policies" (Cooper 1984: 75). They proved to be influential not least through their support of the The Hague Peace Conferences 1899 and 1907, which produced the important Hague Conventions and the Geneva Protocol. Foundations such as the US's Carnegie Endowment for International Peace and the World Peace Foundation, both founded in 1910, were powerful actors that contributed to the establishment of International Relations as an academic discipline after World War I (this will be discussed in the next part of this unit).

In regard to theory, the concerns of society have been reflected in books such as Norman Angell's The Great Illusion (1910). The core thesis of his writing is about the "illusion" of what can be reached by war. The integration of the European states' economies instead increased to a level that made war between them entirely futile.

In 1914 came the end of a century of "organized peace societies" with their hopes for rational European leaders who would recognize the need to regulate international anarchy through the creation of international institutions for the peaceful resolution of conflicts. The experience of World War I demonstrated the extreme significance of interstate relations for societies. The conclusion was reached that, from then on, war and peace should not be left to politicians and diplomats; rather, a systematic study of the causes of war and the conditions for peace was seen as a real "necessity" for helping politics to build peace.

\section{Summary}

The history of International Relations theory is part of a double process:

(1) A historical process of centralization and consolidation of power. The transformation of political organization from the medieval to the modern state is based on centralization, the construction of the independent territorial state (inside the state) and an international states system of consolidated, unified and centralized sovereign territorial states (outside the state). The core function of the central, sovereign state is the provision of core values such as 
security, welfare, freedom. In this historical process, the significance of external relations to society is growing. This gain in significance occurs because of increasingly integrated national economies and the resulting rise in mutual dependence between national economies.

(2) The development of the states system in Europe, the process of intensifying interstate relations, and the growth of worldwide communication, trade, and transportation go hand in hand with a systematic reflection in the fields of philosophy, political theory and international law. In terms of the history of thought, the historical process is at the same time a history of state theory (or Political theory) and interstate theory (later International Relations theory). In this process, state theory (or political theory) increasingly starts to reflect on interstate relations, theoretically "mirroring" the historical process of a rising significance of interstate relations. In fact, theoretical reflection - the historical evolution of inter-state, later inter-national theory - is part of these historical processes of the formation and development of the European state system. We will come back to this argument and discuss it in more detail in Unit 3. Before we do so, however, let us first take a look at the discipline's formation.

\subsection{The "birth" of the discipline in 1919: Institutionalization and International Relations as "science"}

In the first part of Step 1, we discussed a perspective that suggests seeing the history of international relations theory as closely tied to the real-world processes of the historical evolution of the European states system. In this reading, the history of IR theory starts in the mid- $17^{\text {th }}$ century. Political thought on interstate relations before World War I made important contributions to theory building within International Relations as an academic discipline. Concepts such as the balance of power (an important concept in political theory for a stable European system since the $18^{\text {th }}$ century), the idea of the "anarchy" of the international system (derived from Hobbes's state of war), and Kant's philosophical thinking and writing on the conditions for a foedus pacificum (league of peace) in his Perpetual Peace (1789) - which became influential in the political construction of the League of Nations in 1919 and, later, for that of the United Nations - proved to be building blocks for theory formation once IR had been established as an academic discipline. This establishment did not occur before 1919, and it is the objective of this part of the first chapter to discuss the "birth" of IR as an academic discipline. This discussion is a highly relevant for the purposes of the book, as the birth of IR 
as an academic discipline is not only a consequence of World War I and hence an expression of its previously mentioned extreme existential significance to societies, but also indicates a change in the "quality" and status of theory in International Relations.

The birth of the discipline will be discussed with regard to two interrelated aspects: International Relations as science and its institutionalization. For didactical reasons, the next section will discuss the latter aspect, the institutionalization of IR as an academic discipline, first.

\section{Institutionalization of IR as an academic discipline}

Many textbooks on International Relations provide the discipline with a "birthday": May 30, 1919. They choose this date because International Relations as an academic discipline is understood as the "child" of the Paris Peace Conference of 1919. There the British and American delegations agreed upon the establishment of institutes and university departments for the scientific study of international relations. The agreement was born out of a desire to immediately work and reflect on the processes of the Paris Peace Conference, at which the international order after the Great War had been negotiated. The initiative was put into practice through the founding of the British Institute of International Affairs (July 1920, later Royal Institute of International Affairs) and the American Institute of International Affairs (later merged with the Council on Foreign Relations).

One result of World War I was the feeling of an urgent need for a scientific inquiry to explain inter-state conflict and state rivalry. The first chair of International Politics was established in Great Britain (at the University College of Wales, Aberystwyth) in 1919. There was support from the League of Nations and private organizations such as the Carnegie Endowment for International Peace to establish additional chairs of International Relations, for example in 1925 in Paris and 1927 in Berlin. Enthusiasm in Great Britain, the US and France remained high over the following years and, by 1926, 40 American universities and colleges were offering introductory courses to International Relations (Czempiel 1965: 277, quoting Wright 1927: 396-397). However, early systematic work had already been done before. According to Czempiel (1965: 272), the first systematic political science book was published in 1916 by A.J. Grant (An introduction to the study of international relations, London), written at the request of the British Council for the Study of International Relations. In the US, courses on World Politics existed as early as 1913 and courses on International Relations by 1916, at the University of Indiana and Stanford University respectively (Osiander 1996, quoting Kirk 1947: 2-5). 
From this institutionalist perspective, International Relations as an academic discipline started with the first departments and chairs of International Relations. This development strongly emphasized the institutional aspects of "organizing" a discipline by providing the infrastructural underpinnings for research and teaching.

\section{International Relations as science}

With regard to the "quality" of early theory, the information presented above has already indicated that political thought before the establishment of IR as an academic discipline had never consisted of more than political concepts developed to give advice for conducting politics against the background of short-term problems. The ideas have been pragmatic solutions in the historical context of their writing. What they lack, however, is the quality of a systematic and methodical approach to theory building (Czempiel 1965: 271).

Now, coming out of the bitter experience of the Great War, the task of the newly established discipline was to systematically discover the causes of war and conditions for peace in inter-state relations. Peace and war among nations were the fundamental problems to be studied in International Relations.

After the Great War, the criterion of science as a systematic reflection using specific methods was applied to International Relations. This fact indicated a new quality of theoretical reflection. In this early understanding, systematic theory and method differentiate "science" from other paths to knowledge. Since that point, a systematic, generalized study of international relations has been considered an important criterion for thinking of the academic discipline of IR as science. In this regard, the birth of IR as an academic discipline marked the beginning of a qualitative change in approach: academics gradually began to concern itself with the systematic, methodical study of IR and hence with a new quality and status of theory. As you can easily imagine, the self-understanding of an academic discipline claiming to be scientific involves the search for a shared, common understanding of "science". We will learn that the understanding of IR as a science and of scientific theories draws on a European tradition of philosophical thought about science that extends back to ancient Greece. From around the end of the $19^{\text {th }}$ and early $20^{\text {th }}$ centuries, such reflections became the core domain of what is now called "philosophy of science" - an academic discipline that is part of philosophy. The development of IR as an academic discipline after 1919, especially since the 1950s, is closely linked to the philosophy of science discussion.

The history of IR theory and the academic discipline is thus not only bound to the historical evolution of the (European) state system (as discussed in Step 1 of this unit) but also to the historical development of ideas about what scientific 
study in general, and of international relations in particular, implies. We will elaborate on this connection in detail in the next learning unit.

In addition, another consequence of the Great War was a strong connection between the early scientific inquiry into the nature of inter-state relations and the postwar practice of international politics. The League of Nations was the practical political attempt to build peaceful interstate relations based on an international organization. It went hand in hand with the new studies on war and peace in inter-state relations. Broadly speaking, war and peace were the first subjects of the newly established discipline to be studied in a systematic, methodical way. On a practical level, these studies aimed for the first time to reach general conclusions on the causes of war and on what must be done for politics to build a lasting peace in interstate relations.

To "organize" an academic discipline therefore also means finding some agreement on the core subject studied by the newly created academic discipline. We will discuss the core subject of the new scientific study of international relations in the next step in more detail. Please note that for systematic and didactical reasons and in line with the purpose of the book, the aspect of "science" with its new quality and status of theory and method will be discussed in the second and third learning unit of part 1.

\section{Step 2:}

The core subject of International Relations and International Relations theory

\subsection{The modern sovereign state and international relations in the modern states system}

From what has been said in Chapter 1, we know that states and states systems are social/political organizations, tied to social/political practice and therefore subject to transformation and change over time. States and systems of states are historical.

Any abstract statement about the state or the states system as the core subject of the academic discipline of IR therefore has to specify exactly which state and states system is at the core.

Our historical analysis has shown that there is a history of international systems with different states systems at different times. These include the system of city-states in ancient Greece, the Roman Empire, the Persian Empire, the Empire of Alexander the Great, the political order of the European Mid- 
dle Ages with the feudal state, and the European system of states during the $17^{\text {th }}$ century. Climbing the ladder of abstraction, we could think of "types" of states and states systems. The "type" of each states system depends on the "type" of state and the nature of interstate relations.

Historically, it has been shown that the system of states, based on the sovereign territorial state, is a "product" of $17^{\text {th }}$ century Europe. Many textbooks use the term Westphalian order because the basic principles of this European states system (central state power and state sovereignty) were the subject matter of the negotiations that led to the "Peace of Westphalia" (1648), ending the Thirty Year's War in the Holy Roman Empire. The relations of European states became subject to international law and diplomatic practices. Initially European, this system of states expanded globally in the centuries that followed.

It is the Westphalian order of sovereign nation states (or the modern state and modern states system) that is at the core of the academic discipline of International Relations. The origins of the Westphalian state and the Westphalian states system date back to 1648 . However, looking more closely at the "type" of state and states system, it can be determined that the sovereign state and the system of sovereign states are still being discussed as the core of IR as an academic discipline. More precisely, the dynamics and change of the sovereign state and the states system constitute the core of our discipline.

You might already be familiar with the academic (and public!) discussions about the "retreat of the state" in the face of the process of globalization and a diminishing role of the "welfare state". Both public and academic debates are being conducted on the treaty establishing a constitution for Europe and hence the EU as a state-like system, on the problems caused by "failed states" (such as Somalia or Sudan) for contemporary international politics, and on the tension between the principle of state sovereignty and the UN's Responsibility to Protect through military or humanitarian interventions. You can easily see that in one way or another, the sovereign, centralized state (Westphalian type) is still the main point of reference in those discussions.

With regard to the states system and given the perceived diminishing role of the state, we now find ourselves in the middle of debates as to whether the Westphalian model of the state and states system is still the adequate "type" of state and states system to be placed at the core of IR.

Some scholars argue that the global system of states we live in can, for example, be better categorized as a networked world society. That is, questions and problems involving the dynamics and change of the system of sovereign states are very much at the center of International Relations. This argument is certainly easy to follow against the background of the fundamental historicity and therefore transformability of "the state". 
Following the argument above, theorizing about the state thus also means theorizing about the "end" or better transformation of the (Westphalian) state, its transformative processes, the rise and growing importance of other "social organizations" such as private actors, NGOs or international organizations besides the state. Theorizing about the states system also includes asking the following questions: is it still the Westphalian "states system" that we live in; that is, are interstate relations among sovereign states still the most relevant relations that make up the system? Could the system be better characterized as a world society? Even in this context, these two main modes of theorizing (about the state and the state system) still remain at the core of IR theory.

The modern state and the modern states system also still serve as the main point of reference for academic work in the field of IR as well as in practical international politics, for example in the UN. Theoretically, even theories trying to go "beyond the state" usually take the state as a starting point or refer to it. We will learn about those different approaches in the particular theories of IR covered by Part 2 of the book.

For the moment we can therefore conclude that, for more than three centuries (!), the categories of the (Westphalian) state and the Westphalian states system have formed the core of inter-state theory. They also became the core of the newly established discipline of IR after the Great War. Even now, in the 21 th century, a look at IR textbooks will demonstrate the strong persistence of the (Westphalian) state and the state system as the core subject of the academic discipline of IR. Bringing to mind the time periods of the transitions of earlier forms of state and state systems, this should not come as a surprise, even though we are not used to thinking in such lengthy periods of time.

For our further discussions of the core subject in the next step, please remember the central functions of the modern state for society, which resulted from the historical process of centralizing power: to protect society against external and internal threats (security) and to ensure material welfare and freedom. These values are of high social and political relevance for the societies within the modern state. A threat to a state's physical (territorial) existence, material welfare and/or independence/sovereignty is therefore a matter of major concern.

State politics will provide a useful starting point for learning more about the state and the states system as the core subject of IR. 


\subsection{Politics "inside" the modern state: the allocation of values for society as the core function of the state}

The state is usually perceived as the almost natural political organization of separate societal communities (inside the state). According to the American political scientist David Easton, "a political system can be designated as those interactions through which values are authoritatively allocated for a society" (Easton 1965: 21). This is an old, albeit still influential definition of the function of a political system and the nature of "politics": the authoritative allocation of values for a society. Values are distributed by "interactions" and the fact that interactions allocate or reallocate values (or are directed towards influencing value allocation) gives them a political nature. Easton summarizes this definition as follows: "My point is, in summary, that the property of a social act that informs it with a political aspect is the act's relation to the authoritative allocation of values for a society." (Easton 1965: 134). Legitimate political authority plays a central role in this definition of politics: it refers to state authority, the monopoly of power in the hands of government and a hierarchical order with a central command over military and legal forces (army, police). Dominance and subordination are the defining features of social relations between the actors of a political system.

This is the internal aspect of the state: a state as national government with state authority.

Distributive or re-distributive policies based on welfare programs or taxation laws provide one example that demonstrates what we mean by an "authoritative allocation of values for a society" through a political system. Another is environmental legislation that "allocates" the value of, for instance, clean water to society and therefore decides on the degree of healthy living conditions.

If this is the "nature" of politics, then "( $\mathrm{t}$ )he study of politics is the study of authoritative allocation of values for a society" by the academic discipline of Political Science (Easton 1953: 967). What, then, is the study of international politics in the academic discipline of International Relations?

\subsection{Politics "outside" the modern state: the politics of international relations}

As you have learned, the political organization as independent states and the recognition of a state as sovereign by other states is the "external dimension" of the state. Interstate relations therefore belong to the external aspect of state politics. 
Remember that we have defined politics as those "interactions through which values are authoritatively allocated for a society" (Easton 1965: 21). A transfer of this understanding of (national) politics to the context of interstate relations, however, is not a simple undertaking. This difficulty is due to the fact that, in contrast to state-society-relations (inside the state), international relations (outside the state) are not hierarchically organized. There is no centralization or monopoly of power in the international system. Additionally, no "world government" exists to authoritatively set the norms and rules for the conduct of international relations and enforce compliance or to sanction deviant behavior. This "type" of social organization found at the level of the international system is usually called "anarchy": the politics of international relations is understood as politics under the condition of "anarchy".

The anarchy in the international system has traditionally been presented as the first and foremost defining feature of international politics. The difference between "hierarchy" and "anarchy" as forms of social organization is what differentiates international politics from domestic politics. However, despite this fundamental difference, our definition of "politics" provides a useful starting point to better grasp the core subject of IR. If this definition is correct, there must be other sources of "authority" in international relations. These sources will be shown in the following paragraphs through a discussion of the elements of our definition of national (state) politics as applied to international politics in more detail.

First, international relations are interactions in the same sense as there are interactions within the state: international relations are simply social relations between social actors, comparable to social relations between social actors within the state. What differentiates them is that international relations are perceived as social relations crossing (state) borders.

International relations as transborder relations exist between different types of social actors: state, non-state, individual and collective actors such as social groups or organizations. International relations are transborder interactions between state and non-state actors.

The defining feature of social actors is the purpose or intention of their action and interaction. Now remember the definition by David Easton "...that the property of a social act that informs it with a political aspect is the act's relation to the authoritative allocation of values for a society". That is, the allocation or re-allocation of values is the political relevance or the political purpose of those social relations.

More concisely, within the complex field of transborder relations, it is the "political" relevance that differentiates international relations from other "international relations" such as tourism, correspondence, family relations or 
private contacts. There have been attempts to introduce the term "international political relations" (Czempiel 1965: 282) but they have not succeeded.

Politically relevant social interactions allocate or re-allocate basic values for society; human needs such as security and welfare, freedom, and order are core values for a (national) society. The same is true for international relations. Transborder relations are equally political relevant for society: conflict, war, cooperation, intergovernmental relations on a bilateral or multilateral basis, and economic relations such as trade relations or traditional diplomacy are all of concern to societies because they affect basic values. You are already familiar with this argument of the social and political relevance of inter-state relations from the first chapter in this unit.

War and military conflicts are international relations that in essence affect the value of security. Security is certainly the most fundamental value of international relations: the protection of the physical existence of a political community of citizens against external threat. Basically, security involves all issue areas related to the use or threat of force.

Cooperation in trade relations or other economic issue areas are international relations that affect the basic value of welfare. Welfare refers to all issues related to economic growth and material well-being. The production of goods and services and the coordination of economic relations, the welfare gains from market integration and political rules that govern a global or regional market and the distribution of welfare gains from economic integration or poverty are all issues relevant to society.

The international coordination of environmental protection is important for the value of clean air and water and therefore for society's natural health and living conditions (environment).

With regard to the value of freedom, society is concerned with the freedom and rights of the individual not only "inside the state" but also "outside" the state. Therefore, international rules for human rights influence the allocation of the value "freedom".

These are just a few examples of international relations affecting values important to society, given with the intention of demonstrating the applicability of our definition of politics to international relations despite some fundamental differences.

Finally, international relations, the politically purposeful actions and interactions of state and non-state actors, constitute and create the structures of the international system over time. For the moment, the states system is still perceived as a system of sovereign territorial states with a central political authority inside the states, but not outside them. 


\subsection{Summary and conclusion}

The study of international relations is the study of transborder interactions of different types of actors. The defining features of these interactions are their social and political relevance. Politically relevant interactions are those through which values are allocated or re-allocated or whose purpose is to influence value allocation through international politics.

Scholars consider an authoritative allocation of values under conditions of anarchy impossible as long as "authority" is reserved for the state, with a central monopoly of power governing a hierarchically organized political community (inside the state).

In contrast to the study of politics, the study of international relations (international politics) asks questions and provides answers about politics "outside" the state. International politics, or politics "outside the state", is usually understood as politics under conditions of anarchy. The question of "sources of authority" in an anarchical system forms one of the core problems of IR.

While a great deal of agreement exists on what constitutes the core problem of international politics, there are different ways to theoretically and methodically reflect on this core problem. Different theories of International Relations will provide different perspectives on the core problem of politics under the condition of anarchy or even question the concept of anarchy itself. We can briefly illustrate this fact by asking some questions derived from our definition of the core subject of International Relations as an academic discipline:

What is the "nature" of the international system? As an example, in neorealist theory, anarchy is the nature of the international system. Neoinstitutionalists agree, but point to interdependent relationships between states in the international system that offer good opportunities to establish stable patterns of inter-state cooperation. That is, they see chances to "regulate" anarchy. In contrast, neorealism perceives only minimal chances for cooperation, while the condition of anarchy prevents any long lasting international collaboration.

Who are the most relevant actors in international relations and what are the driving forces of their actions and interactions? We will learn that there are theories that consider states or, in some cases, simply the most powerful states as the only relevant actors, while other perspectives point to the influence of non-state actors on outcomes of international politics. These could be private actors such as transnational corporations, non-governmental organizations such as Greenpeace or human rights networks, or international organizations such as the UN. What are these actors' driving forces? Do they be- 
have rationally in terms of cost-benefit calculations? Are normative views such as "justice in our global order" their guide to action? Is their main motivation to maximize national security or welfare gains?

What are the most important values in international politics? Security? Welfare? Human rights? Our natural living conditions?

What are sources of authority in international relations? Is the power politics of the most powerful states in the states system one such authority? Is there authority in the transfer of competencies for the allocation of values from the state to an international organization? What about the voluntary agreements to set rules for behavior in international politics and to comply with these rules and norms, for example by building international regimes? Is the idea of authority that is derived from state politics applicable to international politics at all?

What should the "ideal" international system look like? How does change in international politics occur? Is there "progress" in the development of the international system? What kind of international politics do we want? What kind of international politics do we oppose?

Your perspective on such questions of international relations and your explanations of the outcomes in international politics will depend on theory. Theories of International Relations reflect on the core subject: the state and the states system. However, they provide different ways to conceptualize or to understand the state and the states system, different ways to understand or explain outcomes in international politics, different lines of argumentation to predict the "future" of the state and the states system, and last but not least, different "instructions" and policy advice for real-world international politics.

It is the objective of our book to become familiar with a range of different theories of International Relations in order to learn more about the role and status of theory in and for international politics more generally. However, before we discuss the different approaches to IR in part 2 of the book, we still will have to learn more about the nature of theory building and its status in science in the next learning unit.

Before moving on to the next unit, recap what you have learned so far by carefully reading the following key aspects and answering the review questions. 


\section{Step 3:}

\section{Check your understanding: key aspects and review questions}

\section{Key aspects}

- The history of International Relations theory is closely tied to the historical evolution of the European states system. The transformation of political organization from the medieval to the modern state is based on centralization, the construction of the independent territorial state (inside the state) and therefore an international states system of consolidated, unified and centralized sovereign territorial states (outside the state).

- The core subject of International Relations as an academic discipline and of International Relations theory is the modern sovereign state and the modern system of states whose legitimacy and independence is mutually recognized. Both concepts are of European origin and usually so is theoretical reflection upon them.

- The politics of international relations is normally understood as politics under conditions of "anarchy". Constitutive for this view is the idea of a hierarchically organized "inside the state" and an anarchically ordered "outside the state". Anarchy is conceptualized as the absence of a higher authority that monitors compliance and sanctions non-compliant behavior. Such an authority would be comparable to the state and its power monopoly.

- Based on the fundamental understanding of "inside" and "outside", international relations are usually understood as transborder interactions between state and non-state actors. They thus cross the border between inside and outside.

- It is the "political" relevance that differentiates international relations as the subject of the academic discipline IR from other "international relations" like tourism, correspondence, family relations or private contacts.

- Politically relevant social interactions are those that allocate or re-allocate basic values for society. Human needs such as security and welfare, freedom, and order are core values which international politics can allocate.

- The academic discipline of International Relations was "born" in 1919 as a "child" of the Paris Peace Conference after World War I. The new departments and chairs of International Relations focused on the scientific study of interstate relations, based on systematic, generalizing theories and methods.

- The history of IR theory and IR as an academic discipline is not only bound to the history of the European states system but also to the idea of science as it developed in European philosophy, starting with Greek antiquity. 
- Different theories of International Relations provide different perspectives on the nature of international politics and on how to study it. As a result of their different perspectives they provide different answers to the core problem of politics in the realm of international politics.

\section{Review questions}

1. When and why did theoretical reflection on interstate relations first occur in history?

2. What are the basic criteria for discussing the "birth" of a new academic discipline?

3. What is the core subject of International Relations as an academic discipline?

4. Why is it so difficult to discuss international politics with reference to concepts derived from national politics, such as the "state", "authority" or "politics"?

\section{Step 4:}

Self-study and consolidation

\section{Self-study (1)}

Read the required reading to deepen your knowledge of the history of IR theory.

\section{Self-study (2)}

What are the basic values that are subject to allocation/re-allocation through international politics? Choose two examples out of the issue areas of international relations (security, welfare, freedom or environment) and discuss recent real-world international politics, demonstrating how it affects the allocation of values for societies. 


\section{Required reading}

(1) For a first impression of early writing on interstate relations within the history of IR thought:

Thucydides, History of the Peloponnesian War, transl. Rex Warner, Baltimore: Penguin Books, 1903, 13, 22-23, 25, 358-366, repr. in Williams, Phil/Goldstein, Donald M./Shafritz, Jay M. (eds.) 1994: Classical Readings of International Relations. Belmont: Wadsworth Publ., 183-189.

Niccoló Macciavelli, Il Principe, repr. in Williams, Phil/Goldstein, Donald M./Shafritz, Jay M. (eds.) 1994: Classical Readings of International Relations. Belmont: Wadsworth Publ., 24-27.

Hobbes, Thomas, Leviathan (Oxford: Clarendon Press, 1909, 94-98, repr. in Williams, Phil/Goldstein, Donald M./Shafritz, Jay M. (eds.) 1994: Classical Readings of International Relations. Belmont: Wadsworth Publ., 28-30.

(2) Osiander, Andreas 1996: The interdependence of states and the theory of interstate relations. An enquiry into the history of political thought, in: Law and State Vol. 53/54, 42-68.

(3) Jackson, Robert/Soerensen, Georg 2007: Introduction to International Relations: Theories and Approaches, $3^{\text {rd }}$. ed., Oxford: Oxford University Press, chapter 1, 1-28.

\section{Supplementary reading}

Baylis, John/Smith, Steve/Owens, Patricia 2008: The globalization of world politics. An introduction to International Relations. $4^{\text {th }}$ ed., New York: Oxford University Press. Part 1.

Brown, Chris/Nardin, Terry/Rengger, Nicholas (eds.) 2002: International Relations in Political Thought: Texts from the Ancient Greeks to the First World War, Cambridge: Cambridge University Press.

Jackson, Robert H. 2005: Classical and modern thought on International Relations. London, New York: Palgrave.

Kauppi, Mark V./Viotti, Paul R. 1992: The Global Philosophers: World Politics in Western Thought. New York.

Knutsen, Torbjörn 1997: A History of International Relations Theory. $2^{\text {nd }}$ ed., Manchester.

\section{References in the text}

Cooper, Sandi 1984: The Origins and Development of European Peace Movement: From Vienna to Frankfurt, in: Wiener Beiträge zur Geschichte der Neuzeit Band 11: Friedensbewegungen: Bedingungen und Wirkungen. München: Oldenbourg, 75-95.

Czempiel, Ernst-Otto 1965: The Development of the Study of International Relations (in German), in: Politische Vierteljahresschrift 6: 3, 270-290.

Doyle, Michael W. 1990: Thucydidean Realism, in: Review of International Studies 16, 223-237.

Easton; David 1965: A Systems Analysis of Political Life, New York. 
Easton, David 1953: The Political System. An Inquiry into the State of Political Science. New York.

Osiander, Andreas 1994: The states system of Europe 1640-1990. Oxford: Oxford University Press.

Osiander, Andreas 1996: The interdependence of states and the theory of interstate relations. An enquiry into the history of political thought, in: Law and State Vol. 53/54, 42-68.

Osiander, Andreas 2008: Before the State. Systemic Political Change in the West from the Greeks to the French Revolution. Oxford: Oxford University Press.

Wright, Quincy 1927: Report on Roundtable Conference of the American Political science Association, in: American Political Science Review Vol. XXI, No.2, May 1927, 96397.

Zimmern, Alfred (ed.) 1939: University Teaching of International Relations. A record of the Eleventh Session of the International Studies Conference, Prague 1938. Paris: International Institute of Intellectual Cooperation. 


\section{International Relations as science}

Learning steps

Introduction

Step 1:

Philosophy of science: the "theory behind theories"

(meta-theory)

1.1. Philosophy of science and the role of assumptions ............................... 39

1.2. Ontology, epistemology, methodology …………………………......... 41

Step 2:

Positivism as an example for a philosophy of science .............................. 43

2.1. Positivism ....................................................................................... 43

2.2. Epistemology, ontology and methodology in positivist science ............ 44

2.2.1. Complex 1 ............................................................................... 44

Empiricism .............................................................................. 44

Materialism/physicalism/ontological naturalism .................................. $\quad 45$

Atomism/particularism/individualism ................................................... 46

Phenomenalism ........................................................................... 48

Objectivism .................................................................................. 48

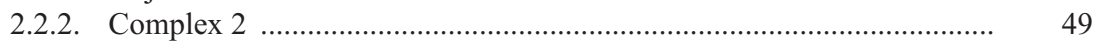

Operationalism and instrumentalism...................................................... 49

Nominalism .................................................................................... 51

Methodological individualism ........................................................... 53

Logical atomism ............................................................................... 55

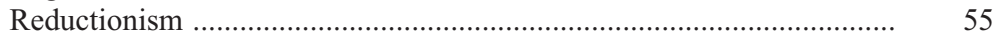

Unity of science ................................................................................... 57

Causal, law-like explanation and the belief in prediction ...................... $\quad 58$

In sum .................................................................................... 61

2.3. Competing philosophies of science in IR ……....................................... 61

Step 3:

Check your understanding: key aspects and review questions .............. 63

Step 4:

Consolidation 


\section{Introduction}

As you have learned in Unit 1, the discipline of International Relations was born after the Great War out of the desire to systematically find the causes of war and the conditions for a lasting peace. Since then, IR's contribution to the practice of international politics has been closely tied to the idea of (social) science. However, even though there was a general acceptance that IR could and should be a science, the exact meaning of the term "science" itself was not quite clear. According to Czempiel (1965: 280), a consensus already existed at the end of the 1930s that, in order to define International Relations as "science", the methods of the natural sciences had to be applied: to collect facts, to arrange them in some sort of "order", and to explain them. For example, in the late 1930s, E.H. Carr argued that realism could provide a scientific theory because of its emphasis on the acceptance of facts and on the analysis of their causes and consequences (Carr 1939). Czempiel's assertion raised an interesting point that shows how the idea of IR as a science progressed towards a very specific understanding of science as closely bound to the idea of natural science. This signalized a departure from an earlier understanding of International Relations as an area of study that synthesizes knowledge from other disciplines, drawing on judicial, economic, historical and technical aspects (Czempiel 1965: 280-281).

In the early years, the issue of science was not a core concern in the theoretical work being done on interstate relations. This situation stands in sharp contrast to later stages in the discipline's development, when debates and controversy about the nature of a scientific study of IR became a permanent feature. This remains true for today's International Relations. As will be shown, however, at the heart of the discipline exists a particular understanding of science - positivism - which has come to dominate and shape the discipline since the 1950s. Positivism provides the philosophy of science background for those IR theories that count as the most influential today. In the time period before, the scientific, or broadly speaking the systematic and methodical study of IR, is often called "traditional" or "classical". In contrast to the positivist understanding of science, the "traditional"/"classical" inquiry into international relations is not based on an understanding of the concept of science drawn from the natural sciences (Little 1980: 7; Wight 2002: 28). 


\section{Self-study (1)}

Read the texts written by Bull (1966: International Theory. The case for a classical approach) and Kaplan (1969: The New Great Debate: Traditionalism vs. Science in International Relations) from the required reading list and then return to this unit. The texts, written in the 1960s, will give you a direct impression of the different understandings of science debated at this time. The readings will help you to better grasp the current debates on IR as a science.

For the moment, let us preliminarily conceive the idea of a scientific approach to the study of International Relations as being simply and broadly associated with the idea of a systematic and methodical study of international relations. In this case, the goal is reaching general, valid knowledge about interstate politics. Both the theoretical "system" and the methods of such a systematic exploration will vary according to the fundamental understanding of science underneath.

Theory is key to such a systematic and methodical study, as it presents a "guide" to the process of gaining knowledge by formulating questions, conjectures or hypotheses about international politics. Theory provides the fundament of the "order" of a systematic inquiry. Therefore, theory always retains a central position in this process of generating "knowledge".

However, as will be shown, no agreement exists among scholars on the question of what exactly is the nature, function and position of a theory in scientific research. The nature and function of theory in the process of knowledge production itself is a highly debated issue.

It is thus worthwhile to take a closer look at the notions of theory and science because "scientific knowledge" is considered to hold a key position in our societies. In the following chapters we will therefore discuss in greater depth both International Relations as a (social) science and the status of theory within IR. The discussion will touch on the status of "theory" within an academic discipline more generally while focusing on IR in particular. The idea of what a theory is and of which role and functions it possesses within an academic discipline is closely bound to that discipline's understanding of the term "science". The understanding of science is a key issue for any social science and, as we will learn, a matter of much debate and controversy with no consensus in sight. 
Step 1:

Philosophy of science: the "theory behind theories" (meta-theory)

\subsection{Philosophy of science and the role of assumptions}

The legitimization of modern academic disciplines as "science" usually involves a reference to a particular philosophy of science. For example, from your reading of the texts written by Bull and Kaplan, you already know that "traditional" IR refers to a different understanding of science than that of the "scientist" understanding that draws on the natural sciences. There are different philosophies of science at the heart of both accounts of science. They take up different positions on such fundamental questions as the "nature" of the relevant subject to be studied by IR, how to gain knowledge about this subject, what counts as valid "knowledge" in IR and which methods should be used in the process of knowledge acquisition.

As a recognizable field of study, the philosophy of science emerged in the 1920s and 1930s with the work of the Vienna Circle and the writings of Karl Popper. The formation as an academic discipline can perhaps be traced back to the end of the $19^{\text {th }}$ century, with the first chair of "History and Theory of Inductive Science" established 1895 in Vienna (the holder being the physicist Ernst Mach). Of course, philosophy of science as a form of philosophical thought about the nature of science and scientific study goes much further back in history and can be traced at least to ancient Greece. In Greek antiquity, this type of thought is associated above all with the work of Greek philosophers such as Democritus, Aristotle or Plato - just to mention a few. In Unit 3 , we will come back to their ideas of science inherent in their philosophy in more detail.

The underlying reason why philosophy of science has become so attractive to the social sciences since the early $20^{\text {th }}$ century lies with the enormous success of modern natural science such as physics, mathematics, chemistry and biology and the prestige natural science has gained in modern societies (Wight 2002: 25; 41). You can easily see the prestigious status of science and its role in our modern world in your everyday life: imagine your life without the $20^{\text {th }}$ century advances in industry and technology. Those advances - and your life as you currently live it - would be unthinkable without the progress of natural sciences.

Within the philosophy of science discipline, the object studied is the nature and practice of science itself. The discipline aims to find out what is distinctive about scientific explanations and theoretical constructions. What is 
the nature of science in contrast to, say, speculation, intuition or religious systems of knowledge?

Any philosophy of science consists of a range of assumptions. These are ontological assumptions (claims about existence and being), epistemological assumptions (claims about what constitutes valid knowledge and the grounds for such claims of valid knowledge), and methodological assumptions (claims about the practice of science and the specific methods of gaining knowledge) (Wight 2002: 41). In short, any philosophy of science is based on all three types of assumptions. Philosophy of science positions are also often referred to as "meta-theory": the theory or philosophy that is "behind" or "above" a theory of International Relations and whose subject is theory itself. It is also important to carefully note the terminology. When talking about philosophy of science, we talk about "assumptions" or "claims": propositions that are taken for granted and that are not subject to being proved as "true" or "false". The idea and term of assumptions originates in ancient Greek philosophy and logic. It is quite similar to an axiom, a premise or starting point of reasoning. In theory building, it serves as a starting point for deducing or inferring theory, to derive a logical conclusion from this starting point. Assumptions are not demonstrable by proof because their very nature is to be "starting points": there is nothing else from which they logically follow.

Consequently, we are talking about intellectual constructs of reality that are not subject to be proved as "true" or "false". It might come to you as a surprise that it is the very nature of science and theory to start with something that is not subject to being "proved". In fact, this is true for all systems of knowledge and the idea of knowledge about the world more generally, and not specific to science.

From what you have learned so far about the nature of assumptions, the logical result is that there is always more than one account of what constitutes science and therefore different philosophies of science within the philosophy of science as an overall discipline. For the purpose of better understanding the nature of a philosophy of science, Step 2 will demonstrate the core elements of a philosophy of science (ontological, epistemological and methodological assumptions) using a specific philosophy of science, positiv$i s m$, as an example. However, before we begin exploring positivism, we will need a basic understanding of the core terms of a philosophy of science. 


\subsection{Ontology, epistemology, methodology}

Ontology is the philosophical study of the nature of being, existence, or reality in general, as well as of the basic categories of being and their relations in particular. In short, ontology is the philosophy of being. The following are ontological questions: What is there? What is? What exists? What is reality made of? What are the most general features and relations of the things and entities? One example is the ontological claim that only material reality can be claimed to exist: the answer to the question "What is?" is "Matter only" (ontological materialism or materialism as an ontological claim). Another example, concerning the relation of "things" to each other, is the classical ontological problem of how a "universal" relates to a "particular". This ontological "problem" is certainly familiar to you as expressed by the question, "Is the whole more than the sum of its parts?" The query could be answered by an ontological individualist claim (the whole is always and only the sum of the single parts) or by an ontological holistic claim (the whole is more than the sum of its parts; it possesses a quality of its own that is not reducible to the properties of the single parts).

So, in the philosophy of science, an ontological assumption refers to a set of things which have been claimed to exist. This is done by means of a particular theory or system of thought. We speak of the ontology of a theory. An example that already is familiar to you from the first unit is the assumption found in many IR theories as the starting point: that states are the basic "units" of the international system and that the international system is "made up" of sovereign states forming an anarchical structure. Remember what has been said above about the nature of assumptions: they serve as the starting points for the purpose of theory building. There are many influential theories of IR that begin at this starting point: the ontological claim about the international system as made of the single states, perceived as the "units" or even unitary actors. However, as Unit 3 will demonstrate, even though assumptions are starting points that do not need to be proved as "true" or "false", they are not "free" experiments of thought. Rather, assumptions are always embedded in and derived from broader, long-term persistent world views and thus reflect specific, culturally variable patterns of thought. As reflections of deeper "orders of thought", assumptions are usually not subject to explicit explication in a theory of IR or even meta-theory. They instead fundamentally shape our cognition and perception of the world. This truth pertains not only to gaining scientific knowledge but to gaining any knowledge. Hence assumptions form part of any system of knowledge, not only science. We will come back to this principle later in more detail. 
In sum, the term "ontology" deals with what-questions, or what there is to know.

Different from ontology is epistemology, which stems from the Greek word episteme (knowledge). Epistemology is the branch of philosophy concerned with the theory of knowledge. In short, epistemology is the philosophy of knowledge or of how to come to know and of how we can know. Epistemological problems are the definition of knowledge, accounting for the sources and criteria of knowledge, determining the kinds of knowledge possible, the relation between the one who knows and the objects known, and the grounds that we have for accepting or rejecting knowledge. In other words, epistemology concerns itself with the criteria for what we perceive to be legitimate or valid knowledge. An example is an epistemological claim called empiricism: the belief that we can only know what we can observe/experience by our senses and that there must be an empirical basis for our knowledge in order for that knowledge to count as valid.

Methodology, finally, is the part of the philosophy of science dealing with the specific ways - methods - of gaining knowledge. Differently put, methodology is the practice of science.

In short, any theoretical reasoning needs a starting point provided by ontological, epistemological and methodological assumptions. Together they form the core of a particular philosophy of science.

These core elements of a philosophy of science (the ontological, epistemological and methodological assumptions) will now be discussed in more detail, using positivism as an example of a philosophy of science. Positivism provides the most relevant starting point, considering that this philosophy of science has so far been the most influential, not only in International Relations, but in all sciences - the natural as well as social science disciplines. Most academic work in IR - implicitly or explicitly - is based on a positivist philosophy of science. Step 2 therefore has a double function; first, positivism is used as an example to demonstrate the basics of a philosophy of science. This should make what has been said so far about philosophy of science easier to understand. Second, at the same time, you will already be familiarizing yourselves with the core assumptions found at the heart of many theoretical approaches to IR. This second aspect will make it easier to understand the single theories of IR presented in Part 2 of this book. At this stage, of course, this understanding will still be on the abstract level of philosophy-of-sciencediscussions (meta-theory). Our discussions will take a more substantive form at a later stage when dealing with specific theoretical approaches to IR. 


\section{Step 2:}

\section{Positivism as an example for a philosophy of science}

\subsection{Positivism}

Positivism as a philosophy of science has a long history that draws on traditions of philosophical thought dating back to ancient Greece. The term "positivism" itself was only introduced in the early $19^{\text {th }}$ century by the French philosopher August Comte (Système de politique positive, 1824 and Cours de philosophie positive, 6 volumes by 1842). He claimed the only authentic knowledge was that which is based on experience obtained through the senses; knowledge is based on positive evidence. "Positive" is used in the same way the term is used in the natural sciences: positive evidence in the case of an examination results in "proof". Knowledge can only and has to be reduced to the interpretation of "positive results": a positive result is the outcome of an experiment that provides the evidence for what has been expected/hypothesized (as formulated in a theory). The opposite is when the experiment's outcome has negative results which do not confirm the hypothesis - the scientist does not find evidence of what he is looking for. This concept should be familiar to all of you from medical tests and examinations. Comte's vision was to develop a science of society based on the methods of the natural sciences, with observation and experiment at the core. He considered all sciences, including those of society, as methodologically unified - an important view that shaped the development of the social sciences in the $19^{\text {th }}$ and $20^{\text {th }}$ century. Comte envisioned a project of positivism as a scientifically based world culture - the third stage in the development of mankind's knowledge, following a theological and metaphysical stage (formulated in his théorie des troits états: theological, metaphysical and positive stage).

The work of Comte is influential due to his epistemological positions. It was highly significant to the natural as well as the social sciences at the end of the $19^{\text {th }}$ century and beginning of the $20^{\text {th }}$ century.

Positivism as a philosophy of science will be now introduced in regard to its major ontological, epistemological and methodological assumptions. For didactical reasons, this introduction will take place through two "complexes" of positivist philosophy of science positions. The first complex will be related to questions of what can be known, what counts as knowledge and what exists. In the second complex, the focus will be more related to how to know and the methodology of knowing. 


\subsection{Epistemology, ontology and methodology in positivist science}

\subsubsection{Complex 1}

Positivism is best understood by starting with its epistemological assumptions. This is not a didactical decision; rather, it is because, for a positivist account of science, epistemology matters more than ontology. Scientific priority is clearly given to epistemology. This is due to the privileged status of observation or, in other words, empirical experience. In positivism any statements about what exists depend on what we can know. What we can know in positivism is intimately linked to what we can observe/experience. As the latter question belongs to the domain of epistemology, the positivist account of science thus prioritizes epistemology over ontology. Epistemology is "philosophically prior" - it gives more importance to "what can be known by science" as compared to "what exists".

\section{Empiricism}

The core epistemological position of positivism is empiricism. Empiricism in philosophy is a theory of knowledge (epistemology) which claims that there is (and must be) an empirical foundation for knowledge. Empirical experience is information perceived by the senses; knowledge ultimately results from sensual observation/experience. Hence, positivist science understands observation/ empirical experience to be a representation of reality, not reality itself - as we can only perceive "reality" through our senses. Consequently, only statements about phenomena that can be observed or that can be experienced count as knowledge. This means that only "observables" are the objects of scientific inquiry in the positivist account of science and can be known by science. It thus follows that theories and hypotheses are only acceptable if they can be inductively proved, that is, proved through experience/observation.

As an epistemological position, empiricism was largely developed through British Empiricism and is associated with the works of Francis Bacon, Thomas Hobbes, John Locke, David Hume, and Adam Smith. In Unit 3, you will find core elements of their ideas of science in more detail. However, as will also be demonstrated in Unit 3, empiricism draws on a long historical tradition of philosophical thought that goes back to ancient Greece.

The central features of empiricism become clearer when compared to the opposite position, called rationalism. Rationalism (from ratio, reason) is the epistemological assumption that knowledge mainly derives from human reason. It gives a privileged epistemological status to the human mind (and not to sensory, empirical experience). Rationalism as an epistemological position 
also has a long tradition in European philosophy and is usually associated with the work of René Descartes, Baruch de Spinoza and Gottfried Wilhelm Leibniz. In fact, like empiricism, rationalism actually dates back to ancient Greece and the ideas of Aristotle and Plato.

In short: in positivist science, knowledge derives from experience. Experience is information received through the senses. Only statements about phenomena that can be directly experienced/observed can count as knowledge, whereas any statements that do not refer to the world of observable objects cannot be granted the status of justified knowledge. Empiricism therefore results in a scientific method which requires that all hypotheses and theories must be tested against observations of the natural world. It is a belief that empirical validation or falsification is at the heart of real inquiry. Science is therefore considered to be methodologically empirical in nature. We will come back to the methodological aspects later in more detail.

\section{Materialism/physicalism/ontological naturalism}

The empiricist epistemological core position of positivism is easier to comprehend when linked to the fundamental materialist ontology of positivism; this philosophical position is called materialism or often physicalism. Materialism/physicalism is the ontological assumption that reality ultimately consists of "matter". According to this assumption, the world is a material world and "governed" by the laws of matter (nature). The position is sometimes also called ontological naturalism, in which everything is "nature" - with an understanding of "nature" as physical nature. Physical nature is material nature, hence the position's interchangeable names of materialism, physicalism and ontological naturalism.

A material/physical/natural world can be "observed" by the senses and thus be known, if not directly, then with the help of technological facilities such as microscopes, telescopes, laboratories, etc.

The ontological position of materialism/physicalism/naturalism usually implies not only that the world is ultimately made of "matter", but also that the human mind and consciousness belong to the material world as a result of their ultimately material/physical nature. This nature consists of nerve cells, neurons and the material structure of the brain, the activity of which can be observed for example in computer-assisted tomography. From a materialist ontological perspective, everything - including ideas and human thought are ultimately attributed to matter.

Here again the argument about ontological materialism/physiccalism/ naturalism should be exemplified by pointing to the opposite position, ontological idealism. From an idealist position, the world is ultimately made of 
(immaterial) ideas, theories and mental constructs. The ontological idealist position goes back as far as Plato's theory of forms (or theory of ideas), which states that reality consists of non-material, abstract forms or ideas and not the material world known to us through the senses. The forms or ideas are present "in" nature/matter (physis). These forms or ideas are understood to be distinct, singular extra-mental entities that are plurally represented "in" particular material objects. Forms and ideas are the "essence" of material objects: there is no being (ontology) of material objects without their intrinsic "idea" or form. For example, the idea or form of "circle" is represented by the many material things expressing the form of circles. The essence of all circles is the idea or form of "circle". Forms and ideas are thus superordinate to matter. Ideas/forms are also transcendent to time and space; they are nonlocal and non-physical, even though they are real. The ideas and forms are often called the "universals" that are represented in the many particular things that we can see: the form/idea (universal) "appears" to be material objects (particulars). True knowledge is thus knowledge that the human mind gains about the world of ideas/forms. For Plato, evidence of the existence of abstract forms is by intuition. For example, a tool-maker's blueprints provide evidence that forms/ideas are real and guide the practice of a manufacturer.

\section{Atomism/particularism/individualism}

The materialist ontology of positivism is an atomist one. Ontologically, atomism is the assumption that the (material) world is made up of the smallest indivisible material particles or can ultimately be reduced to such elementary particles. Atomist materialism as an ontological position dates back to ancient Greece in the $5^{\text {th }}$ century BC, especially to the work of Democritus and his idea of atoms (a-tomos meaning “indivisible). In Democritus' cosmology, the universe is assumed to consist of indivisible atoms that move in an empty space. These particles are discrete, hard, unchangeable, and eternal. Epicurus developed this idea further in the $4^{\text {th }}$ century AD. An opposing position also existed in ancient Greece which assumed the world to be a process of continual flux (Heraclitus), but it was not widely accepted.

As you will learn in this unit, the perspective of atomism fundamentally shaped philosophical thought in European history and culture and forms a key part of classical, modern science, above all classical physics. What Democritus believed in ancient Greece later became part of the dominant world view of the modern natural sciences. With modern physics and chemistry, science finally provided atomism - that is, the idea of a universe made of elementary particles, with a natural foundation and proved though observation and experiments. Elementary particles have been shown to be the entities 
that constitute the material world. Consequently, atomism as a materialist ontological position is mainly associated with modern particle physics (also called classical physics). The search for the ultimate elementary particles that comprise the material world has fundamentally shaped the development of classical physics. The ancient Greek belief in the indestructibility of atoms was disproved by nuclear fission in the $20^{\text {th }}$ century: the atom has been demonstrated as consisting of other elementary particles, e.g.. neutrons and protons. With the progress of modern technology, experiments have now proven the existence of far more elementary particles such as quarks, gauge bosons, leptons, hadrons, and probably quite soon the Higgs-Boson. The idea of a world of matter consisting of material particles is familiar to all of us who have been educated in the findings of natural science, especially classical physics. In case you are not familiar with these topics, take some time and do your own research. For example, read about the search for the HiggsBoson (sometimes called the "God particle") in the Large Hadron Collidor at CERN.

The atomist perspective of the natural sciences about "matter" is important because it can lead to a better understanding of scientific thought in other sciences. In both the natural and social science disciplines, positivist science implicitly (and only rarely explicitly) shares a fundamental atomist material ontological position - sometimes also called particularism or individualism - because all disciplines refer to the most basic, elementary "units". We will come back to the notions of particularism and individualism in more detail in Complex 2 below.

From what we have learned about the materialist/physicalist/ontological naturalist and at the same time atomist/particularist ontology of positivism, you can now better understand the notion of an empirical foundation of knowledge that exists at the heart of positivism.

A material, particularist world is observable. Therefore knowledge about this material world of particulars is possible because it can be experienced by the senses/observed.

It is important to emphasize that atomist materialism/physicalism as an ontological position is not exclusive to a positivist philosophy of science but is also shared by other philosophies. What is, however, exclusive for positivism is the linkage to the empiricist epistemological position as described above and the methodology that will be discussed in section 2.2.2. (complex 2). 


\section{Phenomenalism}

As has been mentioned, positivism considers observation/empirical experience to be information perceived by the senses. As such, sensual experience is a representation of reality and not reality itself. Positivist science's particular ontological view of the nature of existence, or being, is therefore also called phenomenalism. From this viewpoint, physical objects do not exist for the observer "as things in themselves", but only as perceptual phenomena. The object of knowing is therefore not "the thing as such", but rather how these things appear to us (= phenomenon). For this reason, positivism as a philosophy of science is called "anti-realist": for the observer, there is no world, no reality "as such", only a representation of that reality (that is, a representation empirically "mediated" by sensual experience). The sensual experience represents the "thing", the object. In positivist science, scientific theories therefore refer to the phenomena, not to "true" reality. This is the background for the positivist claim that any scientific theory and hypothesis has to be formulated in terms of "observables" - as expressed in variables.

So the question arises: if the objects of knowing are perceptual phenomena and not reality itself, how can we achieve valid knowledge?

\section{Objectivism}

The epistemological positions of empiricism and phenomenalism are connected to the view that there is a distinction between facts and values: in contrast to values, facts are "neutral".

On the one hand this position is easy to follow because of the materialist ontology in positivism: what can be experienced/observed is assumed to be a matter of fact. Facts are observable and hence different than values (values would belong to the world of ideas - they cannot be observed and thus are not objects of positivist science). Facts are therefore assumed to be independent of any theory and value-neutral. Facts also form the basis for "objective" knowledge, which can be provided by (positivist) science and its methods.

In essence, science occupies such a central position in modern societies because of the conviction that it is the only means of "producing" objective knowledge. However, in order for facts to become "objective knowledge", science requires the empirical experience to be made evident by experimental and logical "proof". Only verified knowledge counts as "objective" knowledge. Knowledge can be claimed to be "objective" in a scientific sense only under certain conditions. Firstly, the observation or empirical experience has to be verified. In other words, it must be intersubjectively proved by way of repeatable experiment - repeatable by different researchers, independently of 
each other and given the same experimental conditions. For a theory, this implies that all hypotheses and theories have to be tested by empirical experience. In effect, the business of (positivist) science is testing theories and hypotheses about the world of facts (observables). If the outcome is "positive", the observation counts as valid knowledge. What has been proven can then legitimately be claimed to count as valid knowledge.

Such an epistemological position is referred to as objectivism. Objective knowledge about the material world made of particulars is assumed to be fundamentally possible. Positivist science provides the scientific methods to produce such objective knowledge. However, knowledge counts as objective knowledge only until it can be proved false. All hypotheses and theories are therefore provisional in nature.

\subsubsection{Complex 2}

Given the position of positivist science on what can be known, what counts as valid knowledge and what exists, we may ask ourselves the following questions: How can we know about entities such as "the state", "the international system", or "society"? How can we formulate theories and hypotheses about such entities that are not "observable"? These questions lead us to epistemological and methodological aspects of positivist science that address the fundamental issue of how to know and the methods applied in order to know.

\section{Operationalism and instrumentalism}

We will start with a central methodological position of positivist science referred to as operationalism. Operationalism is the position of positivism that requires theoretical terms to be "translated" into observational ones. Because the validity of a theory ultimately rests on the facts, all concepts must therefore be defined operationally. In other words, they must be made into observables. The concepts of science must be defined in terms of the "operations" by which they are measured or applied. A concept is made measurable in the form of variables, which consist of specific observations. Epistemologically speaking, through operationalism we "make" things observable and hence knowable. This position is related to an instrumentalist treatment of theoretical terms. In positivist science, the theoretical term or concept itself is seen as an analytical instrument: a device to "organize" our observations, an instrument to gain knowledge. In line with the materialist atomist ontology of positivism, a theoretical term or a concept (such as "the state"), ontologically has no "being". It exists only by way of the observables into which the term can be "translated", or, operationalized. 
Instrumentalism in the philosophy of science is also related to the view that theoretical concepts are to be judged by their effectiveness. A concept or theory should be evaluated by how effectively it explains or predicts phenomena as opposed to how accurately it describes objective reality.

The philosophical background of the methodological requirement of "operationalization", or in other words, the "translation" of theoretical terms into "observables", deserves closer attention. Is any theoretical term operationalizeable? Due to its ontological materialist-atomist position (the assumption that the world ultimately is made of material indivisible particles), positivist science basically assumes that all theoretical terms are indeed operationalizeable. However, the question also arises of how to make this operationalization possible. This is a methodological question and subsequently also related to the positivist account of explanation. We will approach these aspects in the next step. Beforehand, however, we first need to discuss epistemological and methodological aspects of atomism/particularism in more detail. So far, atomism has been discussed in terms of its ontological aspects. However, atomism/particularism is also a feature of methodology and the model of explanation in positivist science.

To develop the argument about the methodological and explanatory aspects of atomism, we will first return to the general ontological question of how universals and particulars relate to each other, as discussed in Step 1 of this unit. You know from Section 1 that the question of how universals and particulars relate to each other (remember: is the whole more than the sum of its parts?) is one of the central ontological questions. As will be demonstrated, the question of how universals and particulars are assumed to relate to each other is highly relevant for how science is conducted - for the methodology as well as the epistemological aspect of explanation.

To start, please remember that at the core of positivist science lies theory and the formulation of theoretical hypotheses that have to be tested by empirical experience. That is, when we try to know about "society", "the state", "the states system", "institutional structures", or "foreign policy" in the social sciences, positivist research requires that we formulate theories and hypotheses about these "objects" of inquiry in order to gain general, valid knowledge about them. However, from what you have learned so far in Step 1 and Step 2 , you can see that the empirical testing of hypotheses and theories about "society", "the state", or the "international system" is not actually that easy, as these objects are not "observable". They are general theoretical terms. Linking the discussion back to the previously mentioned ontological problem of how "universals" and "particulars" are assumed to relate to each other, general theoretical terms like "the state", "society", "structure", etc., refer to 
what are also called "universals". That is, in most cases in the social sciences, we operate with concepts and theories that do not directly refer to (observable) particulars. As has been said above, methodologically these concepts and theories have to be operationalized, or "translated" into statements about "observables" (by way of variables). From an ontological perspective, the general theories and concepts themselves - as we have seen above - have no being (ontology) and are not assumed to be "real". In positivist science they are analytical "instruments" only.

A huge ontological controversy exists with regard to what extent theories and concepts can be claimed to exist, to be "real". This argument is often called the "universals controversy" and, in the history of philosophical thought, goes as far back as ancient Greece. Because of its relevance to the status of theory in science, it is worthwhile to take a closer look at this controversy by discussing the issue against the background of the broader philosophical debate.

\section{Nominalism}

A core aspect of the "universals controversy" is the question of whether or not general theoretical terms and concepts (the "universals") exist or are simply pure mental constructions. Remember what we discussed in Step 1: a universal is an abstract term such as "man" or "humankind" or mathematical entities such as "number", "relation" or a "class" in biology. For example, does the class "living being" actually exist? Do theoretical terms exist? Are they? Or are they pure conceptualizations of the human mind and as such do not "exist"? The debate goes back as far as Plato and his theory of forms (theory of ideas). As you have learned above, for Plato, ideas and forms (the universals) exist, they are (real). This controversy reached its peak in scholasticism in the Middle Ages; however, it still continues as a philosophical controversy today.

Positivist science usually takes an ontologically nominalist position in the controversy. Nominalism denies the existence of universals, stating that universals and abstract objects do not exist; they have no being. They are only general terms and concepts to which the objects correspond. No objective meaning exists for the abstract words and concepts we use. Features of a universal are thus as follows: pure mental conception, time independence, lack of observableness, no causal effects. An example already mentioned in Step 1 is a universal such as "human" or "humankind" that needs a reference to a particular point in time and a concrete human. Only as a concrete person at a particular point in time can the "human" be "observed" and have a "causal effect". Research on "Foreign Policy" provides another example: only by reference to a particular point in time and a particular policy (such as American 
Foreign policy during the Cold War) does "Foreign Policy" have "existence". It otherwise remains only a general theory or concept, serving as an "instrument", but ontologically without "being".

In other words, in positivist science only "particulars" are claimed to exist (materialism, atomism). Here, universals are terms that can only be exemplified by many particular elements and by what these "elements"/particulars have in common: characteristics, qualities, properties, relations. Universals are abstract and particulars are concrete; humanity is a universal while a particular person/an individual is a particular. The general - universals - do not exist. Instead, they are products of the human mind. The mind generates universals in a process of abstraction, abstracting from time and space and other factors needed to reference particulars/individuals. It results in an abstract idea (a universal) based on the analysis of the commonalities of the particulars/individuals. The "universal" is only the "name" or the idea.Words and abstract ideas have no being. For example, nominalism considers "movement" to be only a word - for the sum of the single, particular physical movements of a body (a position which an artist, painter, or sculptor would certainly deny).

In short, as products of the human mind, universals have no "being" in a positivist account of science. Only the particulars can be claimed to exist.

Nominalism occupied the core of scientific thought in the $19^{\text {th }}$ century, exemplified for instance in the influential works of John Stuart Mill. It featured prominently throughout the $20^{\text {th }}$ century (above all in the works of the Vienna Circle) and still maintains that prominence today.

With regard to universals, nominalism is anti-realist. Please note that anti-realism in regard to universals is nothing specific or exclusive to positivism; it is shared by other philosophies of science as well. For example, for mathematical constructivism, mathematical "objects" such as "numbers" are not assumed to be ontological entities; they have no being but are simply constructions of the human mind. The "number" or "class" as such has no being. This is in contrast to the realist position that mathematical entities (the universals) have their own existence: they are "there" and have to be discovered by natural science.

In the social sciences, realism about universals can be found in the philosophy of science known as scientific realism (for example in the works of Charles Peirce, Bertrand Russell, Edmund Husserl, or Roy Bhaskar). Scientific realism assumes ontologically the existence, the "being" of abstract terms such as "structure".

This brief excursion to the philosophy of science's realism/anti-realism debate, particularly with regard to the ontology of "universals", demonstrates how fundamental the questions at the heart of philosophy of science are. 
However, the debate about the ontological status of "universals" forms only one aspect of the "universals controversy". In addition to this ontological question as to whether universals "are", there is a related "universals problem": the general question of whether a phenomenon can be expressed by or reduced to individual, particular categories in order to be explained. Alternatively, are there phenomena that cannot be expressed by reference to individuals/particulars and therefore require a different method to be known? For those wishing to conduct scientific experiments, these are questions of epistemology and methodology: do knowing and knowledge come about by knowing the whole (universal) or by accumulating the knowledge about the single, particular elements that comprise an entity?

You know that in positivism, we can only know about the material/physical particulars (observables) because any knowledge rests on an empirical foundation. It will be easy to follow that such an epistemological position is associated with a specific method for how to obtain knowledge. Let us take a closer look.

\section{Methodological individualism}

Methodological individualism is the claim of positivist science that phenomena (natural as well as social) must be explained by showing how these phenomena result from their individual parts or elements. How can one explain the features of something as a result of the structure of its atoms or molecules? How can the social behavior of a group result from individual actions? As you can see from these questions, methodological individualism differs from ontological individualism. Ontological individualism (atomism/particularism) is about existence or being; it holds the view that, for example, society consists of individuals and the whole (society) is nothing more than the sum of the parts (the individuals). In the social sciences we find ontological individualism in the claim that society exists because of its elements, the single parts. In turn, those single parts are individuals that finally and ultimately exist through their elementary particles - the natural substance of human being, their brains, DNA etc.

In contrast, methodological individualism is about giving an explanation. "Methodological" means to prescribe a certain method, rather than to make a substantive claim about reality. This view denies that social collectives such as states, associations, interest groups or business corporations can, for example, be explained as autonomous decision makers or agents. A social science that tries to explain social collectives should ground its theories in individual action. Social collectives should be treated as the results of the organization of individuals' particular acts. The basic unit of social life is the indi- 
vidual human action. Explanations of institutions and social change aim to show how these organizations arise as the result of the actions and interactions of individuals. In short, explanations of macro-phenomena must be provided by micro-foundations. Methodological individualism methodically privileges an action-centered view of social scientific explanation. In the social sciences, this view was formulated by Max Weber (Economy and Society, 1922); in economics, for example, by Friedrich Hayek (Individualism and Economic order, 1948). Individual actions are explained by references to the intentional states that motivate the individual actors. Methodological individualism forms an essential part of modern neoclassical economics. It analyzes collective action, or the structure and dynamics of economic institutions in terms of rational, utility-maximizing individuals (homo economicus). Methodological individualism is therefore closely associated with rational choice theory (theory of rational choice or theory of rational action). Rational choice is not a substantive theory. It is an action theory, based on the assumption that individual actors are rational and seek to maximize utility. Individuals make decisions about how they should act by comparing the costs and benefits of different courses of action. Social outcomes are results of those individual choices.

The opposite of methodological individualism is methodological holism (for example, as formulated in the work of Emile Durkheim: The rules of sociological method, 1895), often also called structuralism. Explanations here are given in terms of social wholes or structures and not in terms of the particulars/individuals. For instance, methodological holism claims that the property of a social system cannot be explained by its component parts alone (because ontologically, the whole is more than the sum of its parts). The "system" (whole) determines how the parts behave. Structuralism therefore claims that understanding social practices requires a focus on the structures and organizing principles within which those social practices are framed (a decentering of individual subjectivity). Structuralism is an attempt to scientifically describe the structural principles (or the "logic" of structures) under which an activity could be explained. You will find this view in many variants of structuralism, historicism or other explanatory models that, for example, view the role of social class, gender roles, ethnicity or identities as determinants of individual behavior.

In Part II of this book, we will learn about theoretical approaches to IR whose models of explanation are based on methodological holism/structuralism in more detail. It is important to understand the differences between these methodological positions because they result in different explanations of phenomena of international politics. These different explana- 
tions in turn have far-reaching consequences for the practice of international politics.

From what has been discussed so far, you can see that atomism/particularrism/individualism can be found in the ontology, epistemology and methodology of positivist science. This core argument will be now further exemplified by a brief introduction to "logical" atomism" (or logical positivism).

\section{Logical atomism}

The term atomism as described above for the world of material particulars is also used for elementary theoretical terms and statements that cannot be explained or reduced any further. This position is called logical atomism (also called logical positivism or sometimes logical empiricism) - in contrast to material atomism. Logical atomism became an influential position within analytical philosophy in the 1920 s and 1930 s and throughout the $20^{\text {th }}$ century (for example with Bertrand Russell's works The Philosophy of Logical Atomism, 1918 and Theory of Knowledge, first published in the Collected Papers 1984). Logical atomism was highly influential to the Vienna Circle (especially for the work of Moritz Schlick and Rudolf Carnap).

For logical atomism, the smallest indivisible elementary "units" (the "atoms") are elements of logic. This stands in contrast to ontological materialist atomism, where the "units" are physical particles. In logical atomism, all meaningful statements are functions of truth of elementary propositions. They can be finally represented by atomic propositions. Theoretical statements are required to be reducible to elementary "protocol statements" or, in other words, statements whose validity can either be proved intersubjectively by sensual experience/observation or at the very least can be brought into a logical relation to protocol statements. Once this relation is established, they can finally be proven (verified) by accepted protocol statements. Accepted protocol statements are understood as conventions - based on intersubjective agreement. For logical positivists, science implied that the content of scientific theories could be finally reduced to truths of logics and mathematics.

\section{Reductionism}

You will have noticed that the term "reduced" has been mentioned in the previous sections on atomism and methodological individualism several times. In positivist science, a system or a thing is not only assumed to be made of particulars (ontology) but can be (methodologically) reduced to and explained by its elements. This has been described above as methodological individualism and logical atomism. For example, in logical positivism, theo- 
ries are reducible to elementary protocol statements; in materialist atomism, things are reducible to smallest indivisible particles etc. Both theories and material entities can finally be explained in terms of the particulars.

The term reductionism might be seen as the broader, more general term. We are discussing it here in a separate paragraph because of its more fundamental nature as a specific mode of thought found at the heart of positivist science. The ontological as well as methodological and epistemological assumptions of positivist science all reflect reductionism. However, when we say "reducible to", we are usually referring to explanation and method.

The notion of emergence provides an example for the opposite of reductionism in explanation. Emergence describes a case in which a system or a thing possesses a property that is NOT reducible to the parts or single properties of its parts. It excludes the principle of reductionism. For example, in systems theory, hierarchically structured systems have properties on the macro-level that cannot be found on the micro-level. On the macro-level they occur, emerging from the interaction of their elements on the micro-level, but cannot be reduced to those elements or explained in terms of them. It requires a different methodology to reach an explanation of the system (the whole). This position has been referred to above as methodological holism.

Reductionism in its broader meaning is also exemplified by the famous "Ockham's razor": the principle of parsimony/lex parsimoniae. It requires giving preference to the explanation based on the smallest number of hypotheses and hence presents the most simple, parsimonious theory. The theory should include as few variables and hypotheses (standing in clear logical relation to each other) as possible. In fact, the position of reductionism dates back to ancient Greece with Aristotle's view that nature chooses the simplest way - which, incidentally, is an ontological claim. But with Ockham, parsimony became an epistemological principle: the requirement that, when building theories, needless elements should be eliminated. Going further, in the case that different theories exist to explain the same phenomenon, Ockham's position would give preference to the most parsimonious theory. This principle became influential in the $19^{\text {th }}$ century and has been spread above all by John Stuart Mill. More recently, the principle has been called "economy of thought" (Denkökonomie, a term probably first used by Richard Avenarius).

In short: In positivist science, the ontological claim of a material, atomist/particularist/individualist world (that is, a world of observables) and an ontological nominalist position in regard to "universals" is complemented by an epistemological and methodological reductionism. For science this implies the following: in order to know about the "whole", we have to study the parts which comprise it. 


\section{Unity of science}

Consequently, reductionism is also found in the positivist belief in the ideal of a unity of science. This belief holds that all phenomena of the world can, in the final analysis, be explained by the fundamental, elementary science: classical physics. This principle reduces all scientific disciplines to an "elementary science", with the expectation of a unified perspective of reality. For example, a belief in the unity of science assumes that chemistry is reducible to physics (because a chemical element is reducible to the arrangement of atoms and molecules), that biology is reducible to chemistry (and chemistry then to physics), or psychology to biology or biochemistry (holding, for example, that the explanation of depression is ultimately reducible to a lack of neurotransmitters, which in turn is "observable"/measurable).

In its most radical form, the belief in the "unity of science" ultimately results in the conclusion that even social sciences are reducible to physics or that a theory of the social sciences should be in line with the major findings of the natural sciences. The idea of the unity of science has been spread since the 1950s. Examples include Oppenheim and Putnam (1958). For a more recent discussion as related to IR see Wendt $(2006,2010)$.

As an epistemological and methodological position, the assumption of a unity of science gives a privileged position to the natural sciences and their methodology. The idea emerges that any science, including the social sciences, should be based on the methodology and model of explanation used in the natural sciences. Social science can therefore be studied in the same manner as natural sciences; there is a single scientific method which can analyze both the natural and the social world.

Contrasting arguments can be found in the works of Max Weber, Emile Durkheim, Wilhelm Dilthey, Martin Heidegger and Georg Gadamer, among others. These works claim that the social world requires a different form of analysis than the natural world, such as hermeneutics- the science of text interpretation and understanding. They take this position because, in the social world, all analysis is embedded in language, history and notions of truth; reason are themselves historically constituted. Further, in the social sciences, there can be no truly objective knowledge because the subject who interprets and observes is part of the world he/she is analyzing.

Reductionism can be seen as the most orthodox position both in the $20^{\text {th }}$ century and today. It can be read as an absolutizing and prioritization of physics. The success of modern science unquestionably provides the background for the success of reductionism. However, a trend of antireductionism has been growing for about 30 years. This trend emerged mainly as a result 
of findings in neurophilosophy or biophilosophy that demonstrate the problems of a reductionist explanation of phenomena such as human consciousness. Phenomena of the social world or such as the human mind appear more generally not to be reducible to phenomena that can be explained by the classical approach of the natural sciences. In the social sciences, the spread of social constructivist theories, theorizing the existence of "immaterial factors" such as the role of norms, collective ideas and collective representations, and learning etc. also provides a good indicator for the growth of antireductionism. In addition, the simple fact remains that a unifying of sciences did not take place in terms of methodology and epistemology. Rather, diversification occurred in terms of the ontological, epistemological and methodological positions that underlie theory building. For IR, this trend away from reductionism became clear at the very latest in the so-called positivism-postpositivism debate, which has been taking place since the 1990s. This debate will be discussed in the next section (2.3.).

Finally, let us conclude our discussion of positivism as an example for a philosophy of science by focusing on its notion of causality and the specific type of explanation. Reductionism goes hand in hand with a specific conception of causality and explanation: the idea that, ultimately, single causes exists for any phenomenon observed.

\section{Causal, law-like explanation and the belief in prediction}

Positivism is based on the assumption that the material world of particulars is governed by laws and that we can gain scientific knowledge about this material world and its laws through (positivist) science. The term "law" refers to regularities or the "order" of the world. With regard to explanation, positivism derives its understanding of the term explanation from a fundamental belief in the existence of regularities or laws in the natural as well as social world. At the heart of these regularities are cause-effect-relationships between the entities.

In positivist science, explanations establish a causal relation, also called a cause-and-effect-relation. This account of cause was originally influenced by the Humean account of the term (David Hume 1748, An Enquiry Concerning Human Understanding). Hume's idea was based on the experience that particular objects temporally appear together: when A occurred, so did B. Establishing a causal relationship in the Humean account of cause means discovering the temporal relationship between observed events.

In positivist scientific inquiry, the cause is the independent variable. The effect is the dependent variable. Variables (consisting of specific observation) stand in interrelation: the value of the dependent variable depends on a 
change in the value of the independent variable. If this occurs, we speak of correlation. Correlation indicates the strength and direction of a linear relationship between two variables. Certain phenomena in international politics provide examples of such a correlation, for example the outbreak of a war or a conflict which can be observed to be linked to a particular type of political system of the conflicting parties. The theoretical statement about the relationship usually takes the form of an if-then-hypothesis. When proved "positive", an explanation indicates the law-like succession of empirical phenomena. Taking up the example mentioned previously, such a "law" has been formulated in the theory of inter-democratic peace. This law is based on the hypothesis that democracies do not fight each other. It has been empirically proved (here by statistical observation with the Correlates of War project at the University of Michigan) and is now usually presented as the empirically best-proven theory of IR. If we were to formulate this theory as a causal relation in terms of "if, then", it would read as follows: if international relations take place between democracies, then there will be no war between them".

However, establishing a correlation between two variables is not a sufficient condition to establish a causal relation. Causal analysis in science is more complex. However, for the purposes of this learning unit, the example of correlation should be enough to indicate the nature of the specific type of causal relation between independent and dependent variables found at the heart of positivism: there is a cause for each phenomenon. The effect of a phenomenon temporally follows its cause; ultimately, a single cause emerges for the effect observed or the explanation is reducible to a single cause. A positivist explanation is thus a statement about the interrelation of an (observable) cause and an (observable) effect. If the (theoretically) hypothesized interrelationship between cause and effect can be scientifically verified, the explanation counts as valid knowledge (law-like).

There are two typical forms of law-like explanations in positivist science: the deductive-nomological and the inductive-statistical forms of explanation.

The deductive-nomological model of scientific explanations developed by Carl Gustav Hempel and Paul Oppenheim at the end of the 1940s (Hempel and Oppenheim 1948: Studies in the Logic of Explanation) was an important stage in the development of positivism. Since the 1950s and 1960s, it has become a standard model of scientific explanation. The deductive-nomological model is the formal structure of a scientific explanation which is derived by way of deduction: from the abstract (the general law as the explanans) to the particular (the statements to be explained, the explanandum). A scientific explanation here is a deductive argument that shows that a particular event is 
"covered" under a general law (nomos in Greek). The model is also known as the "covering law model" or "subsumption theory".

It has been complemented by the inductive-statistical model of explanation. In this model, explanations for an event fall under a statistical law. Statistical or probabilistic laws are established inductively (that is, by inferring from single events to a general law, going from the concrete to the abstract) and are used to show how, given the established law, a specific event is highly likely (Smith 1996: 15).

From what has been said about the causal, law-like nature of a positivist explanation, it follows clearly that positivist science holds the fundamental belief that prediction is possible. An account of explanation as a temporally linked relation of cause and effect enables prediction: if A, then B.

Given the existence of other epistemologies such as hermeneutics, which claim that the social world requires a different form of analysis than the natural world, it is easy to conclude that there will be other notions of explanation in the social sciences. For example, Max Weber argues along these lines against the positivists, stating that to explain human behavior, not only are its external manifestations required (observables), but also knowledge of the underlying motivation. From this argument stems Weber's definition of sociology as a science which aims to produce an interpretative understanding of social behavior in order to gain an explanation of that behavior's causes and effects. For Weber, interpretative understanding is a preliminary step towards causal relation. However, Weber holds that, in order to be considered a scientific explanation, any interpretative explanation must first become causal. Understanding and causal explanation invariably belong together as methods in the social sciences (Weber 1949). The example of hermeneutics should briefly demonstrate that there are different stances as to what counts as a scientific explanation. You will learn about these different models of explanation in Part II of this book.

Based on the example of positivism, you may now have the impression that philosophy of science is an incredibly abstract and complex field. However, if you think about it, philosophy of science in fact forms an intrinsic part of our everyday life. The problems which this field reflects for science are more or less the same problems that exist in human thought in general. Of course, we do not often reflect on this in our day-to-day lives.

The same argument holds true for IR theorists who formulate theories about international politics. Only rarely do they explicitly reflect upon the underlying philosophical positions that shape their theoretical ideas about world politics. Instead, these positions are often taken for granted.

When reading about the theories of IR presented in Part 2 of this book, you will recognize how important it can be to take the time to look more 
closely at the meta-theoretical foundations of our thinking about international politics. Ontological and epistemological claims both have consequences for scientific research and subsequently - and most importantly - for the practice of international politics.

\section{In sum}

Philosophies of science are integrated philosophical complexes. For example, the epistemology and methodology of positivism would be meaningless when combined with an ontological holist position because, in ontological holism, a whole is not reducible to its parts. The whole thus cannot be explained by studying its single parts.

Because of their integration of ontological, epistemological and methodological aspects, I suggest we refer to philosophies of science more generally as "orders of thought". This has been demonstrated, for example, by the discussion of atomism/particularism/individualism and reductionism as integrated complexes of philosophy of science positions with ontological as well as epistemological and methodological aspects. The notion of "orders of thought" will be revived in more detail in Unit 3 of the book.

Before we move on to Unit 3, let us briefly reflect on why discussing philosophies of science is relevant for the academic discipline of IR.

\subsection{Competing philosophies of science in IR}

In the academic discipline of International Relations, systematic references to the philosophy of science on a larger scale started in the 1950s with the behavioral revolution in political science (a good reflection on that is the volume of Knorr/Rosenau 1969). In the early years there was a lack of legitimization in terms of the philosophy of science, partly due to the underdeveloped state of the field at this time. Since the 1950s, legitimization in terms of the philosophy of science has become a typical feature of IR theory. A large part of the historical development of IR as an academic discipline after World War II thus revolved around establishing a more scientific basis for the discipline. From that point onwards, references to the philosophy of science (in the literature you will usually come across references to the work of Thomas Kuhn (1962), Karl Popper (1959), Paul Feyerabend or Imre Lakatos (1970)) has been a common feature of IR theories.

The result has been a subsequent embedding of the positivist philosophy of science within the academic discipline of IR to such an extent that the terms "science" and "positivism" have been used and are still used synony- 
mously. Science became positivist science. The "scientific" study of IR thus came to mean a scientific approach based on positivism. There has been a continuing attempt to see the discipline's development up this point in terms of increasing claims of "scientific" knowledge. From what we have learned earlier in this chapter, it becomes clear why IR scholars claim "cumulative" knowledge in the progression of IR as a science. IR derives from the methodologically refined study of the separate objects of international politics, split into such diverse fields as "foreign policy analysis", conflict studies, security studies, international political economy, international organization, development studies, environmental studies, area studies etc.

On the other hand, there have always been deep debates over the very idea of science and the extent to which International Relations can be and should be a science. This became clear as early as the 1960s, with the widespread controversy between "traditionalists" and "scientists" (positivists) over the appropriate methods for studying IR (remember the arguments in the texts written by Bull 1969 and Kaplan 1969 from your self-study in Step 1). The "classical approach" (Bull 1969) criticized positivism for leaving a large and important part of international politics unexamined because of a strict epistemological view.

The latest controversy in IR between positivism and post-positivism has been taking place since the 1990s and once again involves the issue of science and meta-theory. The debate has become more intense and the positions increasingly more diverse. At its core lies the role of positivism in IR, which has now become a controversial issue. Since these debates started, contentious discussions about which ontology, epistemology and methodology is appropriate for the study of IR have been at the core of the discipline. However, the commonly used label of "post-positivism" to classify all nonpositivist approaches is misleading, since no such thing as a "post-positivist" philosophy of science exists. Rather, the controversy brought to the forefront the existence of a wide range of different understandings of science within the discipline of IR. All of these understandings critique positivist science. However, they draw on different philosophy of science positions such as constructivism, realism (such as scientific and critical realism), pragmatism, or historicism. From what you know about philosophies of science, it is easy to follow that those who reject positivist IR theory do not necessarily oppose systematic inquiry or the general idea of science. Rather, the specific understanding behind the term "science" differentiates those views. Only very few theories of IR are "anti-science", rejecting the very idea that scientific knowledge is possible. What unites most different approaches to IR is an understanding of science as a systematic inquiry that employs method for the 
purpose of gaining knowledge about international politics. They provide, however, different ontological perspectives on the core subject and how it can be studied by IR. In other words, the very idea of science as a system of knowledge lies at the core of debate.

Unfortunately, it is beyond the scope of the book to present the different philosophies of science found in contemporary IR theories in as detailed as a manner as that used for the example of positivism. Different epistemological as well as ontological and methodological claims found in contemporary IR theory will feature at a later stage in our book, when we come to dealing with the single theoretical approaches to IR in detail. While discussing these theories, you will therefore also be learning about other philosophies of science.

\section{Step 3:}

Check your understanding: Key aspects and review questions

\section{Key aspects}

- Academic disciplines legitimize themselves as science through reference to a philosophy of science. There can be different philosophies of science dominant within a discipline at different points in time.

- The object of investigation in the philosophy of science is the nature and practice of science itself. Any philosophy of science is based on ontological and epistemological assumptions, as well as methodological ones.

- In the academic discipline of International Relations, systematic reference to the philosophy of science at a larger scale started in the 1950s with the behavioral revolution in political science.

- Most of IR theory is based on a positivist understanding of social science. For a long time, the positivist philosophy of science dominated the academic discipline to such an extent that the terms "science" and "positivism" have been used synonymously.

- Discussing theories in terms of their underlying philosophy of science is highly relevant because of the ontological effects as well as its consequences for the practice of international politics. 


\section{Review questions}

1. What is a philosophy of science?

2. Which criteria allow International Relations to be counted as a science? What does a "scientific study" of international relations mean?

3. What are the implications of positivism for the study of International Relations?

4. What is the relevance of discussing theories of International Relations in terms of their underlying philosophy of science?

\section{Step 4: \\ Consolidation}

\section{Required reading}

On positivism as a philosophy of science and positivism in IR

(1) Smith, Steve 1996: Positivism and beyond, in: Smith, Steve/Booth, Ken/Zalewski, Marysia (eds.): International Theory: Positivism and Beyond. Cambridge: Cambridge University Press, 11-44.

(2) Wight, Colin 2002: Philosophy of Social Science and International Relations, in: Carlsnaes, Walter/Risse, Thomas/Simmons, Beth A. (eds.): Handbook of International Relations. London: Sage, 23-51.

For the debate about appropriate methods for the study of IR in the 1960s

(3) Bull, Hedley 1969: International Theory: The Case for a Classical Approach, in: World Politics 18: 3, 361-377.

(4) Kaplan, Morton A. 1969: The New Great Debate. Traditionalism vs. Science in International Relations, in: Knorr, Klaus/Rosenau, James (eds.): Contending Approaches to International Relations. Princeton: Princeton University Press, 39-61

\section{Supplementary reading}

\section{On the philosophy of science in general}

Chalmers, Alan 1999: What is this thing called science? Milton Keynes: Open University Press.

Chalmers, Alan 2006: Wege der Wissenschaft. Einführung in die Wissenschaftstheorie. 6. Aufl., Berlin: Springer.

Gellner, Ernest 1968: Holism versus Individualism, in: Brodbeck, May (ed.): Readings in the Philosophy of the Social Sciences, New York: Macmillan, 254-268. 
Hollis, Martin 1994: The philosophy of Social Science. An Introduction. Cambridge: Cambridge University Press.

Okasha, Samir 2002: Philosophy of science: A very short introduction. Oxford: Oxford University Press.

\section{On methodological individualism}

Kidd, Andrew H. 2008: Methodological Individualism and Rational Choice, in: Reus-Smit, Christian/Snidal, Duncan (eds.): The Oxford Handbook of International Relations. Oxford: Oxford University Press, 425-443.

Snidal, Duncan 2002: Rational Choice and International Relations, in: Carlsnaes, Walter/Risse, Thomas/Simmons, Beth A. (eds.): Handbook of International Relations. London: Sage, 73-94.

\section{On reductionism}

Charles, David/Lennon, Kathleen (eds.) 1992: Reduction, explanation and realism. Oxford: Oxford University Press.

Jaegwon, Kim 2005: Physicalism, or something near enough. Princeton: Princeton University Press.

Kolakowski, Leszek 1969: The Alienation of Reason: A History of Positivist Thought. New York: Anchor Books.

\section{On explanations}

Wendt 1998: On constitution and causation in International Relations, in: Review of International Studies 24, 101-117.

Dessler, David 1991: Beyond Correlations. Towards a causal theory of war, in: International Studies Quarterly 35, 337-355.

Van Fraassen, C. 2008: The world of empiricism, in: Hilgevoord, Jan (ed.): Physics and our view of the world. Cambridge: Cambridge University Press, 114-134.

Hollis, Martin/Smith, Steve 1990: Explaining and Understanding International Relations. Oxford: Clarendon Press.

\section{On hermeneutics and understanding}

Baumann, Zygmunt 1978: Hermeneutics and Social Science. London: Hutchinson.

Outhwaite, William 1975: Understanding Social Life: The Method called "Verstehen". London: Allen \& Unwin.

Rabinov, Paul/Sullivan, William M. (eds.) 1979: Interpretative Social Science: A Second Look. University of California Press.

Hollis, Martin/Smith, Steve 1990: Explaining and Understanding International Relations. Oxford: Clarendon Press. 


\section{References in the text}

Czempiel, Ernst-Otto 1965: The Development of the Study of International Relations (in German), in: Politische Vierteljahresschrift 6: 3, 270-290.

Kaplan, Morton A. 1961: Is International Relations a Discipline?, in: The Journal of Politics 23: 3 .

Kaplan, Morton A. 1969: The New Great Debate. Traditionalism vs. Science in International Relations, in: Knorr, Klaus/Rosenau, James (eds.): Contending Approaches to International Relations. Princeton: Princeton University Press, 39-61.

Kidd, Andrew H. 2008: Methodological Individualism and Rational Choice, in: Reus-Smit, Christian/Snidal, Duncan (eds.): The Oxford Handbook of International Relations. Oxford: Oxford University Press, 425-443.

Kuhn, Thomas 1962: The Structure of Scientific Revolutions. Chicago

Lakatos, Imre 1970: Falsification and the Methodology of Scientific Research, in: Lakatos/Musgrave (eds.): Criticism and the Growth of Knowledge, Cambridge.

Oppenheim and Putnam 1958: The Unity of Science as a Working Hypotheses, in Minnesota Studies in the Philosophy of Science.

Popper, Karl 1959: The Logic of Scientific Discovery. London (first 1935 in German).

Smith, Steve 1996: Positivism and beyond, in: Smith, Steve/Booth, Ken/Zalewski, Marysia (eds.): International Theory: Positivism and Beyond. Cambridge: Cambridge University Press, 11-44.

Wight, Colin 2002: Philosophy of Social Science and International Relations, in: Carlsnaes, Walter/Risse, Thomas/Simmons, Beth A. (eds.): Handbook of International Relations. London: Sage, 23-51.

Wight, Colin 2006: Agents, Structures and International Relations. Politics as Ontology. Cambridge: Cambridge University Press.

Weber, Max 1949: Max Weber on the Methodology of the Social Sciences. New York: The Free Press. 


\section{World views and the idea of science in the history of European philosophy}

Learning steps

Introduction

Step 1:

World views

Step 2:

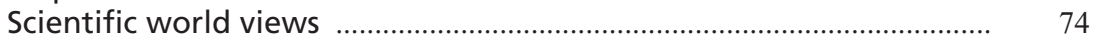

2.1. Greek Antiquity ............................................................................

2.2. The European Middle Ages and Renaissance ……………………...... $\quad 78$

2.3. Scientific revolution and the rise of Cartesian-Newtonian science ........ 80

Copernicus, Galileo, Kepler: The rise of experimental science ............. $\quad 80$

Descartes and Newton .................................................................... 82

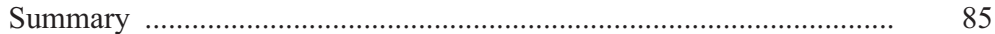

2.4. Cartesian-Newtonian science in transition? "New physics" and the rise of a new scientific world view? ............................................................ $\quad 88$

2.4.1. Einstein and atomic physics ............................................................ 90

The dual nature of light ...................................................................... $\quad 90$

Time, space, matter and energy .......................................................... 90

Elementary particles ....................................................................... 92

2.4.2. Quantum physics .......................................................................... 92

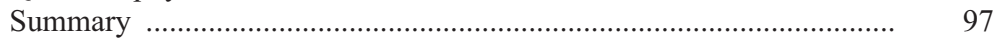

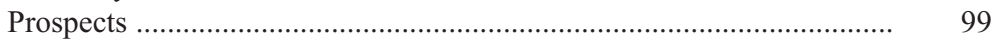

Why is this discussion a relevant one? ................................................ 100

Step 3:

Self-study and consolidation .................................................................. 102

Step 4:

Discussion 


\section{Introduction}

The core argument developed in Unit 1 of this book holds that the history of IR theory is part of a two-fold process: the historical process of centralization and consolidation of power by which the modern state and the modern states system have been historically formed in Europe and which is simultaneously a process of increasing systematic reflection on inter-state relations in the fields of philosophy, political theory and international law. This process of reflection was driven by the rising social and political significance of interstate relations for societies. Put differently: in terms of the history of thought, state theory (or political theory) and interstate theory (later International Relations theory) comprise part of these historical processes of the formation and development of the modern state and the modern states system since the $17^{\text {th }}$ century. Scholars have demonstrated that both the state/states system and theoretical reflection about this state and the states system are historically of European origin.

In this unit, the arguments developed in Unit 1 on the core subject of IR (the modern state and international relations in the modern states system) will now be linked to the arguments about the scientific study of this core subject in the academic discipline of IR (as developed in step 1.2. of unit 1 and in unit 2). This will be done through historical reflection on the idea of science in European history - the same way we reflected before on the core subject of the discipline (the modern state and the modern states system) and on the theory of interstate relations. In short, we will take up the arguments on the European origin of IR's core subject and on the theory of interstate relations by embedding them in a broader discussion of the historical emergence of the (European) idea of science in (European) philosophy. What we in the academic disciplines consider to be the "object" of our scientific study, our ideas of how to study this object, and which methods we should apply to that study are all culturally and historically embedded in overarching orders of thought.

A deeper understanding of theory building in IR therefore requires an awareness of the interconnectedness of these processes. Consequently, it also requires readers to risk separating the discussions on the core subject of the discipline from the theories about the core subject and the general idea of science underlying those theories. In brief, any study of "IR theories" as a separate subject is incomplete when divided from its underlying history and philosophy of science. This broader discussion will finally help us to understand where we derive the assumptions as the "starting points" of theory building and the specific theoretical constructions found at the heart of IR theories. 
The overarching cultural and historical embeddedness of the idea of science will be discussed by using the notion of a "world view".

\section{Self-study (1)}

In case you feel the need to refresh your knowledge about the historical processes of state formation and inter-state theory, it is recommended that you now take some time to go back to the summary at the end of Unit 1, Step 1.1. before you start reading about world views.

\section{Step 1: World views}

What is a world view? This question is admittedly a difficult one, as we are talking about a term that is used in many ways - usually as related to the different "world views" of religious systems or ideologies. For example, there is a philosophical core of Buddhism made of assumptions from which Buddhist thought and practice are logically derived. The same can be said about Islamic philosophy and other religious systems of knowledge. At a first glance, to apply the term "world view" to ideas of science could be confusing, as we usually don't assume that science depends on a "view" or perspective. Rather, we tend to see science as relating to a system that produces "objective" knowledge that does not depend on a view or specific perspective of the world. Let me therefore introduce the idea of world views as it will be used in this chapter. I will do so by way of an example that will be familiar to you and for which the notion of "world view" is a widely used and accepted term: the existence of the geocentric (Ptolemaic) world view as developed in Greek antiquity was universally accepted until it was replaced by the heliocentric (Copernican) world view in the $16^{\text {th }}$ century. In case you need to refresh your knowledge of geocentrism and heliocentrism, please take some time and do your own research on the terms.

To give a brief summary here, the geocentric world view was developed in Greek antiquity and is basically associated with the work of Ptolemy. Ptolemy was a mathematician, astronomer and geographer who likely lived around $90 \mathrm{AD}$ to $168 \mathrm{AD}$. Ptolemy presented a geometrical model for calculating celestial motions based on astronomical observation and for the purpose of calculating astronomical phenomena like the future and past positions of planets. The model was a geo-centric one, meaning that Earth occupied the center of the universe, with the sun, the moon and the planets moving around 
the world on geometric curves. The geocentric model - which was also used by Aristotle - served as the universally accepted model for more than 1400 years. The work of Ptolemy remained the authoritative text on astronomy throughout the Middle Ages. The geocentric world view lasted until the end of the Middle Ages in the $16^{\text {th }}$ century. It was accepted to be "scientifically true" until it was "replaced" by the heliocentric world view.

The heliocentric world view is mainly associated with the works of Nicolaus Copernicus (1473-1543) and is therefore often called the Copernican world view. With his major work De Revolutionibus Orbium Coelestium in 1543, Copernicus formulated a new world view of the universe. In his model, the sun (not the earth) occupies the center of the universe, with the earth and the planets moving around the sun and the earth rotating on its own axis. He was inspired by the work of the ancient Greek Aristarchos of Samos, the first person reported to have promoted such a heliocentric model of the solar system. Aristarchos created his model sometime around the $3^{\text {rd }}$ century, but gained little acceptance for his work at that time. With his own heliocentric model, Copernicus was able to solve the inconsistencies of the geocentric Ptolemaic model by introducing new hypotheses. Copernicus's model was mainly used for the mathematical calculus of astronomical phenomena until around 1610, when Galileo "proved" the model's physical reality based on observations made with his famous telescope. The works of Johannes Kepler (1571-1630), a philosopher, mathematician, astronomer, optician and theologist, further consolidated the heliocentric world view. Kepler formulated the exact mathematical model for heliocentrism, known as Kepler's laws of planetary motion.

The works of Isaac Newton, particularly Newton's law of gravity (1687), finally proved the heliocentric world view to be correct in its physicalist explanation. Just to give you an idea of the time span involved in the transition process, Newton came up with the law of gravity more than 240 years after the publication of Copernicus's major work. After Newton, the heliocentric world view gave rise to the dominance of what is called CartesianNewtonian science in a process well-known to all of us as the scientific revolution. The rise of Cartesian-Newtonian science will feature in our discussion at a later stage (Step 2.3.). Heliocentrism lasted until it was replaced by the world view that our sun system is not the center but only a tiny part of the universe - a view finally accepted in the $18^{\text {th }}$ century. For an excellent overview of the geocentric and heliocentric world views, see Bedenig 2011: Chapters 1 and 2, 19-53.

From this brief introduction to the geocentric and heliocentric world views, you can draw several conclusions. First (1), these world views present attempts of astronomers, mathematicians, and philosophers (in Greek antiqui- 
ty usually all embodied in one person) to describe the "order" of the universe based on models derived from observation and mathematical calculus. The intention of these models was not only to describe and explain but also to predict - for example, anticipating the future positions of planets. Second (2), the world views were accepted as "scientifically true" for long periods of time that encompassed anywhere from hundreds up to more than thousand years. However, world views are (3) not eternal but subject to transition and change, driven by the progress of science. Finally (4), usually different, competing world views exist simultaneously, but only one of them becomes historically accepted.

In short, world views comprise perspectives and persistent, long-term patterns of thought on the "being" of the world, its laws and relation to the cosmos. A world view can be described as the dominant interpretation of an historical age's state of knowledge regarding the most basic questions of humankind; questions about how the world came into being, which position humans occupy in the cosmos, and what and how we can know about the world (Bedenig 201: 16). As such, world views comprise something very comprehensive that goes far beyond what a theory or a philosophy of science can express: world views are fundamental orders of thought. Quite often these world views are also referred to as "world systems" (see Harrison 2000: 2), as they present "systematic" models or "systems" of thought. We usually find the "elements" of a particular historical age's world view in the sciences as well as in literature, arts, architecture, music and many other areas. We will develop this argument of the comprehensive, all-encompassing nature of world views later in more detail.

The world views presented above with the examples of geo- and heliocentrism are both world views associated with ideas of cosmology. Cosmology is the theory or philosophy of the world as it relates to the origin, development and structure of the universe. As a serious scientific area of study and an academic discipline, cosmology began in 1917 with the works of Albert Einstein, especially those on the "static universe". Since then, cosmology has developed from a mathematical and philosophical area of study into a mainstream branch of physics and of science more generally (for an excellent overview see Harrison 2000 and Ellis/Maartens/MacCallum 2012). In this regard, cosmology today forms an integral part of physics, chemistry, astronomy as well as philosophy. It also provides the background of these single disciplines. Cosmology's object of study is the universe as a whole. As a core subject, this is indeed unique compared to other sciences.

To help you to best achieve the learning objective of this unit, the following discussion will draw on those aspects of world views that relate to the 
systematical and methodological study of the order of the universe. Therefore, hereafter the term "scientific world view" will be used because the focus will be on the ideas of science inherent in the world views. As has been mentioned above, world views are not eternal but rather subject to transformation and change driven by the progress of science. This argument points to an intrinsic link between philosophical thought about "the world" and the idea of science. The argumentation in this unit will be guided by the thesis that a mutual dependency of philosophy and science forms a central feature of the history of thought in Europe. Learning about this interdependency will enhance our understanding of theory building in the social sciences and of the particular theoretical constructions found at the heart of all theories. In other words, this unit will present world views by means of the historical understandings of science they incorporate.

As mentioned above, scientific world views are perceived as long-time persistent patterns of thought about the existence of the world, how to learn about the world, what counts as valid knowledge about the world, and the methods used to obtain this knowledge. In other words, the focus will be on ontological, epistemological and methodological "elements" found in scientific world views. These "elements" are already familiar to you from your reading in Unit 2, which introduced ontological, epistemological and methodological assumptions as the core of philosophies of science.

Our discussion of scientific world views proceeds along the same lines of the "elements" of a philosophy of science. However, now the discussion will be extended to the realm of philosophical reflections that go far beyond particular philosophies of science (such as positivism). The focus will be on the idea of science as formed and reflected in the history of European/Western thought more generally. You will learn how important the early scientific world views of Greek antiquity proved to be for the development of European science and to what extent our contemporary study of theory in the diverse disciplines of the natural and social sciences have been shaped by scientific world views that emerged in this historical process. The discussion will also improve your understanding of where philosophies of science (such as positivism) are derived from and which theories they are embedded in. In addition, this unit will provide a framework to discuss other philosophies of science. Finally, this approach will help us to better understand contemporary theory building in IR, especially against the background of the diversity of theoretical approaches that the so-called positivism-postpositivism debate has brought about.

Please note that, as was the case in Unit 1, the term "scientific" here refers to the general idea of a systematical, methodological study of the world, 
based on theory and for the purpose of generating human knowledge. In other words, the term science itself is not attributed to a particular philosophy of science (such as positivism).

This unit is not intended to provide a comprehensive presentation of the European history of philosophical thought. In line with the learning objectives of this book, the discussion will instead draw on selected aspects that are necessary for learning about the historical emergence of the idea of science. The unit aims to provide you, the readers, with the ability to identify the basic lines of philosophical and scientific thought that underlie particular theories of IR. This unit will help you to better understand the following: the nature of assumptions as starting points for theory building; the specific theoretical constructions offered by theories of IR; and the role and status of theory in IR and the practice of international politics. For those keen on learning more deeply about scientific world views in European philosophy, there will be a list of recommended supplementary reading at the end of this unit.

Highly relevant to our learning purposes is a discussion of the idea of science as it emerged in the European history of thought. As you learned in the previous unit on positivism, during the modern age (positivist) science has gained the status of a superior system of providing objective knowledge, considered superior to any other systems of knowledge such as religions or myths. It also claims superiority over any other understanding of science and thus enjoys a very prestigious status in Western societies. However, the question of whether or not it is possible to provide "objective" knowledge, as well as positivist science's claim of being able to causally explain and predict phenomena, are both highly debated issues. This holds particularly true given the complexities of our social, political, economic, technological and cultural world. The current economic, financial, environmental, political and legitimation crises our world is experiencing, their causes, and the strategies used to "solve" these crises all raise serious doubts about the scientific claims of mainstream economic and political science. These and other sciences have driven political, economic and technological processes for long periods of time, in fact since the scientific revolution in the $17^{\text {th }}$ century. A critical reflection and debate on scientific claims has always been part of the theoretical controversies in the diverse disciplines but never has so much been at stake as in the present moment. The crises are serving as indicators that our economy, politics and natural living conditions have been shaken to their foundations. Consequently, a general discourse on the role and status of science and theory in our society is absolutely inevitable. This applies not only to the academic discipline of IR but to international politics as well. At the end of this book, we will take up this issue of the current relevance of a 
discussion of science and you will be invited to actively take part in the debate.

Last but not least, the lines of argument in the discussion below are, out of necessity, based on my personal reading, interpretation and understanding of the history of scientific world views. They stem from my subjective selection of aspects that I have come to perceive as relevant for a better understanding of IR theory building. It should therefore be read as an interpretative approach, an offer of ideas that intend to provide "food for thought" and to invite and encourage critical discussion of IR as a science. The history of European philosophical thought on science is a complex one and is a real challenge for students and teachers alike to study. I therefore take responsibility for all mistakes and misrepresentations and am happy to receive comments and advice on improving the book (see my contact details in the preface).

\section{Step 2:}

\section{Scientific world views}

\subsection{Greek Antiquity}

Based on the human mind's ability to create language and to reflect on the world, it can be assumed that humans have historically always developed ideas about nature, the human being, the seasons, the order of the cosmos and other fundamental questions. For example, Bedenig (2011: 19-32) points to early creation myths that describe and explain how the world came into being and how death and the periodical cycles of season evolved. Other myths reflect on the dualisms of dark and light, heaven and earth, or matter and mind. Evidence for such mythological perceptions of the universe has been found all over the world: myths of the world and of divine creation exist in Chinese, Japanese, Indonesian, Indian, African and many other cultures. The first "scientific elements" have been ascribed to the physical world view of the peasant societies of the Neolithic Age in Europe (around 7000 BC). These societies had ideas and models of a flat earth embedded in the sea with a dome-shaped heaven carrying the sun, the moon and the stars, all created by gods (Bedenig 2011: 31).

In a more narrow sense, however, European history generally attributes the emergence of the idea of science to philosophical thought in Greek antiquity. Greek philosophy is still appreciated today for having invented the scientific method of interpreting observations by a theory, for the idea of using theory to make predictions for unknown phenomena, for the principle of veri- 
fying a theory, and for the idea of a clear separation of science and religion (an excellent overview is provided by Bedenig 2011: 33-48). As has been indicated above by the example of the geocentric world view, it was by using scientific methods of systematic observation and mathematical calculation that the Greeks came to know that the earth was a sphere and assumed that it must be the center of the universe. Ptolemy and his followers formulated these findings in their geocentric geometric model. The world views as described above are "scientific" in that they formulate assumptions, theories and hypotheses about the world/the universe in a systematic way and invent methods to come to know about the world. They reject traditional mythological explanations of the phenomena in favor of "rational" explanations.

This adoption of rational explanations occurred as early as the so-called Pre-Socratics, who asked fundamental questions about the "essence" of "things". These questions included: what is and from where does everything come (ontological questions about being); how do we explain the things and objects we see (epistemological questions about knowing). They also tried to describe nature mathematically. The questions, problems and paradoxes at the core of pre-Socratic thought became the basis for modern mathematics, philosophy and science in general. In the history of Greek philosophy and in subsequent periods, there have been different answers to those fundamental questions. However, the core questions and problems of what is, how to know something, and which methods are needed to obtain that knowledge have remained throughout history, right through to the present. In fact, the very idea of systematic thought in terms of ontology, epistemology and methodology - the core of the idea of science - goes back to the philosophy of Greek antiquity! This period fundamentally shaped the core questions and hence the core subject of what is now called philosophy of science, as defined as a sub-discipline of philosophy (see our discussion in Unit 2).

In short, Greek philosophy heavily influenced our modern idea of science, which was developed in an historical process of European philosophy now encompassing more than 2500 years. To understand our idea of science and the prestigious status science has gained in our societies today, it is worth taking a closer look at some ancient Greek positions in regard to ontological, epistemological and methodological questions. Particularly interesting are those questions and problems for which there have been competing positions and arguments.

For example, the early belief existed that true knowledge could only be gained by applying strict rationality - meaning both logical reasoning and empirical observation (see Bedenig 2011: 44). However, for Aristotle and Plato, whose works shaped European philosophy, only logical reasoning was 
assumed to result in knowledge, not empirical observation. Remember our discussion on the epistemological positions of empiricism and rationalism as two different ways of coming to know something (in Unit 2). Plato and Aristotle's emphasis on logical reasoning (and their disregard of empirical observation) is important because it explains why the idea of science associated with Aristotle - and with Greek philosophy more generally - is theoretical science and not empirical. Aristotle is well known for his systematic presentation of the knowledge of his time, ranging from mathematics to political science. He differentiated between two types of knowledge based on different origins and goals of knowledge: practical knowledge (techne) and theoretical knowledge (episteme). For him, theoretical knowledge derived from rational reasoning was most important. He considered empirical methods always defective, so the only reliable basis of gaining knowledge was rationality through logical reasoning. Thus, in Aristotelian philosophy, logical thought formed the most important starting point for gaining knowledge. European classical philosophy has been fundamentally shaped by the idea of knowledge derived from logical reasoning, while the rise of the natural sciences since the $17^{\text {th }}$ century results from a new emphasis on an empiricist epistemological position. These initial remarks will help you to better understand the rise of the empirical (natural) sciences during the scientific revolution, their focus on the empirical testing of theoretical hypotheses (as will be discussed in Step 2.3.), and the split between (natural) science and the arts still common today.

In short, with Aristotle and Plato, the idea of science first became theoretical. Greek science "produced" philosophy instead of industries and technologies. This development was in line with a Greek society in which only slaves had direct contact with "nature", while the aristocracy focused on contemplation and philosophical reflection. With regard to sciences, in Greek antiquity originally everything was philosophy; only later did new subjects such as geometry and rhetoric emerge. However, the separation between (natural) science and philosophy did not exist in antiquity. Therefore, in ancient Greece, scientists were philosophers. In fact, one single person was often simultaneously a philosopher, an astronomer, a mathematician, etc., a circumstance which differs considerably from the later stages of the development of the idea of science. In the $19^{\text {th }}$ century, the epistemological prioritization of empirical observation brought about a split between the natural sciences and philosophy, leading to a huge diversity of highly specialized academic disciplines and sub-disciplines.

Ancient Greek thought on science was reflected in the geocentric world view of the universe as the all-encompassing cosmological world view in 
Greek antiquity. The basic models and assumptions can be summarized as follows (see Bedenig 2011: 33-48; Harrison 2000: 28-34):

First, the general (ontological) view existed that there is "order" in the cosmos and that the cosmic order is similar to the order of human mind. This view resulted in the belief that, if the cosmic order is akin to the order of human mind, then the cosmic order can be known by the human mind and by human rationality (an epistemological position). Behind the cosmic order a "methodical intelligence" (god) was supposed to exist, bringing to the universe a spirituality and purpose that can be conceived by the human mind. Second, because of its divine origin, the ideas and forms in the cosmos are perfect, as expressed by models such as those of planets and stars with ideal circular orbits. You know about ideal forms and ideas from our discussion of Plato's theory of ideas (or theory of forms) in Unit 2. The geocentric model draws on Euclidean geometry, where such ideas of ideal geometrical forms are modeled, deduced from a small set of axioms and then provided with mathematical proof (Euclid's Elements). Third, the world view is atomistic: it draws on atomism, the idea systematically developed by Democritus and Epicurus that everything in the universe consists of tiny, indivisible atoms (remember the discussion of atomism in Unit 2). The atomized world is made of "matter" - a materialist ontological position. As you know, there have been different ontological positions regarding the make-up of the world; for example, Heraclitus assumed all things in nature to be in a state of perpetual flux, connected by logical structures. Such a position stands in contrast to atomism. However, atomism ultimately became the dominant perspective and has shaped the idea of science throughout European history. We will later return to this argument in more detail. Finally, in the geocentric world view, the belief existed that each movement in the universe has a cause (with the first movement caused by god as the prime mover). Causes of natural phenomena are seen as physical in origin and explanation thus implies the expression of a relation between cause and effect. Cause and effect are linked by natural laws.

From what you know about the "elements" of a philosophy of science, you can easily see that the ideas mentioned above refer to ontological as well as epistemological and methodological assumptions and models of explanation. All these principles and assumptions will sound familiar to you. Many of them have been introduced in more detail in Unit 2 because they are shared by positivism as a philosophy of science. Indeed, European philosophy, culture and science have been fundamentally shaped by the philosophy of Greek antiquity. The work of Greek philosophers such as Socrates, Plato, or Aristotle is reflected in our philosophical and literary terminology, in our 
political and economic ideas of liberalism and pluralism, in our political analysis, in our idea of freedom, in the way we perform and perceive science. Al-Jabri raises an interesting point with his argument that, in fact, the idea of science itself can be seen as the key impetus and driving force for Greek philosophy and thus of European philosophy more generally. Science is considered the "incentive element" for the advancement of philosophy (Al-Jabri 2011: 421).

In the next step we will therefore investigate what happened to the idea of science and to philosophy in the time following late antiquity, which was the last period of the ancient world.

\subsection{The European Middle Ages and Renaissance}

After late antiquity in Europe, the progress of science stagnated for a long time. Providing a world view based on religion - the triumph of Christendom - has usually been perceived as a stumbling block to the further development of science. From the early Middle Ages onwards, belief and religious conviction - instead of observation and analysis - came to dominate the idea of knowledge. The Church and the Holy Scripture held absolute authority, formulating the ultimate "truth". Philosophy now was the "servant" of theology, not the "provider" of scientific thought.

Finally, this situation changed in the $13^{\text {th }}$ century when Thomas Aquinas made one of the greatest contributions to the transformation from medieval thought to early modern thought: he revived the idea of science as derived from Greek antiquity by attempting to combine Christian theology and Aristotelian thought in a kind of synthesis. Thomas Aquinas was one of the main representatives of scholasticism, a method of thought based on dialectical reasoning. Scholasticism aimed to extend knowledge by way of logical inference and with the intention of dissolving contradictions. It was taught at Medieval European universities mainly for the purpose of defending orthodoxy in an increasingly pluralist context. In addition to Thomas Aquinas, wellknown representatives of scholasticism include Albertus Magnus, Wilhelm of Ockham and, later, several Lutheran and Reformed thinkers. In short, scholasticism can be seen as an attempt to reconcile Christian theology with classical and late antiquity philosophy. The latter basically comprised Aristotelian and Neoplatonic thought - both of which, as you have learned, consider logical reasoning as the fundamental means and method of knowing.

The historical background of the revival of Aristotelian philosophy and Neoplatonism is a particularly interesting one. Knowledge and ideas of an- 
tiquity had largely been "forgotten" in the early and High Middle Ages but had nonetheless been preserved in monastic libraries, in Arab culture and in Byzantium. The Greek philosophical writings had been translated into Arabic, allowing Arab scholars to preserve and annotate the intellectual heritage of the Greeks. During Reconquista on the Iberian Peninsula (which ended in 1492), the Christian conquerors captured the writings of these Greek and Arab scholars. In addition, the demise of the Byzantine Empire was followed by the migration of Greek scholars to Italy. They brought with them previously lost knowledge of Greek antiquity. Greek philosophy thus subsequently found its way back to Christian Europe in a roundabout manner, though Arabic, Spanish and Latin texts. During the Renaissance in the $15^{\text {th }}$ and $16^{\text {th }}$ century, a revival of ancient Greek thought took place. This revival is expressed in term Renaissance itself, which originated in the $19^{\text {th }}$ century and means "rebirth". It embodies the idea that, after the Middle Ages, European culture experienced a reorientation towards Greek and Roman antiquity: a "rebirth" of the spirit of antiquity.

This "rebirth" of antique ideas manifested itself in a multifaceted and allencompassing way, reflected in sculpture, architecture, writing and philosophical thought. Above all, arts and sciences were held in high esteem in the Italian city states, in a manner comparable to that of ancient Greece. For example, in the arts, a new tendency to mathematical-scientific clear-cut forms appeared which placed the human body at the center (as shown in Leonardo da Vinci's studies of proportions). The Renaissance also marked the beginning of a new, anthropocentric world view. The idea of the individual as a creative person emerged as well, as expressed by humanism, often called the "spirit" of the Renaissance. Humanism was fundamentally shaped by Greek antiquity, with the Greek idea of education and intellectual development serving as its model of orientation. At the core of humanism lay the interests, dignity, creativeness and value of the single human being, the individual, and the ability to educate and improve oneself. Typical questions posed by humanists included "What is the human?" and "What is 'true' human nature?" Humanism provided a tremendous stimulus to the study of language, literature, and philosophy, this time for their own sake, separate from religion.

In this long-term process, a more anthropocentric view incrementally replaced the theocentric world view of the Middle Ages. This process occurred last but not least because of Martin Luther (Luther 1520: De liberate christiana/On the freedom of a Christian) and the Reformation, which called into question the "natural" authority of the Catholic church and strengthened the attempts to seek a truth free of tradition and dogma. As we will learn in 
the next step, with the end of the Middle Ages, religion lost its prerogative for sole interpretation to modern science and technology. The transition from the geocentric world view to the heliocentric world view proved key to this process, since it was this change that gave birth to the scientific revolution.

\subsection{Scientific revolution and the rise of Cartesian-Newtonian science}

The "scientific revolution" was not a sudden event but rather a process that covered a long period of time; it lasted from the Early Modern Age at the end of the $15^{\text {th }}$ century until the end of the $18^{\text {th }}$ century. The scientific revolution is associated with the works of Nicolaus Copernicus (1473-1543), Johannes Kepler (1571-1630), Galileo (1564-1642), René Descartes (1596-1650), and Isaac Newton (1642-1727) - all of them astronomers, mathematicians, philosophers, and physicists. The scientific revolution resulted in a development towards Cartesian-Newtonian science or a Cartesian-Newtonian world view. This process was crucial for the rise of the natural, empirical sciences and technology, and for their role and current status in the modern world.

\section{Copernicus, Galileo, Kepler: the rise of experimental science}

The transition of the geocentric (Ptolemaic) world view to the heliocentric model as formulated by Copernicus (in 1543) and proved by Kepler's laws and Galileo's observations, is essential to the process of the scientific revolution because it gave birth to a new understanding of science. You can imagine - and certainly know from history - that the Copernican world view was perceived as a threat to Christian cosmology, theology and Catholics morals. The trial against Galileo (1633) marked the height of the confrontation between religion and science but could not stop the spread of the heliocentric world view.

This transition from the geocentric to the heliocentric world view forms an important part of our discussion on the history of the idea of science because it brought about a new ideal of science, one based on new ontological, epistemological and methodological perspectives. Let me illustrate this in a few steps (drawing on Schupp 2003: 85-100; and Bedenig 2011: 75-82). First, it was through systematic observation with a telescope that Galileo discovered the truth of Copernicus's claims. This observation led Galileo to write his famous Dialogo sopra $i$ due massimi sistemi (1632): a dialogue about the two main world systems, the Ptolemaic and the Copernican. Gali- 
leo's work was guided by his belief in a law-like character of physical processes. The search for these general laws has since been seen as the main goal of physics. Galileo claimed it was possible to obtain knowledge about these general laws through observation and measurement and the subsequent formulation of the laws in mathematical language. This continues to be the current objective of physics. For Galileo, there was a central position of the experiment as a scientific method: that a theory can be accepted only when experimentally "proved". In fact, the natural sciences still apply Galileo's experimental methodology today.

Out of fear of the church, Galileo's work was first cautiously considered a "hypothetical model". However, Kepler's work subsequently demonstrated that the heliocentric model of Copernicus was not only a hypothetical model for the purpose of simplifying the calculations of planetary positions. Instead, Kepler "proved" the heliocentric model as a physical fact. Kepler's work Epitome Astronomiae Copernicae was thus perhaps the first textbook on the heliocentric world view.

In short, starting with Galileo, experimental science now formed the core of inquiries about the world. Copernicus, Galileo, and Kepler all employed scientific methods. The methods of the natural sciences, based on empirical observation and its theoretical description and interpretation, had now taken their places at the heart of scientific inquiry. It is important to emphasize that this empirical orientation was a new focus in scientific thought. It was not based on Aristotelian and Platonic theoretical epistemology, but rather on experimental proof.

In sum, with the works of Galileo and Kepler, a process towards the rise of natural sciences as empirical science was put in motion in Europe, based on experience/experiment. This process also provided the foundation for new experiments because of new industrial tools. Thus, science and technology entered a new, mutually advantageous relationship at this time.

Once experimental science emerged with Galileo, European philosophy also entered a new stage with the work of René Descartes. Descartes reestablished philosophy as a science, as part of physics and mathematics. From then on, the progress of European philosophical thought was closely linked to the progress of the empirical sciences, with physics and mathematics at the core (Lefèvre 2001: viii-x). This might sound strange at first, given that our traditional understanding of philosophy is not usually associated with these disciplines. Let us therefore take a closer look at the role mathematics and physics played for philosophy at this time. 


\section{Descartes and Newton}

René Descartes is well-known for his idea of the universe as a machine that operates according to strict mathematical laws (an excellent overview is provided by Schupp 2003: 110-133; see also Bedenig 2011: 83-86). His works can be seen as representative for the rise of the mechanical world view, which was developed further by Isaac Newton, the father of classical mechanics. Descartes formulated many of his major ideas in his Discours de la méthode pur bien conduire sa raison et chercher la vérité dans les science (1637), which discussed the "right method" of applying human reason to science. Descartes assumed the existence of rules responsible for the movements of things (with the world itself being of divine origin). Descartes' aim was to come to know those rules; the question was, how?

While trying to fulfill this aim, Descartes systematically transferred atomism to the Copernican world view. He drew on the atomistic world view of Democritus and Epicurus, whose ideas had been revived in Renaissance. In an Epicurean-like way, Descartes assumed an atomistic world of matter and motion that operates under natural laws (see Harrison 2000: 2). Please remember that, in its ontological aspect, atomism refers to the view that the universe consists of tiny indivisible atoms, moving in infinite neutral emptiness, and the idea that all phenomena result from the collisions and the combinations of these atoms. Scholars such as Giordano Bruno already saw an analogy between the Greek idea of atomism and the Copernican system: atomism corresponds to the Copernican system in that the earth is not the center of the universe but is itself a part (atom) of a neutral, infinite space with other celestial bodies (atoms). However, it was Descartes who finally expressed this idea in a systematic manner. The atoms/particles were referred to as "corpuscles" during Descartes' time and it was by name of "corpuscle theory" that Descartes spread the idea of atomism in his work. Corpuscle theory is similar to atomism in that all matter is seen as being composed of minute particles; however, Descartes did not believe in the indivisibility of these "corpuscles". Corpuscle theory became an influential perspective at this time and remained so for many decades afterwards. For example, Thomas Hobbes drew on it when formulating his political theory in the Leviathan (1651) and Isaac Newton used it in his "corpuscular theory of light", which will be discussed below.

In the Cartesian, mechanical, machine-like view of the world, it was assumed that each corpuscle remains in a neutral state until it is given a "push" from the outside. After this initial contact, the corpuscle starts to move and continues to move constantly in a straight line until it collides again with an- 
other "corpuscle" (Bedenig 2011: 84). Descartes transferred this idea to the movement of celestial bodies. Its application to the solar system results in the conclusion that there must be a mechanism responsible for the earth moving around the sun: a "force" which compels the planets to move towards the sun and not "fly away" in straight lines (Bedenig 2011: 84). This "force" is in fact gravity, later discovered by Isaac Newton. The "mechanism" involved was mathematically formulated in Newton's law of gravity.

Newton's work thus "completed" the new mechanical world view. Isaac Newton is well-known as the father of classical mechanics and is hence a major contributor to what is known as classical physics. This term applies to physics until the end of the $19^{\text {th }}$ century; that is, before Einstein (for an overview see Bedenig 2001: 86-88). Newton formulated many of his major ideas in his Philosophiae naturalis principia mathematica (1687). Please note the term; physics at this time was considered to be a "natural philosophy".

In the year 1666, Newton made groundbreaking insights in a diverse range of fields: infinitesimal calculus (mathematics), optics and the theory of gravity. Of all his achievements, he is best-known for this last contribution, the discovery of the gravitational pull as the physical law according to which each body in the universe exerts gravitational force towards other bodies. Newton's laws of motion and of universal gravitation transformed astronomy (Bedenig 2001: 87-88). Starting with Kepler's Laws and continuing with Newton's work, astrophysics developed as the "new astronomy", merging physics and astronomy (with a basic understanding of physics as "natural philosophy").

As has been mentioned above, Newton's work on the nature of light draws on corpuscle theory. Newton understood light as "corpuscle (particle) radiation", the idea that light consists of tiny particles that are emitted from a light source in a linear manner. As you will learn in more detail in Step 2.4., this search for the nature of light belongs to the most important objectives in physics and cosmology.

From the introduction in Unit 2, you know that atomism is a specific position on the philosophical problem of how particulars relate to the whole. You are also familiar with the argument that, in addition to ontological aspects of atomism, epistemological and methodological implications exist as well. These result in methodological individualism and reductionism. It will therefore be easy for you to see that the mechanical world view and corpuscle theory are closely linked to methodology. For Descartes, to understand a system we have to divide the system into sub-systems. These sub-systems have to be analyzed separately, allowing the single effects of each sub-system to be examined more easily. Complex systems thus have to be "reduced" to simpler ones until causes of phenomena can be analyzed separately, undisturbed by 
interfering effects. Following this method, the direction of scientific thought should progress from the "simple" to the more complex (Bedenig 2001: 8485). This principle is referred to as reductionism or methodological individualism, a major feature of positivist science with which you are already familiar from your reading in Unit 2. Reductionism and methodological individualism continue to be central positions in the sciences today. As we will see, they also play a crucial role in IR theory building.

Both Descartes and Newton have proven to be highly influential, as their concepts of atomism/reductionism/methodological individualism became widespread in European scientific thought. This prevalence is reflected in many ways, ranging from the general ontological assumption of an atomized material world to the specific types of explanation and methodology found in the sciences. For example, in the natural sciences atomism is prototypically embodied in classical, that is, particle physics (Harrison 2000: 2). In the social sciences, the perspective is prototypically reflected in (neo)classical economics and liberal theory. Both these areas perceive the individual as a separate entity, the basic unit of society and its institutions. In IR, the interpretation of the state building processes in Europe as progressing towards "units" (the sovereign states) and models of a states system comprised of these separate entities (states) also embodies the fundamental atomist order of thought as developed by Newton and Descartes in European philosophy.

In short, since the $17^{\text {th }}$ century, atomism/reductionism/individualism has come to shape the ontology, epistemology and methodology of the idea of science to such an extent that it is now in fact taken for granted and remains to a great extent unquestioned. For a critical engagement with the atomism of Descartes from a sociological perspective, see for example Norbert Elias 1987: The society of individuals. Other titles in the recommended reading section at the end of this unit also provide a more critical view of the perspective.

In addition to atomism, the work of Descartes resulted in a consolidation of dualist thought on body and mind (Bedenig 2001: 85). Descartes assumed body and mind to be separate entities, as expressed by his well-known Ego cogito, ergo sum (I think, therefore I am). The scientific, philosophical and theological repercussions were far-reaching: with the work of Descartes, the body-mind duality became a "sharp" divide (Harrison 2000: 2). Dualism on the classical body-mind/body-soul/matter-mind problem - the claim that neither mind nor matter can be reduced to each other - became typical for European/Western philosophy and is deeply embedded in the European idea of science as well. The body-mind/matter-mind problem is not only an abstract philosophical puzzle, but also has implications for how we assume the ontology of a core subject in an academic discipline, how we perceive the human 
mind and thus mental constructs and theory, how we ascribe ontological status to social phenomena, how we perceive the position of the scientist in regard to the "object" of scientific inquiry, etc. We will come back to these questions in more detail in the final section of this unit and at the end of the book.

The Cartesian-Newtonian perspective is further associated with utilitarianism, a concept which goes back to the influential works of Francis Bacon (1561-1626). According to this view, the purpose of natural science was to control and dominate nature and to utilize nature to improve human culture (Schupp 2003: 60-62). Knowledge was given value through its utility for technology and the progress of civilization. The ideas of Francis Bacon had their heyday with the industrial revolution and with the rise of positivism as the dominant philosophy of science in the $19^{\text {th }}$ century. In addition, you can easily see that the natural laws inherent in Cartesian-Newtonian science can evoke a strong belief in determinism. This belief is exemplified in the works of Pierre Simon Laplace, a French astronomer and mathematician. His famous Laplace's Demon (1814) incorporates determinism, depicting a strict deterministic world governed by laws, with the task of natural philosophy (mechanics/physics) being to formulate these laws through mathematics (for Laplace, this takes place in terms of differential equations).

\section{Summary}

The rise of Cartesian-Newtonian science was a process of transition towards a new scientific world view. Transition occurred in the form of a new status for the natural sciences. Natural science became empirical science.

During this $17^{\text {th }}$ century process, the Cartesian and Newtonian systems "mathematized and mechanized" the scientific view of the world (Harrison 2000: 2). The Cartesian-Newtonian world view imagined the universe as a complex mechanical system of divine origin. This universe consisted of innumerous material particles moving in infinite space according to a range of physical laws that were mathematically presentable (for example, according to the law of gravity). In this world view, light consists of the smallest mechanical particles. The earth moves around the sun on an elliptic path, as do all the other planets, with the sun being only one star among many (an atomistic model of the universe). This model is linked to the idea of an infinitely expanding universe. From this perspective, there are clearly defined natural laws that govern life on earth and in the entire universe. The relations are causal; that is, a cause exists for each single event on earth or in the universe. The role of the human is to come to know the laws of the cosmos and to make use of them. Theory and experiment form equal parts of scientific methodology, but theories cannot be accepted until they have 
been verified by experimental proof. However, this verification also implies the need and willingness to question "old" knowledge and, if necessary, replace it with new knowledge as soon as the new knowledge has been proved correct.

Through this process, philosophy (of science) became naturalized, mathematized and mechanized. This transformation can be regarded as almost natural, as the philosophy of the early modern age cannot be separated from what was happening in the sciences and vice versa (Lefèvre 2001: viii, viii$\mathrm{x})$. The single scholars (exemplified by Descartes and Newton) contributed to the development of more than one field of knowledge (e.g. mathematics, physics, astronomy, philosophy, optics) or, in some cases, to all of them. For example, Descartes' mathematics strongly affected his philosophy and vice versa. These are "processes of co-evolution" among different fields of knowledge, with the linkage between mathematics, mechanics and philosophy at the core (Lefèvre 2001: viii). Philosophy, mathematics and the sciences thus formed a "unity of parts" (Lefèvre 2001: ix) in terms of overarching patterns/orders of thought. This unity can be seen, for example, in the philosophy of Immanuel Kant. Kant drew on Newtonian physics and its theoretical concepts, especially with regard to the concepts of absolute time and absolute space. The same holds true for Gottfried Wilhelm Leibniz, whose "monadology" (1714) drew on both the biological concepts of microorganisms current at this time and the hypotheses of the mathematical calculus of infinite regression/infinitely smaller entities (derivative and differential calculus). The interrelation of science, mathematics, philosophy and methodology thus obtained a new quality in the $17^{\text {th }}$ century, with those fields of knowledge becoming intimately interdependent (Lefèvre 2001: viii).

Furthermore, the scientific revolution was important not only for the idea of science, but also for political, cultural, industrial and technological development in Europe. These developments ultimately led to Europe's worldwide predominance, while the Enlightenment and the French revolution further strengthened both the rights and position of the individual in Europe and the strict separation of church and state. These changes worked to further stimulate the development of the natural sciences. For example, Charles Darwin's work in biology (1859: On the origins of species by means of natural selection, or the preservation of favored races in the struggle for life) enhanced the strict separation of natural science and religion. At the core of Darwin's theory was the principle of evolution, the idea that the universe and life develop incrementally by adapting to the demands of their surroundings. The structure and development of nature are not results of a divine plan, but rather consequences of an existential fight to survive. In that world, "survival of the 
fittest" determines outcomes; the characteristics that helped animals to be "fit" - to reproduce as much as possible - became dominant in a population. The human mind suddenly was no longer of divine construction but rather a biological instrument resulting from evolution. However, it should be noted that Darwin also introduced "accident" to the natural sciences: in his work, accident was a mechanism of mutation - the spontaneous, inadvertent change of genotype that played such a crucial role in evolution. Pure accident in the form of mutation had now become part of a scientific theory. This development is significant because it violates the argument of strong causality: if accident has such an important role in evolution, then determining a prognosis is difficult if not almost impossible. This conclusion holds true not only for biology; in fact, we will come back to this issue in the final section of this unit when learning about "new physics".

The $19^{\text {th }}$ century was therefore particularly important for the continued development of the new scientific world view. With the industrial revolution in England and particularly after the publication of Darwin's theory of evolution, the significance of the natural sciences and technology was rising tremendously in Europe. In philosophy of science, positivism became the dominant scientific perspective; positivism as a philosophy of science in fact embodies the close linkage between philosophy and the idea of natural (empirical) science as described above. Al-Jabris' argument of science as the "incentive element" for the advancement of philosophy (Al-Jabri 2011: 421) again turns out to be plausible. Natural science based on physics and mathematics became the driving force of philosophy of science and shaped the idea of philosophy itself. This new understanding of science is a philosophy of the world view of mechanics/physics, and holds philosophy to be a natural/empirical science.

This mutual dependency of philosophy and science has far reaching implications, as scientific world views are not only reflected in the conduct of the sciences, but as broader orders of thought that pervade society. They appear in economics, political thought, sociology, linguistics, arts, literature, culture, etc.

Therefore, in regard to the discipline of IR, it will be easy to see how the Cartesian-Newtonian world view is embodied in most of our theoretical descriptions and explanations of the rise of the European state and the state system. This world view also appears in our theories on inter-state relations, later inter-national relations. Inter-state theory as formulated by Hobbes, Locke and Kant all fundamentally reflect the idea of science as developed at their time - the $17^{\text {th }}$ and $18^{\text {th }}$ century (described above). So, in fact, does the huge body of IR theory that draws on the understanding that IR's core subject is 
the modern state and the modern states system. In a nutshell: a co-evolution has taken place with regard to the processes of the rise of the modern state and state system (the core subject of the discipline), of inter-state theory as a systematic reflection on the state and state system, and of the rise of the Cartesian-Newtonian scientific world view being incorporated in the application of "science" to the study of international relations. I believe that being aware of this interconnectedness will help us to better understand the complex world of IR theory, an argument which we will return to again at a later stage of this book. At that point, we will take a closer look at the ways a selected range of IR theories theoretically and conceptually perceives the state, the state system, politics, international politics, their actors and structures (in Part 2).

\section{Self-study (2)}

Please read Capra 2010: Chapter 1 (The way of physics) and (for German readers) Brodbeck 2011: Chapters 2 (Social Physics) and 5 (Rationality) from the required reading list.

In addition, choose one or two of the recommended titles from the section on "Philosophy/science, physics - Classical world view" from the supplementary reading list.

Then please take some time and reflect on:

1) the general argument that our (European) view of the world is fundamentally shaped by the Cartesian-Newtonian idea of science (the role of science in and for society/politics/economics/culture/arts/literature etc.), and

2) the argument that the natural sciences (with physics and mathematics at the core) are key to our scientific world view (science as physics?).

You are invited to exchange your views in our course on iversity in the working group "Physics and politics". For the iversity contact details and enrollment requirements, please see the information in the preface.

\subsection{Cartesian-Newtonian science in transition? "New physics" and the rise of a new scientific world view?}

In recent years, a huge debate has been taking place on whether or not a process of replacing the Cartesian-Newtonian world view with a new world view based on "new physics" (for example, Dürr 2012: 16; Capra 2012: 51) has been set in motion. "new physics" is a term that refers to physics since the 
beginning of the $20^{\text {th }}$ century, with the focus on the works of Einstein and the atomic and quantum physicists. The development of new physics began with early $20^{\text {th }}$ century physics experiments which led to the discovery of phenomena that could not be described in the language of classical physics and predicted by its (classical) mathematical laws (Capra 2012: 66). These findings resulted in the development of new models and theories that tried to describe and predict those phenomena more accurately. Physicists accepted that new physics had transformed and replaced many of the central laws of classical Newtonian physics. Consequently, it shook the Cartesian-Newtonian scientific world view to its very foundations. In fact, Einstein's theories of relativity, the discovery through atomic physics of the structures of the subatomic world and the findings of quantum theory completely destroyed the fundamentals of the classical mechanical Cartesian-Newtonian world view. The idea of space and time as absolute, the idea of elementary particles as the fundamental components of matter, the idea of a causal, deterministic nature of physical phenomena and the idea of an objective description of nature were no longer valid (Capra 2012: 59).

However, while the laws of new physics have been proven experimentally since the 1920s and have since been driving technological developments for decades, only since the turn of the millennium have the implications of new physics for our understanding of the world and of science more generally been discussed in a broader spectrum of sciences as well as in the public discourse on science (see, for example, the contributions in the volume of Hüther/Spannbauer 2012. There are additional titles in the supplementary reading list). More than 80 years have gone by since physicists proved the laws of atomic and quantum physics and since Einstein revolutionized the discipline. However, from what you know about the time spans of such transition processes, this should not come as a surprise to you.

What has happened? Are we witnessing another historical transition process towards a "new scientific world view"? Assuming the argument about the principles and laws of natural sciences (with physics and mathematics at the core) strongly determining our scientific world view holds true: what will the implications be in the case that our world view of physics is changing? Will this change be relevant for the study of IR and for the way IR theories are constructed? Will it matter for the assumptions on which theory building is based and for the explanatory models and methodological principles used to study international relations? Or does physics and mathematics have no relevance for the study of IR at all?

In order to explore these questions, let us take a closer look at "new physics" in the next steps. 


\subsubsection{Einstein and atomic physics}

\section{The dual nature of light}

While Newton believed that light is made of corpuscles - which was the accepted perspective on the nature of light for 200 years - Einstein's revolutionary work on light (1905) demonstrated a dual nature of light as both a particle and $a$ wave (see the overview in Bedenig 2011: 129-134). There are phenomena that can only be explained by the particle-nature of light and other phenomena that can only be explained by the wave-nature of light. Thomas Young, Michael Faraday and James C. Maxwell paved the way for these ground-breaking insights, starting with the double-slit-experiment by Thomas Young in 1804 in which he first demonstrated the wave-nature of light through interference patterns. The wave-nature of light could explain phenomena that were not compatible with the corpuscle theory of light as formulated by Newton. Young's experiment later played an important role in the development of quantum mechanics. Faraday, with his work on light as a wave-movement in an electromagnetic field (1846) and Maxwell with his famous Maxwell equations (1861-1864) were additional forerunners of discoveries to come. The Maxwell equations provided the mathematical description for Faraday's electromagnetic field and thus the proof that light is a phenomenon of electromagnetic waves. In 1900, Max Planck then demonstrated that light is not disseminated in continual waves but rather in "energy packages" called "quanta" (later "photons"). Max Planck is therefore seen today as the father of quantum theory. In 1919, he was awarded the Nobel Prize in physics for his discovery of Planck's constant.

In addition to his demonstration of the dual nature of light, Einstein is famous for showing that the speed of light is a universally valid constant, independent of the state of movement of the observer: nothing can move faster than light.

\section{Time, space, matter and energy}

However, Einstein is above all well-known for his revolutionary ideas about time and space. Before Einstein, classical physics/classical mechanics accepted time and space as absolute - they existed everywhere in the universe and independently of the observer. For example, this belief was reflected in Kant's philosophical thought about space and time as absolute categories of human thought that are "a priori" given, not to be questioned and with no need to be explained; they are axioms. With his special theory of relativity, Einstein was able to show that space and time are not absolute, but flexible 
and relative. Beyond that, space and time are inextricably linked with each other, forming spacetime. The new physical laws formulated by Einstein in his special theory of relativity thus replaced the ideas held by Newton and classical mechanics that an absolute time and an absolute space exist in which all physical phenomena happen (Bedenig 2011: 137-148).

The incompatibility of Einstein's special theory of relativity with Newton's law of gravitation provided a driving force for additional insights in the field (see the overview in Bedenig 2011: 150-157). Einstein tried to extend the framework of his special theory of relativity to include gravitation. This forms the core of his general theory of relativity (1915): the idea that the same linkage as exists between space and time also holds true for matter and spacetime. The two are inextricably linked to each other and this interdependency is called gravitational force. Einstein demonstrated that gravitational force causes the curvature of spacetime. Curved spacetime is due to the distribution of matter within spacetime. The idea of curved spacetime was important in that it replaced the old ideas of geometry that dated back to Euclid's Elements and which had been formulated for a homogenous, not curved space. As proven by Einstein, Euclid's geometry was no longer valid for curved space. However, it had been accepted as the truth for 2500 years!

Consequently, Einstein replaced Newton's s laws of gravitation with his general theory of relativity. This theory is now used by astrophysics and cosmology to describe the universe (Capra 2012: 62). The terms "absolute space" and "absolute time" are no longer valid. With the demonstration that the structure of the space-time-continuum depends on the distribution of matter in the universe, the idea of "empty space" lost its meaning (Capra 2012: 63). However, Newton's laws are still accepted as valid for all terrestrial cases of gravitation - that is, for our life on Earth - while Einstein's laws of the general theory of relativity are laws for outer space (under conditions of great masses). The same holds true for the relativistic effects observed by Einstein's special theory of relativity: they apply under conditions of speed close to speed of light. In short, the theories of relativity are for the "big picture" (for high speed and great masses that can be found only in space) or, alternatively, for the "small picture" (the micro-cosmos/sub-atomic world of elementary particles and of photons that move at the speed of light). In contrast to these two areas is life on Earth, where Newton's laws still apply (Capra 2012: 63).

From his special theory of relativity, Einstein derived his famous formula on the transformation of mass $(\mathrm{m})$ into energy $(\mathrm{E})$ : $\mathrm{E}=\mathrm{mc} 2$. In other words, Einstein could demonstrate that mass and energy are two manifestations of the "same". They can be transformed into each other (with the atomic bomb 
being a shocking example for the transformation of mass, released in nuclear fission, into energy). Einstein was able to show that mass is not a material substance (made of particles), but a form of energy. Energy is a dynamic, active, physical quantity, related to processes (not substance) (Capra 2012: 61, 76).

\section{Elementary particles}

Atomic physics in the early $20^{\text {th }}$ century discovered phenomena that could not be explained by classical physics - as based on the idea of atoms as solid, indivisible material particles. With the discovery of X-rays and, later, radioactivity, it became clear that atoms did have a structure. In 1919 Ernest Rutherford discovered that atoms were not solids but rather spaces where electrons move around the atomic nucleus - as epitomized by the planetary model of atoms (Capra 2012: 65). By the 1930s, physicists had proved that the structure of all atoms consists of protons, neutrons, and electrons. With the advent of nuclear fission, it was finally accepted that atoms are not the smallest, indivisible particles that make up the universe. Thus began the search for the ultimate elementary particle which is still at the core of particle physics today. At first, physicists found only three elementary particles; by 1935, the number had increased to six and by 1955 to 18 . Today, more than two hundred have been recognized (Capra 2012: 75). You likely know about the search for the Higgs-Boson (also called the "God-particle") from the recent news. If not, please take some time now and research this topic.

However, even though Einstein's new theories and the new findings of atomic physics did not change our day-to-day experience of the world, they did change our ideas about light, space, time and matter and thus the fundaments of the classical Cartesian-Newtonian mechanical world view. This influence holds even truer for quantum physics.

\subsubsection{Quantum physics}

Classical physics/mechanics draws on a distinction between particles (matter) and energy. It holds that only the latter possesses a wave-nature, while matter is particularistic (atomism). The properties of a material particle are "given" and the particle can be observed or measured through experiment. Objective knowledge about the particle is then possible due to the "objective", given properties of the physical object (observable) and the "objective" position of the researcher in the process of measurement. The properties being measured are thus independent of the observer and the measurement process. This is a position that was still shared by Einstein as well, based on classical phys- 
ics/mechanics' belief in fundamental, deterministic laws of nature that can be known by science. In this respect, however, Einstein was wrong.

The new findings of quantum mechanics are based on the experimental observation that the sub-atomic particles that make up both matter and atoms have a double nature: sometimes appearing as particles, sometimes as waves. That is, matter has characteristics of both a wave and a particle (as demonstrated above by the nature of light, which can be made of particles or be an electromagnetic wave). So far, this will sound familiar to you and there might be no need to question classical physics in this regard. However, quantum physicists have come to recognize that phenomena that in classical physics can only be alternatives (wave or particle), can actually be consistent, complementary aspects of reality: wave and particle. This property, the dual nature of matter and light, was difficult to understand; how can something be both particle and wave at the same time? (Capra 2012: 66). Ultimately, quantum theory and the formulation of the new laws of quantum mechanics solved this perceived contradiction (Capra 2012: 66). These laws will be briefly described in the next step. Nevertheless, please be aware that it might be difficult to follow this description if you are not familiar with the paradigms on which contemporary physics is built. There will therefore be recommended reading at the end of the unit that - depending on your familiarity with physics - you might already begin to consult while reading this text.

As mentioned above, it was Max Planck who paved the way in quantum physics with his findings that thermal energy is not emitted continuously but rather in "energy packages" called quanta (Capra 2012: 66). Based on extended versions of Young's double slit experiment, in 1926 and 1927 Erwin Schroedinger, Max Born, Niels Bohr and Werner Heisenberg formulated the basic laws of quantum theory. They can be briefly summarized as follows (drawing on Bedenig 2011: 161-178):

In his famous Schroedinger equation, Erwin Schroedinger, an Austrian physicist and Nobel laureate for physics in 1933, described the development of the quantum state of a physical system (that is for example, atoms, molecules, sub-atomic particles) over time when there is no measurement and no experiment. The Schroedinger equation is equal to Newton's second law for the motion of a mechanical system in classical mechanics. However, in quantum mechanics, it is a linear partial differential equation that describes a wave function of the physical systems (that is of atoms, molecules and subatomic particles as well as of macroscopic systems/the universe).

This quantum mechanical wave function was formulated by Max Born, a German mathematician and physicist and a 1954 Nobel laureate, as a statisti- 
cal interpretation. It is known as the Born rule or Probabilistic Interpretation. This function is a law of quantum mechanics and describes the probability with which the measurement of a quantum system will bring about a specific result. In other words, the descriptions of nature, of physical objects, and of the laws of nature are interpreted as essentially probabilistic (and not deterministic, as in classical mechanics).

Then Niels Bohr, a Danish physicist and a 1922 Nobel laureate, formulated his famous Complementarity Principle. Another law of quantum mechanics, it demonstrated the principle of fundamental complementary aspects of physical phenomena. One example is the previously mentioned "particle and wave" aspect of physical objects, emissions and matter: "particle" and "wave" are two complementary phenomena (and not alternatives). However, experimental measurement can only demonstrate either one or the other aspect, but never both phenomena in the same measurement process. The demonstration of one aspect necessarily precludes the other. They cannot be simultaneously measured, even though there are always two aspects of phenomena in one and the same process. As complementary aspects, they belong together and form a "whole". Nevertheless, which aspect will be measured depends on the observational practices of the experiment.

With the principle of complementarity, paradoxes have thus been shown to be a feature of reality. Each phenomenon has an "other side", an aspect contrary to the one being currently observed. Observation thus never results in "facts", but only in aspects of perception, aspects of reality.

In addition, Niels Bohr demonstrated that the measured properties of a physical object are affected by the measurement process, by the process of experimental observation. That is, objects governed by quantum mechanics do not have intrinsic properties that are independent of the process of measurement. There are no "given" properties of objects independent of the observer or the observation. The measurement process itself has an impact on what is measured. This effect was discovered through extended double-slitexperiments, which were constructed to find out what happens when a wave passes the double slit. Normally, it would result in the classical interference patterns due to the nature of waves, for example of light. However, the extended Young experiments proved that when observed, the wave appeared as a particle when passing the double slit. In other words, under observation, there were no interference patterns. Without observation, however, the classical interference pattern of the wave-nature appeared. This might sound "spooky" to you. I therefore recommend that you do your own search on the extended double slit experiment and its interpretation. Knapp (2011: 65-79) provides a good and readable overview. 
Werner Heisenberg, a German physicist and 1932 Nobel laureate, found out that uncertainty always exists when measuring quantum systems. This uncertainty is a fundamental limit to the precision with which pairs of physical properties of particles (such as position and momentum) can be known simultaneously. Heisenberg's discovery is well-known as the Heisenberg Uncertainty Principle. For example, the more precisely the position of a particle can be determined in an experiment, the less precisely the particle's momentum can be known and vice versa. This observation applies to other pairs of physical properties, too. Hence, uncertainty is an important aspect of the property of matter, due to the wave-nature of physical objects. "Uncertainty" is therefore a statement about a fundamental property of a quantum system (not a statement about defective measurement devices), a principle not compatible with the deterministic view of classical physics.

The laws of quantum mechanics briefly described above form the basis of the famous Copenhagen interpretation of 1927 - an attempt to explain the mathematical formulations of quantum mechanics and the experimental results (see Heisenberg 1977: 28-40).

All laws of quantum physics have been experimentally proved. Among these experimental proofs, the 1981 experiments of John Bell deserve closer attention, as they highlight another aspect of quantum phenomena that is important for our discussion of the transition of the Cartesian-Newtonian world view. Bell provided the experimental proof of quantum entanglement (a term from the German physicist Schoedinger; in German, Verschränkung). He demonstrated that a fundamental connectedness of interacting particles such as photons, protons, or molecules exists even when those particles are subsequently separated. The two or more particles in question stay entangled; they cannot be described as single particles with clearly defined properties, but only as a whole system. One object cannot therefore be fully described without considering the other. For instance, this entanglement occurs in atomic decay, where pairs of particles can be generated in one and the same process. Additionally, physicists have proved that the measurement of the properties of one particle, resulting in a definite physical value, will simultaneously cause the other particle to take the correlate value. This correlation has even been observed when the entangled parts are located far away from each other.

Recently, experiments on quantum teleportation have demonstrated this correlation for a distance of $143 \mathrm{~km}$ (see FAZ from 23 August 2012 - Rekordjagd beim Beamen - for a German language explanation or ScienceDaily from 05 September 2012: Quantum Physics at a distance for more detail in English). The findings of these experiments were also published in the journal Nature (vol. 11472, 2012). 
Quantum teleportation is an application of quantum entanglement that has found its way into quantum technology. In this case, quantum information is "transmitted" without the information "crossing space". This seeming impossibility can occur because of entanglement; once the properties of the first particle have been fixed, the "other" particle takes correlate properties. Because of entanglement, there is "nothing" to be transmitted. This experimental evidence of quantum entanglement disprove Einstein's classical view of physical particles, which had defined properties independent of each other and independent of the measurement process. Interconnectedness between physical properties is fundamentally incompatible with the atomist view of single, separated entities at the heart of classical physics. Einstein fundamentally disbelieved in the findings of quantum physics, expressed in his famous comment that entanglement was a "spooky action at a distance" and, as related to the probabilistic interpretation of the wave function, his oft-quoted "God does not play dice".

Quantum entanglement has now been experimentally proved and recognized as a valid feature of quantum mechanics. The focus now lies instead on technological research that will enable us to utilize the knowledge for communication and computing.

In fact, a great deal of today's technology and industry is already based on the findings of quantum physics. Above all, quantum technology is used in communication technology and information processing. Quantum technology has advanced to such an extent that it has been split into subfields such as quantum mechanics, quantum information technology, quantum optics, quantum computing, and quantum cryptography. For example, quantum imaging as a subfield of quantum optics is used to take images of objects with a resolution far beyond what classical optics can achieve. Other subfields include quantum lithography, quantum electronics and quantum nanomechanical devices, quantum mathematics, and quantum chemistry. It has also been predicted that the quantum internet will be the next generation of the information-processing platform (see Ma/Herbst et al 2012). Therefore, it will likely not surprise you that, starting in 1918 with Max Planck, and later Schroedinger, Bohr and Heisenberg, many quantum physicists have received the Nobel prize for physics for their contributions to this field. In the most recent example of this trend, the 2012 prize went to Haroche and Wineland for their work with quantum systems. For readers interested in expanding their knowledge of this area, Milburn (1997) wrote one of the first books on the technological applications of quantum physics and provides an excellent overview of quantum technology. 


\section{Summary}

In classical physics (and as still believed by Einstein), all particles have defined properties that are independent of measurement. The properties are "fixed"; that is, they are given before the measurement process. We can use measurement to know about the properties of the particles in an objective manner.

In quantum physics, particles do not have defined properties. The state of any sub-atomic particle can be described by a wavefunction. The wavefunction is a mathematical expression which calculates the probability that a particle, when measured, will have specific properties; for example, if it will be in a given location or state of motion. It is a wave of possibilities. The properties of the particles are not given. Instead, they are possibilities - elements of the wavefunction, which is a statistical law of probability. Their very existence as a particle is a wave-like probability. In other words, elementary particles do not exist as material particles "as such", but as a "possibility", as an element of a quantum possibility wave. Thus no certainty exists with which to predict an atomic or sub-atomic phenomenon (Capra 2012: 67).

With this new information, the particle, which in classical physics is a solid, material, separate entity, can no longer be understood as a static object. It has instead become a dynamic structure, a process of energy that can manifest as the mass of a particle (Capra 2012: 77, 80). The atomist material ontological statement that matter is made of tiny, indivisible elementary particles can no longer be sustained. Against the background of quantum physics, we should instead speak of processes as the ontology of matter.

As mentioned above, a central feature of these processes is that particles never exist as single, separate entities, but are entangled, connected. For quantum physics, the relations between particles are more important than their individual, particular manifestations. In classical physics, it is not the relations between the entities but rather their individual properties and appearances (atomism) that proves key to the world view. In quantum physics, in contrast, the properties of a particle can only be understood as having been derived from that particle's activity and interdependencies.

With the mounting evidence in favor of processes of quantum mechanics, classical models of atomism such as the model of the atom as a planetary system cannot be sustained. There are thus no solid particles moving around the nucleus, but rather waves of probabilities (Capra 2012: 69). Quantum physicists therefore suggest that, in order to better understand the universe, we view it as a dynamic web of inseparable energy structures, an integrated whole (Capra 2012: 80-81). Quantum physics points to a fundamental unity 
and a dynamic character of matter. Particles are thus not isolated entities but integrated parts of a whole (Capra 2012: 80). This unity takes us back to the old ontological view held in Greek antiquity that "physical/mechanical forces" and "matter" are distinct (Capra 2012: 81). In quantum mechanics, matter is a web of interrelations between the parts of a whole (Capra 2012: 68). These interrelations include the observer, as the properties of an atomic object can only be understood in terms of the interdependency between the object and the observer/the measurement process. The classical view of an objective description of nature being possible no longer holds true for quantum mechanical systems; the Cartesian distinction between observer and observed cannot be maintained in the subatomic world. Observer and observed are instead part of a single system. Furthermore, there is no independent observation and hence no objective knowledge.

Admittedly, these new models and theories are not easy to bring into line with the way "objects" are observed on the macro-level of everyday life. As quantum physicists admit, the predictions of quantum laws are actually counter-intuitive. However, exactly this paradox has been proved by quantum physics: the ontology of physical objects is contradictory and paradoxical and yet, as complementary aspects, those paradoxes themselves are a central feature of reality.

At present, a widespread discussion is taking place on whether the findings of quantum physics are valid for the macroscopic world of our day-to-day life "on earth" or whether they only hold relevance for our view of the microscopic sub-atomic world and for cosmological phenomena relating to the entire universe. In fact, the current state of knowledge in physics is now going to be based on different, partly incompatible paradigms - classical physics and the laws of new physics. We will not find satisfying answers in such discussions, last but not least because we have only recently developed an increasing awareness of the potential implications of new physics for our perspective of the world. We must first study and understand the counterintuitive laws of new physics, a complex and difficult task given that we perceive new physics through the lenses of our classical, Cartesian-Newtonian world view. In fact, analyzing the implications of new physics for our world view requires us to see things from a totally different perspective than the classical one in which we have all been trained and socialized. In that regard, the discussions about the rise of a new scientific world view require rethinking, seeing things with a different order of thought. It is exactly this need to rethink previously held perspectives and beliefs that makes a discussion of the science-physics-nexus so interesting for the social sciences as well. We will come back to this idea in the final paragraph of this unit and at the end of the book. 


\section{Prospects}

Quantum physics fundamentally calls into question the very foundations on which the classical, Cartesian-Newtonian world view rests: the atomistmaterialist ontology; dualism in regard to mind and matter; determinism and the idea of a law-like nature of the order of the world; the view that researcher and his/her object of scientific inquiry are separate entities. You can easily conclude that, in such a world, reductionism and methodological individualism will not make any sense for the practice of science. In addition, scientific knowledge will lose its status as "objective" knowledge. If science's current high-prestige status in our societies depends on its association with "objective knowledge", then the interpretation of new physics will have far-reaching consequences for the way we perceive the role and function of science more generally. If this is the case, we must confront the question of what will then provide a "valid" basis for economic and political action.

This unit has been written with the intention of raising some thoughtprovoking issues with regard to our idea of science and our world view. It also invites you as readers to actively take part in a debate on the implications of our scientific world view for how WE (!) - researchers, students, teachers, practitioners of international politics - actually do science, use science, "produce" knowledge and thus actively shape "reality" by what we do.

I would also like to link our discussion to the current debate about the need for a new world view. This debate is extremely broad and goes far beyond what has been described above based on the findings of new physics. However, I see the current debates on the implications of quantum physics as a part of this broader public and societal debate. For us as teachers, students and practitioners of international relations, the quantum physics aspect of the debate is particularly interesting because of its relevance for science. An increasing number of scientists are convinced that quantum physics has the potential to radically change our classical scientific world view, which is still based on Cartesian-Newtonian science (see Dürr 2012, Capra 2012, Bedenig 2011, Hüther 2012, Knapp 2011). In fact, in recent years physicists have produced an increasing number of publications in which they "go philosophical", pointing to the implications of quantum physics' recent findings for changing our "world view". You will find a range of such titles in this book's supplementary reading section "New world view". However, this increase in "philosophical" publications holds true for biologists, neuroscientists, neurophilosophers and other scientists too (for biology, see for example the overview in Hüther 2012; in biology and immunology see also Han 2010: 516 and Tomasello 2001, 2009). 
In addition, the broader debate about a new world view demonstrates an increasing awareness of the implications of "other" world views, such as those based on Chinese, Indian or Arabic philosophies, for the conduct of science, politics and economics. These "non-Western approaches" are increasingly being recognized in the natural sciences (for example, Traditional Chinese Medicine or Ayurveda in the medical field), philosophy (the new interest in Arab philosophers such as Al Kindi and Ibn Khaldun or in Indian and Chinese philosophy), in politics (e.g. a new interest in Indian political theory or Chinese IR theory), and business (an awareness of different cultural approaches to firms, management and political economy more generally). Analogous to the impact classical Greek thought had on European/Western culture, science, politics and economics, we can equally assume that the philosophies found at the heart of Confucianism, Taoism, Hinduism, Buddhism or Arab philosophy shaped world views beyond Europe. Furthermore, these world views are equally reflected in the science, politics and economics of those areas in the same way European thought is reflected in the European/Western understanding of science, politics, economics, etc. (for IR, see for example Acharya/Buzan 2010). Learning about these regions thus, requires an understanding of positions on international politics that are not European in origin.

\section{Why is this discussion a relevant one?}

This book started with the core argument of international politics' intrinsic social and political relevance for societies and the thesis that this relevance has historically been a driving force for theoretical reflections about international relations. I would like to conclude this learning unit on world views and the idea of science by taking up this core argument once again. The common background that unites the different strands of the current debates on the need of a new world view is the devastating condition of our environment, the deep crises of economics, finances, and legitimation, the tremendous social dislocations in our societies, and the deadlocks in almost all areas of international politics that require true and genuine cooperative solutions for the sake of humankind. This need for cooperation holds true not only for international environmental politics, but also for North-South relations and developmental policy, food and agricultural policy, and many other areas. There is an increasing awareness that social, political, economic action requires rethinking and constructing political and economic systems based on something other than the individualist rivalry and competition which has such devastating consequences for our natural living conditions. For those who promote such a reevaluation and rethinking, no less is at stake than the future of the planet and of mankind (see for example the 
excellent contributions of scientists in the volume of Hüther/Spannbauer 2012). In short, this is a debate about the very basics, the fundamental assumptions and orders of thought as reflected in our world view. What is the role and position of science therein, provided the thesis holds true that a mutual linkage exists between the way we conduct science and the overarching orders of thought? What is the role and position of the academic discipline of International Relations in such a world view? What is the role of our own academic work, our own theoretical research? Conceptual and theoretical inquiry is a prerequisite for any academic research as well as for the practice of politics. As you have learned, all inquiries and all engagement with the "world" begin from certain premises. This holds true for science as well. Do we really understand the basis of these premises? Are we truly aware of those starting points and their implications for the way we do science?

You are invited to more deeply reflect on the idea of science in IR and on the role and status of science in our societies more generally. For advanced students of IR who are already familiar with theories of International Relations, you may engage in this discussion right now by going straight to the end of the book, reading the questions and (after having registered) entering the discussions in our forum on iversity.

For all those who are not yet familiar with theories of International Relations, you are invited to learn about a selected range of IR theories first before joining the discussion. For this purpose, in the next unit we will compile core criteria and questions - derived from the philosophy of science discussions in Units 1, 2 and 3 - that facilitate structured learning about particular theories of IR. These criteria and questions will also make it easier to compare these theories with regard to the nature of their theoretical constructs and their approach to science and theory. 
Step 3:

Self-study and consolidation

\section{Self-study (3)}

Familiarize yourselves with the findings of quantum physics by consulting two or three titles from the "Quantum physics"-section of the supplementary reading list. In addition, please read Munro 1927 and diZerrega 1991 from the "Politics/IR and Quantum theory" section.

\section{Step 4:}

Discussion (optional, for advanced students)

Enroll in the discussion on IR as a science on the iversity platform.

\section{Required reading}

Brodbeck, Karl-Heinz 2011: Die fragwürdigen Grundlagen der Ökonomie. Darmstadt: Wissenschaftliche Buchgesellschaft, Kapitel "Soziale Physik" und "Rationalität" (in German only).

Capra, Fritjof 2010: The Tao of Physics. $5^{\text {th }}$ ed. Boston: Shambala, Part 1: The way of physics (17-84).

Feyerabend, Paul 2008: Has the scientific view of the world a special status compared with other views? In: Hilgevoord, Jan (ed.): Physics and our view of the world. Cambridge: Cambridge University Press, 135-148.

Sayer, Andrew 2010: Reductionism in Social Science, in: Lee, Richard (ed.): Questioning $19^{\text {th }}$ century assumptions about knowledge: Reductionism. New York: State University of New York Press, 5-56.

\section{Supplementary reading}

\section{Philosophy and science/physics - Classical world view}

Bedenig, Dieter 2011: Physikalische Weltbilder. Solothurn: Weissenstein Verlag (in German only).

Carrier, Martin 2012: Die Struktur der Raumzeit in der Klassischen Physik und der Allgemeinen Relativitätstheorie, in: Esfeld, Michael (ed.) 2012: Philosophie und Physik. Berlin: Suhrkamp, 13-31 (in German only).

Chalmers, Alan 2010: The Scientist's Atom and the Philosopher's Stone: How Science succeeded and Philosophy failed to gain knowledge. New York: Springer.

Cohen, Bernhard 2008: The Newtonian Revolution. Cambridge: CUP. 
Damerow, Peter/Renn, Jürgen 2010: The transformation of ancient mechanics into a mechanistic world view, in: Toepfer, Georg/Böhme, Hartmut (eds.): Transformationen antiker Wissenschaften. Berlin: de Gruyter, 243-268.

Dieks, Dennis 2008: The scientific view of the world, in: Hilgevoord, Jan (ed.): Physics and our view of the world. Cambridge: CUP, 61-78.

Donath, Judith 2010: The imperfect observer: Mind, Machines and Materialism in the Twenty-First century, in: Lee, Richard (ed.): Questioning $19^{\text {th }}$ century assumptions about knowledge: Dualism. New York: State University of New York Press, 105152.

Esfeld, Michael (ed.) 2012: Philosophie und Physik. Berlin: Suhrkamp (in German only).

Esfeld, Michael 2011: Einführung in die Naturphilosophie. 2. Aufl. Darmstadt Wissenschaftliche Buchgemeinschaft (in German only).

Garber, Daniel 2010: Descartes embodied. Reading Cartesian Philosophy through Cartesian science. Cambridge: CUP.

Hilgevoord, Jan (ed.) 2008: Physics and our view of the world. Cambridge: CUP.

Knight, David 1986: The Age of Science. Scientific World view in the Nineteenth century. London: Blackwell.

Lefévre, Wolfgang (ed.) 2001: Between Leibniz, Newton and Kant: Philosophy and Science in the Eighteenth Century. Dordrecht: Kluwer.

Novack, George 1965: Origins of Materialism. The Evolution of a scientific view of the world. Pathfinder Books.

Renn, Jürgen/Valleriani, Matteo/Staude, Jacob et al. (eds.) 2009: Galilei und die Anderen: Hintergründe einer Revolution der Astronomie. Heidelberg: Spectrum der Wissenschaft.

Stöckler, Manfred 2012: Demokrits Erben. Atomismus zwischen Philosophie und Physik, in: Esfeld, Michael (ed.) 2012: Philosophie und Physik. Berlin: Suhrkamp, 137-157 (in German only).

\section{Quantum physics}

Bedenig, Dieter 2011: Physikalische Weltbilder. Solothurn: Weissenstein Verlag (in German only).

Buschhorn, Gerd/Wess, Julius (eds.) 2004: Fundamental Physics. Heisenberg and Beyond. Berlin: Springer.

Davies, P.C.W./Brown, J.R. 2010: The Ghost in the Atom. Discussions of the Mysteries of Quantum Physics. Cambridge: CUP.

Heisenberg, Werner 2007 (1958): Physics and Philosophy. London: Harper.

Heisenberg, Werner 1977: The Copenhagen Interpretation of Quantum Theory, in: Physics and Philosophy, Frankfurt a.M.: Ullstein, 28-40 (Repr. in Heisenberg, Werner 2011: Quantum Theory and Philosophy. Stuttgart: Reclam, 42-61).

Heisenberg, Werner 1969: Der Teil und das Ganze. München.

Hey, Tony/Walters, Patrick 2003: The New Quantum Universe. $2^{\text {nd }}$ ed. Cambridge: CUP.

Malin, Shimon 2003: Dr. Bertlsmann Socken. Wie die Quantenphysik unser Weltbild verändert. Leipzig (in German only).

Schroedinger, Erwin 2008 (1954; 1951): Nature and the Greeks and Science and Humanism. Cambridge: Cambridge University Press.

Wilber, Ken (ed.) 1985: Quantum questions. Boston. 
Zeilinger, Anton 2010: Dance of Photons. From Einstein to Quantum Teleportation. Farrar Straus \& Giroux.

Zeilinger, Anton 2005: Einsteins Spuk. Teleportation und weitere Mysterien der Quantenphysik. München.

\section{New world view}

Brockman, John (ed.) 2009: This will change everything: Ideas that will shape the future. New York: Harper

Descola, Phillippe 2011: Jenseits von Natur und Kultur. Suhrkamp (in German and French only).

Dürr, Hans-Peter 2009: Warum es ums Ganze geht: Neues Denken für eine Welt im Umbruch. München (in German only).

Dürr, Hans-Peter, Popp, Fritz-Albert/Schommers, Wolfram (eds.) 2000: Elemente des Lebens: Naturwissenschaftliche Zugänge. Kusterdingen: Graue Edition (in German only).

Hüther/Spannbauer 2012: Connectedness. Warum wir in neues Weltbild brauchen Bern: Verlag Hans Huber (in German only).

Hüther, Gerald 2012: Paradigmenwechsel in den Life Sciences, in: Hüther/Spannbauer (eds.): Connectedness. Warum wir in neues Weltbild brauchen Bern: Verlag Hans Huber, 103-124 (in German only).

Knapp, Nathalie 2011: Der Quantensprung des Denkens. Reinbek: Rowohlt (in German only).

Leggewie/Welzer 2011: Das Ende der Welt wie wir sie kannten. Fischer Verlag (in German only).

Ricard, Matthieu/Thuan, Trinh Xuan 2004: The Quantum and the Lotus: A Journey to the Frontiers where science and and Buddhism meet. New York: Thee Rivers Press.

Searle, John 2010: Why Dualism (and Materialism) fail to account for Consciousness, in: Lee, Richard (ed.): Questioning $19^{\text {th }}$ century assumptions about knowledge: Dualism. New York: State University of New York Press, 5-48.

Welzer, Harald 2012: Die Revolution des "Wir", in: Hüther/Spannbauer (eds.): Connectedness. Warum wir in neues Weltbild brauchen Bern: Verlag Hans Huber, 61-80 (in German only).

\section{Politics/IR and Quantum Theory}

Akrivoulis, Dimitris 2007: The "Quantum Politics" Metaphor in International Relations: Towards a Hermeneutics of Political Metaphoricity. Paper presented at the $57^{\text {th }}$ Political Studies Association Annual Conference, University of Bath, UK, 11-13 April.

Becker, Theodore L. (ed.) 1991: Quantum Politics. Applying Quantum Theory to Political Phenomena. New York: Praeger.

diZerrega, Gus 1991: Integrating Quantum Theory with Post-Modern Political Thought and Action: The Priority of Relationships over Objects, in: Becker, Theodore L. (ed.) (1991): Quantum Politics. Applying Quantum Theory to Political Phenomena, New York: Praeger, 65-100.

Munro, William B. 1927: Physics and Politics: An Old Analogy Revisited, repr. in Becker, Theodore L. (ed.) 1991: Quantum Politics. Applying Quantum Theory to Political Phenomena, New York: Praeger, 3-10. 
Slaton, Christa D. 1991: Quantum Theory and Political Theory, in: Becker, Theodore L. (ed.) (1991): Quantum Politics. Applying Quantum Theory to Political Phenomena, New York: Praeger, 41-64.

Wendt, Alexander 2006: Social Theory as Cartesian Science, in: Guzzini/Leander (eds.): Constructivism and International Relations. Alexander Wendt and his critics. New York: Routledge, 181-239.

Wendt, Alexander 2010: Flatland: Quantum Mind and the International Hologram, in: Albert, Mathias et al (eds.): New Systems Theories of World Politics, 279-310.

\section{Additional references in the text}

Acharya, A./Buzan, B. (eds.) 2010: Non-Western International Relations Theory. Perspectives on and beyond Asia. London: Routledge.

Al-Jabri, Mohamed A. 2011: The Formation of Arab reason: Text, Tradition and the construction of modernity in the Arab world. London: Tauris.

Ellis, George F.R./Maartens, Roy/MacCallum, Malcom 2012: Relativistic Cosmology, Cambridge: Cambridge University.

Han, Byung-Chul 2010: Müdigkeitsgesellschaft. Berlin. Matthes \& Seitz.

Harrison, Edward 2000: Cosmology: The science of the universe. $2^{\text {nd }}$ ed., Cambridge: Cambridge University.

Heisenberg, Werner 1977: The Copenhagen Interpretation of Quantum Theory, in: Physics and Philosophy, Frankfurt a.M.: Ullstein, 28-40 (Repr. in Heisenberg, Werner 2011: Quantum theory and Philosophy. Stuttgart: Reclam, 42-61).

Lefévre, Wolfgang 2001: Introduction, in: Lefévre, Wolfgang (ed.): Between Leibniz, Newton and Kant: Philosophy and Science in the Eighteenth Century. Dordrecht: Kluwer, i-x.

Looijen, Rick C. 1999: Holism and Reductionism in Biology and Ecology, Dordrecht: Kluwer.

Ma, Xiao-Song/Herbst, Thomas/Zeilinger, Anton et al 2012: Quantum teleportation over $143 \mathrm{~km}$ using active feed-forward, in: Nature 489, 269-273.

Milburn, Gerard 1997: Quantum technology. London: Allen \& Unwin.

Tomasello, Michael 2001: The cultural origins of human cognition. Boston: Harvard University Press.

Tomasello, Michael 2009: Why we cooperate. Cambridge, MA: MIT Press.

Schupp, Franz 2003: Geschichte der Philosophie. Felix Meiner Verlag (in German only).

Wilson, Robert A. 2008: Cartesian Psychology and Physical Minds: Individualism and the Science of the Mind. Cambridge: CUP. 


\section{Didactics and method}

Introduction

Criteria for a structured learning process about theories of IR

1. Core question/problem

2. Ontological assumptions about actors and structures in international relations

2.1 Assumptions about actors

2.2 Assumptions about structures

2.3 Assumptions about the interrelation between agency and structure

3. Epistemology and methodology

3.1 Type of explanation and notion of causality

3.2 Approach to "levels of analysis"

4. General approach to IR as a science and to the practice of international politics

Overview: Criteria for a structured learning process

Review questions

Consolidation 


\section{Introduction}

As has been discussed in the learning units 1 and 2, theory building is "informed" by and embedded in meta-theory: there is theory "behind" the particular theories of IR in that a theory of IR implicitly or explicitly is built on a set of assumptions that are derived from a specific understanding of science. Moreover, the understanding of science is part of a broader scientific world view, a specific historical "order of thought". Unit 2 was designed in the belief that, for a better understanding of the differences between theoretical approaches to IR, you need some basic understanding of general problems of theory building in the social sciences. In Unit 2 you therefore gained knowledge about theory formation as linked to the meta-theoretical level of philosophy of science. You are now familiar with the core elements of any philosophy of science: ontological claims about what is, what exists, what reality is made of and what the most general features and relations of the things and entities are; epistemological claims about the kinds of knowledge possible and the criteria for legitimate knowledge; and methodological assumptions that define how to best come to know and explain. In addition you know about how philosophies of science are embedded into broader world views. Without these world views, it would be difficult to understand where we derive the assumptions and the particular theoretical constructions found at the heart of theories. While even the philosophy of science position that underlies a theory is only rarely spelled out explicitly, this is even truer for the broader (scientific) world view. Both can be understood as a type of "hidden" theory that shapes our fundamental perception of (social) reality and of what and how we can know about it.

Now we will take the next step and link our philosophical discussions to the study of International Relations. Our purpose will be to define a set of questions and criteria for the more qualified study of particular theories of IR. Terms such as ontology, epistemology and methodology have very specific uses and functions within the philosophy of science. For the purpose of our book, they have to be "translated" and applied to International Relations. The aim is to define a range of criteria that can be used for a structured process of learning about particular theoretical approaches to IR. In other words, the following chapter presents a set of criteria that will be used later to discuss five particular theories of International Relations. It is important to emphasize once again that the discussions in Part 2 of the book will be based on "learning by example": the broader intention is to offer meta-theoretically and philosophically informed guidance for your structured self-study of any IR theory - not only those presented in the book. The application of this concept will be 
demonstrated by way of five sample theories. The method is based on the conviction that a structured learning process along the lines of criteria derived from philosophy of science discussions will offer important insights on theory construction that, because of a neglect of their embedding in philosophy, would otherwise not be reached.

As this learning unit is basically about the didactics and method to be applied in Part 2 of the book, there will be only one self-study instruction and two review questions. Key aspects will be given in form of a tabular overview of the criteria developed in this unit.

\section{Criteria for a structured learning process about theories of IR}

\section{Core question}

Each learning unit dealing with a particular theoretical approach will start by asking: what is the core question or core problem of the approach? Which phenomena of international politics does the theory explain? What is the purpose of constructing this particular theory of IR?

An introduction of different theories of IR with regard to their core question will offer a first and important insight on the understanding of the underlying theory and science.

\section{Ontological assumptions about actors and structures in international relations}

As you have learned in Units 2 and 3, theoretical constructions in the social sciences are always built on assumptions: ontological, epistemological, and methodological starting points in the process of theory construction.

For a theory of International Relations these are usually assumptions

(1) about the relevant actors of international relations, the "type" of actors considered to be most important and their "properties";

(2) about the context of interaction, that is, the structures of international relations;

(3) about interrelations between the entities; how the actors and structure relate to each other. 
You know that these are ontological assumptions as long as they involve claims about existence and being (what is), the entities that exist, and their properties and relations. They are epistemological assumptions insofar as they concern questions of how to come to know and what counts as valid knowledge. They are methodological assumptions when they relate to the ways and methods in the practice of gaining knowledge.

Let me now elaborate on what we are looking for in IR theories when applying the criterion of "assumptions about actors and structure".

\subsection{Assumptions about actors}

In order to reflect on the politically relevant interactions, a theory will usually ask about actors. Who are the relevant actors in international politics? What is the "nature" of the actor and what is the "nature" of interactions taking place?

Remember that the answers to these questions are "starting points", not subject to any "proof", but instead fall under the category of what we call "assumptions". An example is the general assumption that the "nature" of international relations is inter-state politics, that states are the central and most important actors, and that they act rationally. This is a claim shared by the most influential theoretical approaches in IR. However, other theories exist as well, starting for example from the assumption that the "nature" of international politics is a world of interwoven, network-like social relations between diverse types of actors within a "global society". Here, any social actors, state and nonstate, are relevant for the "existence" of international relations. For each example, the view of the "being" of international politics - the view of ontology differs. This difference - whether you think of international relations as state interactions within a system of states or, alternatively, have a world society in mind when talking about "international relations" - affects both the theoretical construction and the explanatory model that a particular theory offers.

The precondition of action and interaction between social actors is usually perceived as an intentional state: action is, by its very nature, intentional and purposeful (even though, of course, it can have unintentional effects and consequences). Therefore, theories usually make assumptions about the "driving forces" of actions/interactions and about how actors reach decisions. These are ontological assumptions related to the actor's motivation, goals, needs, cognitions (such as values, beliefs, attitudes, knowledge, and perceptions), interests or preferences; in short, they are ontological assumptions about actors and their "properties". 
For example, many theories in IR draw on action theory and assume actors are "rational actors". For rational actors, the "source" of action is assumed to be "internal" (their "interest") and to involve utility-maximization, which is perceived as being a "property" of the individual actor. With regard to an actor's decision-making style, utility-maximization assumes that actors have individual preferences for various possible outcomes in any situation and, as a result, can rank the outcomes in terms of their desirability. They then choose whatever strategy or course of action makes the better outcomes most likely, thereby maximizing the actor's "utility" (rational choice). You will find such assumptions in economics as well as in most other social science theories. Those theories that draw on mathematical models of decision-making in a formal manner demonstrate individualism and the rational actor-assumption most clearly. Examples are decision theory, which focuses on single decision makers, and game theory, which focuses on small groups of actors interacting strategically (for a good overview of rational choice in IR see Kydd 2008).

In line with these ontological assumptions, IR theories assuming rational actors ultimately explain outcomes in international politics in terms of the individual actors' rational actions. Depending on the particular actors assumed to be relevant for international relations (these could be individual actors from a state's society as is the case in liberal theory, or unitary states as in neorealist theory), different theories of IR operate on the general assumption of rational individual actors. Here, philosophy of science discussions become particularly relevant. Only a superficial difference arises between theories of IR because they assume different actors to be relevant; from a philosophy of science perspective, the theories are the same in terms of their underlying individualist ontology. In the example of neorealist theory, as in many other theories of IR, the state is theoretically treated as an "individual": it assumes the state is a unitary actor analogous to an individual, with a rational - state interest and engaged in rational interaction with other states (as individual actors). You can find such state individualism in many IR theories.

What these theories express is in fact the ontological position of atomism/individualism you learned about in Units 2 and 3. Treating the state as if it were an individual actor reflects an ontological view of international relations made up of individual "units". At the level of international relations, this atomism can sometimes be difficult to see. As you already know, this fundamental ontological position has epistemological and methodological implications: when the state is treated as an individual and the basic unit of international relations, outcomes of international politics are usually explained in the final analysis by referring to the individual state's motivation and interest. You know that this approach is called methodological individu- 
alism. In IR, it is sometimes referred to as "methodological nationalism" or "methodological statism" because the "individual" in this case is the state. Generally, the question of how to treat actors theoretically in international politics is difficult. This holds true not only for the state, but for other actors as well. For example, how can we account for actors such as international organizations? How can we conceive theoretically of the UN or the EU as actors in international politics? Ontological assumptions regarding the "being" of collective and individual actors have important consequences for explanations. This point is also closely related to the fundamental ontological question of how the "whole" relates to the "parts": is, for example, the UN as an international organization more than the sum of its constituents - the states? Is the UN a "collective" actor to be perceived as a collective "global community" with a "quality" that goes beyond the sum of the individual actor's (state) interests? Is "society" more that the sum of its components, the individual societal actors? The theories presented in Part 2 of the book will be discussed with regard to the difficult ontological, epistemological and methodological aspects of theorizing actors and their "properties".

\subsection{Assumptions about structures}

In addition to actors, theories of the social sciences usually reflect on the "context" for social actions: the social environment of actors is often called the structural context or "structure". "Structure" refers to the social order or organization within which actors act and interact. For example, "inside" the state, individual and collective actors (citizens, interest groups, parties, trade unions etc.) act within state structures. Structures are not only material institutions; they also embody the norms and rules of authority (e.g. laws) that govern and regulate the behavior of actors and sanction deviant behavior. "Outside" the state in international relations, states and non-state actors are usually assumed to act and interact within an international system. We have already discussed the fundamental assumption that the "type" of social order found in the international system is often perceived as "anarchy" (as opposed to hierarchy inside the state). The assumption of an anarchical international system is usually an assumption about the structural features of the international system. No higher authority exists "to govern" international politics. Sovereignty is the basic norm inherent in the structure of the international system (when understood as a system of states).

In short, theories of IR (implicitly or explicitly) build on assumptions about the most relevant structures of international relations, the "nature" of 
those structures and their "effects" on actors in international relations. A very basic ontological question is the "nature" of the structural context: to what extent can we assume that the structures of the international system consist of material conditions? Do they instead consist of ideas such as norms or collective knowledge? Or, alternatively, both? We can easily think of structures in terms of how material resources, technology, weapons, economic power, etc., are distributed. But we can also think of structures in terms of (immaterial) norms and rules inherent in the system or in social institutions found in international relations, such as international organizations or international regimes. From what you have learned in Units 2 and 3, you know that assumptions of material and/or ideational features of the world belong to the most fundamental ontological "starting points" of any reasoning.

The theories presented in this book will thus not only demonstrate different ontological perspectives on actors, but on structures too. We will learn about different theories of IR because they have different theoretical ways of ontologically taking into account the structural context of actors' interactions.

\subsection{Assumptions about the interrelation between agency and structure}

The relationship between active and self-reflecting agents and the structural context in which their activity takes place lies at the core of the agentstructure-problem in IR. Agency usually refers to the capacity of human actors to act independently and to make their own free choices. Structure consists of all factors of the social context that constrain (or enable) human action.

The "nature" or "being" of this relation is a question of social ontology, an ontological position of the primacy of structure or agency. Is social structure ontologically "prior" to human behavior or is human agency? This query involves further questions about the nature of the entities, in this case that of actors and social structures, as we discussed them in the previous section. For systematical reasons, the following units will discuss ontological aspects of the interrelation between agency and structure together with the epistemological and methodological implications of different ontological positions on the agent-structure-problem. Please be aware that this problem is, at its core, ontological. For that reason, it is discussed in the section "Ontological assumptions about actors and structures". However, in the overview at the end of this unit, the agent-structure problem will take a separate position because of its epistemological and methodological implications. 
In short, the question of how agency and structure interrelate is not only ontological but also epistemological and methodological. As an epistemological question, it seeks an explanation in terms of the interrelation of agency and structure: does structure "cause" agency or does agency "cause" structure? Perceived as a causal relation, this is usually understood as a temporal cause-effect-relation in the Humean sense described in Units 2 and 3. However, as will be shown later, there are theories of IR that assume a different "causality" in the interrelation between agency and structure. We learned in Unit 2 that there are two basic positions with regard to this question: methodological individualism and methodological holism. Both aspects, the ontological and the explanatory, relate to each other as follows:

1) Social existence IS a "whole"; it has its own "ontological quality" that is more than the sum of the parts (ontological holism, often called ontological structuralism). "Structure"/the "whole" is ontologically prior to agency. Agency can thus mostly be explained by the operation of this structural whole (epistemological and methodological holism). The explanation of agency (such as individual behavior or individual identity) always occurs "in terms" of structure. "Structure" is also epistemologically "prior" to agency in that the structure is seen as the "cause" for actors' behavior. In other words, agency is explained as a causal effect of structure.

2) Social existence IS agency; in other words, the "being" of the world is individual actors constructing and reconstructing their worlds. The whole (for example "society") is not more than the parts (the individual actors). Ontologically there is no social whole with its own quality. There are only individuals that act according to their (internal) "properties"; that is, their individual interests (ontological individualism). Social worlds then can mostly be explained by their construction through the agency of individual human actors (epistemological/methodological individualism). The "social" is finally explained "in terms" of the parts (actor's individual interests).

You can easily see that "individualists" and "holists" agree that agents and structures are somehow interdependent. However, they assume this interrelation in different ways. Theorists committed to the notion of epistemological and methodological individualism share the ontological view that actors are the central elements in social systems. In terms of explanations, social structures are the result and the consequences of actions and interactions between individual actors. The structures can be reduced to the properties and interactions of agents. You are familiar with this concept from what you have learned about reductionism. Theorists committed to methodological holism, on the other hand, view actors as being embedded in (ontologically prior) so- 
cial structures that constrain, enable or generally shape individuals' dispositions and capacities to act. Structure has irreducible "emergent" properties that determine an actor's course of action. Here social structure should be taken as the primary and most significant explanatory factor.

The agent-structure-problem resembles the more general problem of individual/society, or the micro/macro problem. In IR theory, we will find both structuralist views that point to the structural effects on an actor's behavior (structuralist theories) and actor-centered views emphasizing the relevance of action's effects on structure (agency-centered theories). However, you will learn that there is a third philosophical "solution" to the agent-structureproblem which ontologically assumes agency and structure are mutually dependent. Here, the "problem" arises when it comes to explanation: if there is agency and structure in the social world and neither is ontologically prior, how can you then explain their interrelation? How can you give equal explanatory weight to agency and structure? As you will see, this third ontological perspective that agency and structure are ontologically interdependent poses a serious challenge to our traditional notion of causality as a temporal relation of cause and effect, with the cause preceding the effect in time. As an explanation, this ontological position of mutual dependency is usually expressed in the notion of "mutual constitution". Agency and structure mutually constitute each other; each entity explains the other. This type of explanation is often called "constitutive". This idea of "causality", if taken seriously, is very different from the well-known Humean causation. This observation leads us to the next criterion for learning about theories of IR: the type or model of explanation and the notion of causality.

Before we discuss this criterion, let us sum up the previous one. The ontological as well as the epistemological and methodological assumptions about the interrelation of agency and structure will be an important third criterion applied to our structured learning process about theories of IR. Each unit will ask if the explanation offered by the theory is structuralist or agency-centered or, alternatively, if the theory offers an explanation of a different type.

At the end you will know about explanation in terms of structural effects, explanation in terms of individual action, and explanation in terms of mutual constitution of agency and structure. The next question is about a more specific topic: the nature of explanation itself. What counts as an explanation of international politics? What is valid scientific knowledge about international relations? 


\section{Epistemology and methodology}

Ontological questions are intimately linked to epistemological problems of knowledge and of how we come to gain that knowledge. In most theories, these problems basically revolve around explanation and/or understanding, what type of knowledge counts as valid knowledge, and how to gain valid knowledge. In this book, we will approach such epistemological and methodological assumptions by discussing different types of explanations offered by different theoretical approaches to IR. How can we best explain international politics? What is the nature of the explanation? What reasons can a theory of IR give so that an explanation is taken and accepted as "legitimate", valid knowledge about international politics?

These are examples of guiding questions that help outline each theory's specific answer to the core question/problem (Criterion 1) in the respective theoretical approaches. Three aspects will be particularly relevant. First, what is the interrelation of agency and structure found at the heart of the explanation? This is primarily an ontological problem and has been introduced in the previous section through our discussion of the ontological core and the combined epistemological and methodological implications. For systematic reasons, I am mentioning it here again. Second, what is the "nature" or type of the explanation and the notion of causality therein? The third aspect will be the approach the theory takes to what is known in the social sciences as the level of analysis problem, which is in fact an analytical concept rather than a philosophy of science criterion. It will be used here in an indirect manner because it is a well-known "problem" in IR and most theories of IR refer to it. This also holds true for theories that reject the concept because of their different understanding of science: they refer to the level of analysis problem to clarify their position on science. Learning how different theories of IR approach the level of analysis problem will offer important insights into their general understanding of theory and science.

\subsection{Type of explanation and causality}

The "type" of explanation is important with regard to a central epistemological criterion: how can one come to know something and what counts as valid knowledge? It requires taking a closer look at explanation itself - that is, how the interrelation between the ontological entities is perceived epistemologically. In fact, when we ask about explanation, we ask about knowledge. What counts as valid knowledge of international politics in the discipline of IR? 
Usually "knowledge" takes the form of a "causal relation" as it has been described for the positivist account of science in Unit 2: law-like regularities that can be expressed in terms of if-then temporal sequences and that make prediction possible. Take, for example, the theory of inter-democratic peace; based on empirical observation proved by statistics, the findings of the Correlates-ofWar project at the University if Michigan have been formulated into a quasilaw that "democracies do not fight each other". This finding can be transformed into the following if-then statement: if a state is a democratic state, then the risk of war and conflict with other democratic states will be diminished. The knowledge has been used to legitimize a politics of democratization by the West in such areas as human rights and development policy, based on the conviction that democratization will contribute to peace and stability.

However, as you have learned in Units 2 and 3, neither "explanation" nor "causality" are fixed scientific terms, but instead depend on the underlying understanding of science. A scientific explanation does not necessarily take the form of a law-like generalization, nor does "causality" necessarily have to be perceived as a sequential relationship of cause and effect with the cause temporally preceding the effect. For example, social constructivist theory as formulated by Wendt points to a distinction between constitutive and explanatory theory. The criterion "type of explanation and notion of causality" will therefore be used in the structured learning process to explore different understandings of "knowledge" that lie at the hearts of different theories of IR.

\subsection{Approach to "levels of analysis"}

As has been mentioned above, "levels of analysis" is not a philosophy of science criterion in the strictest sense. Let me briefly explain why I will nonetheless integrate it to the criteria for our structured learning process.

Usually, this concept is introduced as the level of analysis problem. The problem is where (in terms of levels) we should focus our study of International Relations. As an analytical concept, "levels of analysis" originated with Waltz (1959) and Singer (1961). In his study on war, Waltz (1959) uses the term "images of the world" or "images of international relations". The first image is the individual; analyzing international conflict at the individual level means explaining the outcome of international politics as a result of human behavior. The second image is the state level, where international conflict is explained by the internal structure of states. The third image is an explanation of international politics at the system level, where structural features of the international system account for international conflict. 
More generally, the concept operates on the assumption that we can study international relations at the level of the international system (systemic level), the level of the state (state-level or domestic level) or the individual level.

System-level analysis explains the outcomes of international politics by referring to the systemic level. Explanations of outcomes in international politics are "systemic". Domestic or state-level analysis means that states and their internal processes (e.g. the "type" of political system, the powerful interest groups within the state that shape its foreign policy) count most when explaining outcomes in international politics. Explanations of outcomes in international politics are "domestic". Individual-level analysis focuses on individual human actors. This can be done by analyzing complex processes of decision-making, explanations such as "human nature" or "organizational behavior" of individuals in organizational settings, or the specific world views or beliefs of single foreign policy decision-makers. Explanations of outcomes in international politics are "individual". In fact, these three level of analysis result in three different types of theory building in IR.

From what we learned in Units 2 and 3, you will easily be able to conclude that the levels of analysis problem reflects the idea of modern positivist science that reality can be separated analytically into spheres or levels in order to gain better knowledge about the objects of inquiry. As such, this concept belongs to reductionism.

However, discussing theories of IR in terms of how they approach the positivist concept of "levels of analysis" will result in important insights on the idea of science that underlie a particular theory of IR. We will see that some IR theories categorically reject the notion of "levels of analysis" because of their different position on science altogether. We will study the reasons given for their rejection and, in so doing, will learn more deeply about each theory's understanding of science and valid knowledge.

\section{General approach to IR as a science and to the practice of international politics}

By way of summarizing, we will make a final statement about the general approach to the scientific study of IR and to the practice of international politics that is inherent in the theoretical approach at the end of each chapter on a theory. This statement will be primarily related to three aspects:

First, we will ask about the philosophy of science at the heart of the theoretical construction. Second, we will ask about the normative perspective of 
the theory. By its very nature, any social theory has a normative perspective (implicit or explicit): what should the "ideal" international system look like? We will try to identify the kind of normative perspective or ethics that the different theoretical approaches entail. In addition, we will learn more about the theories by asking about each one's particular view of change in international relations. Is there "progress" in the development of the international system? How does change in international politics occur?

These questions are also closely related to the third criterion: we will ask about the particular perspective on the study of international relations in terms of how the theorist/researcher/scientist relates to the "object" of study/research/theorizing. What position does he or she hold as to how theory of IR and the practice of international politics are linked to each other?

\section{Self-study}

Below you will find an overview of the criteria introduced in this unit and two review questions. Please take some time to reflect on the criteria and how they relate to what you have learned in Units 1, 2, and 3. Then try to answer the two review questions below.

\section{Overview of criteria for a structured learning process about theories of IR}

- Core question/core problem of the theory

- Ontological assumptions about actors and structure

- "Agency and structure": ontological, epistemological and methodological assumptions

- Type of explanation and notion of causality

- Approach to „levels of analysis“

- Philosophy of science

- Normative perspective

- Theory and practice/role of the scientist 


\section{Review questions}

1. What are some basic ontological questions that the theories of IR attempt to answer through assumptions?

2. What is the nature of the agent-structure-problem in IR? What exactly is the "problem"?

\section{Consolidation}

\section{Recommended reading}

Kydd, Andrew H. 2008: Methodological individualism and rational choice, in: Reus-Smit, Christian/Snidal, Duncan (eds.): The Oxford Handbook of International Relations. Oxford: OUP, 425-443.

Singer, David 1961: The level-of-analysis problem in International Relations, in: World Politics 14: 1, 77-92

Taylor, Michael 1989: Structure, culture and action in the explanation of social change, in: Politics and Society 17: 2, 115-162

Wight, Colin 2006: Agents, structures and International Relations. Politics as ontology. Cambridge: Cambridge University Press.

\section{References in the text}

Waltz, Kenneth N. 1959: Man, the State and War. A theoretical analysis. New York: Columbia University Press.

Singer, David 1961: The level-of-analysis problem in International Relations, in: World Politics 14: 1, 77-92

Dessler, David 1991: Beyond correlations: towards a causal theory of war, in: International Studies Quarterly 35: 337-55

Wendt, Alexander 1999: Social Theory of International Politics. Cambridge.

Ruggie, John G. 1998: Constructing the World Polity. New York: Routledge. 

Part II:

Theories of International Relations: Five Approaches 



\section{Neorealist theory}

Learning steps

Introduction

Step 1:

Background and core question

Step 2:

Assumptions about actors and structures

Step 3:

The neorealist explanation of international politics

3.1. Level of analysis

3.2. The neorealist concept of structure

3.3. Structures as causes

3.4. Balance of power politics

3.5. Peace and stability in the international system

\section{Step 4:}

Check your understanding:

key aspects and review questions

Step 5:

Final self-study and consolidation 


\section{Introduction}

This unit marks the beginning of Part II, which covers five theories of IR. At the core of this unit will be neorealist theory as developed by Kenneth Waltz in his Theory of International Politics (1979). By discussing neorealist theory's core assumptions and explanatory model in detail, we will learn about the particular perspective of international politics that neorealist theory provides.

When learning about theoretical approaches to International Relations, there are several reasons to start with neorealist theory.

Within the academic discipline of International Relations, neorealist theory - developed continuously by Kenneth Waltz beginning in the 1950s and completely worked out in his book "Theory of International Politics" (1979) - is the first "scientific" theoretical approach to IR. It was Waltz's objective to construct a general theory of IR which could explain the way all of international politics functions. At the heart of neorealism lies a strong belief that general, legal-like knowledge about international politics is possible. Within IR, Waltz was the first scholar to build his theoretical argument on the grounds of clearly demarked assumptions about actors and structures in international politics.

Neorealist theory is also the most parsimonious, or least complex, theory of International Relations. This alone makes it easy to start with. However, even more important than being the first "scientific" theoretical approach, the position neorealism holds within the academic discipline of IR almost necessitates beginning theoretical studies with neorealism. As you will learn, almost all theoretical approaches draw on neorealism as a point of reference against which to sharpen their own theoretical arguments.

In terms of "intellectual traditions", realism is the oldest "theory" of international politics. Please be aware that we are now talking about realism as a theoretical strand of IR. It should not be confused with realism as a philosophy of science (as discussed in Part 1 of the book). Realism as realist thinking about interstate relations in terms of power politics or balance-of-power politics can be traced back in history as far as Thucydides. However, this argument only holds true if we take into account the core of political thinking about power politics that is found in all strands of realist theory. For the purpose of our book, it might therefore be useful to differentiate between realist thinking and neorealist theory right from the beginning. This difference is important because the type of theoretical construction and nature of theoretical explanation found in neorealism as a theoretical approach will be the central issue for our discussions. However, as one aspect of dealing with our theoretical approaches will be questions about the normative perspective, we 
will come back to realist thinking in terms of realist international politics at the end of this unit.

These points are closely related to a final aspect, the relevance of theory for the practice of international politics. Realist thinking and neorealist theory clearly belong to the most influential perspectives of International Relations. This can be seen through their role as a guide to the political actions of US administrations after World War II until the 1970s and again since the 1990s. In the US, the study of IR was (and often is) closely tied to a practical political purpose: to optimize American foreign policy under "new" conditions of international politics, such as of superpower rivalry after World War II, world economic turbulences with the oil price shocks in the 1970s, following the end of the Cold War in the 1990s, or now against the background of new rising powers such as China. In the early years it was Hans Morgenthau's realism as formulated in his Politics among Nations (1948), together with the work of John Herz, Reinhold Niebuhr, subsequent US Secretary of State Henry Kissinger and Arnold Wolfers, which shaped American foreign policy. Neo-realism, developed by Waltz as a critique of early realism, along with the diverse strands of neorealist theory today, have also mainly been developed and modified in the US. The frequently debated move of the US from multilateralism to unilateralism since the 1990s and the hopes that the Obama administration would bring a new multilateralist approach to US actions cannot be reasonably understood without taking into account the relevance of a (neo)realist world perspective. Much of international security politics, not only in America, is guided by (neo)realist perspectives. Investigating the neorealist perspective thoroughly is thus not only a theoretical endeavor but also helps us to better understand the perspectives behind much of contemporary world politics.

\section{Step 1: \\ Background and core question}

The differentiation between realist thinking and neorealist theory in the modern usage of the terms provides a good starting point for illustrating the background behind the formation of neorealist theory. Realist thinking, with its central categories of "political power" and the "national interest", formed the core of IR after World War II. This tendency increased with the advent of the Cold War. However, approaches to International Organizations and conflict studies have also constituted a large part of the academic study of IR since the 1950s; their role should not be downplayed. The dominance of realism 
within IR was the answer to politically motivated questions at the core of the American discipline until the late fifties and sixties. At this point, there was a move towards more basic or fundamental research. Comparative studies - using systematic comparison as a method to find general explanations for international relations (since the 1950s) - and theories applying game theory to the social sciences/International Relations (especially since the 1960s) were attempts to find scientific explanations for international relations. In the US, a strong dominance of decision-making approaches to International Relations was the result of a transfer of emphasis from politics to foreign policy studies (Snyder R.C./Bruck, H.W./Sapin, B. 1962). Foreign policy decisions such as the American choice in favor of the Korean War were at the core of these theoretical programs. In terms of theory, the controversial point was whether these studies should be classified as foreign policy studies or as studies of international relations. These are questions closely related to the level-of-analysis problem, which was an issue of our discussions in Unit 4 of the book. They reflect the fundamental problem of how best to explain international politics in terms of "locating" the most relevant explanatory variables.

Out of the belief that theories of foreign policy do not constitute adequate explanations of international politics, Kenneth Waltz claimed that there was a lack of a genuine international political theory within the discipline. Explanations of international politics are not to be found at the state or individual level of political decision makers, but at the level of the international system. His theoretical project is basically the construction of a system level theory of IR. He developed early ideas about such a systemic theory of international politics in the 1950s with his Ph.D. dissertation on Man, the state and the state system in theories of the causes of war at Columbia University in New York (1954) and his book Man, the State and War: A Theoretical Analysis (1959). Waltz argues that, in order to study international conflict, we have to look at the systemic level of international politics. The causes are not to be found in human behavior or in the internal structures of the state.

Subsequently, Waltz developed a comprehensive system-level theory of international politics, published in 1979 as Theory of International Politics. The core question for the construction of the theory is a theoretical explanation of war and peace in international politics. As we know, questions of war and peace have been at the core of the discipline right from the beginning. What particularly interested Waltz was the following question: How can we explain that history shows phases of war and conflict while other periods proved to be stable and peaceful? His observation of these recurrent patterns of state behavior and repeated and enduring patterns in the history of international politics awakened his interest in finding a theory to explain those re- 
current patterns: the cycles of war and peace in international politics. More precisely, it was the recurrent formation of balances of power by the great powers in international systems that interested him.

The objective was to create a general theory of International Politics that could aid in discovering law-like regularities within the confined realm of international politics. These regularities in turn help to explain the patterns observed.

In Waltz's eyes, such a general theory had to be both a system theory and a balance-of-power theory. The search for the "right" theory of international politics within the discipline of IR therefore forms the academic and intellectual background for the construction of neorealist theory as a system theory. Neorealism's further development as balance-of-power theory allows the system-level theory to specify more clearly its implications for the conduct of real-world international politics. The bipolar system of the Cold War formed the political-historical context at the time the Theory of International Politics was written. From Waltz's point of view, the Cold War proved to be an astonishingly stable period - at least in terms of the absence of major wars despite phases of high-risk confrontation between the two superpowers. The central issues of neorealist theory are the implications for the prospects of peace and stability resulting from two major changes: first, from the previously multipolar international system to a post-1945 bipolar world with two superpowers; and, second, from the bipolar world to a new international system with the end of the Cold War. In addition, the theory has to be interpreted against the background of a declining American hegemony vis-à-vis the economic rise of Europe and Japan after the 1970s.

Let us now take a closer look at the theoretical argument.

\section{Step 2:}

\section{Assumptions about actors and structure}

Neorealist theory is built on a strict distinction between national and international politics. International politics is considered to be a confined realm or domain separate from national politics. The starting point of neorealist theory is the international system. For the purpose of constructing a theory, the international system is assumed to consist of two elements: the structure of the system and the states as acting and interacting "units" within the system.

As we have learned in Part 1 of the book, theory in the social sciences is always based on assumptions about the most relevant actors, their properties 
and their behavior. They are assumed, not explained by the theory. Assumptions play a central role for the construction of the theoretical argument and hence for its explanation. In this way, neorealism is based on the assumption that states are the most important, relevant actors in international politics. States are unitary actors. In regard to their motivations and interests, or in other words, the driving forces of their behavior, neorealist theory assumes that states are at a minimum seeking their own survival and preservation and at a maximum striving for universal domination within the international system. Therefore, states seek to increase their military strength and economic capability (inside) and to strengthen and enlarge their alliances (outside). Power is assumed to be the most important political means in international politics, used to achieve the state's aims. There is a clear hierarchy of state goals with security (high politics) on top.

Waltz does not deny that there are other actors in international politics in addition to states and he agrees on the importance of non-state actors and transnational activities (Waltz 1979: 93-94). However, for him, this does not mean that a state-centric view of international politics is obsolete. We will later see (Step 3), that the neorealist assumptions of states as unitary actors as well as the most relevant ones have a central function for the concept of structure. This function leads in turn to the "structural realist" explanation of international politics at the conclusion of the neorealist line of argument.

Now recall what you have learned in the fourth unit of Part 1 about the social context of actors and their interactions. Social action and interaction occur in a structural context.

For neorealism, the structural context for states is the international system. The basic structural feature of the international system is anarchy. Being the opposite of hierarchy, anarchy means the absence of any higher authority in the international system that sets the rules for state behavior and has the power monopoly to punish non-compliance with the rules and norms. For states, this poses a serious security dilemma.

In the words of John Herz in his famous book International Politics in the Atomic Age, a security dilemma

"is a social constellation in which units of power (such as states or nations in international relations) find themselves whenever they exist side by side without higher authority that might impose standards of behavior upon them and thus protect them from attacking each other. In such a condition, a feeling of insecurity, deriving from mutual suspicion and mutual fear, compels these units to compete for ever more power in order to find more security, an effort which proves selfdefeating because complete security remains ultimately unobtainable." (Herz 1959: 231, emphasis mine) 
Under conditions of anarchy, states must rely on themselves; they therefore coexist, act and interact in a self-help system. Self-help is the principle of action within structures for which anarchy is the central feature: "A self-help system is one in which those who do not help themselves, or who do so less effectively than others, will fail to prosper, will lay themselves open to dangers, will suffer." (Waltz 1979: 118).

\section{Assumptions of neorealist theory}

- States as unitary actors ("units" of the international system) and the most important actors in international politics

- Power as the most important political means used by actors

- Hierarchy of actor's (state) goals: „high politics“ (security) and „low politics" (all other issue areas)

- Anarchy of the international system

- Actors (the "units"/states) motivated by self-interest because of the security dilemma

\section{Step 3:}

The neorealist explanation of international politics

\subsection{Level of analysis}

Having discussed the basic assumptions, we will now take a closer look at the explanation a neorealist theory offers for the outcomes of international politics. In the fourth unit of the first part, we defined outcomes of international politics as the patterns of interaction such as conflict, war, peace and cooperation. These are what have to be explained by a theory of international politics (the explanandum). The explanans is what explains these outcomes. A central question is where the explanans is "located", i.e. where to focus our study in terms of levels of analysis.

For Waltz, statements about war and the conditions for peace in international politics are made according to the level at which the causes are located - whether they originate with man, the state or the state system (Waltz 1959). He shows a clear preference for explaining international politics at the systemic level. In fact, for Waltz, a theory of international politics is a systemlevel theory. He supports his preference for the systemic level by drawing a sharp line between reductionist and systemic theories. Please be aware that 
the term "reductionist" as used by Waltz should not be confused with "reductionism" as introduced in Part 1 from a philosophy of science perspective. Theories that concentrate causes at the individual or state level are reductionist. According to Waltz, we have to distinguish between a theory of international politics (systemic) and a theory of foreign policy (reductionist). Reductionist theories understand international politics in its entirety by knowing the attributes and the interactions of its parts (the states), either through explanations of group behavior resulting from the psychological study of the group's members or through efforts to explain international politics by studying state bureaucracies (Waltz 1979: 18). Reductionist theories explain international outcomes through "elements" or "combinations of elements" located at the national or subnational level; internal forces produce external outcomes. For Waltz, reductionist theories do not provide adequate explanations for outcomes in international politics. His "project" is the construction of a non-reductionist, system level theory. In this regard, Waltz builds on criticism of the dominating studies in international politics in the 1950s, 1960s and 1970s.

\section{Self-study (1)}

Now take some time and read chapters 2 and 4 of Waltz 1979: Theory of International Politics carefully. Why do reductionist theories fail as theories of international politics?

Reflect on the neorealist view that only a system's level theory is a "real" theory of international politics.

\subsection{The neorealist concept of structure}

The alternative to reductionist theories conceptualized by Waltz is a specific type of system theory. It cannot be understood without discussing the concept of structure at the heart of this theory first. To think of any political system national or international - in terms of its structure is the starting point of the neorealist theoretical program. This is why neorealist theory as formulated by Waltz is called "structural realism". Please note that "structural" is different from "structuralism" (holism). "Structural" relates to the re-formulation of classical realism by introducing the concept of "structure" as part of the neorealist explanation; it is a structural realist explanation and will be discussed in detail below. In contrast, "structuralism" (holism, as introduced in Unit 2) relates to an ontological and methodological philosophy of science position. 
For Waltz, structure is the system-wide component that makes it possible to think of a political system as a whole. His aim is to independently define the "elements" of a political system (national or international), to define structure on one hand and units and processes on the other. For him, this is necessary to "disentangle" causes of different sorts (that is, not to "mix" levels of analysis) and to make possible a clear specification of structural causes and effects (Waltz 1979: 78). Defining structure independently of the "units" is necessary to explain the constraints that confine all states. The concept of structure serves the purpose of explaining why a certain similarity of behavior is expected under systemic constraints.

Following the definitional approach, structures have to be defined free of the attributes and the interactions of their units. The characteristics of the units (the type of political system, the types of political leaders, the social and economic institutions, the ideological commitments of states), their behavior and their interactions (the cultural, economic and military interactions of states) are not included in the definition of structure. They belong to the unit (state) level. This is an omission made in order to distinguish between variables at the unit level and variables at the system level (Waltz 1979: 80). The question of how to define a structure thus is simply a question of how units are "arranged" or positioned within the system (Waltz 1979: 80). For Waltz, the way the units/states are arranged or positioned is not a property of the units themselves but a property of the system. Waltz calls it a "positional picture" (Waltz 1979: 80).

In short, the structure of a system is defined by the arrangement of its parts and by the principle of the arrangement. Each unit's behavior is different and they produce distinct interactional outcomes when differently arranged or positioned in the system.

To make the concept easier to grasp and to understand the concept of structure as applied to international politics, Waltz illustrates his definition by describing domestic political structures. He asks three questions about a political system in order to define its structure:

\section{Defining political structures}

- Ordering principle: How are the units arranged in the system?

- Differentiation of units and functions: What functions do the formally differentiated units perform?

- Distribution of capabilities: How is power distributed across the units? 
Domestic political structures, or a national political system, are hierarchically ordered and centralized; hierarchy is the ordering principle. The units (institutions and agencies within the state) stand in relations of super- and subordination to each other. Political actors within the state are formally differentiated by the degree of their authority and the functions they perform (actors responsible for jurisdiction, legislation, bureaucratic actors, etc.). There is a specific distribution of capabilities (power) across the units of a national political system. Because political structures shape political processes, we can expect different political processes according to different structures in a national political system. For example, with regard to the type of political system, structures in autocratic or democratic systems will differ from each other, as will those in presidential and parliamentary democracies. The behavior of the units (the actors in the political system) and the outcomes of their interaction will be different depending on the structural features of the system.

In international politics, the ordering principle is different. Anarchy, not hierarchy, is the ordering principle of the international system. International systems are decentralized and anarchic. There are no formal relations of super-or subordination, but rather an absence of agents with system-wide authority. In place of relations of super-and subordination in the international system, we can only find coordination of formally equal units. The units of the international system, the states, are not differentiated by the functions they perform. There is no "division of labor" in the international system. All states have to fulfill the same tasks regardless of the type of political system: ensuring survival in a self-help-system. Anarchy therefore implies the "sameness" of the units in the international system (Waltz 1979: 93). In contrast to a national political system, the criterion of functional differentiation is not needed to define the structure of the international system. States are "like units“, meaning that all states are alike in being an autonomous political unit, a sovereign state or sovereign political entity. Only if the organizing principle changes (that is, from anarchy to hierarchy) a functional differentiation might be possible.

However, states differ according to their capabilities (power). States have greater or lesser capabilities for performing similar tasks. Capabilities/power are attributes of units. In contrast, for Waltz, the distribution of capabilities is not: In neorealist theory, the distribution of capabilities across units becomes a defining criterion for the structure of the system. Here the notion of the "positional picture" becomes clearer: states in the system are placed or positioned by their power. Depending on how power is distributed in the international system, we can think of multipolar, bipolar or unipolar international systems. This definition enables a distinction between international po- 
litical systems according to the number of great powers and how they are positioned.

The structure of a system changes with variations in the distribution of capabilities across the units. Changes in structure alter expectations about how the units of the system will behave and about the outcomes their interactions will produce (Waltz 1979: 101).

\section{Political structures: national and international}

\begin{tabular}{|l|l|l|}
\hline & $\begin{array}{l}\text { National political } \\
\text { system }\end{array}$ & $\begin{array}{l}\text { International political } \\
\text { system }\end{array}$ \\
\hline Ordering principle & Hierarchy & Anarchy \\
\hline $\begin{array}{l}\text { Functional differentiation } \\
\text { of units }\end{array}$ & Yes & $\begin{array}{l}\text { No. Like units. States as sov- } \\
\text { ereign political units and } \\
\text { unitary actors. }\end{array}$ \\
\hline $\begin{array}{l}\text { Distribution of } \\
\text { capabilities across units }\end{array}$ & $\begin{array}{l}\text { Distribution of power as a } \\
\text { "structural feature" of the } \\
\text { political system. }\end{array}$ & $\begin{array}{l}\text { Distribution of power as a } \\
\text { "structural feature" of the } \\
\text { system. Change in the dis- } \\
\text { tribution of power is a } \\
\text { change in the system. }\end{array}$ \\
\hline
\end{tabular}

\subsection{Structures as causes}

For a system theory of international politics, political structures have to be defined in a way that enables an identification of their causal effects. "Causal effects" of structures means that the structure of the system "acts" as a constraining and disposing "force". Actions of agents and agencies, their interactions and the outcomes of their interactions are all affected by the system's structure. Outcomes in international politics cannot be inferred from the intentions and behaviors of the units ("inside" states), but have to be explained in reference to the "external" structures. They can only be explained structurally. Effects vary as structures change.

For Waltz, a structural realist explanation (that is, through his concept of structure) is the only way to answer the core question of neorealist theory: why do recurrent patterns of state behavior and repeated and enduring patterns in the history of international politics, cycles of war and peace, and periods of conflict and stability in the international system occur? An explanation in neorealist theory is to say why patterns of behavior recur, why events repeat themselves, why the range of expected outcomes falls within certain limits (Waltz 1979: 69). Recurrences and repetitions within a system cannot 
be explained by reductionist theories. It is a constancy of structure that explains the recurrent patterns and features of international politics.

For Waltz, a structural realist theory can explain why war recurs and define conditions that make war more or less likely, but it will not predict the outbreak of particular wars. According to Waltz, structures explain some "big, important and enduring patterns" (Waltz 1979: 70). These are the continuities within a system. Phases of stable international systems and phases of conflict and war are the "big and important" patterns. It is not the objective to explain single, particular events and short-term outcomes in international politics. This is the domain of theories at the state level.

The core question therefore is: What are the causal effects of an anarchical structure of the system and of a specific distribution of capabilities? Here Waltz draws on an analogy: he uses the theory of the market to explain how the structure of the international system shapes the behavior of states in the same way that the market forces of a competitive market economy shape the behavior of the single firms.

\section{Self-study (2)}

Read chapter 5 of Theory of International Politics. Learn about the analogy used to explain the effects of international structures. Do states behave like firms under constraints of market forces?

\subsection{Balance-of-power politics}

How do states behave under structural constraints? What kind of politics do they have to choose?

As we know, in neorealist theory, survival is the motive and reason for action in a world where the security of states is not assured (security dilemma). Under conditions of anarchy, security is the highest goal; survival has to be assured in a system that has no rules set by a central authority. Mistrust and uncertainty about the ambitions of other states are the dominating conditions in such a system.

According to the neorealist explanation, an anarchical system "encourages" the units to seek security (Waltz 1979: 126). The fate of each state depends on its response to what other states do; this is why we have arms races, competition and imitation in the field of military technological innovations. Power, the buildup of military, economic and technological strength, is the means (not an end) to achieving security. The first concern of states therefore 
is not to maximize power, but to balance power, and to maintain their position in the system (Waltz 1979: 126). An anarchical system that is defined by the distribution of power induces states to behave in such a way that they seek the balance of power. States balance power by, for example, building up military strength or forming and joining alliances.

However, this assertion applies first and foremost to the great powers in the system. It is a defining feature of neorealist theory to focus on great powers: the "units" of greatest capability count most for the behavior of states. "Concern with international politics as a system requires concentration on the states that make the most difference. A general theory of international politics is necessarily based on the great powers." (Waltz 1979: 73). "Secondary", less important and not-so-capable states usually join the weaker of two coalitions or alliances; states do not wish to maximize power (in this case they would join the stronger side), but to balance power. If states wished to maximize power, no balances would be formed.

In terms of politics, the structural constraints of an anarchical system "encourage" the states in the system to adopt "Realpolitik" (Waltz 1979: 117). The system thus indicates to a certain extent the "methods" by which foreign policy is conducted and provides a "rationale" for them. Structural constraints explain why the methods are repeatedly used despite differences in persons and states: the "structure of the international system" encourages a certain type of politics in which a state's interest is the rationale of actions. This is based on a strong belief that the necessities of politics are derived from the unregulated competition between states and that calculation based on these necessities can lead to the policies that will best serve a state's interest. "Success", defined as preserving and strengthening the state, is the ultimate test of policy (Waltz 1979: 117).

A balance-of-power theory can explain the results that such policies produce at the system level: results that may not be included in any of the actor's motives or as objectives in the policies of actors. Balance-of power theory can be understood as a further development of system theory. It offers predictions in terms of tendencies: states can be expected to behave in ways that result in balances of power. The dynamics of the system limit the freedom of the individual units. This is why their behavior and the outcomes of their behavior become predictable.

In sum: In neorealist theory, international structures are defined in terms of the distribution of power between the primary political units of an era. Under the "structural constraints" of international politics, the result is that the units behave in a way that tends towards the creation of balances of power. A balance of power is the outcome of international politics that results from 
states' actions and interactions, shaped by the system's constraints. A balance of power is an outcome that can only be explained by a system level theory. Such a theory predicts a strong tendency toward balance in the system. Balances will be disrupted and restored again; thus, balances of power form on a recurrent basis.

A theory of international politics claims to explain certain aspects of the foreign policy of nations, particularly in regard to the international conditions with which national policies have to cope.

\subsection{Peace and stability in the international system}

The purpose of neorealist theory is explanation and prediction: how can one explain recurrent patterns of war/conflict and peace and stability in the international system? In terms of the theory, the objective is to define the conditions for peace. A commitment to balance-of-power-politics is the outcome of the theory in terms of "policy advice". Peace and stability are defined as the absence of major conflict and war, provided by phases of balance of power.

In the absence of authoritative regulation (anarchy) Waltz favors a "loose coupling" and a certain amount of control exercised by large states in order to help promote peace and stability. Most important in international politics is control (not regulation) and prevention (not coordination) (Waltz 1979: 209). For Waltz, the use of force in international politics will be prevented by the threat of force. Thus, employing the threat or use of force to influence states' policies is the most important means of control in security politics.

In an anarchical system, states with superior power are able to "absorb" destabilizing changes simply by virtue of their greater power (Waltz 1979: 210). Neorealist theory therefore can be read as a strong plea for a "constructive management" of international affairs by great powers (Waltz 1979: 210). In such a system, the basic condition of anarchy will prevail and will be reproduced by the actions and interactions of states. The security dilemma cannot be solved. International politics is "timeless" in that it is an endless cycle of war/conflict and peace/stability, governed by the logic of balance-ofpower.

Now recap what you have learned by carefully reading the key aspects in the synopsis below and answering the review questions. 
Step 4:

Check your understanding: key aspects and review questions

Key aspects

\begin{tabular}{|c|c|}
\hline & Neorealism \\
\hline Core question & $\begin{array}{l}\text { - Explanation of recurrent patterns of state action } \\
\text { and interaction (war and peace) in international } \\
\text { politics }\end{array}$ \\
\hline $\begin{array}{l}\text { Ontological assumptions about } \\
\text { actors and structure }\end{array}$ & $\begin{array}{l}\text { - } \text { Anarchy } \\
\text { - States as unitary actors/"units" of the system and } \\
\text { - } \text { Actors are "like units" } \\
\text { - } \text { Rationality assumption } \\
\text { - } \text { Actors differ with regard to their capabili- } \\
\text { ties/power } \\
\text { - Actors ("units") motivated by self-help: survival, } \\
\text { power }\end{array}$ \\
\hline $\begin{array}{l}\text { Assumptions about "agency and } \\
\text { structure" }\end{array}$ & $\begin{array}{l}\text { - Ontological priority of actors/" units" with inter- } \\
\text { ests and capabilities (ontological individualism) } \\
\text { - "Structure" is a theoretical concept: it is defined } \\
\text { in terms of the distribution of actor's capabilities } \\
\text { (ontological individualism) } \\
\text { - "Management of international affairs" by the } \\
\text { most powerful actors/" units" }\end{array}$ \\
\hline $\begin{array}{l}\text { Type of explanation and notion } \\
\text { of causality }\end{array}$ & $\begin{array}{l}\text { - Explanation through the concept of structure: } \\
\text { structural realist explanation } \\
\text { ist explanation because "structure" is a theoret- } \\
\text { ical concept and is defined as the distribution of } \\
\text { actors' capabilities (methodological individualist } \\
\text { explanation) } \\
\text { - Causality: structure (as a concept, defined as the } \\
\text { distribution of actor's capabilities as the inde- } \\
\text { pendent variable explains actor's behavior (de- } \\
\text { pendent variable); } \\
\text { "Systemic constraints" (defined in terms of the } \\
\text { distribution of actor's capabilities) causally im- } \\
\text { pose balance-of power politics of actors in the } \\
\text { international system }\end{array}$ \\
\hline Approach to „levels of analysis" & - System level \\
\hline Philosophy of science & - Positivism \\
\hline
\end{tabular}




\begin{tabular}{|c|c|}
\hline & Neorealism \\
\hline Normative perspective & $\begin{array}{l}\text { - Skepticism. } \\
\text { - } \text { Cycles of war/conflict and peace. } \\
\text { ma cannot be resolved. } \\
\text { - Peace and stability only as the absence of major } \\
\text { conflict and war. }\end{array}$ \\
\hline $\begin{array}{l}\text { Theory and practice/role of the } \\
\text { scientist }\end{array}$ & $\begin{array}{l}\text { - Contribution to peace and stability in the inter- } \\
\text { national system by providing objective, law-like } \\
\text { knowledge about international politics. } \\
\text { - Policy recommendation based on objective } \\
\text { knowledge: Realpolitik (balance-of- power poli- } \\
\text { tics) as a contribution to stability. }\end{array}$ \\
\hline
\end{tabular}

\section{Review questions}

1. What is the core question of the neorealist theoretical research program?

2. What function do assumptions about actors and structure have for the construction of neorealist theory?

3. Outline the neorealist explanation of international politics.

4. What is balance-of-power theory?

\section{Step 5:}

Final self-study and consolidation

\section{Self-study (3)}

Now read Waltz 2000 and Wohlforth 2008 from the required reading list.

\section{Self-study (4)}

In addition to the required reading, choose at least three texts out of the supplementary reading. Outline briefly a) the basic lines of critical arguments against neorealist theory or b) current developments within the neorealist paradigm. Think for a moment about contemporary world politics. Do you see problems of real-world international politics for which a neorealist explanation could be relevant? 
Self-study (5)

Re-read Unit 2 about positivism as a philosophy of science. Why, from a philosophy of science perspective, does the neorealist theory belong to positivism?

\section{Required reading}

Waltz, Kenneth 1979: Theory of International Relations, chapters 2, 4, 5 and 6.

Waltz, Kenneth 2000: Structural Realism after the Cold War, in: International Security 25: $1,5-41$.

Wohlforth, William C. 2008: Realism, in: Reus-Smit, Christian/Snidal, Duncan (eds.): The Oxford Handbook of International Relations, 131-149.

\section{Supplementary reading}

Brooks, S.G. 1997: Dueling Realisms, in: International Organization 51, 445-477.

Legro, Jeffrey W./Moravcsik, Andrew 1999: Is anybody still a Realist?, in: International Security 24: 2, 5-55.

Schörnig, Niklas 2013: Neorealism, in: Schieder, Siegfried/Spindler, Manuela (eds.): Theories of International Relations. London and New York: Routledge (forthcoming).

Schweller, Randall 1996: Neorealism's Status-Quo Bias: What Security Dilemma?, in: Security Studies 5: 3, 90-121.

Schweller, Randall L. 2003: The progressiveness of neoclassical realism, in: Elman/Elman (eds.): Progress in International Relations Theory: Appraising the Field. Cambridge, MA: MIT Press, 311-347.

Schweller, Randall/Wohlforth, William C. 2000: Power test: evaluating realism in response to the end of the Cold War, in: Security Studies 9: 60-107.

Taliaferro, J.W. 2000-01: Security Seeking under Anarchy: Defensive Realism revisited, in: International Security 25: 128-161.

Wohlforth, William 1999: The stability of a unipolar world, in: International Security 24: $5-41$.

\section{Recommendations for further reading}

Gilpin, Robert 1981: War and Change in World Politics. Cambridge: Cambridge University Press.

Little, Richard 2007: The Balance of Power in International Relations. Metaphors, Myth and Models. Cambridge: Cambridge University Press

Mearsheimer, John J. 2001: The Tragedy of Great Power Politics. New York: Norton.

Vasquez, J.A. 1998: The Power of Power Politics: From Classical Realism to Neotraditionalism. Cambridge: CUP

Waltz, Kenneth 2008: Realism and International Politics. New York: Routledge 


\section{References in the text}

Waltz, Kenneth 1959: Man, the State and War: A Theoretical Analysis. New York: Columbia University Press.

Snyder R.C./Bruck, H.W./Sapin, B. 1962: Foreign Policy Decision Making. An Approach to the Study of International Politics, New York).

Herz, John H. 1959: The Security Dilemma in the Atomic Age, in: Herz, John (ed.): International Politics in the Atomic Age. New York: Columbia University Press. 


\section{Neoinstitutionalist theory}

Learning steps

Introduction

Step 1:

Neoinstitutionalist theory as "modified structural realism"

1.1. Power, structure and rationality: concepts and assumptions ................... 145

1.2. The objective and core question of neoinstitutionalist theory ................ 147

1.3. Normative perspective and the significance of IR as policy analysis .... 148

1.4. Summary ................................................................................... 149

\section{Step 2:}

The neoinstitutionalist explanation of international politics

2.1. The concept of interdependence

2.2. Power and interdependence

2.3. International cooperation, international institutions and the "civilization" of world politics

\section{Step 3:}

Check your understanding:

key aspects and review questions

\section{Step 4:}

Final self-study and consolidation 


\section{Introduction}

This unit will introduce you to the second theoretical approach in Part II: neoinstitutionalist theory in International Relations.

Institutionalist theory is one of the most influential perspectives in the social sciences, as well as in economics and law. Political scientist Elinor Ostrom won the 2009 Nobel Prize for Economic Sciences for academic work carried out within an institutionalist framework. Ostrom's work, above all her book Governing the Commons. The evolution of institutions for collective action (1990) is an excellent example of institutionalist political science and economics. Ostrom's objective is to understand the fundamental problems involved in governing and managing natural resource systems, and to find out how and what type of institutions can contribute toward solving the collective actions problems inherent in the use and distribution of natural resources. Research based on Ostrom's institutionalist analysis includes case studies on the capabilities and limitations of self-governing institutions for regulating resources such as fisheries, water resources, irrigation or land.

In a number of disciplines, collective goods, for which a clean and healthy environment is a good example, constitute a core field of institutionalist studies. What unites all strands of "institutionalism" found in sociology, political theory, comparative government, economics and law is a strong belief that "institutions matter" in social and economic life. In general, institutionalism focuses on the influence of the rules, norms or procedures of social institutions on human behavior and individual preferences and actions. This is also true for institutionalist theory in the academic discipline of IR, where the focus lies on the impact social institutions have on the interests and behavior of states and other actors in international politics, and on how interstate cooperation and an increasing institutionalization of international politics contribute to solving the fundamental problem of order in an anarchical international system.

Recall for a moment how we learned that the historical development of the modern state system goes hand in hand with theoretical reflections on interstate relations. As discussed in Part I of this book, the idea and principle of state sovereignty, as well as the idea of viewing international politics as an anarchical realm, were both developed parallel to the advent of the modern, centralized territorial state of the Westphalian order. These theoretical reflections not only provide descriptions of the "conditions" in international politics, but also transfer ideas on political solutions to the problem of anarchy: how to create rules and norms for conducting international politics in the absence of a "world government", how to prevent or formulate rules for conflict 
and war among nations, and how to achieve cooperation. We briefly discussed the important contributions of Hugo Grotius to the development of international law and Immanuel Kant's visions of a foedus pacificum, i.e. international organization and international law as a means of conducting peaceful interstate relations. With regard to establishing such interstate institutions, these "solutions" to the problem of anarchy are directly opposed to the early ideas of the realist tradition that power and balance-of-power-politics present the best means to stabilize interstate relations. We know that different theories of IR provide different explanations for outcomes in international politics and therefore also different solutions for the actual practice of international politics.

Although theoretical reflections on the ways in which institutions affect social life and society date back as far as Ancient Greece, it was not until the late $19^{\text {th }}$ and first half of the $20^{\text {th }}$ century that the study of institutions gradually became more systematic and "scientific" in the way we discussed while considering the issue of "science" in Unit 2. In the US and Britain, the study of political institutions has dominated large areas of the social sciences since at least the 1950s. The focus of this early institutionalist analysis ("old" or classical institutionalism) was on the formal institutions of government and the state, often in comparative perspective.

In International Relations, the term "old institutionalism" relates to the early systematic study of the role and functions of (formal) international organizations in the 1950s and 1960s, in particular the United Nations and its many related organizations and specialized agencies, as well as the European Communities. In fact, we can think of a "tradition" of institutionalist theoretical reflection in International Relations. This tradition comprises theories such as functionalism (the "classic" being David Mitrany's $A$ Working Peace System, 1943), federalism (the work of C.J. Friedrich in the 1960s) and neofunctionalism (the standard works being Ernst Haas' The Uniting of Europe (1958) and Beyond the Nation State. Functionalism and International Organization (1964) ). However, as theories of regional integration, the focus was essentially on the role and function of institutions in regional, especially European, processes of integration. This focus also extended to the effects of integration and the establishment of institutions on the prospect of peace, stability and the future of the nation-state.

It was not until the mid-1970s that an attempt was made to formulate a general theory of International Relations on the basis of an institutionalist perspective and with a clear explanatory approach following the dominating (positivist) perspective of IR as a "science". In the academic discipline of International Relations, the advent of this new or neoinstitutionalism (the prefix 
"neo" indicating a "revival" or new "wave" of institutionalism in IR) is associated with the publication of the works Power and Interdependence. World Politics in Transition by Robert O. Keohane and Joseph Nye (1977) and Keohane's After Hegemony. Cooperation and Discord in the World Political Economy (1984). In the late 1980s and 1990s, interdependence analysis and the neoinstitutionalist regime theory formulated in After Hegemony were subsequently developed into a complex and influential institutionalist research program within IR. The concept of interdependence was an important building block in regime theory, which has been broadened into what is now called neoliberal institutionalism. However, it should be noted that the terminology used in connection with the neoinstitutionalist theory can sometimes be confusing. For instance, the terms "neoliberal institutionalism" and "neoliberalism" are used in the literature interchangeably. In the theoretical debate on neorealism in the 1990s "neoliberalism" was a common term (Baldwin 1993).

The "revival" of the study of institutions in IR since the mid-1970s and 1980s again reflects the more or less parallel advent of neoinstitutionalism in all social and political sciences, as well as in economics. In sociology, for example, the advent of neoinstitutionalism is associated with the works of John Meyer and Brian Rowan (1977), and of DiMaggio and Powell (1983); in economics a similar connection can be made to the work of Douglas North $(1973,1990)$. With the advent of new institutionalism in the social sciences, the previous focus on institutions in a formal and often legal and descriptive way has now been overcome. Apart from this commonality, institutionalist theory is so diverse that it has proved almost impossible to provide a systematic introduction to this multi-faceted theoretical strand. In Political Science and the Three New Institutionalisms (1996) Peter Hall and Rosemary Taylor facilitate a better understanding of new institutionalism by differentiating between rational choice institutionalism, sociological institutionalism and historical institutionalism (Hall/Taylor 1996).

Within the academic discipline of IR, neoinstitutionalist theory as developed by Robert Keohane belongs to rational choice institutionalism: a "utilitarian" or interest-based neoinstitutionalism found at the heart of regime theory and its subsequent development into neoliberal institutionalism. Regime theory and neoliberal institutionalism are the results of a critical engagement with Waltz' neorealist theory of international politics. It may come as a surprise to learn that the outcome of this critical engagement is a modified structural realism. For the purpose of this book, learning more about this "modification" will be a promising undertaking, as it will provide an important insight into theory building in the social sciences in general. 
Therefore, we will devote the first learning step to those elements of neorealist theory that challenged neoinstitutionalist criticism in the 1970s and 1980s. Please note that the term "neoinstitutionalist theory" will be used throughout the text to refer to the interest-based neoinstitutionalism developed by Keohane and Nye.

\section{Step 1:}

\section{Neoinstitutionalist theory as "modified structural realism"}

\subsection{Power, structure and rationality: concepts and assumptions}

There is agreement with neorealism that the fundamental issues of power, interests and rationality are at the core of a theory of international politics, as well as agreement that a system level theory must be able to explain outcomes in international politics adequately (Keohane 1986b: 182). However, in terms of theory construction, a range of critical points exist related to the concepts and assumptions at the core of neorealist theory: the concept of power, the concept of structure and the rationality assumption.

As we learned in the previous unit, in neorealist theory, state interests are "given" and patterns of outcomes in international politics are determined by the overall distribution of power among states. The distribution of power is claimed to be a "systemic" feature and the neorealist explanation of international politics therefore a structural realist one. In neorealist theory, "power" in a very general way refers to resources that can be used to induce other actors to do what they would not otherwise do (in accordance with the interests of the state exercising its power). Each international system has one structure and therefore one context of state action, which is defined by the general distribution of power in the system.

For Keohane, the neorealist conceptualization of power and structure creates problems for the explanation of outcomes in international politics, as well as for predictions. The neorealist concept of power is overaggregated and state interests therefore underspecified (Keohane 1986b: 191). The concept of power has to be modified, especially with regard to the relationship of power to the context of action. Keohane suggests a disaggregation of power resources by issue-areas (Keohane 1986b: 190). What does this mean for a theory of international politics?

Issue areas in international politics include, for example, security, welfare, freedom and environmental politics. To split international politics into 
issue areas means to renounce the neorealist concept of international politics as one separate domain (dominated by security concerns). In neoinstitutionalist theory, different issue areas constitute different contexts of action. In fact, modifying the system means thinking of its structure in terms of several structures according to different issue areas. It has been suggested that such a disaggregation will enhance the ability to explain and to predict with the structural realist model of explanation (Keohane 1986b: 190).

Thus, the concept of structure as developed by Waltz will remain a valuable starting point. The question posed by Keohane is: how much should the concept of structure in a system's level theory include? He is convinced that the concept requires greater complexity. The problem can only be solved by modifying the concept of structure to include the explanatory factors that are not found in Waltz's concept of structure: further "elements" of the international system. Neoinstitutionalist theory highlights the factors that Waltz downgrades or ignores: international (economic) interdependence and the role of international institutions. For systematic and didactical reasons we will return to this key issue at a later stage (Step 2).

With regard to the concept of power, the emphasis similarly is on power resources as an explanation of outcomes in neoinstitutionalist theory. However, the assumption that power is fungible across different issue areas of world politics is rejected. Moreover, Keohane not only introduces a disaggregated power model that differentiates between issues areas, but he also calls attention to links between issue areas that need to be understood systematically (Keohane 1986b: 189).

Such a modification avoids the direct deduction of national interests from the (one) system's structure simply on the basis of the rationality assumption. For Keohane, such a direct prediction of outcomes from assumed interests and an overall distribution of power would fail (Keohane 1986b: 190). State interests cannot be derived solely on the basis of rational calculation of the "external" positions of states. The implication of neoinstitutionalist critique is that the neorealist assumption of states seeking (at most) to maximize power is wrong: States do not always seek to maximize power. They will not do it, for example, when they are not "in danger". Modifying the neorealist assumption of states seeking to maximize power enables us to consider other, competing goals of states in international politics.

The assumptions of neoinstitutionalist theory as a modified structural realism are therefore: (Overview in Keohane 1986b: 194): 


\section{Assumptions of neoinstitutionalist theory}

1) States are the principal actors in world politics.

2) Rationality assumption: world politics can be analyzed as though states were unitary rational actors that calculate the costs of alternative courses of action and seek to maximize their expected utility across a set of ordered objectives. Like neorealism, neoinstitutionalist theory is based on microeconomic theory and seeks to explain an actor's behavior by specifying a priori utility functions for actors.

3) The neorealist assumption that states seek power and calculate their interests accordingly will be modified. Power and influence are seen to be important state interests (as ends and means), but the implication that to seek power is always the overriding state interest is rejected: "Under different systemic conditions states will define their self-interest differently." (Keohane 1986b: 194)

4) Neoinstitutionalist theory is based on the assumption that the value of power resources for influencing state behavior depends on the goals of states: "Power resources are differentially effective across issue-areas..." (Keohane 1986b: 194).

For the outcomes of international politics (the explanandum) this implies, that different patterns of outcomes in different issue areas can be anticipated with hypotheses. The differences have implications for the ability of actors to link issue areas and use power resources from one area to affect the results in another (Keohane 1986b: 195). We will return to this issue in Step 2, which is devoted to the neoinstitutionalist explanation of international politics.

With regard to the level of analysis and in terms of concepts and assumptions, the modifications do not affect the fundamental belief that neoinstitutionalism shares with neorealism, that a theory should be elaborated at the systems level. There are two reasons behind this belief: first, the context in which a state's actions take place has to be appreciated before a state's actual actions can be accounted for and second, because a "good structural theory" is easier to test than a theory at state level. It would therefore most effectively fulfill the requirements for acquiring scientific knowledge as stipulated by positivism according to Lakatos (Keohane 1986: 18; 1986b: 193).

\subsection{The objective and core question of neoinstitutionalist theory}

So far, we know that neoinstitutionalist theory aims to develop a systemic theory that is built on structural realism, but is also able to deal with the dif- 
ferences between issue areas and the implications these differences have for exercising power in order to reach state goals. The modified structural approach is seen as the basis for further systemic research.

The following question lies at the core of neoinstitutionalist theory: "How can order be created out of anarchy without superordinate power (...)?" (Keohane 1986b: 199) Whereas in neorealist theory, order is created either by exercising power or by hegemony, neoinstitutionalist theory believes that the core problems of anarchy can be reduced under conditions of interdependence and through the institutionalization of international cooperation. What are the conditions for interstate cooperation? Why and how do states construct international institutions? Neoinstitutionalist theory therefore forms part of the research into questions of order in international politics. Theoretical work on international regimes is particularly devoted to these questions.

Neoinstitutionalist theory also investigates the effects of international cooperation and institutions on peace and stability in international politics, i.e. through questions relating to peaceful change: "Under what conditions will adaptations to shifts of power, e.g. in current technologies or in fundamental economic relationships, take place without severe economic disruption or warfare?" (Keohane 1986b: 198, 199)

The outcomes of international politics to be explained here differ from those put forth in neorealism. Neorealism as a balance-of-power theory explains large-scale patterns of state action over long periods of time. It is an important approach to the study of conflict, bargaining and war (Keohane 1986b: 188-170). In contrast, neoinstitutionalist theory seeks to explain outcomes of international politics such as international cooperation and changes to the rules and institutions that regulate relations among governments in world politics.

\subsection{Normative perspective and significance of IR as policy analysis}

The issues of change and peaceful change are crucial for assessing the normative perspective at the heart of neoinstitutionalist theory. For Keohane, neorealist theory is unable to explain change and provides a pessimistic view of international politics (Keohane 1986: 18). Neoinstitutionalist theory strongly rejected the "pessimistic" neorealist view right from the start. "Reasons of humanity" define the need to find a way "out of the trap" of anarchy and provide hope for a stable world order: "If we are to promote peaceful change, we have to focus not only on the basic long-term forces that determine the shape 
of world politics independently of the actions of particular decision-makers, but also on variables that can, to a certain extent, be manipulated by human action." (Keohane 1986b: 199; my italics). These "variables" are international institutions and cooperation. They involve the calculation of state interests and can be influenced by political action. International institutions therefore have to be subjected to an investigation by the academic discipline IR. At the same time, they also form an issue of policy: "International relations must be a policy science as well as a theoretical activity" (Keohane 1986b: 198). Theory must be linked to practice in order to bring the insights of modified structural theory into the practice of international politics and solve contemporary world political problems.

In short, neoinstituionalist theory sees itself as contributing toward a better understanding of how to achieve cooperation and build international institutions. Dealing with international institutions will provide insights into processes of change. A strong normative belief exists that international cooperation and institutions can reduce the effects of anarchy and bestow order, peace and stability on the international system. In terms of the practice of international politics, this belief implies discontent with neorealist Realpolitik. The practical political implications of neoinstitutionalism indicate a need to devise new international institutions or regimes (beyond the nation state), and move towards changes in the principle of sovereignty (Keohane 1986a: 25).

\subsection{Summary}

The new elements of a modified structural realism are (1) the splitting of international politics into issue areas, (2) the focus on international institutions and (3) the issue of peaceful change.

Any given international system can consist of several structures that differ with respect to issue areas and according to the resources that can be used by states to affect outcomes. Here, military force is no longer assumed to be at the top of a hierarchy of power resources. In neorealist theory, states must enhance their power - this is the result of an anarchical international system, in which security is not guaranteed (self-help system).

The starting points of neoinstitutionalist theory are different structural conditions for international politics: insecurity is reduced in a system in which interdependence is an additional structural feature. States can, but do not have to, strive for power. They are free to pursue other goals. States do not have to focus on security as the only or most important issue area but can 
also define goals and objectives in other issue areas. This perspective of world politics results from the different assumptions and conceptualizations of the structural conditions of state action and state power in neoinstitutionalist theory. The modified structural research program offers a structural explanation of the emergence of international rules and procedures, as well as of state compliance to those rules. The theoretical explanation of international politics is issue-area-specific. Different outcomes of international politics can thus be expected in different issue areas.

\section{Step 2:}

The neoinstitutionalist explanation of international politics

Having established the neoinstitutionalist critique, its core question, basic concepts, assumptions and normative perspective, we will now look at the neoinstitutionalist explanation in more detail. This explanation cannot be understood without discussing the concept of interdependence from the first step.

\subsection{The concept of interdependence}

The neoinstitutionalist explanation starts by conceptualizing the rising levels of international interdependence in world politics in the $20^{\text {th }}$ century. Interdependence is a theory with a systemic, structural approach. The concept, developed in Power and Interdependence by Keohane and Nye in 1977, is presented as a systemic or structural feature of the international system that modifies the structural realist argument. Interdependence points to variations in systemic characteristics, such as mutual economic dependencies and different levels and quality of information in the international system.

The theoretical modification discussed in Step 1.1. is easier to understand if Power and Interdependence in the real-world international politics of the 1970 s is "contextualized". According to Keohane (1986b), the declared objective of neoinstitutionalist theory was to modify structural realism to "fit contemporary reality better" (193). "Contemporary reality" of the 1970s was dominated by two oil price shocks that caused a severe economic crisis in the Western industrialized world. These price shocks demonstrated the high levels of interdependence among globally integrated national economies at that time and caused serious conflicts about the question of what was the "right" economic policy to manage the crises. Learning that unilateral, i.e. national, crisis management was powerless under conditions of interdependence was a 
bitter political experience. It was during this time that global economic forums for the coordination of economic policy such as the G7 were born.

Keohane and Nye had an explicit policy-oriented purpose for writing Power and Interdependence. Their intention was to optimize American foreign policy under the "new conditions" of interdependence (hence the subtitle World Politics in Transition). Against the backdrop of recognition that an "autonomy illusion" exists under conditions of economic interdependence, the realist perspective was criticized as inadequate for coping with the new realities. Keohane and Nye came to the conclusion that "(u)nilateral leadership under the conditions of complex interdependence is (...) unlikely to be effective" (1977: 232). The objective was to formulate an alternative scientific perspective for policy advice (Keohane/Nye 1975: 359, 1977: vii-viii, 242).

What is interdependence? In the words of Keohane and Nye (1977), "interdependence, most simply defined, means mutual dependence" (Keohane/Nye 1977: 8). In turn, interdependence has to be distinguished from "interconnectedness", which "...refers to the volume or frequency of communication, interaction, or exchange between two sociocultural systems. Interconnectedness is most often expressed in the exchange of goods and services, i.e. in trade (...)." (Inkeles 1975: 469-470).

The concept of interdependence emphasizes the political significance of these interactions: Interdependence is politically significant because it creates costs (Keohane/Nye 1977: 9). It is costly because it constrains autonomous state action: National political objectives (security, welfare) depend on the politics of all actors being part of the interdependent relationship. Interdependence becomes particularly costly as soon as states in interdependent relationships become vulnerable: "Vulnerability can be defined as an actor's liability to suffer costs imposed by external events even after policies have been altered." (Keohane/Nye 1977: 13) Keohane and Nye (1977) posit that the vulnerability dimension of interdependence proves important and "particularly relevant for the analysis of the structure of relations" (Keohane/Nye 1977: 370, emphasis in the original). This argument will be taken up and developed further when looking at the politics of interdependence in more detail (Step 2.2.).

To sum up, interdependence is conceptualized as a structural feature of the international system. Interdependence is issue area-specific (remember the several-structures-argument). At the same time, mutual dependencies are central features of interrelations between particular (state) actors. The questions for Keohane/Nye are: What is the scope of state action under such conditions of interdependence? What should a successful "politics of interde- 
pendence" look like? The answer can be found through a critical engagement with neorealist theory.

Self-study (1)

Read chapters 1,2 and 3 of Power and Interdependence. World Politics in Transition written by Keohane/Nye (1977). Learn about the function the concept of "complex interdependence" as an "ideal type" has for theory building.

\subsection{Power and interdependence}

The core question of the book is an issue that relates to (American) foreign policy, i.e. how to exercise power under conditions of interdependence (hence the title). The question is relevant because conventional power cannot be used under conditions of interdependence: military force proves ineffective in such situations. In order to understand the answer given to this question by Keohane and Nye, we have to understand the position of interdependence in the theoretical explanation. Interdependence as a systemic, structural feature is introduced as an intervening variable. It "works" between power (as the independent variable) and the outcomes of international politics (as the dependent variable). This "condition" changes the context and the structure of international bargaining processes.

As we have seen already, neoinstitutionalist and neorealist theories are based on the assumption that states are rational actors and make rational choices in accordance with cost-benefit calculations. The neoinstitutionalist argument is that interdependence constrains the autonomy of states as actors. Due to the effects of interdependence as an intervening variable, it becomes impossible to "directly translate" power resources and political power into political outcomes. In terms of the distribution of power under conditions of interdependence, different issue areas of international politics have distinct structures. Mutual dependencies in issue areas are not necessarily symmetrical. Asymmetrical interdependence therefore constitutes an important source of power and enhances the state's scope for less dependent action. States may be tempted to manipulate the international system in their own interests. The problem exists on two levels:

1) "From the foreign-policy standpoint, the problem facing individual governments is how to benefit from international exchange while maintaining as much autonomy as possible." 
2) "From the perspective of the international system, the problem is how to generate and maintain a mutually beneficial pattern of cooperation in the face of competing efforts by governments (and non-governmental actors) to manipulate the system for their own benefit." (Keohane/Nye 1987: 730, my italics).

Because unilateral action cannot be successful under conditions of interdependence and against the background of declining American hegemony, Keohane and Nye suggest multilateral politics as a strategy of policy coordination and international leadership (Keohane/Nye 1977: 239). According to the two scholars, "multilateralism is based on action to induce other states to help stabilize an international regime". (Keohane/Nye 1977: 231)

In the politics of interdependence as suggested by Keohane and Nye, the US plays a leading role in establishing international policy coordination. This is based on the conviction that international cooperation and international institutions are the best means of achieving policy goals under conditions of international interdependence. Keohane develops this argument further in After Hegemony. Cooperation and Discord in International Politics (1984), in which he formulates regime theory.

\subsection{International cooperation, international institutions and the "civilization" of world politics}

Interdependence has two effects: first, under conditions of interdependence, military power becomes meaningless; and second, interdependence enhances the need for international cooperation. Under conditions of interdependence, states as rational actors have a strong interest in international cooperation and peaceful international politics. They seek not to enhance their power, but to achieve absolute gains. International cooperation is a win-win solution to collective action problems in international politics. By cooperating, all parties in the interdependent relationship that is causing a collective action problem will be better off.

Robert Axelrod has done some important work on cooperation among egoists under conditions of interdependence, which was modeled on the game of prisoner's dilemma and published in his book The Evolution of Cooperation (1984). In the book, Axelrod demonstrated that expectations about the future significantly influence the results of cooperation ("shadow of the future") and that they will lead to stable patterns of cooperation. However, levels of uncertainty can inhibit the evolution of cooperation; information that reduces uncertainty thus constitutes an important factor in world politics. 
International institutions can reduce uncertainty by providing information, therefore affecting international political behavior (Keohane 1986b: 195, 196). Finally, stable cooperation will foster and increase interdependence again, as well as enhancing institutionalization in international politics. In the long term, institutionalization can be understood as an evolutionary process in the construction of a peaceful world order that will lead to a "transformation" of anarchy. Anarchy will continue to persist as a structural feature of international politics but, in the long run, this will develop into "regulated anarchy" and world politics will become "civilized".

\section{Self-study (2)}

Expand what you have learned about the role of cooperation and institutions in international politics. First, please read chapters 4, 5 and 6 of Keohane 1984: After Hegemony. Then return to the text and read the key aspects and review questions below.

\section{Step 3:}

Check your understanding: key aspects and review questions

Key aspects

\begin{tabular}{|c|c|}
\hline & Neoinstitutionalist theory \\
\hline Core question & $\begin{array}{l}\text { - Chances of cooperation in an anarchical internation- } \\
\text { al system, peaceful change }\end{array}$ \\
\hline $\begin{array}{l}\text { Assumptions about actors } \\
\text { and structure }\end{array}$ & $\begin{array}{l}\text { - States as unitary actors and the most important ac- } \\
\text { tors in international politics (interest-based institu- } \\
\text { tionalism) } \\
\text { - Rationality assumption } \\
\text { - Anarchy } \\
\text { - No hierarchy of actor's/state goals }\end{array}$ \\
\hline "Agency and structure" & $\begin{array}{l}\text { - } \text { Actors ontologically prior to structure (ontological } \\
\text { individualism) } \\
\text { - } \\
\text { - } \text { Actors (states) construct international institutions } \\
\text { ganizations) as structural features of the internation- } \\
\text { al system }\end{array}$ \\
\hline
\end{tabular}




\begin{tabular}{|c|c|}
\hline & Neoinstitutionalist theory \\
\hline $\begin{array}{l}\text { Type of explanation and } \\
\text { notion of causality }\end{array}$ & $\begin{array}{l}\text { - Agency-centered explanation: causal explanation of } \\
\text { cooperative outcomes in international politics in } \\
\text { terms of actors' rational actions (methodological in- } \\
\text { dividualism) } \\
\text { - Structure of international system, defined as distribu- } \\
\text { tion of actor's capabilities (independent variable) ex- } \\
\text { plains state behavior (dependent variable): but dif- } \\
\text { ferent outcomes across issue areas because of inter- } \\
\text { dependence (intervening variable) } \\
\text { Interdependence as a "structural constraint" of state } \\
\text { action (intervening variable): Interdependence de- } \\
\text { fined in terms of political significance (costs) for indi- } \\
\text { vidual actors/states (methodological individualism) }\end{array}$ \\
\hline $\begin{array}{l}\text { Approach to } \\
\text { „levels of analysis" }\end{array}$ & - System level \\
\hline Philosophy of science & - $\quad$ Positivism \\
\hline Normative perspective & $\begin{array}{l}\text { - Cooperation and institution-building desirable be- } \\
\text { cause of collectively useful political outcomes (win- } \\
\text { win solutions in security, welfare, environment etc.) } \\
\text { - Optimism and belief in progress. Civilization of in- } \\
\text { ternational politics through institutionalization. } \\
\text { - Transformation of anarchy: anarchy becomes "regu- } \\
\text { lated anarchy". }\end{array}$ \\
\hline $\begin{array}{l}\text { Theory and practice/role of } \\
\text { the scientist }\end{array}$ & $\begin{array}{l}\text { - Social scientists provide objective knowledge about } \\
\text { international politics. } \\
\text { - Objective knowledge used for policy recommenda- } \\
\text { tion: politics of interdependence, multilateralism and } \\
\text { international cooperation. }\end{array}$ \\
\hline
\end{tabular}

\section{Review questions}

1. Compare the assumptions made in neorealist and neoinstitutionalist theory. Reflect on reasons for commonalities and differences.

2. What is the core question of the neoinstitutionalist research program? Compare it to that of neorealist theory.

3. Explain "interdependence" a) as a real-world phenomenon of international politics and b) as an analytical concept. What function does interdependence as an analytical concept have in the neoinstitutionalist model of explanation?

4. Outline the neoinstitutionalist explanation of international politics. 


\section{Step 4:}

Final self-study and consolidation

\section{Self-study (3)}

Try to explain the increasing number and scope of international organizations in the 20th and 21st century from a neoinstitutionalist point of view.

\section{Self-study (4)}

What kind of policy advice for the practice of international politics would be given from a neoinstitutionalist perspective? Discuss against the background of the positivist claim to provide "objective knowledge".

\section{Required readings}

Keohane, Robert O./Nye, Joseph 2001 (1977): Power and Interdependence. World Politics in Transition. $3^{\text {rd }}$. ed. New York: Longman, chapters 1,2,3.

Keohane, Robert O. (1984): After Hegemony. Cooperation and Discord in the World Political Economy. Princeton: Princeton University Press, chapters 4,5,6.

Hasenclever/Mayer/Rittberger 1997: Theories of international regimes. Cambridge: Cambridge University Press, chapters 4 and 5.

Hall, Peter/Taylor, Rosemary 1996: Political Science and the Three New Institutionalisms, in: Political Studies 44: 5, 936-957.

\section{Supplementary readings}

Axelrod, Robert 1984: The evolution of cooperation. New York: Basic Books.

Baldwin, David (ed.) 1993: Neorealism and Neoliberalism. The contemporary debate. New York: Columbia University Press

Keohane, Robert O. 1986a: Realism, Neorealism and the Study of World Politics, in: Keohane, Robert O. (ed.): Neorealism and its Critics. New York: Columbia University Press, 1-26.

Keohane, Robert O. 1986b: Theory of World Politics: Structural Realism and Beyond, in: Keohane, Robert O. (ed.): Neorealism and its Critics. New York: Columbia University Press, 158-203.

Keohane, Robert O. (ed.) 1986: Neorealism and its Critics. New York: Columbia University Press

Koremos, Barbara/Lipson, Charles/Snidal, Duncan 2001: The Rational Design of International Institutions.

Spindler, Manuela 2013: Interdependence, in Schieder, Siegfried/Spindler, Manuela (eds.): Theories of International Relations. London and New York: Routledge (forthcoming). 


\section{References in the text}

Di Maggio/Powell (eds.) 1991: The New Institutionalism in Organizational Analysis. Chicago: University of Chicago Press

Friedrich, C.J. 1968 Trends of federalism in theory and practice, New York: Praeger

Hall/Taylor 1996: Political Science and the Three New Institutionalisms, in: Political Studies 44: 5, 936-957

Meyer, John W.; Rowan Brian (1977), Institutionalized Organizations: Formal Structure as Myth and Ceremony, in: American Journal of Sociology, 83: 2, 341-361.

North, Douglas C. 1990: Institutions, Institutional Change and Economic Performance. Cambridge: CUP.

North, Douglas, C.; Thomas, Robert P. 1973: The Rise of the Western World: A New Economic History, Cambridge.

Scott, Richard W. 2001. Institutions and Organizations, 2nd ed. Thousand Oaks: Sage Publications 


\section{New liberal theory}

Learning steps

Introduction

Step 1:

New liberalism as a "positive" IR theory: assumptions about actors and structures

1.1. Assumptions about social actors

1.2. Assumptions about domestic structures: the state as a "representative institution"

1.3. Assumptions about the nature of the international system

Step 2:

New liberalism as a general theoretical approach to IR

2.1. The new liberal explanation and prediction

2.2. Levels of analysis: the logic of two-level-games

2.3. New liberalism as a contribution to multi-causal analysis

Step 3:

Check your understanding: key aspects and review questions

Step 4:

Final self-study and consolidation 


\section{Introduction}

Following our criteria for a structured learning process for theoretical approaches to IR, this unit will introduce you to the third approach presented in Part II: new liberal theory in International Relations.

Within the discipline, a great deal of controversy exists concerning the term "liberal theory". You will become aware of a variety of usages when you have taken a closer look at the textbooks, where you will find such differing "labels" for liberal theory as, "domestic theories of international politics" (Putnam 1988), "theories of state-society relations" (Moravcsik 1993), "pluralism" (Viotti/Kauppi 2005), "second image approach" (Waltz 1959) or "reductionist theories" (Waltz 1979).

From our discussions in unit 5 (neorealist theory), you are already familiar with the basic criticism of "reductionist" approaches as expressed by Waltz as well as with core neorealist arguments on why a theory of international politics should be a system-level theory. From the conceptual tool "levels of analysis" introduced in unit 4, we know that "reductionist" theories provide explanations for outcomes in international politics at the level of the state. They do so by drawing attention to explanatory factors at the unit level, i.e. to all the "attributes", which Waltz suggested we omit in order to construct a system-level theory. Taking the neorealist perspective as the starting point, liberal approaches would fall into this group of "reductionist" theories.

Liberal thinking has a long intellectual tradition. The term "liberal" points to the roots of liberal theory in the European Enlightenment, as well as to the liberal theory of politics/political liberalism. Immanuel Kant (The perpetual peace, 1795), already known to us as an intellectual precursor of institutionalist thinking in International Relations, also belongs to the "liberal tradition". Kant believed that a "republican constitution" of states is the first and most important requirement for stable and peaceful inter-state relations. We will come back to his arguments when discussing the (liberal) theory of interdemocratic peace. The core argument here is one of a causal link between a liberal type of political order within the state and that state's foreign policy and international politics. Peace and international cooperation as outcomes of international politics are more likely to exist among states with a liberal domestic order. Other well-known contributors to liberal theory in international economics and international politics are Adam Smith, John Stuart Mill and Woodrow Wilson. In their philosophical, economic and political thinking, these "liberals" drew important conclusions about the relationship between internal (domestic) factors and foreign policy behavior. What the intellectual precursors of liberal theory had in common was a normative perspective that 
a "civilization of international politics" was desirable and societal progress possible. For this reason, they have often either been acclaimed as "idealists" or have had their approaches labeled as "utopian", in particular by the realist "camp". Owing to these intellectuals' strong normative commitments, which sometimes come close to political ideology, social science has not really classified their work as "theories".

However, liberal theory in the $20^{\text {th }}$ and $21^{\text {st }}$ century has been built explicitly on these early ideas. Attempts have been made to develop coherent theoretical programs in accordance with the dominant positivist ideal in social science. The label "liberal", in the most basic understanding, encompasses those theories that explain outcomes of international politics by referring to domestic actors, structures and processes. It goes back to neofunctionalism as a theory of regional integration (Ernst Haas), the work of Graham T. Allison on bureaucratic politics (Allison 1971), the transnationalist theory of Keohane/Nye and the early works of James Rosenau. Bruce Russett, Michael Doyle, Robert Putnam, Peter J. Katzenstein, and Andrew Moravcsik also made important contributions to liberal theory in contemporary International Relations. In the German-speaking world, the works of Ernst Otto Czempiel $(1979,1981)$ and Thomas Risse are associated with a liberal perspective on international politics. What these works have in common is a pluralist, liberal conception of state and society.

However, liberal theory in IR is diverse and different strands of contemporary liberal theory can be distinguished by the particular factors that are expected to shape foreign policy behavior. Zacher/Matthew (1995: 120-137), for example, distinguish republican liberalism, commercial liberalism, military liberalism and sociological liberalism, just to mention the most important strands. To briefly illustrate the differences: whereas republican liberalism makes a statement about democratic states being more peaceful and more cooperative in their foreign policy than non-democratic states, sociological liberalism points to the impact of communication flows and cultural patterns on state's ability to cooperate. The latter was pioneered by Karl Deutsch $(1953,1957)$. Others point to the impact of transnational relations on the cooperative behavior of states and analyze how transnational relationships pressure governments into seeking cooperative solutions to problems in international politics (for example, Keohane/Nye 1970). We will come back to these different strands in Step 2.

Whereas, for a long period of time, neorealist and neoinstitutionalist theory dominated IR and liberal thinking was marginalized, there has been a "renaissance" of liberal theory since the 1990s. The real-world background to this "renaissance" of liberal approaches is the end of the Cold War and the "implo- 
sion" of communist regimes in Middle and Eastern Europe. No "event" in international politics has revealed the importance of societal actors (inside the state) for the conduct of international politics more strongly (Risse-Kappen 1994). The failure of neorealism and neoinstitutionalism to predict the breakdown of the Eastern bloc resulted in the empowerment of those approaches that attempt to explain international politics by looking "inside the state".

Credit for bringing liberal theory back into the center of IR theory belongs, in particular, to Andrew Moravcsik. His theoretical project is the reformulation of liberal theory in a non-ideological and non-utopian way, making it a systematic theory of international politics $(1993,1997)$. His intention was to put liberal theory as an empirical social science on a par with neorealist and neoinstitutionalist theory within IR (1997: 513). For the purpose of our book, Moravcsik's "new liberalism" (Moravcsik 2008; Schieder 2013) is of particular interest as it represents the most advanced attempt to formulate a "scientific" liberal theory of IR (please recall our discussions in Units 2 and 3 on what counts as "scientific" theory in International Relations). Additionally, Moravcsik's work leaves behind the "level-of-analysis problem", constructing a liberal theory that - while starting with the domestic level in the "classic" liberal way - also provides a systemic explanation of international politics. This liberal theory thus draws level with neorealist and neoinstitutionalists explanations of international politics (Moravcsik 2008). With this reformulation, liberal theory enters the stage of general, scientific theoretical approaches to International Relations. New liberalism thus becomes a fascinating "candidate" within the group of theoretical approaches that form the center of our book.

The terms "new liberalism" or "new liberal theory" will be used throughout the chapter. They refer to new liberalism as a general, scientific theoretical approach, as developed by Andrew Moravcsik.

\section{Step 1:}

\section{New liberalism as a "positive" IR theory: assumptions about actors and structures}

New liberalism has been reformulated in line with the idea of IR as a positive social science (Moravcsik 1997: 514). The basis of Moravcsik's theory is the clear distinction between liberal philosophers or classical liberal publicists, and liberal social scientists (Moravcsik 2008: 236). It begins with the basic liberal insight already mentioned in the introduction: the liberal claim of the centrality of state-society relations to world politics (Moravcsik 1997: 515). 
State-society relations are the relationships of states to the domestic and transnational social context in which they are embedded. The domestic and transnational social context is assumed to have an impact on the behavior of a state in international politics: state preferences are derived from domestic and transnational social pressure and demands (Moravcsik 2008: 236). Those demands in turn influence the "social purposes" that underlie state preferences (Moravcsik 1997: 516).

In attempting to reformulate liberal theory as a social scientific theory, this basic liberal insight is first "translated" into premises in order to ground liberal theory in a set of social scientific assumptions. There are three "positive" assumptions which concern the nature of social actors, the state, and the international system. These assumptions give rise to the arguments, explanations and predictions of a new liberal theory (Moravcsik 1997: 514).

Before exploring these arguments and explanations in detail in Step 2, let us first begin with the assumptions underlying new liberal theory.

\subsection{Assumptions about social actors}

The first assumption of new liberal theory is the primacy of societal actors: individuals and groups of individuals are assumed to be the most important actors in international politics (Moravcsik 1997: 516-517; 2008: 236-237). This ontological individualist assumption is based on the pluralist conception that society is characterized by competing interests, conflicting values and variations in influence, i.e. a plurality of public actors, private actors and civil society. Society is understood as a collection of individuals and groups who act rationally in their pursuit of material and ideal welfare. Individuals define their interests independently of politics and then try to force their interests on the political agenda. Consequently, in the analysis, the differing interests and demands of individuals and societal groups are treated as though they come before politics. In this way, new liberalism gives a bottom-up-view of international politics: a "pluralist" view of individuals and groups that define material and ideational goals and attempt to realize them at the political level (AFTER having defined their material and ideational interests).

But where do the material and ideational goals of social actors arise? The "source" of the social interests relevant to the study of international politics is globalization. Globalization - defined economically, socially and culturally has an impact on the interests and preferences of social actors. Individuals and groups have demands with regard to international affairs. Such demands could be a different arrangement of the economic, cultural, social and political "or- 
der", an order that is in the social actor's best interests. In liberal theory, the demands of social actors are treated as variables, which can change owing to the fact that globalization produces "winners" and "losers". Globalization has consequences in terms of distributional effects on societies. Competing or conflicting societal demands on a state's "management of globalization" can therefore be assumed. Thus domestic actors (individuals and groups) aim to influence the foreign policy of their states und so shape outcomes in international politics in a way that best matches their interests and goals. These actors have different goals and the power to force their goals onto the political agenda.

For the liberal explanation, this means that domestic actors are the most important factors in explaining foreign policy and the behavior of states in international politics. Which actors prevail and are instrumental in determining foreign policy and with which goals, are dependent on a state's internal structures (sub-systemic or "domestic" structures).

\subsection{Assumptions about domestic structures: assumptions about the state}

It may come as a surprise that the first point raised under the headline "assumptions about structures" is an assumption about the nature of the state itself. In our units on neorealist and neoinstitutionalist theory, assumptions about structures have been assumptions about the actual international system. Assumptions about the state, on the other hand, have been assumptions about actors in international politics.

This pattern differs in new liberal theory; here, states are assumed to be representative institutions, not actors (Moravcsik 1997: 518-520; 2008: 237239). The state as a representative institution represents the parts of domestic society whose interests shape the definition of state preferences (see Step 1.1, Assumptions about actors). The state as representative institution forms a "transmission belt" that "translates" the preferences of individuals and groups into foreign policy. The sub-systemic, intra-state structures have selective effects which influence the choice of actors that will be successful in shaping the political agenda. In this manner, sub-systemic structures impact foreign policy through their selective effects.

Different sub-systemic structures can be formed either as a result of the type of socio-economic organization (modern or traditional societies) or the type of political order (liberal democratic states or non-democratic, autocratic or authoritarian states). The different ways in which internal decision-making processes and interest intermediation are organized (for example, pluralist or 
corporatist structures) also result in varied structures. These differences in sub-systemic structures have implications for power relations, i.e. power distribution between state and society. The power of the state in state-society relations is crucial; there can be a "strong" state with a highly centralized state apparatus or a "weak", fragmented state with federalized or decentralized state functions. In new liberal theory, differences in the type of democracy (such as consensus democracy or majoritarian democracy, according to a well-known differentiation drawn by Lijphart, 1999) could be relevant for the final explanation of outcomes in international politics.

In terms of structures, this means that in liberal theory the most relevant structures are domestic, sub-systemic structures. These are the structures of the state and of society. Anarchy is not the dominating structure in explaining either outcomes in international politics (as we have learned in our unit on neorealist theory) or interdependence as a systemic structural feature (as in neoinstitutionalist theory).

State preferences are derived from social preferences through the selective effects of sub-systemic structures. Political action is therefore "embedded" in domestic and transnational civil society. State preferences are endogenized in new liberal theory. This endogenicity contrasts with neoinstitutionalist and neorealist theory, in which state interests are treated as "exogenous" or "given". In new liberal theory, the state (as a representative institution) serves to aggregate domestic interests before presenting them to the outside. State preferences are FIRST derived from social preferences; only THEN does the state present these preferences to the outside. State preferences are instrumental in managing globalization - the "source" of social interests that is relevant to the study of international politics (1.1). In the words of Moravcsik, "states act instrumentally in world politics to achieve particular goals on behalf of individuals, whose private behavior is unable to achieve such ends as efficiently." (Moravcsik 2008: 237)

However, this raises another question: what happens once states present their preferences to the outside?

\subsection{Assumptions about the nature of the international system}

We now enter into the realm of international politics, where states present the preferences they have derived from societal actors - this is the outside. AFTER the foreign policy preferences have evolved in the internal decisionmaking processes, the governments then interact on the international scene. The "outside" is the international system in which states interact, negotiate, 
cooperate or interfere (the outcomes in international politics are e.g. conflict, war, cooperation). The point here is to show how the sub-systemic structures and the preferences they brought about relate to each other, i.e. the constellation of structures and preferences. New liberal theory assumes the nature of the international system to be a "constellation" of sub-systemic structures characterized by a "configuration" of interdependent state preferences (Moravcsik 1997: 520-524; 2008: 239-240). This "configuration" of interdependent state preferences shapes international political interaction. This is where similarities or differences in sub-systemic structures and state preferences are significant for outcomes in international politics. A state's actual behavior in international politics then depends on the constellation of sub-systemic structures and the foreign policy goals of all interacting states. Whether or not interacting states share preferences defines the scope of the cooperation or conflict among those states. For example, transparent internal decision-making processes enhance the tendency to cooperate. The relevant internal structures here are the role of the public, checks and balances and the rule of law. These internal structures all serve to reduce uncertainty and mistrust and their effects. They thereby build confidence. However, this generalization only applies when all interacting states have similar internal structures. The resulting effect is then mutual trust, which reduces the dilemma in international politics and contributes towards peace, cooperation and stability. In neoinstitutionalist theory, this effect is due to international institutions. In new liberal theory, on the other hand, it is due to the constellation of those subsystemic structures that are conducive to peace and international cooperation.

The crucial link between state preferences and state behavior is the concept of "policy interdependence". Policy interdependence refers to a particular configuration of state preferences. Here Moravcsik adopts the classical definition of interdependence developed by Keohane and Nye (1977): the pursuit of state preferences under conditions of interdependence imposes costs upon other states (Moravcsik 2008: 239). In new liberal theory, besides the sub-systemic structures of the state, the pattern of interdependent preferences forms one of the most important significant structures in the new liberal explanation. This pattern of interdependent state preferences influences state behavior in international politics. Such a structure of policy interdependence is defined by the extent to which basic national goals are compatible. "The lower the net gains and the greater the distributional conflict, whereby the realization of interests by a dominant social group in one country necessarily impose costs on dominant social groups in other countries, the greater the potential for interstate tension and conflict" (Moravcsik 2008: 239 , emphasis in the original). In contrast, the incentives for international 
policy coordination or convergence are greater where policy coordination generates mutual gains (with low distributive consequences).

We can think of different preference constellations, such as harmony, conflict and interdependence (Moravcsik 1997: 520f). Harmony offers the best chance of cooperation because state preferences are similar. Under conditions of interdependence states have to cooperate in order to realize their goals (comparable to the neoinstitutionalist concept of interdependence). Whether interdependence, conflict or harmony prevails as a preference constellation depends on societal goals and internal selection processes within the state (as a representative institution).

The concept of policy interdependence is considered to be a distinctive conception of inter-state power (Moravcsik 2008: 239). At the heart of this concept lies variation in state preferences, not variation in capabilities (neorealism). This is why, from the new liberal perspective, the plea for "Taking preferences seriously" (the title of Moravcsik's work 1997) marks the start to bringing a reformulated liberal theory back to IR. Particular preferences have to be theorized and explained, not assumed (Moravcsik 2008: 250).

To sum up, whereas in domestic politics the state is a representative institution (structure) representing coalitions of interests, in international politics the state is a purposive actor.

\section{Assumptions of new liberal theory at a glance}

- Social actors (individuals and groups of individuals) are the most important actors in international politics.

- Political outcomes in international politics can only be explained by looking "inside" the state: domestic actors, structures and processes (state-society relations).

- States are not unitary actors: states act as "representative institutions". State preferences are derived from sub-systemic structures and social interests.

- State actions present the preferences of the most powerful social actors capable of shaping the political agenda to the outside.

- Policy interdependence in the international system: outcomes in international politics depend on the configuration of interdependent state preferences. 


\section{Step 2:}

\section{New liberalism as a general theoretical approach to IR}

\subsection{The new liberal explanation and prediction of international politics}

At the core of new liberal theory lies the issue of finding general explanations for international cooperation, conflict and war as systemic phenomena in international politics. Moravcsik aims to formulate a general theory of IR that applies equally to liberal and non-liberal states, economic and security politics, conflict and non-conflictual situations, as well as to the behavior of individual states (foreign policy) and "aggregations" of states (international relations). New liberalism therefore competes with neoinstitutionalist and neorealist explanations as a general theory of IR (Moravcsik 1997: 515-516). Based on the assumed primacy of societal actors, new liberal theory is interested in the conditions under which the behavior of self-interested social actors will bring about cooperation or conflict in international politics. According to the new liberal explanation, the cause of these outcomes in international politics is variation in state preferences (independent variable). The dependent variable is the outcome in international politics: i.e. conflict or cooperation? New liberal theory therefore provides a unicausal explanation based on variation in state preferences. Accordingly, peace and international cooperation thus depend on the constellation of state preferences. These constellations are brought about by interacting states whose internal structures produce cooperative foreign policy. Such states comply with agreed-upon rules without requiring control or sanctions by an international institution (neoinstitutionalism) or a hegemon (neorealism).

What matters in the new liberal explanation is the variation in the substantive content of foreign policy across issues, regions or international orders (Moravcsik 2008: 246). The "substantive content" could be economic interests, environmental protection, human rights or different goals and institutional designs of international regimes and organizations. By focusing on the "content" of foreign policy, it is even possible to account for "altruistic" goals in international politics. This contrasts with neoinstitutionalist theory, which does not specify actors' exact goals but simply assumes that rational actors have an interest in absolute gains. New liberal theory, however, is not only interested in the fact THAT states cooperate by constructing international regimes to cope with climate change, but also in HOW states purse a policy of climate change, for example, through state prohibitions or tradable emission permits. It is here that the interests of social actors matter; the answer to the 
"how"-question depends on the dominant internal policy preferences (economic actors, environmental NGOs, etc.). Such an approach can explain why OECD countries have protectionist agricultural trade policy, but also an "open" industrial trade policy (Moravcsik 2008: 246). According to Moravcsik, "[T]he stronger the aggregate benefit from social interactions across borders, the greater the demand to engage in such interactions" (Moravcsik 2008: 236). For this reason, corporations lobby for (or against) trade liberalization depending on how much they can gain (or lose) by opening an economy to the outside. Helen Milner (1988) has contributed some important work on these and similar political-economic issues in international trade.

In short, from the new liberal perspective, the fundamental problems of international anarchy must be addressed by focusing an analysis on factors inside the state. It is not anarchy, as a structural condition in the international system, that produces the problems of international politics, but rather the states and societies that constitute this anarchical system and which must interact in international politics. New liberal theory attempts to explain even long-term historical change in world politics by creating a causal link between long-term economic, political and social transformations and state behavior (Moravcsik 2008: 247). New liberal analysis should be able to predict war and peace, as well as such political-economic outcomes as trade liberalization and trade protection.

In brief: The new liberal "bottom-up"-model of explanation

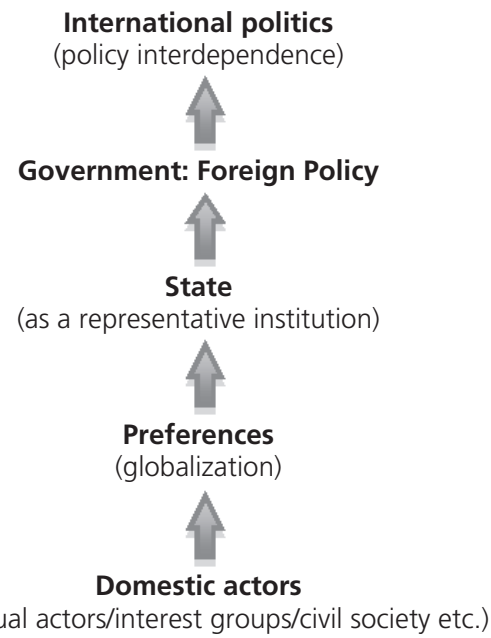




\section{Self-study (1)}

Now read Moravcsik 1997 and Matthew/Zacher 1995. Their texts give an overview of different strands of liberal theory. What distinguishes the different variants of new liberal theory? Draw the line of causality for each variant of new liberal explanation: show the dependent variable, the independent variable and the causal relationship between the two.

\subsection{Levels-of analysis in new liberalism: The logic of two-level- games}

New liberal theory goes beyond "traditional" liberal theory in that it extends analysis beyond the sub-systemic state level towards the systemic level of the international system. Whereas "traditional" liberalism is a sub-systemic theory, new liberalism provides a step-by-step explanation in that it refers first to the state and then to the system level. The explanation is systemic (second step) in the sense of Waltz's neorealist theory because the constellation, or "distribution", of state preferences - comparable to the distribution of capabilities in neorealism - is perceived as an "attribute" of the international system (Moravcsik 2008: 248; as discussed in Step 1.3). This "distribution" cannot be controlled by the state. Constraints are imposed on a state's behavior by the preferences of other states (via "policy interdependence"). Similar to neorealist theory, the theory employs a "configuration" to explain state behavior, i.e. how states stand in relation to each other (Moravcsik 2008: 248). However, state preferences have their sources in domestic society. According to Moravcsik, the "management of globalization" (Moravcsik 2008: 249) lies at the core of foreign policy and international politics. "Managing globalization" means managing the results of interactions between societies. Moravcsik views this management as being a "systemic quality" (Moravcsik 2008: 249).

Therefore, in new liberalism, the concept of "levels of analysis" does not make sense in the study of international politics (Moravcsik 2008: 249). In fact, as there is no boundary between domestic and systemic levels of analysis in new liberal theory, international negotiations take place under both subsystemic and systemic constraints. They must therefore be analyzed as "twolevel games" (Putnam 1988): governments must bargain with each other AND with their respective domestic societal actors. 
Self-study (2)

Now read Putnam 1988. What is the "logic" of two-level games?

\subsection{New liberalism as a contribution to multi-causal explanations}

For Moravcsik, new liberal theory demonstrates that there is no "superiority" of systemic theories in IR. He criticizes the fact that over a long period of time the "image" of domestic theories was that they could only be used to explain those "anomalies" in international politics that could not be explained by a systemic theory. Moravcsik regards this as being inconsistent with the rationality assumption and empirically biased (Moravcsik 2008: 251). Instead, he holds that the converse is true: new liberal theory is "analytically prior" to neorealism and institutionalism because liberal theory defines the conditions upon which the assumptions of neorealism and neoinstitutionalism are based (Moravcsik 1997: 515-516). State behavior must be modeled in a multi-causal manner, as a "multi-stage process of constrained social choice" (Moravcsik 2008: 250). This kind of stage-model gives precedence to the variation in state preferences. States first define the state preferences and only then do they become engaged in bargaining processes and negotiations. This can be explained by liberal theories of state-society relations. Preferences therefore take analytical priority over strategic action and only after this do states reach agreement on institutional solutions, which can be explained by realists, institutionalists, and new liberal theories of strategic interaction (Moravcsik 2008: 250). This order means that the role of strategic factors, such as power and information, comes last. Moravcsik is convinced that new liberalism can be synthesized with other theories to form a multi-causal explanation that is consistent with social theory (Moravcsik 1997: 515-516; 2008: 235). 
Step 3:

Check your understanding: key aspects and review questions

Key aspects

\begin{tabular}{|c|c|}
\hline & New liberal theory \\
\hline Core question & $\begin{array}{l}\text { - Explanations of outcomes in international politics: } \\
\text { cooperation and peace, conflict and war. }\end{array}$ \\
\hline $\begin{array}{l}\text { Ontological assumptions } \\
\text { about actors and structure }\end{array}$ & $\begin{array}{l}\text { - Social actors (individuals and groups of individuals) } \\
\text { are the most important actors in international poli- } \\
\text { tics (ontological individualism). } \\
\text { - Rationality assumption } \\
\text { - States as "representative institutions"/structure }\end{array}$ \\
\hline "Agency and structure" & $\begin{array}{l}\text { - Individuals and groups with interests ontologically } \\
\text { and epistemologically prior to politics: demands of a } \\
\text { "management of globalization" through the state } \\
\text { - Structures and processes in international politics as } \\
\text { the result of social action (individuals, social groups, } \\
\text { etc.): ontological individualism and methodological } \\
\text { individualist, agency-centered explanation. }\end{array}$ \\
\hline $\begin{array}{l}\text { Nature of explanation and } \\
\text { causality }\end{array}$ & $\begin{array}{l}\text { Political outcomes in international politics (coopera- } \\
\text { tion, peace) can only be explained by looking "in- } \\
\text { side" the state, to individual societal actor's inter- } \\
\text { ests: outcomes causally explained in terms of the in- } \\
\text { terests of domestic social actors (methodological in- } \\
\text { dividualism, agency-centered explanation) }\end{array}$ \\
\hline Level of analysis & - State (sub-systemic) level and system level \\
\hline Philosophy of science & - Positivism \\
\hline Normative perspective & Self-Study (3a) \\
\hline $\begin{array}{l}\text { Theory and practice/role of } \\
\text { the scientist }\end{array}$ & Self-Study (3b) \\
\hline
\end{tabular}

\section{Review questions}

1. What is "new" in new liberal theory compared to "traditional" liberal approaches?

2. What are the assumptions of new liberalism in regard to the relevant actors and the state? Compare to neorealist and neoinstitutionalist theory.

3. Discuss the relevance of the "level-of-analysis problem" for new liberal theory.

4. Outline causality according to the new liberal explanation. 


\section{Step 4:}

Final self-study and consolidation

\section{Self-Study (3)}

Reflect on what you have learned in this unit and fill in the missing blanks in the key aspects.

\section{Self-study (4)}

Re-read Unit 2 of Part 1 and then return to this unit: Why, from a philosophy of science perspective, can neorealist, neoinstitutionalist and new liberal theory all claim to be based on ontological individualist and methodological individualist assumptions? Why can all three theories of IR claim to offer methodological individualist, agency-centered explanations of international politics?

\section{Required reading}

Moravcsik, Andrew 1997: Taking preferences seriously: A liberal theory of international politics, in: International Organization 51, 512-553.

Matthew/Zacher 1995: Liberal international theory: Common threads, divergent strands, in: Kegley, Charles (ed.): Controversies in International Relations Theory. Realism and the Neoliberal Challenge. New York: St. Martin's Press, 107-150.

Putnam, Robert D. 1988: Diplomacy and domestic politics: The logic of two-level games, in: International Organization 42, 427-460.

\section{Supplementary reading}

Doyle, Michael W. 1986: Liberalism and world politics, in: American Political science Review 80, 1151-69.

Long, David 1995: The Harvard School of Liberal International Theory: A case for closure, in: Millenium 24: 3, 489-505.

Moravcsik, Andrew 2003: Liberal international relations theory: a scientific assessment, in: Elman/Elman (eds.): Progress in International Relations theory: Appraising the Field. Cambridge, MA: MIT Press, 159-204.

Schimmelfennig, Frank 2004: Liberal Intergovernmentalism, in: Wiener, Antje/Diez, Thomas (eds.): European Integration Theory. Oxford: Oxford University Press, 75-94.

Schieder, Siegfried 2013: New liberal theory, in: Schieder, Siegfried/Spindler, Manuela (eds.): Theories of International Relations. London and New York: Routledge (forthcoming). 


\section{Further reading}

Evans, Peter B./Jacobson, Harold K./Putnam, Robert D. (eds.) 1993: Double-Edged Diplomacy. International Bargaining and Domestic Politics. Berkeley: University of California Press.

Gourevitch, Peter 1978: The second image reversed: The international sources of domestic politics, in: International Organization 32, 881-912.

Ikenberry, John 2006: Liberal Order and Imperial Ambition: Essays on American Power and International Order. Cambridge: Polity Press.

Milner, Helen 1988: Trading places: Industries for free trade, in: World Politics 40, 350376.

Milner, Helen 1997: Interests, institutions, and information: Domestic politics and International Relations. Princeton: Princeton University Press.

Moravcsik, Andrew 2005: The European Constitutional Compromise and the neofunctionalist legacy, in: Journal of European Public Policy 12, 349-386.

Moravcsik, Andrew 1998: The Choice for Europe. Social Purpose and State Power from Messina to Maastricht. Ithaca, NY: Cornell University Press.

Moravcsik, Andrew 1993: Preferences and Power in the European Community: A liberalintergovernmentalist approach, in: Journal of Common Market Studies 31: 4, 473-524.

Richardson, James 1997: Contending Liberalisms. Past and Present, in: European Journal of International Relations 3: 1, 5-33.

Risse-Kappen, Thomas 1994: Ideas do not float freely. Transnational coalitions, domestic stuctures and the end of the Cold War, in: International Organization 48: 2, 185-214.

\section{References in the text}

Allison, Graham 1971: Essence of decision: explaining the Cuban Missile Crisis. New York: Longman.

Czempiel, Ernst-Otto 1979: Amerikanische Außenpolitik. Gesellschaftliche Anforderungen und politische Entscheidungen. Stuttgart: Kohlhammer.

Czempiel, Ernst-Otto 1981: Internationale Politik. Ein Konfliktmodell. Paderborn: Schöningh.

Deutsch, Karl 1957: Political Community and the North Atlantic Area. Princeton: Princeton University Press.

Moravcsik, Andrew 2008: The New Liberalism, in: Reus-Smit, Christian/Snidal, Duncan (eds.): The Oxford Handbook of International Relations. Oxford: Oxford University Press, 234-254.

Moravcsik, Andrew 1997: Taking preferences seriously: A liberal theory of international politics, in: International Organization 51, 512-553.

Matthew/Zacher 1995: Liberal international theory: Common threads, divergent strands, in: Kegley, Charles (ed.): Controversies in International Relations Theory. Realism and the Neoliberal Challenge. New York: St. Martin's Press, 107-150.

Keohane, Robert O./Nye, Joseph (eds.) 1970: Transnational Relations and World Politics. Cambridge, MA: Harvard University Press.

Putnam, Robert D. 1988: Diplomacy and domestic politics: The logic of two-level games, in: International Organization 42, 427-460. 
Milner, Helen 1988: Trading places: Industries for free trade, in: World Politics 40, 350376.

Risse-Kappen, Thomas 1994: Ideas do not float freely. Transnational coalitions, domestic structures and the end of the Cold War, in: International Organization 48: 2, 185-214.

Lijphart, Arend 1999: Patterns of Democracy. Government Forms and Performance in Thirty-Six Countries. New Haven: Yale University Press. 


\section{World-systems analysis}

Learning steps

Introduction

Step 1:

World-systems analysis: ontological, epistemological and methodological claims

Step 2:

World-systems analysis

2.1. The historical social system as a unit of analysis

2.2. Social times: structural time/the longue durée

2.3. Conclusion

Step 3:

The modern world-system

3.1. The modern world-system: a capitalist world-economy .......................... 184

3.2. Structures and processes of the capitalist world-economy ...................... 185

3.2.1. Core-periphery and cyclical rhythms ................................................ 185

3.2.2. Political structures and processes: states, the inter-state system and hegemonic cycles

3.3. Crises and transition

Step 4:

Check your understanding:

key aspects and review questions

Step 5:

Final self-study and consolidation 


\section{Introduction}

After our learning units on neorealist, neoinstitutionalist and new liberal theory in IR, you are now familiar with three examples of theoretical approaches based on a positivist philosophy of (social) science. With regards to philosophy of science criteria, these theories share an individualist ontology, methodological individualism, and a strong commitment to causal explanation. However, as could be demonstrated, variances in the underlying (ontologically positivist) assumptions have implications for how outcomes in international politics are explained and for the policy advice that would be given based on each perspective.

Having discussed these three theories, Unit 8 and Unit 9 will introduce two approaches that differ with regard to their major ontological as well as epistemological and methodological assumptions: world-systems analysis and social constructivist theory. In accordance with our criteria for the structured learning of theoretical approaches to IR, you will now learn about the specifics of world-systems analysis as a holistic and structuralist approach to the social reality of international politics.

Before we start please re-read Unit 2, Step 2 (Positivism as an example for a philosophy of science) and Unit 4, Step 2.3. (Assumptions about agency and structure). Review the features that define positivism as a philosophy of science, i.e. its ontological, epistemological and methodological claims, and the different solutions to the agent-structure problem in the social sciences.

World-systems analysis is a theoretical perspective of international relations that began in the early 1970s. It developed from a critique of the positivist accounts of social sciences found at the heart of IR. You will notice that representatives of the approach carefully avoid the term "theory". Worldsystems analysis claims not to be a theory about the social world but is instead understood to be "a protest against the ways in which social scientific inquiry was structured for all of us at its inception in the middle of the nineteenth century" (Wallerstein 2000: 129). As such, it is based on a fundamental critique of the a priori assumptions of positivist social science. The argument is that a positivist social science leads to the exclusion of the most important questions of social reality. Recall our discussion from the second unit in Part I on the implications that different philosophies of science have for the study of international politics. By learning about world-systems analysis, a particular non-positivist approach to IR that basically refers to the work of Immanuel Wallerstein, we can now investigate such questions in more detail. The intellectual roots of this perspective are found in the works of Frantz Fanon, Fernand Braudel, Ilya Prigogine, Karl Marx, Sigmund Freud, Joseph 
Schumpeter, and Karl Polanyi. However, world-systems analysis is a school of thought that encompasses further scholars and world-systems analysts, such as Samir Amin, Giovanni Arrighi, Christopher Chase-Dunn and Peter J. Taylor (you will find a list of their works in the bibliographical guide in the section headed "consolidation").

The intellectual context for the development of world-systems analysis is Wallerstein's engagement with four debates in the social sciences (Wallerstein 2004: 11-22):

The first of these relates to the discussions on underdevelopment as a consequence of capitalist development. The concept of core-periphery, as developed in the 1960s by Raúl Prebisch, the first executive secretary of the UN Commission for Latin America (ECLA), and the dependency theory (as formulated by Andre Gunder Frank) both had major impacts on Wallerstein's thought. In contrast to the dominant liberal economic theory, which claimed that comparative advantages - and therefore international trade - enhanced welfare for all, the concept of core-periphery views international trade as being an "unequal exchange" with surplus value flowing in one direction only, i.e. from the periphery (the Third world) to the core (the developed world). For the dependency theory, the free trade promoted by the core states and their multinational corporations renders the periphery ever more dependent and results in a "development of underdevelopment".

The second debate that influenced Wallerstein's thinking was the debate on Marx's concept of an "Asian mode of production". His observation of the particular mode of production found in the large empires in China and India was not consistent with the idea of the linear progression of capitalist development. The debate questioned the idea of inevitable stages of development and therefore developmentalism as an analytical framework and form of policy advice.

The third source for Wallerstein's work was the controversy among West European historians regarding the transition from feudalism to capitalism. At its core was the question of the origins of modern capitalism and how to study them: can the transition from feudalism to capitalism be explained by studying countries or larger units?

Finally, Wallerstein's work is strongly influenced by the so-called $A n$ nales School of historiography, which emerged in the 1920s in France and became influential after 1945. Scholars of the Annales School shared the perspective of a "total" historiography, i.e. viewing historical developments in terms of an "integrated picture" with a strong emphasis on the economic and social underpinnings of historical development. For Annales scholars, longterm generalizations of historical phenomena are both possible and desirable. 
For Wallerstein, the synthesis of these four separate debates is a fundamental critique of the existing structures of knowledge. This view was imposed in the 1970s by the 1968 revolutions and the epistemological discussions of the social sciences (Wallerstein 2004: 16-17). The intention behind the formulation of world-systems analysis was to address questions on the unit of analysis for social science and social "temporality" and to remove the barriers between the different social science disciplines.

However, Wallerstein still denounces the dialogue with positivist accounts of social sciences as a "dialogue of the deaf" (Wallerstein 2004: 19). Indeed, world-systems analysis is noticeably missing in most books on IR theory. This is a regrettable neglect of a complex and insightful theoretical approach to international politics that is well worthy of discussion.

\section{Step 1:}

\section{World-systems analysis: ontological, epistemological and methodological claims}

In Part 1, it was noted that those who reject positivist IR theory do not necessarily oppose systematic inquiry. The understanding of the term "science" distinguishes these views. Few theories of IR are "anti-science" or actually reject the idea that scientific knowledge is possible. Indeed, most different approaches to IR are united in an understanding of science as a systematic process of inquiry that employs methods.

This understanding also holds true for world-systems analysis. Wallerstein demonstrates a clear commitment to science, but not to positivist science. "(I)t is on the basis of scientific claims, that is, on the basis of claims related to the possibilities of systematic knowledge about social reality, that world-systems analysis challenges the prevailing mode of inquiry" (Wallerstein 1987/2000: 129).

For Wallerstein, a "real world" exists and is the object of scholarly observation (Wallerstein 2000: $\mathrm{xx}$ ). However, this social reality is socially constructed. A construction that is social is by implication therefore collective (not individual).

He also criticizes the "prevailing mode of inquiry", i.e. theories of IR based on a positivist philosophy of science, for several reasons (Wallerstein 1987/2000: 130-148):

Firstly, Wallerstein is fundamentally critical of the division of social science into a number of different "disciplines" such as sociology, political sci- 
ence, economics and history. He sees the split as originating in the $19^{\text {th }}$ century when the then-dominant liberal ideology defined "modernity" by differentiating three separate social spheres with different logics: the market, the state and civil society. These spheres were then studied in different fields: economics for the market, politics for the state, and sociology for civil society (Wallerstein 2004: 6). For Wallerstein, our contemporary departmental/disciplinary university structures still reflect this division, which has become a defining feature of an expanded world university system. In contrast, Wallerstein sees the individual disciplines in the social sciences as one single discipline because the "spheres" of collective human action (the economic, the political and the social/sociocultural) are not separate domains of social action. As these spheres have no separate logics, "no useful research model can isolate 'factors' according to the categories of economic, political, and social and treat only one kind of variable, implicitly holding the others constant" (Wallerstein 1987/2000: 134). Overcoming the "divorce" of the social science disciplines means, for world-systems analysis, that "(a)ll the presumed criteria - level of analysis, subject-matter, methods, theoretical assumptions either are no longer true in practice or, if sustained, are barriers to further knowledge rather than stimuli to its creation." (Wallerstein 2000: 133). Because it does not recognize the legitimacy of the separate disciplines, worldsystem analysis is therefore unidisciplinary and not multidisciplinary (Wallerstein 2004: 19).

Through Wallerstein we become aware that the categories used to understand history and our accounts of social reality are themselves historically formed, and must therefore be examined critically (Wallerstein 1987/2000: 145).

Second, Wallerstein challenges the common distinction between idiographic (as in historical disciplines that describe the unique and the particular) and nomothetic (the theoretical search for universal laws governing social reality) modes of analysis, which also originated in the $19^{\text {th }}$ century. The dominant view of the social sciences was that "objective" knowledge of the world is possible and must be formulated by law-like generalizations based on empirical analysis and inductive reasoning (Wallerstein 2004: 6). Wallerstein also questions the superiority of science over philosophy, i.e. the split between the "search for the good" and the search for "knowledge" (Wallerstein 1997/2000: 195). He views social science as being the basis for a "reunited world of knowledge" (Wallerstein 1997/2000: 203).

Third, Wallerstein denies that the sovereign state is the basic social entity (and hence "unit of analysis"). He sees neither the state nor the inter-state system of sovereign states as being the appropriate unit of analysis. He intro- 
duces the "historical system" as a new perspective of social reality and, therefore, unit of analysis (Wallerstein 1987/2000: 139).

Fourth, Wallerstein introduces another perspective to contrast with a nomothetic social science that emulates the natural sciences. In his view, the method of going from the particular to the universal, from the concrete to the abstract, should be inverted (Wallerstein 1987/2000: 148). A historical social science must start with the abstract and progress to the concrete. The approach is not to reduce complexity to simpler variables, but to contextualize the simpler variables and make them more complex and able to explain real social situations (Wallerstein 2004: 19). This contextualization of variables will result in a coherent interpretation of the processes of particular historical systems. An interpretation is necessary to provide a plausible account of how the processes of particular historical systems followed a particular historical path (Wallerstein 1987/2000: 148). Epistemologically, this means to search for substantive interpretative patterns (Wallerstein 1997/2000: 198). In short, world-systems analysis attempts to "make sense" of the complexity of social reality, to "interpret" it usefully and plausibly (Wallerstein 1997/ 2000: 202). The core task of social science is to offer plausible explanations of historical reality. This requires long-term, large-scale social change to be placed at the center of analysis. This describes the core of world-systems analysis as analysis. The topic will be discussed in the next chapter in more detail.

Fifth, world-systems analysis is theory and praxis: analyses must be "socially useful". In the words of Wallerstein: "Those scholarly analyses that are more correct are more socially useful in that they aid the world to construct a substantively more rational reality" (Wallerstein 1997/2000: 200).

In sum, world-systems analysis is a call for a holistic historical social science (Wallerstein 2004: xi). It is based not on the antinomies common for most social science approaches: macro and micro, global/local or structurelagency - but on their unity (Wallerstein 1997/2000: 185). In fact, this unity actually "permits us to see that micro and macro, global and local, and above all structure and agency are not unsurpassable antinomies but rather yin and yang." (Wallerstein 1997/2000: 196).

On the basis of these perspectives of the philosophy of science, we will now take a closer look at the substantive theoretical body of world-systems analysis. 


\section{Step 2:}

World-systems analysis

\subsection{The "historical social system" as the unit of analysis}

The social reality to be analyzed by world-systems analysis is not that of the states themselves or even that of the states system but "something larger": a world-system or historical system (Wallerstein 2004: x). The term worldsystem comes from the work of Fernand Braudel.

"Historical systems" as a unit of analysis was first introduced in Volume 1 of The Modern World-System (Wallerstein 1974). In this perspective, the state and the inter-state structure (usually the core subject matter of IR) is just one institutional structure among others, and therefore only part of an integrated framework of the modern world-system. A world-system (or historical system) is "a spatial/temporal zone which cuts across many political and cultural units, one that represents an integrated zone of activity and institutions which obey certain systemic rules" (Wallerstein 2004: 17). There are three variants of historical systems. Wallerstein first distinguishes between mini-systems and world-systems, then defines two types of world-systems: world-economies and world-empires. Please note that the hyphens in "world-system", "worldeconomies" and "world-empires" are important, as it is "not about systems, economies, empires of the world, but about systems, economies, empires that are a world" (Wallerstein 2004: 17, emphasis added). The systems do not necessarily encompass the entire globe.

The criterion used to distinguish between the varieties/forms of worldsystems is the specific mode of division of labor, the "logic" of a particular system. The mode of division of labor determines how the systems are reproduced (Wallerstein 1987/2000: 139). This idea goes back to the economic historian Karl Polanyi (Polanyi 1944: The Great Transformation). Polanyi distinguished three forms of organizing an economy: by reciprocity, by redistribution and by the market. The historical systems defined by Wallerstein are related to these three forms of economic organization; reciprocity of exchanges is a defining feature of the mini-systems (about six generations, with highly homogenous structures). The extraction and redistribution of tributes from local, self-administered, direct producers by a central organ is characteristic of world-empires with vast political structures and diverse cultural patterns. In addition to multiple political structures, integrated production structures and market exchange provide the organizational logic of reproduction in world-economies (Wallerstein 2004: 17; 1987/2000: 139-140). 
In short, there is a link between the "logic" and "form" of historical systems (Wallerstein 1987/2000: 139). A world-system is a "historical system governed by a singular logic and a set of rules within which persons and groups struggle with each other in pursuit of their interests and in accord with their values" (Wallerstein 1996: 87).

The choice of the "historical system" as the unit of analysis reflects Wallerstein's view of a unity of historical social science: the "unit" or "entity", i.e. the specific historical system, is simultaneously systemic and historical (Wallerstein 1987/2000: 139).

The system is socially created; it has a history, is driven by mechanisms and goes through crises. The social processes of a historical system are understood as integrated, complex wholes. The introduction of the historical system as a unit of analysis is therefore the introduction of a different vision of social reality compared to positivist approaches to IR. The core object of the scientific approach of world-systems analysis is to define and explain the units of analysis - historical systems.

\subsection{Social times: structural time or the longue durée}

Having discussed the systemic quality of the unit of analysis, we will now investigate its historical character in more detail. The systemic quality points to long-lasting structures.

For Wallerstein, historical systems are both systemic and historical: "They remain the same over time yet are never the same from one minute to the next. This is a paradox, but not a contradiction." (Wallerstein 2004: 22). The categories of time and space (referred to by Wallerstein as "TimeSpace"; Wallerstein 2004: 22) are important for an understanding of the systemic-historical argument. "TimeSpaces" are constantly evolving, socially constructed realities. Their construction is part of the social reality to be analyzed. The specific approach to time in Wallerstein's work is inspired by the concept of "social times" developed by Fernand Braudel (the Annales School), which originated both as a critique of the "event-dominated" or "episodic" history writing (the idiographic approach), and the positivist search for "timeless truths" (nomothetic social science). In his works, Braudel identified a multiplicity of social times such as "structural times", or what he called the "longue durée". The concept of structural time (the longue durée) has since been integrated into world-systems analysis and is the concept of grasping the duration of a particular historical system. The longue durée has a crucial function within world-systems analysis in that it reflects the self-evidence that world-systems analysis does not have to 
search for "timeless truths" and is also a critique of the concept of timeless structures. For Wallerstein, time-bound structures do exist (Wallerstein 2004: 21): a world-system has a lifespan, i.e. a beginning, a period of development and an end/a final transition (Wallerstein 2004: 18). "Structural time", or the longue durée, relates to the long-lasting fundamental structures underlying historical systems and to the cyclical processes within those structures. These will be discussed in more detail in Step 3.

In sum, by Wallerstein's standards, social science must be historical and the focus of social scientific study must be on the core phenomena of long periods and large spaces.

\subsection{Conclusion}

The particular mode of analysis provided by world-systems analysis is the simultaneous historical and systemic description and explanation of the social phenomena of the real world.

World-systems analysis overcomes the traditional boundaries in social sciences; it is the analysis of "total social systems over the longue durée" (Wallerstein 2004: 19). The world-systems analysis scholar is an historical social scientist: s/he analyzes both the general laws of particular historical systems and the particular processes the systems have gone through (Wallerstein 1987/2000: 127). It thus becomes possible to distinguish between longlasting structures and momentary expressions of reality. Epistemologically, world-systems analysis claims to explain two things: that the world has enduring structures and that it is constantly changing.

The first task of analysis is to locate the structures that govern the longue durée, i.e. the regularities, and therefore the relevant structures that constrain individual and collective action. The analysis describes the concept and sequence of the system's cyclical rhythms, as well as the patterns of internal transformation (Wallerstein 1987/2000: 136).

"(I)t is only when we have mastered the structures, yes have invented 'master narratives' that are plausible, relevant, and provisionally valid, that we can begin to exercise the kind of judgement that is implied by the concept of agency. Otherwise, our so-called agency is blind, and if blind it is manipulated..." (Wallerstein 1997/2000: 202).

Please note the particular approach to structure/agency taken here. We will come back to it in our discussions at the end of the unit.

The next chapter will focus on one particular world-system: the capitalist world-economy. 


\section{Step 3:}

\section{The modern world-system}

\subsection{The modern world-system: a capitalist world-economy}

Most of Wallerstein's work is devoted to the study of our contemporary world-system: the modern world-system. According to the definitions discussed in Step 2, our contemporary historical system is a world-system. This world-system is a capitalist (logic) world-economy (form). According to Wallerstein, the present system is not the first world-economy, but the first one that has lasted for any length of time. It originated in the $16^{\text {th }}$ century, when it covered only part of the globe (Europe and the Americas), and then expanded throughout the entire world. The modern world-system is the result of the transition from feudalism to capitalism. The "zone" or unit considered to be capitalist is not "the state", but a larger unit: a world-economy (hence the unit of analysis).

According to Wallerstein, a world-economy is "a large geographic zone within which there is a division of labor and hence significant internal exchange of basic or essential goods as well as flows of capital and labor" (Wallerstein 2004: 23). The defining feature and core principle of a capitalist world-economy is the priority of the endless accumulation of capital: the capitalist logic of accumulated and unequally distributed surplus. For this reason, only the modern world-system was a capitalist system (Wallerstein 2004: 24). For his definition of capitalism, Wallerstein draws on $19^{\text {th }}$ century liberal and Marxist thought.

Historically, all three forms of historical systems have coexisted. Whereas mini-systems were predominant in the pre-agricultural era, between $8000 \mathrm{BC}$ and 1500 there were multiple historical systems of all three types. However, the world-empire was the predominant form, and this destroyed and absorbed the contemporary mini-systems and world-economies. For this reason, the history of that period is typically a history of world-empires. Wallerstein's historical argument is therefore that, sometime around the year 1500, one world-economy "survived" and became what he calls the "modern worldsystem". On the basis of its inner capitalist logic (absorbing mini-systems and world-empires), this modern world-system was able to develop fully and expand to cover the entire globe. Wallerstein posits that, during this longue durée from the $16^{\text {th }}$ century on, a number of crucial events led to the modern world-economy becoming a long-lasting one. He points to the industrial revolution in England and the French Revolution, over the course of which state interference in the economy was reduced and the pre-capitalist ancien 
régime transformed into a capitalist state (Wallerstein 1987/2000: 144). During another important time period at the end of the $18^{\text {th }}$ and the beginning of $19^{\text {th }}$ centuries, capitalists achieved state-societal power in key states (Wallerstein 1987/2000: 141). By the late $19^{\text {th }}$ century, for the first time, only one global historical system was in existence: the modern world-system as a capitalist world-economy (Wallerstein 2004: 8).

The defining features of the modern world-system as a capitalist worldeconomy are a single division of labor, multiple state structures within an interstate system - and therefore the lack of a unifying political structure -, and multiple cultures within a "geo-culture" (Wallerstein 2004: 58). A capitalist world-economy is an "interconnected web of structures" (Wallerstein 1996: 103): a system of interrelated institutions and processes. The basic institutions of the world-system are markets, productive firms that compete in the markets, multiple states within an interstate system, households, classes, and identity-/status-groups. They are all created and re-created within the framework of the capitalist world-economy. These institutions form a "matrix" that permits the system to operate. At the same time, the "matrix" stimulates conflicts and contradictions (Wallerstein 2004: 24).

The defining features of the modern world-system in terms of structures and processes will now be discussed in more detail.

\subsection{Structures and processes of the capitalist world-economy}

\subsubsection{Core-periphery and cyclical rhythms}

The capitalist world-economy is a historical system that is based on an integrated axial division of labor. Drawing on Raul Prebisch, Wallerstein describes this axial division of labor with the concept of core-periphery as a relational concept: a capitalist world-economy has a division of labor between core-like production processes and peripheral production processes:

"A core-periphery relation is the relation between the more monopolized sectors of production on the one hand and the more competitive on the other, and therefore the relation between high-profit (and generally high-wage) and low-profit (low wage) production activities" (Wallerstein 1996: 88).

The result is an unequal exchange that benefits the core. There is a constant flow of surplus value from the producers of peripheral products to the producers of core-like products. The capitalist world-economy therefore possesses both a core and a peripheral "zone". The geographical consequence of core-periphery relationships is the concentration of core-like processes in a 
few states and peripheral processes in many states. Over time, core-like processes become peripheral processes by downgrading products and shifting production to semi-peripheral zones (with strong exports to peripheral countries, but imports of more advanced products from the core, such as South Korea, Brazil and India today), and then to peripheral zones. It is important to note that it is the production processes that are core-like and peripheral, NOT the states.

For world-systems analysts, all historical systems function cyclically. The key cyclical rhythm of the modern world production system is the Kondratieff-cycle of expansion and contraction in the world-economy: an up and down curve of A-phases (expansion) and B-phases (stagnation) (Wallerstein 2004: 30-31). A Kondratieff-cycle is about 50-60 years in length. Any measures taken to leave the B-phase and enter a new A-phase will change the parameters of the world-system (Wallerstein 2004: 31).

\section{Self-study (1)}

In order to deepen your knowledge, please now read chapter 2 of Wallerstein 2004 (The modern world system as a capitalist world-economy: production, surplus-value, and polarization).

\subsubsection{Political structures and processes: states, the inter-state system and hegemonic cycles}

A defining feature of a world-economy is that it is not bounded by a unitary political structure (in contrast to a world-empire). There are many political units within a world-economy.

The political units of the modern world-system are the states. These political units combine to form the inter-state system. The state of the modern world-system is the sovereign (nation) state within an inter-state system of sovereign states. In 1648, the inter-state system was institutionalized as a system of sovereign states in the Peace of Westphalia. Wallerstein emphasizes that "sovereignty" as a concept is a development of the modern worldsystem. The steady increase in state power is considered to be a secular trend of the modern world-system: from its beginning in the $16^{\text {th }}$ century through the 1970s (Wallerstein 2004: 43).

The state and the inter-state system as political structures of the modern world-system have specific functions. According to the capitalist logic of the system, the "market" guides decision-making, but it is never fully and freely 
functional. In fact, the totally free market only functions in an ideological sense. For the world-economy as a whole, a totally free market would make the endless accumulation of capital impossible. A partially free market is the prerequisite for the capitalist system and only the political structures guarantee a partially free market. It is by the authority of the sovereign state that property rights are protected, rules for cross-border transactions of goods, capital, and labor are defined, employment is regulated, taxation set and state subsidies given. States provide transportation infrastructures such as bridges, railway networks and airports. Powerful states put pressure on weak states to maintain open boundaries for the flow of production factors that are of use to their firms.

In short, not only does capitalism require a large market, it also requires political structures, i.e. the states and the states system. In fact, the relationship between states and productive firms is central for understanding how the capitalist world-economy functions (Wallerstein 2004: 46).

Looking at the system as a whole, at first glance inter-state relations appear paradoxical, as states are rivals in the competitive system of the worldeconomy, yet have a common interest in stabilizing and preserving the interstate system and maintaining the world-economy as a whole (Wallerstein 2004: 56). Wallerstein holds that this seeming paradox explains a state's simultaneous interest in both an anarchical interstate system AND an order of the interstate system (Wallerstein 2004: 56). This tension gives rise to "structures that are normally in between the two types" (Wallerstein 2004: 56).

The political structure of the modern world-system as a multiplicity of states within an inter-state system corresponds with the needs of a capitalist system. This would not be true for a world-empire: Capitalism (logic) and world-empire (form) are not compatible. A world-empire gives priority to political structures and not to the endless accumulation of capital.

Please bear in mind that the defining feature of a world-empire is a structure with a single political authority for the whole world-system. According to Wallerstein, all attempts by dominant states to transform the modern world-economy into a world-empire in the modern world-system have failed (Charles V in the $16^{\text {th }}$ century, Napoleon, Hitler) (Wallerstein 2004: 57).

This also holds true for all attempts to attain long-lasting hegemony, but for a different reason: the rise and fall of hegemons plays a special role in the functioning of the system. The inter-state structure of the modern world-system is governed by key cyclical processes known as hegemonic cycles. A hegemonic cycle is the rise and fall of a hegemonic power in the modern world-system. Hegemony means that the world-system as a whole has only one power at a particular time. Hegemonic cycles are longer than 
the 50-60-year Kondratieff-cycle and are important for capital accumulation processes.

From the historical perspective, hegemonies have existed at different times in the modern world-system: the Netherlands in the mid- $17^{\text {th }}$ century, the United Kingdom in the mid- $19^{\text {th }}$ century and the United States in the mid- $20^{\text {th }}$ century. Hegemonies are based on the superiority of productive efficiency. The hegemonic status is the result of market transactions and state power that are used to secure advantages for the hegemonic power in the world-economy. Hegemony is a structurally privileged position (Wallerstein 1996: 99). Hegemonic states dominate the world economy by exerting powerful economic and political influence with minimum military force, as well as with a hegemonic "cultural language". However, hegemons only define the rules of the interstate system for a certain period of time (Wallerstein 2004: 58). Hegemony can only be maintained as long as the hegemonic power is able to impose constraints on the free world market (such as forcing other markets to open to the products of the hegemonic power, protectionism of own producers, the imposition of a currency for world transactions, being involved in all decisions in the world-system) and maintain a military force strong enough to be used as a threat. The actual policies of the hegemonic power are in fact the eventual cause of their decline: power in hegemonies is self-destructive owing to the cost of its political and military role. Other states gain sufficient economic strength to challenge the hegemonic power. At this point, the hegemonic power uses military force (the source of further decline), thereby further undermining its power both economically and politically (Wallerstein 2004: 59). The productive efficiency of the hegemon declines and rival states with superior productive efficiency gain strength (Wallerstein 1996: 101). This decline goes hand in hand with attempts by other states to replace the hegemonic power (which takes a long time). According to Wallerstein, the final phase in the struggle for hegemony is usually a "thirty years war" involving all the major military powers and resulting in massive physical destruction, including the destruction of production facilities (Wallerstein mentions the Thirty Years War of 1618-1648, the Revolutionary and Napoleonic wars between 1792-1815, the first/second World Wars between 1914-45). For Wallerstein, the result is quite clear. In all "thirty years wars", the winner has always been the power committed to maintaining the structure of the capitalist world-economy while the power aiming to transform the system into a world-empire has been defeated (Wallerstein 1996: 99-100). The end of each "thirty years war" has always constituted a break in the construction of the interstate system: the Treaty of Westphalia (1648), the Concert of Europe (1815), and the founding of the United Nations (1945) (Wallerstein 1996: 100). 
Hegemony therefore occurs following a breakdown of world order. It creates the period of stability needed by capitalist firms, especially in leading states (Wallerstein 20054 58). Hegemony is therefore a systemic condition. As a result, "...hegemony is crucial, repeated, and always relatively brief. The capitalist world-economy needs the states, needs the interstate system, and needs the periodic appearances of hegemonic powers." (Wallerstein 2004: 59). In other words, capitalism and the modern states-system are not separate "historical inventions" (or conceptions), but rather developed simultaneously as parts of a whole.

In sum: the functioning of the modern world-system depends on a world production system with Kondratieff cycles and a stable inter-state system with hegemonic cycles.

\section{Self-study (2)}

The modern world-system is stabilized by a geo-culture. Read Wallerstein 2004, Chapter 4 (The creation of geoculture) and other relevant texts of your choice from the supplementary reading material. Reflect on ,geoculture" as part of the explanation offered by world-systems analysis.

\subsection{Crises and transition: towards a new world-system}

As you learned in Step 2, a world-system has a lifespan. Therefore, all historical systems come to an end and are succeeded by another system. For Wallerstein, the modern world-system is in a crisis, which has been brought about by secular trends (Wallerstein 1996: 103-105): capitalist development is understood to be a polarizing process and the gap between "winners" and "losers" is expected to widen. South-North migration, in particular, will have a huge impact on the functioning of the world-system. In addition, the steady rise of marginalized populations will cause multiple conflicts. States' fiscal crises and the decline of the welfare state will foster the state's political crisis. Wallerstein is also concerned about the ecological crisis and its massive destructive potential for the modern world-system. In addition, he feels there will be a strong ideological turn against the liberal geo-culture. Finally, Wallerstein also observes the loss of faith in science. He predicts that the crisis will continue for the next 20-50 years and bring about a new alternative interstate system. He admits, however, that this process will be difficult to predict (Wallerstein 1987/2000: 147). 
The crucial phase is the period of transition from one historical system to the next, which brings us back to the debate on structure/agency. In Wallerstein's view, the debate is one of determinism versus free will. From what we have learned so far, it is apparent that Wallerstein's analysis is strongly deterministic: the process inherent in historical systems, i.e. the logic of the system, is "translated" into self-reinforcing institutional structures that determine the long-term trajectory of the system. Agency, such as all forms of social struggle for change, can only be understood within the world-system as a whole. In world-systems analysis, actors and structures are the "products" of the inner logic of the system. They are not ontologically prior to but rather "part of a systemic mix out of which they emerged and upon which they act" (Wallerstein 2004: 21). For Wallerstein, "free will" occurs mainly during the process of "transition" to a new system. Historical choices and historical alternatives only arise because the system's structures break down in times of crisis. Here the strong normative commitment of world-systems analysis as a contribution to the transformation of the world becomes apparent: worldsystems analysis is both theory and praxis. The task of social sciences is "to present rationally the real historical alternatives that lie before us" (Wallerstein 2000: 129). The aim is to provide plausible interpretations of social reality, which are more useful for making political and moral decisions (Wallerstein 2000: xviii):

"But if reality is a constructed reality, the constructors are the actors in the real world, and not the scholars. The role of the scholars is not to construct reality but to figure out how it has been constructed, and to test the multiple social constructions of reality against each other." (Wallerstein 1997/2000: 200).

Wallerstein therefore attempts to formulate "temporarily useful structures/ categories that bear within them the processes by which they are transformed into other structures/categories." (Wallerstein 2000: xxi). 
Step 4:

Check your understanding: key aspects and review questions

Key aspects

\begin{tabular}{|c|c|}
\hline & World-systems analysis \\
\hline Core question & $\begin{array}{l}\text { - What does historical social science as a form of analy- } \\
\text { sis contribute to the transformation of social reality? }\end{array}$ \\
\hline $\begin{array}{l}\text { Ontological assumptions } \\
\text { about actors and structure }\end{array}$ & $\begin{array}{l}\text { - The "historical social system" as the basic unit of the } \\
\text { social world } \\
\text { - The whole (system) is ontologically prior to its parts } \\
\text { (ontological holism) } \\
\text { - The social whole is not reducible to its constituent } \\
\text { elements (ontological and methodological holism) } \\
\text { - Unity of the spheres of social life (politics, econom- } \\
\text { ics, society) }\end{array}$ \\
\hline "Agency and structure" & $\begin{array}{l}\text { - Ontological priority of structure (ontological holism) } \\
\text { - Social structures are ontologically independent of } \\
\text { the actions } \\
\text { - Agents (persons, identity groups, states, and class } \\
\text { tem, they are determined by structure. Agency is ex- } \\
\text { plained in terms of the "whole" (methodological ho- } \\
\text { lism) } \\
\text { - Agency only in the transition phase from one histori- } \\
\text { cal system to another: historical choices. Here, hu- } \\
\text { man actions are crucial for the transformation of } \\
\text { structures }\end{array}$ \\
\hline $\begin{array}{l}\text { Nature of explanation and } \\
\text { causality }\end{array}$ & $\begin{array}{l}\text { - Explanation is structuralist/holistic, constitutive form } \\
\text { of causality } \\
\text { - Structuralist/holistic explanation: structures (the } \\
\text { whole) are generative (explanation NOT in terms of } \\
\text { the properties of individuals or their relations). Struc- } \\
\text { tures constitute or generate actors (e.g. the state, } \\
\text { classes, identity groups) } \\
\text { - Actors/actions are explained in relation to the world- } \\
\text { system as a whole (methodological holism) }\end{array}$ \\
\hline $\begin{array}{l}\text { Approach to "levels of } \\
\text { analysis" }\end{array}$ & $\begin{array}{l}\text { - No "level of analysis" (concept is not applicable be- } \\
\text { cause positivism is rejected) }\end{array}$ \\
\hline Philosophy of science & - Holistic historical social science. \\
\hline
\end{tabular}




\begin{tabular}{|c|c|}
\hline & World-systems analysis \\
\hline Normative perspective & $\begin{array}{l}\text { - Social reality is not governed either by states or the } \\
\text { states system, but by time-bound structures of "his- } \\
\text { torical systems". } \\
\text { - Progress not linear and inevitable. Progress as possi- } \\
\text { bility. } \\
\text { - Alternative historical choices in the transition phase } \\
\text { from one historical system to another. } \\
\text { - Analysis of these structures helps formulate the his- } \\
\text { torical choices for transforming the systems. }\end{array}$ \\
\hline $\begin{array}{l}\text { Theory and practice/role of } \\
\text { the scientist }\end{array}$ & $\begin{array}{l}\text { - World-systems analysis as both theory and praxis. } \\
\text { - Social science contributes to the transformation of } \\
\text { torical choices. }\end{array}$ \\
\hline
\end{tabular}

\section{Review questions}

1. What are the core assumptions of a "holistic historical social science"?

2. What is a "historical social system" or "world-system"?

3. Outline world-systems analysis as a model for explaining international politics.

4. Discuss the theory and praxis of world-systems analysis.

\section{Step 5:}

Final self-study and consolidation

\section{Self-study (3)}

To deepen your knowledge of different types of explanation from a philosophy of science perspective, compare the individualist explanation of new liberal theory with the holistic/structuralist explanation of worldsystems analysis.

\section{Required reading}

Wallerstein, Immanuel 2004: World-Systems Analysis. An Introduction. Durham and London: Duke University Press, Chapters 2, 3, 4, 5. 


\section{Supplementary reading}

Nölke, Andreas 2013: World-system theory, in: Schieder, Siegfried/Spindler, Manuela (eds.): Theories of International Relations. London and New York: Routledge (forthcoming).

Skocpol, Theda 1977: Wallerstein's World Capitalist System: A Theoretical and Historical Critique, in: American Journal of Sociology 82: 5, 1075-1102.

Wallerstein, Immanuel 1994 (2000): Peace, Stability and Legitimacy, 1990-2025/2050, in: Lundestad, G. (ed.): The Fall of the Great Powers. Peace, Stability, and Legitimacy. Oslo: Scandinavian University Press, 331-349, repr. in Wallerstein 2000, 435 453.

Wallerstein, Immanuel 1996: The inter-state structure of the modern world-system, in: Smith/Booth/Zalewski (eds.): International theory: Positivism and beyond. Cambridge: Cambridge University Press, 87-107.

\section{Recommendations for further reading}

\section{Primary literature}

Wallerstein, Immanuel 1979: The Capitalist World-Economy. Essays by Immanuel Wallerstein. Cambridge: CUP.

Wallerstein, Immanuel 2000: The Essential Wallerstein. New York: The New Press.

Wallerstein, Immanuel 2004: World-Systems Analysis. An Introduction. Durham and London: Duke University Press.

Wallerstein, Immanuel: The Modern World-System, 3 vols, 1974, 1980, 1989. Academic Press.

\section{Epistemological arguments}

Wallerstein, Immanuel 2000: The Essential Wallerstein. New York: The New Press, Part II (chapters 5-12).

\section{Geoculture}

Wallerstein 1991: Geopolitics and Geoculture. Essays on the Changing World-system. Cambridge: CUP.

Wallerstein 1995: After Liberalism. New York: The New Press.

\section{Secondary literature}

Arrighi, Giovanni 1994: The Long Twentieth Century. London: Verso.

Denemark, Robert A. et al (eds.) 2000: World System History. The Social Science of Long-Term Change. London/New York: Routledge.

Godfrank, Walter R. 2000: Paradigm Regained? The Rules of Wallerstein's WorldSystem-Method, in: Journal of World-Systems Research 6: 2, 150-195.

Hall, Thomas D. (ed.) 2000: A World-System Reader. New Perspectives on Gender, Urbanism, Cultures, Indigenous People and Ecology. Lanham: Rowman \& Littlefield. 
Hobden, Steve/Jones, Richard 1997: World-System Theory, in: Baylis, John/Smith, Steve (eds.): The Globalization of World Politics. An Introduction to International Relations. Oxford: OUP, 125-145.

Shannon, Thomas R. 1996: An Introduction to the World-system Perspective. $2^{\text {nd }}$ ed., Boulder, Col.: Westview Press.

\section{References in the text}

Wallerstein, Immanuel 1996: The inter-state structure of the modern world-system, in: Smith/Booth/Zalewski (eds.): International theory: Positivism and beyond. Cambridge: Cambridge University Press, 87-107.

Wallerstein, Immanuel 1987: World-systems analysis, in: Giddens, A./Turner, J. (eds.): Social Theory today. Cambridge: CUP, 309-324. Repr. In Wallerstein 2000, 129-148.

Wallerstein, Immanuel 2004: World-Systems Analysis. An Introduction. Durham and London: Duke University Press.

Wallerstein, Immanuel 2000: The Essential Wallerstein. New York: The New Press.

Wallerstein, Immanuel 1997/2000: Social Science and the Quest for a just society, in: American Journal of Sociology, CII, 5, March 1997, 1241-57, repr. in Wallerstein 2000, 185-203. 


\section{Social constructivist theory}

Learning steps

Introduction

Step 1:

The ontological status of "structure" as an unobservable and an

"object" of scientific inquiry

1.1. "Structure" is real and an "object" of scientific inquiry

1.2. Social structures are also real and legitimate "objects" of scientific inquiry

Philosophical materialism/physicalism

Epistemological individualism

Moments of reflexivity: blurring the object/subject distinction

Truth of theory

Summary

\section{Step 2:}

The ontological status of "structure" as comprising ideas: Common and collective knowledge (culture)

Step 3:

Agents and social structure: ontological interdependence as "mutual constitution"

Step 4:

Explanation

4.1. A question-driven approach ................................................................ 213

4.2. Causal and constitutive explanation .................................................. 214

Causal theory: historical explanation .................................................. 215

Constitutive theory: structural explanation …………………………... 215

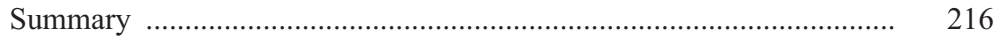

4.3. Epistemological interdependence: explaining through structuralhistorical analysis

4.4. Political relevance: reification is disempowering 
Step 5:

Check your understanding:

key aspects and review questions

Step 6:

Final self-study and consolidation 


\section{Introduction}

In the previous unit you learned about world-systems analysis as a nonpositivist approach based on a holistic ontology, methodological holism, and an interpretivist epistemology ("understanding"). At the core of the current unit will be social constructivist theory as formulated by Alexander Wendt. In addition to the works of Immanuel Wallerstein, social constructivist theory provides another particularly interesting case when seen in the context of this book's philosophy of science orientation. There are several reasons to choose Wendt's works as a reference theory for this learning unit:

First, Alexander Wendt's declared objective is to find "a via media between positivism and interpretivism by combining the epistemology of the one with the ontology of the other" (Wendt 2006: 182, my italics). He therefore attempts to synthesize what appear to be opposed positions: the epistemology of positivism and what he perceives to be the ontology of "interpretivism". As will be shown later in more detail, the term "interpretivism" as used by Wendt refers to ontological holistic/structuralist and social constructivist philosophical assumptions.

Second, with the so-called "positivism versus post-positivism debate" (or "Third Debate") in the 1980s and 1990s, social constructivism in IR came up as one of the main challengers of positivist IR theorizing (see Ashley 1984 for an early critique of neorealism; Kratochwil/Ruggie 1986 on regime theory; Wendt 1987 and Dessler 1989 on agency and structure). The work of Alexander Wendt, especially his meta-theoretical perspective of agency and structure as mutually constituted entities (Wendt 1987) and the theoretical argument of a social construction of "anarchy" (Wendt 1992) have been associated with social constructivism in IR. It was above all his seminal Social Theory of International Politics (1999) for which Wendt has been recognized as one of the major representatives of social constructivism in IR.

Third, Wendt's work belongs at the center of this learning unit because he is one of the meta-theoretically most informed IR theorists. His writings illustrate his philosophy of science positions in an exceptionally precise and systematic way, making them ideal for this book concept.

Fourth, following the intellectual development Wendt undertakes regarding his philosophy of science positions between 1987 ("The agent-structure problem in international relations theory") and his recent writings (2006: "Social Theory as Cartesian Science" and 2010: "Flatland: Quantum Mind and the International Hologram", and his forthcoming 2014 Limits of International Relations) may well be key to being well-prepared for upcoming metatheoretical debates in IR. Wendt's Social Theory of International Politics re- 
flects an ontological turn towards the philosophical positions of scientific realism - a turn that can be found in almost all social sciences, including economics. This makes this turn a particularly interesting case for broader metatheoretical discussions in IR. Moreover, the ontological and epistemological re-orientation towards philosophical interpretations of quantum physics in Wendt's more recent work presents the first attempt to transfer quantum theory to International Relations. In doing so, Wendt recently completely revised the philosophy of science basis of his constructivist Social Theory of International Politics. For this reason, the end of this text unit will be devoted to the new lines of thinking in Wendt's work, even though they leave behind the social constructivist approach of Wendt's Social Theory.

Before we start to learn more about the social constructivist perspective of Alexander Wendt, we have to keep in mind that "social constructivism" in general does not qualify as a coherent theoretical perspective in IR. There are many different social constructivist theories in IR that are based on quite different ontological and epistemological assumptions. Hence "social constructivism" is a term that subsumes many different approaches. In fact, constructivism can be considered a philosophy of science itself (see also Jørgensen 2010: 160-164). A theory is "constructivist" when it shares basic assumptions of constructivism as a philosophy of science. Consequently, the term can be applied to many theories of IR which share constructivist features (such as world-systems theory, a range of postmodern theories, Neogramscian approaches etc.) However, no coherent social constructivist theory of IR exists. There are theories of IR that to varying degrees share constructivist assumptions. In fact, this is ontologically true for almost all post-positivist approaches.

It therefore comes as no surprise that all disciplines in the social sciences had a "constructivist turn" (and not only in the social sciences) that produced a variety of social constructivist-informed theories in those disciplines. For example, there is social constructivism in disciplines such as sociology (Berger/Luckmann 1966) and political geography (Reuber et al. 2003) In linguistics, a constructivism exists that draws on the so- called linguistic turn (Ludwig Wittgenstein, John R. Searle 1995), hence pointing to the ontological position of acts of language and speech in social reality.

What social constructivist IR theories have in common is that they challenge the ontology of positivist IR theory by pointing to the importance of "social factors" such as ideas, norms, shared meanings, collective knowledge, culture, language and texts for the explanation of outcomes in international politics. According to these theories, reality is (to varying degrees and due to different social factors) socially constructed. "Social factors" are usually factors ascribed to "collectives", not individuals. Different theories do this in different 
ways and based on a range of other, often varying epistemological assumptions, hence the existence of a number of diverse social constructivist theories of IR (for a good overview see Ruggie 1998 and Jørgensen 2010: Chapter 7).

To strengthen the argument of the previous paragraph about social constructivism as a philosophy of science, it might be helpful to recap what you have learned in our previous units about the distinction between philosophy of science positions (often called meta-theory) and IR theories. Wendt (1999: 4-6) calls it "first- and second-order theorizing": "Second order" relates to philosophy of science positions, that is, assumptions about the nature of human agency, its relation to structure, the role of ideas and material factors etc. You are already familiar with "second order theorizing" from the first part of the book. It encompasses the ontological, epistemological and methodological assumptions (in short: philosophy of science) that any theory building rests on. Wendt calls it "social theory". In contrast, "first order" relates to "substantial", domain-specific theories. In IR, a "substantial theory" would be for example neorealist, new liberal or neoinstitutionalist theory etc. Theories are "domain-specific" in that they refer to particular social systems such as the international system, a particular institution such as sovereignty, and the specific relevant actors acting within these specific structures, such as states or non-state actors (Wendt 1999: 6). In contrast, "second order theory" or "social theory" refers to the abstract categories of "actor", "structure", "system", etc., and how these categories are interrelated.

Understanding the difference between "social theory" and "International Relations theory" is crucial when it comes to the core question of Wendt's theoretical work. Wendt is interested in the implications of second-order theorizing (philosophy of science) for first-order theorizing, i.e. for the substantive theory of IR. He calls this approach "applied philosophy" (Wendt 1999: 6). Using his terminology of "social theory" for second order theorizing (philosophy of science), the title of his seminal book (1999) perfectly reflects the approach he takes: Social Theory of International Politics (my italics).

Following the logic of the previous paragraphs, it then becomes clear that a substantial theory of IR (first order theory) would qualify as "social constructivist" when it shares assumptions of constructivism (second order, the philosophy of science or social theory). IR theories informed by social constructivism challenge the ontology of positivist IR theory. Ontologically social constructivist theorizing is different to positivist IR theorizing because of its focus on shared meaning and norms; ideas matter in social reality, while reality is perceived as a social construction.

Following along those lines, Wendt's work is claimed to be ontologically "social constructivist" because of his theoretical position on the ideational na- 
ture of the deep unobservable structure of the international system that constitutes the agents and rules of interaction in international politics.

These social constructivist positions are post-positivist positions in that they challenge the positivist ontology.

In the next step, let me briefly reflect on the term "post-positivism" as used in this unit. What has been said above about social constructivistinformed IR theorizing is true more generally for "post-positivist" IR theory: it can relate to a diversity of different ontological, epistemological and methodological claims. What unites these approaches is no more than the fact that none are positivist. In terms of their underlying philosophy of science perspectives, however, they are quite diverse; what is referred to as "postpositivism" artificially unifies a variety of approaches with competing perspectives. It reflects the broader search for different, alternative metatheoretical foundations for the formulation of theories of IR after or "post"positivism. The label "post-positivism" thus unites theories that are as diverse as post-structuralism (genealogical, discourse-analytical and deconstructive studies drawing on the works of French philosophers Michel Foucault, Jaques Derrida or Francois Lyotard), critical theory based on the work of the Frankfurt School, normative IR theory, (different types of) feminist IR theory, Neo-Gramscian and Neo-Marxist approaches as well as social constructivist IR theories.

However, to place all these theories into a "positivist/post-positivist" dichotomy obscures the nature of the challenge. A philosophy of science perspective will reveal the diversity of the so-called "post-positivist" approaches. At the same time, it will highlight the commonalities of positivist approaches. In contrast, most traditional textbook presentations depict the differences between IR theories within a positivist philosophy of science approach.

To return to our focus on Wendt, this argument retains its relevance there as well: Wendt's work is basically post-positivist in that it challenges the positivist ontology. More specifically, his post-positivist approach is ontologically social constructivist; however, he aims at keeping a positivist epistemological position. For Wendt, the so-called "Third Debate" in IR is about two different things: ontology (what the world is made of) and epistemology (what questions we should ask) (Wendt 1998: 103). For him, the meta-theoretical Third Debate should be focused on the former, not the latter (Wendt 1999: 90, also Wight 2006). Wendt claims that a shift to the "nature" of the problems in international politics is required in IR theory because the "content" of substantive IR theory (i.e. ontology) is distorted (Wendt 1999: 48).

When we apply philosophy (that is, philosophy of science) as described above, the central question for Wendt in his Social theory of International 
Politics (1999) emerges as: “...given a similar substantive concern as Waltz, i.e., states systemic theory and explanation, but a different ontology, what is the resulting theory of international politics?" (Wendt 1999: 6).

In other words, what he has in mind is a new type of systems theory for international politics.

In Step 1, we will examine the ontological assumptions of this new type of systems theory. Before you continue reading, please take some time to recap what you have learned about the implications of different philosophy of science positions for the study, explanation and hence practice of international politics. In this unit, we return to this issue in more detail. As you will have recognized while reading this introduction, this unit may well be the most theoretically complex and difficult one in the book. As a result, you will probably need to allocate more time for your work than has been the case for other units in the book.

\section{Step 1:}

The ontological status of "structure" as an unobservable and "object" of scientific inquiry

Social Theory of International Politics as formulated by Alexander Wendt (1999) is based on a systems-theoretic standpoint (Wendt 2006: 217, my italics). It is Wendt's objective to formulate a new approach to structural theorizing about international relations (Wendt 1987: 336, my emphasis). Wendt's approach to structural theorizing is novel because it employs a new ontological status of "structure" as an unobservable. Compared to the ontology of other forms of "structural" theorizing (Wendt mentions neorealism and world-systems theory), the concept of "structure" of the international system has been ontologically re-thought.

Wendt's new ontological approach to "structure" is best understood by starting with a reflection of his critique and a comparison of what he perceives to be two different types of "structural theory" in IR: neorealism and world-systems theory. You will find the basic arguments in his famous article "The agent-structure problem in International Relations" (1987). The article, together with that of Dessler (1989), marked the beginning of the so-called "constructivist turn" in IR in the second half of the 1980s. They are part of the post-positivist challenge to positivist theorizing mentioned in the introduction. In the follow-up to these publications, the attention of the IR community has been heavily directed towards meta-theoretical questions related 
to the interrelation of "actors" and "structures" in international politics (see also Wight 2006 for an excellent overview).

In addition to the article mentioned above, the comparison and critique of neorealism and world-systems theory is formulated in Chapter 1 of Wendt's Social Theory of International Politics (1999: 1-44). The core of his argument is that different ontologies lie at the heart of both attempts to formulate a structural theory of international politics; neorealist theory is based on an individualist ontology, world-systems theory on a holistic ontology (Wendt 1987: 336). For Wendt, both perspectives are reductionist: either the actors are assumed to be ontological prior to structure and hence "given" (ontological individualism/neorealism) or structure is assumed to be ontological prior to actors and hence given (ontological structuralism/world-systems theory).

\section{Self-study (1)}

Recap what you have learned about neorealist theorizing and about worldsystems theory. Then read Wendt 1987: The agent-structure-problem in International Relations, 335-349. Learn about the ontological and methodological individualist status of "structure" in neorealism and the ontological and methodological holistic status of "structure" in world-systems theory. Complement and deepen your knowledge about the philosophy of science positions at the heart of neorealism and world-systems theory. For didactical reasons, the recommendation is not to read the full text, but simply to focus on pages $335-349$ and then return to the unit text.

Wendt's attempt to formulate a new structural theory has its philosophical foundation in scientific realism (basically drawing on the work of Roy Bhaskar) and applies structuration theory from sociology (Giddens 1979, 1984) to International Relations. Wendt requires the use of both scientific realism and structuration theory in order to base IR theory on a new ontology. They are the "meta-physical foundations" of his new approach to theorizing international politics (Wendt 2006: 182). Adopting them thus has implications for the "substantial" IR theory he has in mind.

Step by step, we will now learn about the ontological position on which Wendt's new approach to structural theorizing is based. The starting point is the status of "unobservable" phenomena in scientific inquiry: in Wendt's words, "we cannot see the structure of the international system, whether conceptualized in material or social terms" (Wendt 1999: 49). This problem raises questions and doubts as to whether unobservables such as the structure of the international system are legitimate objects of scientific inquiry. How can 
we know about things we cannot observe? Wendt's answer is to ground IR theory in a scientific realist understanding of science. Please note that "scientific realism" refers to a philosophy of science and thus is on equal terms with positivism as a philosophy of science. It should not be confused with "realism" as a (substantive) theory of International Relations.

In order to learn about the "new ontology" in more detail, the next section will start with scientific realist assumptions about "structure". We will then discuss the relevance scientific realism has for the scientific study of international politics.

It should be emphasized that Wendt's decision to draw on scientific realism reflects a broader movement of re-orientation in the social sciences towards realist ontology. Using Wendt's work therefore serves a double purpose: it demonstrates and reflects a broader ontological reorientation (philosophy of science aspect) while at the same time demonstrating its application to IR theory (as shown in Wendt's formulation of a specific theory of IR). The question of ontology is a highly relevant question as it relates to the nature, the "being" or "reality" of the subject of our studies, such as the state and the international system of states.

\section{1. "Structure" is real and object to scientific inquiry}

Wendt, drawing on scientific realism as formulated by Roy Bhaskar (1979: The possibility of naturalism), contends that any "structure" as an unobservable entity is real and knowable (Wendt 1999: 47-48). For him, this is true for the world of natural sciences (here examples of unobservable "structures" include the atom or the double helix of DNA) as well as for the social sciences (the structures of any social system). The ontological position of scientific realism is that structures are unobservable; however, it is contended that they are real and knowable. For the study of the international system, the assumption of structures as unobservables but real and knowables implies that the state system and the state are assumed to be "real structures" (ontology) (Wendt 1999: 47-48). The reality of structures is assumed to be independent of human thought. As real structures, independent of human thought, they are also knowable, legitimate objects of science (epistemology). More concretely, because they are real and independent of the human mind, they can be approached and examined by science despite being unobservable. The purpose of scientific theories is to refer to this world of observables as well as "unobservables". Theory is thus understood as a reflection of reality: "ontology before epistemology", a position that is in contrast to positivism ("epistemology before ontology"). 
To clarify these statements even further, we can compare them to the empiricist position of positivism. While in empiricism theoretical concepts such as "the international states system" or "structure of the international system" are only instruments, devices for the purpose of organizing our experience (that is, concepts that do NOT refer to the real world), in scientific realism the concepts of states system or structure refer to real structures (Wendt 1999: 49). In short: In positivism, theories about unobservables are treated instrumentally, not realistically. As we know from the second unit in Part 1 of the book, observation has a privileged epistemic status in positivism compared to theory: "What we can claim to exist depends on what we can know, and we can only know what we can see" (Wendt 1999: 60). Hence, in empiricism, only observable reality is real and can be known through science.

Regarding the concept of "structure" in neorealism, this explanation consequently means that structure has "no being". It is not an ontological entity, as "structure" is a concept; a device to organize our observation. Hence in a positivist approach, structure is operationalized by "translation" into observables: the distribution of power, with a concept of power as the capability of the state (measurable).

However, despite these differences in the treatment of theoretical terms, scientific realism and positivism do share an important feature: "Scientific realism assumes that reality exists independent of human beings - that subject and object are distinct - and can be discovered through science" (Wendt 1999: 49). However, for scientific realism and in contrast to positivism, this holds true for unobservables as well. A scientific realist interpretation of science depends on a distinction between subject and object (Wendt 1999: 50).

At the core of Wendt's work is an interest in the scientific inquiry into the unobservable "deep structure" of the international system (Wendt 1999: 49). He takes this approach with the intention of building an argument against the claim from positivist IR that structural analysis of unobservables is unscientific.

However, Wendt faces a fundamental problem: social structures are different to material structures. This is because of the ideational nature of social structures. This nature calls into question the argument of an independence of social (ideational) structures from the human mind and raises doubts that subject and object are distinct - the precondition for being knowable through both positivist and realist science. A scientific realist position about natural science seems to be unproblematic because it is based on a materialist ontology where an object-subject distinction is possible. But what about scientific realist social science? Here the core question is: How can social kinds remain "objective" despite their basis in shared ideas? (Wendt 1999: 72). How can 
they be claimed to be legitimate objects of science the same way that natural kinds are?

In Wendt's words the central question is: "How is it possible to adopt an idealist and holist ontology while maintaining a commitment to science, or positivism broadly understood?" (Wendt 1999: 47). Is the ontology of the social world consistent with scientific realism? Wendt is convinced that it is. Let us therefore continue on to the line of argument for this affirmative position.

\subsection{Social structures are also real and legitimate "objects" of scientific inquiry}

We have learned that Wendt's aim is to formulate a scientific realist perspective about the structure of social systems. In his writings he uses the term "social kinds", a term derived from John Searl (1995: The Construction of Social Reality). It refers to the "things in the social world", such as "society", the "state", "money", the "family", the "school" etc.: It is the nature of "social kinds" that they are "made of ideas" (Wendt 1998: 103). We will read and learn about the social (that is, inherently ideational) nature of "social kinds" in more detail later (Step 2). For didactical reasons, we will first start with the arguments to establish the status of social structures as legitimate objects of science, i.e. as objects of scientific inquiry for which a fundamental subject/object distinction is claimed to be possible (in line with scientific realism). To recall the "problem of social kinds": If social kinds are made of ideas, then we can hardly claim an independent existence from human beings and their minds, language etc. At a more general as well as abstract and philosophical level, this problem is known as the mind/body or mind/matter problem: are the material/nature and the ideational distinct entities or not?

\section{Philosophical materialism/physicalism}

Wendt's solution to this problem is to claim a final, ultimate fundamental basis of the social world in nature (materialism). He holds that society is not reducible to nature, but nature is perceived as the material foundation of society (Wendt 1999: 51, my italics). In other words, Wendt's position is rooted in the belief that the world is ultimately made of material things: at the most basic level, sub-atomic particles (matter/material nature to be studied by physics). This position is called philosophical materialism or physicalism. In a nutshell, Wendt commits to a social science that is not distinct from the natural sciences (Wendt 1999: 52). The underlying assumption is that the world ultimately contains "natural kinds", or material entities with "causal power" due to intrinsic 
thought-independent structures. The material entities hence have the effect of "reality constraints". In other words, social science theories should conform to the findings of natural science regarding natural kinds (matter) (Wendt 1999: 58). In the second unit of Part 1, this positivist position has also been called "naturalism" (a materialist or physicalist position).

So how can "social kinds" remain "objective" despite their basis in shared ideas? The answer is a metaphysical argument that points to an ultimate material base of society and/or the social world in physical, material properties. Human beings are thus perceived as "natural kinds" with "intrinsic material properties" such as brains or genetic predispositions (Wendt 1999: 72). The mind (ideas/theories/the social etc.) ultimately rests in the material world (body/matter/ material, physical world): "In the last analysis a theory of social kinds must refer to natural kinds, including human bodies and their physical behavior, which are amenable to a causal theory of reference" (Wendt 1999: 72). For Wendt, there is a need for a theory that takes account of the contribution of mind and language "yet is anchored to external reality." (Wendt 1999: 57, my italics). Wendt sums up his materialist position with the words "Constructivism without nature goes too far!" (Wendt 1999: 72, emphasis mine).

\section{Epistemological individualism}

A naturalist position or "constructivism with nature" allows one to think about "social kinds" as "objective" and hence able to be known by human subjects. However, there is a second step in Wendt's argument that makes the thesis of an object-subject-distinction for social kinds too strong: "Even though social kinds are not mind/discourse-independent of the collectivity that constitutes them, they are usually independent of the minds and discourse of the individuals who want to explain them" (Wendt 1999: 75, italics in the original). It is the nature of social kinds that they are collectively constituted. This is an ontologically idealist position (to be elaborated in more detail in Step 2) that is attached to an epistemological position of "objectivism". This attachment allows one to think of the social world as "confronting the individual as objective social facts". Wendt calls it epistemological individualism (Wendt 1999: 75, my italics), in which "(t)he international system confronts the IR theorist as an objective social fact that is independent of his or her beliefs (...)" (Wendt 1999: 75). For Wendt, the same is true for the political decision-makers: "As lay scientists, foreign policy decision-makers experience a similar dualism of subject and object in their daily efforts to negotiate the world" (Wendt 1999: 75). 
In sum, "social kinds" such as a "state" or the "states system" confront the researcher as natural facts, as objects. To be objects, they have to be "reified" (Wendt 1999: 76). As the result of reification, the "states system" is assumed to exist independently of social scientists. It therefore becomes a legitimate object of scientific inquiry or for political decision-making by (foreign) policy-makers. The interaction with the reality of the states system regulates the theorizing about it (Wendt 1999: 63): ontology is before epistemology.

\section{Moments of reflexivity: Blurring the object/subject distinction}

In contrast to the natural world, however, Wendt maintains that the subjectobject distinction varies when it comes to the social world (Wendt 1999: 73, my italics) because the extent to which material forces determine social kinds varies. The influence of material forces is treated as a variable and, as a variable, can be examined empirically. Nevertheless, due to the fundamental naturalist position there ultimately is a subject-object-distinction.

Exceptions to the "rule" of an object-subject distinction occur "when collectives become aware of the social kinds they are constituting and move to change them, in what might be called a moment of 'reflexivity' (Wendt 1999: 76 , emphasis original). This potential of reflexivity is unique to the social world as compared to the natural world. "In effect, if a social kind can 'know itself', then it may be able to recall its human authorship, transcend the subject-object distinction, and create new social kinds (Wendt 1999: 76). In such "moments of reflexivity", social scientific theories can become part of their world. Only then is reality caused by theory and the distinction between subject and object becomes blurred. However, for Wendt, this happens only as an exception and is very rare. A different position would make a scientific realist approach to the social world impossible; as Wendt argues, "[i]f societies were constantly doing this - in a sort of 'permanent conceptual revolution' we could not be realists about society." (Wendt 1999: 76).

\section{Truth of theory}

Against the background of the position "ontology before epistemology" (i.e. reality/ontology conditions theory/epistemology; theory as a reflection of reality), the "ultimate argument for realism" is that science has been a success in helping to manipulate the world (Wendt 1999: 59-64). By formulating scientific theories we are getting closer to the (unobservable) structures of reality and hence gradually gaining a better understanding of the world. In line with scientific realism, Wendt argues that a theory is "true" to the extent that it reflects the causal structure of the world (also called "correspondence theo- 
ry of truth"). In essence, theories are always being tested against other theories, not against pre-theoretical foundations (realism is anti-foundationalist). We thus cannot know for certain that a claim of reference is true, as there is only "approximate truth". For this reason, scientists have to rely on "mature theories" that have proven successful in the world (Wendt 1999: 59).

\section{Summary}

For Wendt, the ideational structure of the social world does not prevent a scientific realist approach to the study of this world. This is because of his conviction that a) there is an ultimate material base for social kinds (although to varying degrees) and b) social kinds have intrinsic powers and dispositions that exist independently of the mind/discourse of those who wish to know them. These two core arguments establish the ontological status of unobservable social structures as "real" and as legitimate objects of scientific inquiry, independent of the subject of inquiry itself.

Let us now take the next step in learning about the new ontology on which Wendt's social theory is based. As a social constructivist, Wendt is interested in the difference that ideas make. In contrast to Waltz, Wendt feels that not only material factors count when it comes to the structure of the international system. For him, immaterial, ideational factors are also essential. More than this, for Wendt "(...) the role of the material base in international politics is relatively small, even if it remains essential for preserving a causal theory of reference" (Wendt 1999: 73; emphasis mine).

This discussion now brings us back to the ideational nature/ontology of social structures in more detail.

\section{Step 2:}

\section{The ontological status of "structure" as "made of ideas": Common and collective knowledge (culture)}

Wendt's interest in the effects of ideational/social structures has led to that theoretical approach being called "social constructivist". Reality is socially constructed, based on collective ideas (idealism of social constructivism). The position points to the intersubjective quality of the social world, the role of ideas, constitutive rules and norms, and the endogenous forming of interests and ideas. When compared to ontologically positivist theorizing, these aspects demonstrate different statements and assumptions about the "substance" of international politics and lead to different theoretical results about 
such central issues of international politics as "anarchy" or "sovereignty". This focus on the ideational nature of structure caused Wendt to become associated with social constructivism in the first place: in his words, "Anarchy is what states make of it" (Wendt 1987), a social construction that varies depending on the collective ideas that constitute the structure. Both the structure of "anarchy" and the institution of "sovereignty" are theoretically rethought as "social kinds"; they are constructed by the way actors act and depending on which collective ideas they share.

In this section, we will learn about the idealist ontology of social constructivism in more detail.

For Wendt, the structure of any social system consists of three "elements": a material structure, a structure of interests, and an ideational structure (Wendt 1999: 139). It is only for analytical purposes that he treats them as separate structures. According to Wendt, "[t]he task of structural theorizing ultimately must be to show how the elements of a system fit together into some kind of whole" (Wendt 1999: 139).

Particularly relevant for Wendt is the ideational aspect of social structure; he defines the ideational structure of any social system as the "distribution of knowledge" (Wendt 1999: 140). Knowledge is the ideational "substance" of structure and can be private or shared. Private or "common" knowledge are the ideas and beliefs that individual actors hold. They are not shared by other actors. Shared knowledge, on the other hand, is collective knowledge; it is socially shared knowledge, or "culture" (Wendt 1999: 141). In regard to collective knowledge, Wendt's work owes an intellectual debt to Emile Durkheim (Durkheim 1898: Individual and collective representations, see also Ruggie 1998 for the intellectual roots of Wendt's thought on collective ideas).

Through interaction, private beliefs also emerge as a social structure of knowledge. In other words, private beliefs when aggregated become an emergent, systemic phenomenon. Collective knowledge, or "culture" as the ideational structure, cannot be reduced to the individual knowledge held by individual actors (ontological and methodological holistic perspective). Culture takes many forms, including norms, rules, institutions, ideologies, organizations, etc. Please note that "culture" here refers to the collective ideational quality of any social structure, not to a sphere of society distinct from the economy or polity.

Wendt's idealist, holistic ontology therefore points to a cultural structure of the international system. 


\section{Self-study (2)}

In order to learn more about the ideational or cultural structure of the international system please now read Wendt 1999: chapter 6 (Three cultures of anarchy), 246-312, before returning to the text of the learning unit.

The core of Wendt's work is the description of structure as "made of ideas". However, going beyond that description is the question of which effects the ideational structures of a social system have (Wendt 1999: 139). He is interested in the difference ideational structures make. This question is ultimately one of explanation; however, in order to better understand the theoretical positions that answer that question, we have to take another step in learning about the new ontology. We will do so next by outlining the meta-theoretical perspective on agency and structure at the heart of Wendt's theory.

\section{Step 3:}

\section{Agency and social structure: Ontological interdependence as "mutual constitution"}

Remember what you already know from the fourth unit of Part 1 about the ontological as well as epistemological aspects of the so-called "agentstructure-problem". For Wendt's attempt to formulate a "social theory" of international politics based on a new ontology, it is the ontological aspect that is central. Together with his position on scientific realism, the specific solution to the ontological aspect of the agent-structure problem is the key to understanding the new ontology of Wendt's project of formulating a new type of structural theorizing in IR.

You have already learned in Unit 4 of this book that individualists and holists both agree that agents and structures are somehow interdependent. For ontological individualism (such as neorealist theory, neoinstitutionalism and new liberal theory), actors are assumed to be ontologically prior to structure. In an ontological manner, structure can be reduced to the properties and interactions of individual agents. For ontological holists/structuralists (such as world-systems theory), structure is assumed to be ontologically prior to actors. Ontologically, structure has irreducible emergent, systemic properties.

Wendt goes beyond the two positions by choosing a third variant of thinking about agency and structure that draws on structuration theory from sociology (Giddens 1979: Central Problems in Social Theory; and 1984: The Consti- 
tution of Society. Outline of the Theory of Structuration). Structuration theory puts forward an ontological perspective of a mutual constitution of agency and structure. It is presented as an alternative social ontology to individualist and structuralist approaches to the agent-structure problem. The basic theoretical statements of agents and structures as being mutually constituted, or codetermined, entities can be summarized as follows (see Wendt 1987: 355-356):

1) Agents and structures are assumed as mutually constitutive, but ontologically distinct entities. There is no ontological priority of either agency or structure, but a mutual dependency/co-determination (or what Wendt calls "dialectical synthesis"). Structure and agents are each an effect of the other.

2) Structures are constitutive for actors and their interests. At the same time, actors constantly produce and reproduce structure. Structures of social systems are thus both a medium and an outcome of the practices that constitute such social systems. Social structures are results of intended and unintended consequences of human action. On the other hand, those actions presuppose and are mediated by structural context. This is also called duality of structure (a term from Giddens).

3) The constitutive rules and norms inherent in structure allow structure to constrain and enable action.

4) Social structures are bound to spatial and temporal structures: they are space-time-specific. Specifically, time and space have to be integrated into theoretical research. Social theories are not trans-historical.

In other words, at the heart of structuration theory is the position of an ontological interdependence of agents and structure. Agents and structure are assumed to be ontologically distinct entities, but ontologically assumed to be dependent upon each other. The ontological interdependence is conceptualized as "mutual constitution" or co-determination.

Please keep in mind that structuration theory is a meta-theory, NOT a substantive theory. It belongs to "second order theorizing" (social theory), which, according to Wendt, can be used for or applied to first-order theorizing (substantive IR theory). Hence structuration theory is not about "substance" of the social world, i.e. not about particular, concrete social systems, agents, and structures (Wendt 1987: 355). Instead, it frames our thinking about it in a meta-theoretical way.

So what are the benefits of structuration theory being applied to formulate a new structural theory of IR? For Wendt, structuration theory aids in going beyond reductionist structural theorizing because the perspective preserves the "generative and relational aspect" of structuralism while at the same time conceptually and methodologically NOT drawing on a separation of genera- 
tive structures from the self-realizations and practices of human agents (duality of structure, no "reification" of structure) (Wendt 1987: 355). The reasons for this lie in the different ontological perspective of the agent-structure problem as described above.

The generative and relational aspect of structure can be described as follows: structure is defined as a "set of internally related elements" (Wendt 1987: 357) such as agents, practices, technologies, territories, etc. These "elements" have a position within the social organization of the system. They are internally related; that is, they cannot be defined or conceived independently of their position in the social structure (we know this position from world-systems theory). The perspective of structuration theory when applied to IR holds that states (agency) are generated or constituted by the system's internal relations. Thus, states can be defined or conceived as "states" only by their position in a global (systems) structure. Structures generate agents and their behavior; they constitute the conditions of existence for states and state action and make the concepts "state", "state power", or "foreign policy" possible. The properties of the elements of a relation are internal to the relation itself; they do not exist apart from it (Wendt 1998: 114). This position is in contrast to neorealism, in which structures are externally related to preexisting state agents. An example for a structural relation is "sovereignty" as an organizing principle of the interstate system; sovereignty generates and constitutes states as states.

From what has been written so far and from your self-study (all of which are related to the "substantive" theory of IR as the result of "applied philosophy"), it becomes clear that Wendt sees "agency" as the "state". The core question is thus how states (agency) are constituted by the generative and relational aspect of structure.

However, social structures do not exist independently of the activities and practices of agents. The deep structures of the state system exist only through the practices of states. This is in contrast to the structuralism of worldsystems theory with its position of an ontological priority of structure that determines or prescribes the actors' actions.

For Wendt, there are two relevant types of structure: social kinds are constituted by internal (organizational) structures and by external social structures. Both form a "constituting social structure", a set of relationships that define a social kind as such (Wendt 1998: 113).

With an emphasis on structuration theory and a holistic ideational perspective on structure, agents are mainly perceived as being constituted by external social structures. Internal organizational structures (Wendt calls them "anatomy") explain intrinsic causal powers and interests of agents. "Internal structure" refers to the "structure of a thing as such" (Wendt 1998: 112). Ex- 
amples for this include water being constituted by an atomic structure, human beings constituted by genetic structure and brain, or states constituted internally by organizational structures. Because of their internal structure ("anatomy"), actors are able to reflect on their activities. Reasonable action, reflection and adoption of behavior, and the ability to make decisions are all therefore possible (Wendt 1987: 359): Wendt applies the idea of internal structure to states and treats them as agents/persons - a position that has been heavily criticized but revised in his later work (for a critique and auto-critique of the treatment of the state as an agent/person see the contributions in Guzzini/Leander 2006 and Wendt 2006: 182).

The distinction of internal organizational structures and external social structures is demonstrated by using the example of state sovereignty: here, "internal structure" refers to exclusive political control and territorial monopoly and the legitimate use of violence. For example, "internal sovereignty", is treated as the intrinsic properties and causal powers of agents/states. "External sovereignty" exists because of states' mutual recognition of each other's sovereignty, a relational, generative aspect. Sovereignty is an institution (social structure) between states that is decisive for their rights. Sovereignty (as the external social relation) does not exist independently of or prior to these internal rights. On the other hand, internal rights do not exist when they have not been constructed by the external social relations of mutual recognition (see in more detail Wendt 1998: 114).

The ontological and conceptual interdependence of agents and structures as mutually constitutive agencies (as derived from structuration theory) thus has implications for explanation. We will learn about the specific approach to explanation in the next step. For this purpose, please keep in mind that Wendt is interested in the effects of (unobservable) ideational structures.

\section{Step 4: \\ Explanation}

\subsection{A question-driven approach}

Just as structuralist (holistic) and agent-based (individualist) approaches are distinct in their underlying ontology, structural and individualist approaches are distinct in their explanation of social action. An explanation that takes "structure" as the starting point (such as in the structuralist approach of world-systems theory) epistemologically usually draws on "understanding" 
(or interpretation). Recall what you have learned about interpretation in our learning unit on world-systems theory. An explanation that takes actors as the starting point (actor-centered approach, such as in neoinstitutionalism or new liberal theory) usually involves "explanation" (recall "explanation" in neoinstitutionalist and new liberal theory). For Wendt, such a distinction between an "insider approach to knowledge" (understanding) and an "outsider approach to knowledge" (explaining) is not helpful (Wendt 1998: 102-104). What he is criticizing is the "second-class status" for "understanding" in the social sciences (Wendt 1998: 104; for explaining and understanding see Hollis/Smith 1990: Explaining and Understanding International Relations). Traditionally, only "explaining" is associated with "science". This comprises an epistemological perspective that equates positivism with science - a position that has already been discussed in the Part 1 of this book.

Wendt takes a position against the view that there is a distinction between explanation and understanding as science and non-science. For him, explanation and understanding are not mutually exclusive (Wendt 1998: 103). Explanation and understanding should not be distinguished by drawing a line between "science" versus "non-science", but by the type of questions that the researcher is asking. Hence Wendt epistemologically suggests a "questionoriented approach" (Wendt 1998: 103). For him, non-causal inquiry (traditionally associated with understanding) can be explanatory: "The distinction between Explanation and Understanding is not one between explanation and description, but between explanations that answer different kinds of question, causal and constitutive" (Wendt 1998: 104, my italics).

BOTH are necessary elements of a complete explanation of social action (Wendt 1987: 362). This epistemological position will be elaborated in the next section in more detail.

\subsection{Causal and constitutive explanation}

In order to understand the question-oriented approach to explanation, it is important to keep in mind that scientific realism emphasizes "ontology before epistemology". In other words, as opposed to positivism, it is ontology and not epistemology that legitimates scientific practice (Wendt 1999: 91, see also Step 1). For the purposes of explanation, this reversal implies that the form of scientific explanation depends on the nature and causal properties of entities. In short, the type and form of explanation depends on ontology. Explanation in turn depends on the object of the question, on "what is taken to be problematic" (Wendt 1987: 362). 
The position of an ontological and conceptual interdependence of agents and structures as "mutually constitutive" (structuration theory) thus has implications for explanation. These implications emerge because, ontologically, both (agency and structure) are involved in the production of the social world (mutual constitution, co-determination).

Wendt makes a distinction between two types of questions:

1) "Why (did X happen rather than $Y)$ ?"

2) “How (is action X possible) and what?" (Wendt 1987: 362)

The former is a causal question to be answered by causal theory, the latter a constitutive question to be answered by constitutive theory.

\section{Causal theory: historical explanation}

Causal theory offers answers to Why-questions and requires a type of explanation in the format " $X$ causes $Y$ ". It is the classical form of explanation that rests on independent and dependent variables and establishes a causal relation between them. That is, $\mathrm{X}$ and $\mathrm{Y}$ exist independently of each other, $\mathrm{X}$ precedes $\mathrm{Y}$ in time, and without X, Y would not have occurred (Wendt 1998: 105). This type of causal explanation is an explanation of changes in the state of some variables. Factors of a change in the dependent variable exist independently and temporally prior to the transition. Causality is a relation of logical necessity to initial conditions and laws: if A, then B. It establishes a causal relation of temporally sequenced observed events. Explanation is thus a generalization about observable, sequenced behavior. Wendt calls it a "historical explanation" (see also Wendt 1998: 105).

\section{Constitutive theory: structural explanation}

The type of questions answered by constitutive theories is different; at the core are how-possible-questions and what-questions. Remember, underneath is the ontological position of a mutual constitution of agency and structure. An answer to a how-possible-question thus is to show how the properties of a social system are constituted. Constitutive theory offers knowledge about the conditions of possible natural and social kinds (Wendt 1998: 105). How-possible questions explain "how the elements of a social kind are composed and organized so that it has the properties that it does" (Wendt 1998: 112; also called "morphological" explanation, a term borrowed from Haugeland 1978).

In contrast to how-possible-questions, what-questions are requests for what it is that "instantiates" a phenomenon (not why). It is also called "explanation by concept". An example for a what-question is, What kind of po- 
litical system is the EU? (Wendt 1998: 105; Wendt 1999: 110). In the absence of the structures, the properties of a phenomenon would not exist. This is a "conceptual" necessity, NOT a causal one as described above for the case of causal theories and explanation. Wendt presents the example of the Cold War: the factors constituting the social kind "Cold War" define what a Cold War is (but no causal determination) (Wendt 1998: 106). Here the assumptions of causal explanation, i.e. dependent and independent variable plus temporal sequence (if A, then B), are not applicable. The factors constituting the Cold War do not exist apart from a Cold War nor do they ontologically precede the "Cold War" in time. Rather, according to Wendt, "when they come into being, a Cold War comes into being with them, by definition and at the same time" (Wendt 1998: 106; my italics). When the constituting conditions vary, the effects of constitutive structures vary. However, in this case the dependency in this variation is conceptual and not causal (Wendt 1998: 106).

Answers to constitutive questions of the what-type are descriptive but explanatory: They classify observations and "unify" them as parts of a whole (Wendt 1998: 110). "Explanations - what explain by subsuming observations under a concept - as opposed to a law" (Wendt 1998: 110, emphasis orig.). Explanation by concepts is thus about achieving explanatory power by "unification" (Wendt 1998: 111-112).

\section{Self-study (3)}

Learn more about the type "explanation by concept", that is, explanation by classifying and unifying complex phenomena under a concept, based on the example of the EU in the text of Wendt (1998). What is the EU? Make use of the concepts of "federation", "international state", "postmodern state", "confederation", "international regime", "governance without government", "neo-medievalism".

\section{Summary}

In line with scientific realism, a constitutive explanation is usually the identification and description of the underlying causal mechanisms of the structure that generated the social phenomenon. Underlying causal mechanisms make an event naturally necessary (ontology before epistemology). There is a need for abductive inference from (observable) phenomena to the existence of underlying naturally necessary relations between cause and effect (unobservable structures and their effects). Explanation thus is showing how the unobservable causal mechanism (which makes observable regularities possible) works 
(Wendt 1987: 354). Explanation is a process of abduction based on the question "what must exist for these events to happen?" It is about abstracting from the observable phenomena to the social and internal organizational structures which make the phenomena and events possible (Wendt 1987: 363).

A hint: These statements of explanation are easier to understand if you always bring them back to their ontological positions (remember the positions on agency and structure of structuration theory, and that ontology is before epistemology). For example, structures do NOT CAUSE the properties of social kinds (as being antecedent conditions for a subsequent effect); instead, they constitute these properties, they make those properties possible. Social kinds are constituted in a holistic way by the external structures in which they are embedded. What these kinds are (what) or how they come into being (how possible) is dependent on the specific social structure (Wendt 1999: 84). This is exactly the line that a constitutive explanation takes (because ontology before epistemology: epistemology reflects ontology).

In sum: Wendt holds that "ideas or social structures have constitutive effects when they create phenomena - properties, powers, dispositions, meanings, etc. - that are conceptually or logically dependent on those ideas or structures, that exist only 'in virtue of' them" (Wendt 1999: 88). A constitutive explanation describes causal mechanisms and inference ranging from (observable) phenomena to underlying causal mechanisms (unobservable structures and their constitutive effects), not subsuming events under laws and regularities (Wendt 1999: 82).

To ask constitutive questions is usually the domain of interpretivists, critical theorists and postmodernists, and requires interpretive methods (Wendt 1999: 85). Constitutive theories thus have a large descriptive dimension, but there is also an explanatory function for this type of theory.

In fact, what Wendt offers is epistemologically quite a "relaxed" position: "In my view the real lesson of realism in the realm of causal explanation is to encourage a pragmatic approach, with the methodological criterion being whatever helps us understand how the world works. Methods appropriate to answer one question may differ from those for another. Scientific realism corrects philosophies of science which say that all explanations must conform to a single model, but otherwise leaves science to scientists" (Wendt 1999: 83; my italics). 


\subsection{Epistemological interdependence: explaining by "structural- historical analysis"}

For Wendt, there is a need for an explicit epistemological and methodological distinction between the two "logics" of the questions: structural (constitutive) analysis explains the "possible" (how-possible and what-questions), while "historical analysis" explains the "actual" (why-question). However, explaining the "possible" and "what" by constitutive theory is only the first step. If the relevant activating conditions are not there, then they will not be actualized by the behavior of actors (Wendt 1998: 111, my emphasis). When dispositions are actualized, this is the domain of causal theories. In other words, causal theories explain actual behavior (historical explanation): Why-questions require answers to how-questions (Wendt 1987: 363, my emphasis).

Finally, Wendt perceives the two forms of explanation as distinct, but epistemologically interdependent (Wendt 1987: 363). His work is a plea for structural and historical explanations to be integrated into "structuralhistorical analysis" (Wendt 1987: 362, my italics; the term "structuralhistorical analysis" or "dialectical analysis" is borrowed from dependency theorists Cardoso and Faletto).

"Structural-historical analysis" in IR therefore involves abstract structural analysis by constitutive theory to explain the causal powers, practices and interests of states. It also necessitates concrete historical analysis (causal theory) to reveal the causal sequence of choices and interactions that lead to particular events (and to the reproduction of structures) (Wendt 1987: 364).

Structural analysis is thus only one part of a complete explanation; it uncovers "tendencies" for structures (possibilities) that can be "actualized" in a certain way. However, a structural explanation cannot offer generalization or prediction. This is instead the domain of historical analysis, the other part of a complete explanation. Historical analysis takes the interests and powers of agents as given and explains the emergence and persistence of structural conditions. Structural and historical analyses are distinct modes of explanation, as each explains the properties of the central objects of the other (Wendt 1987: 364). In order to provide a complete explanation, they must be integrated (epistemological interdependence). A complete explanation of state action therefore explains how the action was possible and why that possibility was actualized in a particular form at a given moment (Wendt 1987: 364).

Thus, for Wendt, structuration theory offers a research agenda for theorizing both actors (state agents) and system structures. Its core is comprised of structural analysis, which serves to theorize the conditions of the existence of state agents. The use of historical analysis complements structural analysis by 
explaining the genesis and reproduction of social structures by concrete action. However, Wendt is aware of the methodological difficulty this approach involves: the distinct modes of explanation are not simultaneously possible and need to take temporally either structures or agents as given in order to examine their respective explanatory effects. For a general critique of this problem of structuration theory, see Archer 1982, 1995. In fact, as reflected in Wendt's social constructivist "substantive" IR theory, he himself gives preference and priority to the structural aspect of explanation.

\subsection{Political relevance}

Wendt claims that a scientific realist approach to IR is "revolutionary" in that it gives scientific legitimacy to structural theorizing. At the same time, Wendt perceives his work as "critical" science in that it requires looking beyond the observable forms and appearances of phenomena and events and uncovering underlying unobservable social structures that generate the observable phenomena (Wendt 1987: 363, 370). In short: Phenomena in international politics are not always what they seem to be. The particular social constructivist perspective attached to the scientific realist understanding of science points to the ideational nature of social structures and their constitutive effects. In other words, transformative potentials exist in social structures because of their ideational quality of collectively shared ideas that constitute and hence make possible the social kinds. Constitutive analysis can then show that social kinds like "sovereignty" or the "state" can take different forms. This revelation opens up political possibilities that would otherwise not exist (Wendt 1999: 87). Wendt presents the example of the Cold War, during which a failure to account for the role of ideas in generating the conflict politically contributed to the "naturalization"/reification of the conflict itself. As a consequence, social scientists "were not helping to empower policymakers to end it, just to manage it." (Wendt 1998: 109). Only the "new thinking" of Gorbachev and hence "reflexivity" contributed to end the reification of the Cold War. For Wendt, this example at the same time provides the best evidence for the truth of a social constructivist perspective: "If shared ideas do not explain the Cold War, then policymakers could not end the Cold War by changing their ideas." (Wendt 1998: 109). Another example for Wendt is state sovereignty. In his view, a denaturalizing of sovereignty by uncovering it as "social" increases the ability of international society to make progressive changes by re-thinking sovereignty and transforming the shared ideas and meanings which underlie this particular social structure. We could thus change the 
meaning of a sovereignty that constitutes rights that enable states to repress their people or to keep out refugees (Wendt 1998: 114-115).

For Wendt, the lessons learned from a perspective based on a scientific realist and constructivist ontology combined with a question-driven approach to explanation means being aware of the "politics of questions". He adds that politics is always for someone and for some purpose. The criteria for adequate knowledge always depend on the question asked. This criteria is difficult to determine, as " (...) it is not individual scientists who naturalize things but whole communities of them, who may be organized, often for decades, around certain uncontested assumptions" (Wendt 1999: 89). Wendt's work can be read as strong encouragement to ask new questions. Unfortunately, in the academic literature, neither these critical aspects nor the political relevance of Wendt's social theory have usually been at the center of attention and debate.

\section{Self-study (4)}

Reflect on the practical political implications a social constructivist perspective holds for current problems of international politics.

Are theories of IR themselves part of the social construction of reality?

\section{Step 5:}

Check your understanding: Key aspects and review questions

Key aspects

\begin{tabular}{|l|l|}
\hline Core question & Social constructivist theory \\
\hline Assumptions about actors \\
and structure & $\begin{array}{l}\text { - A new systems theory in IR, based on a "new ontol- } \\
\text { ogy" }\end{array}$ \\
& $\begin{array}{l}\text { Unobservable structures are real, independent of the } \\
\text { quiry (scientific realism) } \\
\text { - Social structures are "made of ideas" (constructivist } \\
\text { ontology, idealism) } \\
\text { Social structures are not reducible to their constitu- } \\
\text { ent elements (ontological holism) }\end{array}$ \\
\hline
\end{tabular}




\begin{tabular}{|c|c|}
\hline & Social constructivist theory \\
\hline "Agency and structure" & $\begin{array}{l}\text { - No ontological priority of either agency or structure } \\
\text { - Ontological interdependence of agency and struc- } \\
\text { ture: Agents and structures are mutually constitutive, } \\
\text { but ontologically distinct entities } \\
\text { - Duality of structure: Social structures are constitutive } \\
\text { for actors and their interests, at the same time actors } \\
\text { constantly produce and reproduce structure } \\
\text { - Actors: Constituted by internal, organizational struc- } \\
\text { - } \text { tures ("anatomy") }\end{array}$ \\
\hline $\begin{array}{l}\text { Type of explanation and } \\
\text { notion of causality }\end{array}$ & $\begin{array}{l}\text { - Questions-driven approach to explanation: Form of } \\
\text { - } \quad \text { Conplanation depends on the type of questions } \\
\text { and what-questions. Causality as a relation in na- } \\
\text { ture/conceptual necessity } \\
\text { - Causal (historical) explanation: Why-questions. Cau- } \\
\text { sality as a relation in logic. } \\
\text { - Epistemological interdependence: Structural and his- } \\
\text { torical explanation to be integrated to "structural- } \\
\text { historical analysis" as a complete form of explanation }\end{array}$ \\
\hline $\begin{array}{l}\text { Approach to "levels of } \\
\text { analysis" }\end{array}$ & $\begin{array}{l}\text { - Micro-level structures: Actors and their interactions } \\
\text { (domain of causal theory) } \\
\text { - Macro-level structures/"external" social structures } \\
\text { (domain of constitutive theory) } \\
\text { But: Ontological and epistemological interdepend- } \\
\text { ence (see "nature of explanation" and "agency and } \\
\text { structure") }\end{array}$ \\
\hline Philosophy of science & $\begin{array}{l}\text { - Scientific realist ontology (unobservables are real and } \\
\text { legitimate objects of scientific inquiry; material- } \\
\text { ism/physicalism) } \\
\text { - Social constructivist ontology (idealism) } \\
\text { - Positivist epistemology (for causal, historical analysis } \\
\text { at the micro-level of actors and interactions) }\end{array}$ \\
\hline Normative perspective & $\begin{array}{l}\text { - Social constructivist perspective is "critical science". } \\
\text { - Transformative potentials in social structures due to } \\
\text { the ideational quality of collectively shared ideas. } \\
\text { - Reality is a social construction. Ideas make a differ- } \\
\text { ence: Opens up political possibilities (transformation } \\
\text { and change). } \\
\text { - Tendencies/possibilities inherent in structure to be } \\
\text { actualized by agents in a concrete way. }\end{array}$ \\
\hline
\end{tabular}




\begin{tabular}{|l|l|}
\hline $\begin{array}{l}\text { Theory and practice/role of } \\
\text { the scientist }\end{array}$ & $\begin{array}{l}\text { Social constructivist theory } \\
\text { object of scientific inquiry, an objective social fact. } \\
\text { - Social scientific theories can become part of their } \\
\text { world only in "moments of reflexivity" }\end{array}$ \\
\hline
\end{tabular}

\section{Review questions}

1. What are the core assumptions of "constructivist" ontology?

2. Explain the ontological position of a "mutual constitution" of agency and structure.

3. Outline the constitutive in contrast to the causal model for explaining international politics.

\section{Step 6:}

Final self-study and consolidation

In his more recent writings (Wendt 2006, Wendt 2010) Wendt formulates critical positions and presents a fundamental revision of the ontology of his Social Theory (1999). In light of the findings and philosophical interpretations of quantum physics, he revises his ontology in favor of a new position of non-duality of subject and object and a naturalism based not on classical physics (Cartesian Science) but on quantum physics. In so doing, Alexander Wendt intends to bring the discipline back to the very basic questions of philosophy of science: Is there a reality "out there" and what are the ontological features? Is reality material or ideational? Is reality independent of our mind? As has been introduced in Unit 3, many disciplines, including the natural sciences, philosophy, neurosciences, neurophilosophy, biophilosophy, philosophy of mind and sociobiology, are currently heavily debating these very general questions of mind/matter, ideas/material world. There is a rising awareness of the findings of quantum physics and their interpretations. It has been argued in Unit 3 that the debates about how to interpret these findings for the "macro-world" might set the parameters of meta-theoretical discourses in the years to come. Additionally, they might fundamentally call into question dual thinking in scientific inquiry and contribute to a major shift in the fundamental understanding of science in all disciplines. While this has been happening increasingly over the past decade, Wendt probably was and is the first to de- 
pict IR theory in light of the findings of quantum physics in recent years (2006, 2010).

\section{Self-study (5)}

Now please read Wendt 2006, Social Theory as Cartesian science: An auto-critique from a quantum perspective. In this "auto-critique", Wendt claims that the ontology of his Social Theory of International Politics (1999) is "probably false" (p.189). Why?

\section{Required Reading}

Ruggie, John G. 1998: What makes the world hang together? Neo-utilitarianism and the Social Constructivist challenge, in: International Organization 52: 5, 855-885

Wendt, Alexander 1987: The Agent-Structure-Problem in International Relations Theory, in: International Organization 41: 3, 335-370.

Wendt, Alexander 1999: Social Theory of International Politics. Cambridge: Cambridge University Press, Chapter 6 (246-313).

Wendt, Alexander 1992: Anarchy is what states make of it: The social construction of power politics, in: International Organization 46: 2, 391-425.

\section{Supplementary Reading}

Guzzini, Stefano/Leander, Anna 2006: Wendt's constructivism: A relentless quest for synthesis, in: Guzzini/Leander (eds.): Constructivism and International Relations. Alexander Wendt and his critics. New York: Routledge, 73-92.

Price, Richard 2008: The ethics of constructivism, in: Reus-Smit, Christian/Snidal, Duncan (eds.): The Oxford Handbook of International Relations. Oxford: Oxford University Press, 317-324.

Ulbert, Cornelia 2013: Social constructivism, in: Schieder, Siegfried/Spindler, Manuela (eds.): Theories of International Relations. London and New York: Routledge (forthcoming).

Wight, Colin 2006: Agents, Structures and International Relations. Politics as Ontology. Cambridge: Cambridge University Press.

\section{Recommendations for further reading}

Adler, Emanuel 2002: Constructivism in International Relations, in: Carlsnaes, Walter/Risse, Thomas/Simmons, Beth A. (eds.): Handbook of International Relations. London: Sage, 95-118.

Wendt, Alexander 1998: On constitution and causation in International Relations, in: Review of International Studies 24, 101-117. 
Wendt, Alexander 1999: Social Theory of International Politics. Cambridge: Cambridge University Press, Chapters 4 and 5.

Wendt, Alexander 1994: Collective Identity Formation and the International State, in: The American Political Science Review 88: 2, 384-396.

Wendt, Alexander 2006: Social Theory as Cartesian Science, in: Guzzini/Leander (eds.): Constructivism and International Relations. Alexander Wendt and his critics. New York: Routledge, 181-239.

Wendt, Alexander 2010: Flatland: Quantum Mind and the International Hologram, in: Albert, Mathias et al (eds.): New Systems Theories of World Politics, 279-310.

Onuf, Nicholas 1998: Constructivism: A User's Manual, in: Kubálkova, Vendulka/Onuf, Nicholas/Kowert, Paul (eds.): International Relations in a Constructed World. Armonk, London: Sharpe, 58-78.

Guzzini/Leander 2006 (eds.): Constructivism and International Relations. Alexander Wendt and his critics. New York: Routledge.

Kubálkova, Vendulka/Onuf, Nicholas/Kowert, Paul 1998 (eds.): International Relations in a Constructed World. Armonk, London: Sharpe.

\section{References in the text}

Archer, Margaret 1982: Morphogenesis versus Structuration: On combining structure and action, in: British Journal of Sociology 33, 455-483.

Archer, Margaret 1995: Realist Social Theory: The Morphogenetic Approach. Cambridge: Cambridge University Press.

Dessler, David 1989: What's at stake in the agent-structure debate?, in: International Organization 43: 3, 441-473.

Haugeland, John 1978: The nature and plausibility of cognitivism, in: The Behavioral and Brain Sciences 2, 215-226.

Jørgensen, Knud E. 2010: International Relations Theory. A New Introduction. London: Palgrave Macmillan.

Reuber, Paul et al (eds.) 2003: Kulturgeographie. Spectrum Akademischer Verlag.

Wight, Colin 2006: Agents, Structures and International Relations. Politics as Ontology. Cambridge: Cambridge University Press. 


\section{Instead of a conclusion: Invitation to a discussion}

As introduced in the preface, the book is based on the idea of learning and studying as an active process that requires a great deal of self-organization. The intention behind the didactical and methodical concept was to offer a structured concept for learning about theory and theories of International Relations, the application of which has been demonstrated in the book. The objective was to enable students to subsequently apply the concept themselves when learning about International Relations theory.

Having finished reading the book and your self-study by now, there are several options for proceeding with this process.

In line with the concept of "learning by example", the criteria for the structured learning process have been applied during the presentation of five selected theories of International Relations. You might be interested in learning and studying more than just those five selected theories of IR, thereby broadening your knowledge about the range of particular theoretical approaches to International Relations. There are a huge number of textbooks on theories of IR. You will notice that the range of theories included in the textbooks varies greatly depending on the concept of the book, the author's understanding of theory and, of course, the understanding of what IR as a science comprises and what not. Just for a start, it might be helpful to have a look at the textbooks on theories of IR presented at the end of this section.

For those students not as interested in particular theories of IR but who would instead rather focus on our discussion of theory and IR as a science, I recommend going back to our learning Units 2 and 3, re-reading the text and reflecting again on the arguments about the relevance of philosophies of science and of scientific world views for theoretical thought and the fundamental understanding of IR as a science. You might be interested in reflecting on such questions in courses on IR or related subjects in which you are currently enrolled.

In case you would like to exchange your ideas in a broader forum on iversity, you are invited to actively participate in a discussion on the role of theory and IR as a science. There you can exchange your ideas, share your 
knowledge and contribute to a debate about such fundamental questions as the role of science and scientific knowledge, not only in our contemporary world but, most importantly, for the future.

For admission to the debate on the platform iversity (iversity.org), please send an email with a short statement about your interests to SpindlerIRTheory-Book@yahoo.de. Depending on students' interests, there will be different working groups on a range of topics derived from our discussions in Units 2 and 3 of the book.

I hope you enjoyed reading the book and engaging in the recommended self-study activities as well as those that additional ones that go beyond the texts. Ideally, these activities should help you find your own means of accessing the world of theory of IR and a path worth following to learn more. I look forward to meeting you on iversity. I am also happy to receive any comments and suggestions for improving what has been written in the book.

\section{Manuela Spindler}

\section{References}

Burchill, Scott/Linklater, Andrew/Devetak, Richard et al. (eds.) 2009: Theories of International Relations. $4^{\text {th }}$ ed., Basigstoke: Palgrave.

Daddow, Oliver 2009: International Relations Theory. London: Sage Publications.

Dougherty, James E./Pfaltzgraff, Robert L. (eds.) 2009: Contending Theories of International Relations. A Comprehensive Survey. $8^{\text {th }}$ ed., New York: Longman.

Dunne, Tim/Kurki, Milja/Smith, Steve (eds.) 2010: International Relations Theories: Discipline and Diversity. $2^{\text {nd }}$ ed., Oxford: Oxford University Press.

Elman, Colin/Elman, Miriam Fendius 2003: Progress in International Relations Theory. Appraising the Field. Cambridge, MA: MIT Press.

Jackson, Robert H./Sørensen, Georg 2012: Introduction to International Relations. Theories and Approaches. $5^{\text {th }}$ ed., Oxford: Oxford University Press.

Jørgensen, Knud E. 2010: International Relations Theory. London: Palgrave.

Schieder, Siegfried/Spindler, Manuela (eds.) 2013: Theories of International Relations. London and New York: Routledge (forthcoming).

Schieder, Siegfried/Spindler, Manuela (eds.) 2010: Theorien der Internationalen Beziehungen. Opladen: UTB (in German). 


\section{Index}

Agency and structure 106, 112, 113, 114, $115,137,176,197,210,215,217,221$, 222

Allison, Graham T. 160, 173

American Institute of International Affairs 22

Anarchy 32, 129, 132, 133, 137, 138, 139, 154, 164, 209, 223

Ancient Greece 17, 23, 24, 39, 43, 44, 45, $46,51,56,76,79$

Angell, Norman 20

Annales School 177, 182

Antireductionism 57

Aquinas, Thomas 78

Aristarchos of Samos 70

Aristotle 39, 45, 56, 70, 75, 76, 77

Astrophysics 83, 91

Atomism 36, 46, 50, 52, 53, 55, 61, 77, 82, $83,84,92,97,110$

Atomist materialism 46

Authoritative allocation of values 27, 28, 30

Axelrod, Robert 153, 156

Bacon, Francis 44, 85

Balance of power 123

Balance-of-power politics 134

Balance-of-power theory 127, 135, 138, 148

Behavioral revolution 61, 63

Bell, John 95

Bhaskar, Roy 52, 202, 203

Biology 39, 51, 57, 86, 99

Biophilosophy 58, 222

Body and mind 84

Bohr, Niels 93, 94, 96

Born rule 94

Born, Max 93

Braudel, Fernand 176, 181, 182

British Institute of International Affairs 22

Capitalist world-economy 175, 183, 184, $185,186,187,188,189$
Carnap, Rudolf 55

Carnegie Endowment for International Peace 20,22

Cartesian science 103, 223

Cartesian-Newtonian science $67,70,80,85$, 88,99

Causal analysis 59

Causal effects 51, 133, 134

Causal relationship 58, 169

Causal theory $65,119,206,208,215,218$, 221

Causality 58, 87, 106, 113, 114, 115, 116, $118,137,155,169,171,191,221$

Cause-effect-relationships 58

CERN 47

Chemistry $39,46,57,71,96$

Christendom 17,78

Classical mechanics 82, 83, 90, 93, 94

Classical physics $46,57,83,89,90,92,93$, $95,96,97,98,222$

Cold War 52, 125, 127, 139, 160, 173, 174, 216, 219

Collective actors 28,111

Collective ideas 58, 208, 209

Collective knowledge 112, 195, 198, 208, 209

Collective representations 58, 209

Commercial liberalism 160

"Common" knowledge 209

Complementarity Principle 94

Comte, August 43

Concept of interdependence 141, 144, 150, 151,166

Concert of Europe 19, 188

Congress of Vienna 19

Constitutive explanation 195, 214, 216, 217

Constitutive theory 195,215

Constructivist turn 198, 201

Cooperation 29, 30, 100, 129, 141, 142, 143, $148,149,153,154,155,156,159,165$, $166,167,171$

Copenhagen interpretation 95

Copernicus, Nicolaus 67, 70, 80, 81 
Core-periphery 175,185

Corpuscle theory $82,83,90$

Correlates of War project 59

Correlation 59, 95

Cosmology 46, 71, 80, 83, 91

Council on Foreign Relations 22

Covering law model 60

Cyclical rhythms 175, 183, 185

Darwin, Charles 86, 87

Decision theory 110

Deductive-nomological model 59

Democritus 39, 46, 77, 82

Denkökonomie 56

Dependency theory 177

Dependent variable 58, 137, 152, 155, 167 , 169,215

Derrida, Jacques 200

Descartes, René 45, 67, 80, 81, 82, 83, 84, 86,103

Deutsch, Karl 160, 173

Dilthey, Wilhelm 57

Distribution of capabilities 131

Domestic or state-level analysis 117

Domestic politics 28, 166, 172, 173

Doyle, Michael W. 17, 34, 160, 172

Dual nature of light 67,90

Durkheim, Emil 54, 57, 209

Easton, David 27, 28, 34, 35

Einstein, Albert 67, 71, 83, 89, 90, 91, 92, 93, 96, 97, 104

Elementary particles 46, 67, 92

Elias, Norbert 84

Emergence 56, 68, 73, 74, 150, 218

Empire 17, 18, 177, 181, 184

Empirical experience 44, 48, 50

Empiricism 36, 44, 45

Epicurus 46, 77, 82

Epistemological 40, 42, 43, 44, 45, 47, 48, $49,50,53,56,57,58,61,62,63,72,75$, $76,77,80,83,107,108,109,110,112$, $113,114,115,118,175,176,178,198$, 199, 200, 206, 210, 214, 218, 221

Epistemological individualism 195, 206

Epistemological interdependence 195, 218 , 221

Euclid's Elements 77, 91

(European) idea of science 68

European Middle Ages 13, 16, 17, 18, 25, 67,78
(European) philosophy 68

European states system 14, 16, 19, 21, 25, 32

Experimental science $67,80,81$

Explanandum 59, 129, 147

Explanans 59, 129

Falsification 45

Faraday, Michael 90

Feudal state 16, 25

Feudal tenure system 17

Feyerabend, Paul 61, 102

Foedus pacificum 21, 143

Foreign policy $20,50,62,117,125,126$, $130,135,136,151,152,159,160,163$, $164,167,169,206,212$

Foucault, Michel 200

Freedom 21, 26, 29, 32, 33, 78, 79, 135, 145

Functionalism 143

Gadamer, Georg 57

Galileo $67,70,80,81$

Game theory 110, 126

General theory of relativity 91

Geneva Protocol 20

Geocentric (Ptolemaic) world view 69, 80

Geocentric model 70, 77

Geocentric world view 69, 70, 75, 76, 77, 80

Geocentrism 69

Geo-culture 185, 189

Great Powers 193

Great War 22, 23, 24, 26, 37

Greek antiquity 32, 39, 69, 71, 72, 74, 75, 76, $77,78,79,98$

Greek philosophy $40,74,75,76,78,79$

Grotius, Hugo 19

Haas, Ernst 143

Hague Conventions 20

Hayek, Friedrich 54

Hegemonic power 187,188

Hegemony 127, 148, 153, 187, 188, 189

Heidegger, Martin 57

Heisenberg Uncertainty Principle 95

Heisenberg, Werner 93, 95, 96, 103, 105

Heliocentric world view 69, 70, 80, 81

Heliocentrism 69, 70, 71

Hempel, Carl Gustav 59

Heraclitus 46, 77

Hermeneutics 65, 104

Herz, John 125, 128, 140

Higgs-Boson 47, 92

Historical explanation 195, 215, 218, 221 
Historical institutionalism 144

Historical system 180, 181, 182, 184, 185, $190,191,192$

Historicism 54, 62

Hobbes, Thomas 19, 21, 34, 44, 82, 87

Holistic ontology 197, 202, 209

Human mind 44, 45, 46, 51, 52, 58, 74, 77, $85,87,203,204,220$

Human rights 29, 30, 116, 167

Humanism 79, 103

Hume, David 44, 58

Husserl, Edmund 52

Hypotheses 38, 44, 45, 49, 50, 56, 70, 75, 76, 86,147

Idealism 45, 208, 220, 221

Ideas $14,19,23,39,44,45,46,48,51,52$, $60,68,69,71,72,74,77,78,79,82,83$, $85,90,91,92,112,126,142,160,195$, 198, 199, 204, 205, 206, 208, 209, 210, $217,219,220,221,222,225$

Ideational structure 208, 209

If-then-hypothesis 59

Individual action 53, 114

Individualism 36, 46, 47, 53, 54, 55, 61, 65, $83,84,99,110,113,119,137,154,155$, $171,176,202,206,210$

Inductive-statistical model 60

Industrial revolution $16,85,87,184$

Institutions $20,54,84,111,112,131,132$, $141,142,143,144,146,148,149,153$, $154,163,165,166,171,173,181,185$, 209

Instrumentalism 36, 49

Inter-democratic peace $59,116,159$

Interdependence $16,19,34,35,141,144$, $146,148,149,150,151,152,153,155$, $164,165,166,168,169,195,210,211$, $213,215,218,221$

International cooperation 149, 153, 165, 167

International institutions 20, 149

International interdependence 150, 153

International law 19, 21, 25, 68, 143

International peace movement 19

International Relations as science 9, 13, 22, 23,36

Interpretivist epistemology 197

Interstate interdependence 16

Issue-areas 145, 147

Italian states system 16
Kant, Immanuel 21, 86, 87, 90, 103, 105, 143, 159

Katzenstein, Peter J. 160

Keohane, Robert O. 144, 145, 146, 147, 148, $149,150,151,152,153,154,156,160$, 165,173

Kepler, Johannes 67, 70, 80, 81, 83

Kissinger, Henry 125

Kondratieff-cycle 186, 188

Kuhn, Thomas 61, 66

Lakatos, Imre 61, 66, 147

Laplace, Pierre Simon 85

Law-like explanation 36,58

League of Nations 21, 22, 24

Leibniz, Gottfried Wilhelm 45, 86, 103, 105

Level of analysis problem 115,116

Liberal theory $9,84,110,158,159,160$, $161,162,163,164,165,166,167,168$, $169,170,171,172,173,176,192,210$, 214

Linguistic turn 198

Locke, John 44, 87

Logical atomism 55

Logical positivism 55

Logical reasoning 75,78

Longue durée 175, 182, 183, 184

Luther, Martin 79

Lyotard, Francois 200

Mach, Ernst 39

Machiavelli, Niccolò 18

Macro and micro 180

Macro-level structures 221

Magnus, Albertus 78

Materialism 36, 45, 103, 104

Matter 25, 26, 38, 45, 46, 47, 48, 67, 74, 77, $82,84,89,90,91,92,93,94,95,97,98$, $99,142,167,179,181,199,205,206$, 222

Maxwell, James C. 90

Mechanical world view 82, 83, 92

Medieval European state 17

Medieval tenure system 18

Meta-theory 36, 39, 40, 41, 42, 62, 107, 199, 211

Methodological holism 54, 113

Methodological individualism 54

Methodological nationalism 111

Methodological statism 111 
Methodology 36, 41, 42, 43, 44, 47, 50, 53, $55,56,57,58,61,62,75,81,83,84,85$, $86,106,107,115$

Meyer, John 144, 157

Micro-level structures 221

Military liberalism 160

Mill, John Stuart 52, 56, 159

Milner, Helen 168, 173, 174

Mitrany, David 143

Modern Age 13, 18, 80

Modern state 13, 18, 19, 20, 25, 26, 27, 32, $68,88,142$

Modern states system $13,24,25,26,68,88$

Modern world-system 175, 181, 184, 185 , $186,187,188,189,193,194$

Moments of reflexivity 207, 222

Monopoly of power 27, 28, 30

Moravcsik, Andrew 139, 159, 160, 161, 162, $163,164,165,166,167,168,169,170$, 172,173

Morgenthau, Hans 125

Multi-causal explanation 170

Multilateralism 125, 153, 155

Mutual constitution 114, 195, 210, 211, 215, 222

Nationalism 16, 19

Natural kinds 205, 206

Natural sciences 37, 39, 43, 46, 47, 57, 58, $76,81,84,85,86,87,88,89,100,180$, $203,205,222$

Naturalism 36, 45, 203, 206, 222

Nature of light 83, 90, 93

Neofunctionalism 143, 160

Neoliberal institutionalism 144

Neoliberalism 144

Neorealist theory $30,110,124,125,127$, $128,129,130,132,133,134,135,136$, $138,139,144,145,148,149,152,155$, $159,164,169,202,210$

Neurophilosophy 58, 222

New liberalism 158, 161, 167, 170

New ontology 202, 203, 208, 210, 220

New or neoinstitutionalism 143

New physics 67,88

New scientific world view $67,85,87,88,89$, 98

Newton, Isaac $67,70,80,82,83,84,86,90$, 91, 93, 103, 105

Newton's law of gravity $70,83,85$

Niebuhr, Reinhold 125

Nominalism 36, 51, 52
Non-state actors $28,29,30,32,111,128$, 199

Normative perspective $117,124,148,150$, 159

Norms 28, 31, 58, 111, 112, 128, 142, 198, 199, 208, 209, 211

Nye, Joseph 144, 145, 150, 151, 152, 153, $156,160,165,173$

“Objective" knowledge 69, 73, 99

Objectivism 49, 206

Object-subject distinction 204, 207

Observables $44,48,49,50,51,53,56,60$, 203, 204

Observation $43,44,46,48,55,58,69,71$, $75,76,78,80,81,93,94,95,98,114$, $116,126,177,178,204$

Ockham, Wilhelm of 56,78

Ockham's razor 56

Old institutionalism 143

Ontological entities 52, 115

Ontological individualism 53, 202

Ontological naturalism 45

Ontology 36, 41, 42, 44, 45, 46, 47, 48, 49, $51,52,55,62,75,84,97,98,99,107$, $109,110,112,119,176,197,198,199$, 200, 201, 202, 203, 204, 205, 207, 208, 209, 210, 211, 213, 214, 216, 217, 220, $221,222,223$

Operationalism 36, 49

Operationalization 50

Oppenheim, Paul 57, 59, 66

Orders of thought $41,61,68,71,84,86,87$, $98,101,107$

Paris Peace Conference 22, 32

Parsimonious theory 56

Particle physics $47,84,92$

Particularism 36, 46, 47, 50, 53, 61

Particulars 46, 47, 49, 50, 52, 53, 54, 55, 58, 83

Peace of Westphalia 18, 25, 186

Peace Societies 19

Peaceful change 148, 149, 154

Peirce, Charles 52

Phenomenalism 36, 48

Philosophical materialism 195, 205

Philosophy of being 41

Philosophy of science $5,6,23,36,37,39$, $40,41,42,43,47,48,50,52,58,60,61$, $62,63,64,68,71,72,73,75,77,85,87$, 
$101,107,110,115,116,117,124,130$, $139,172,176,178,180,192,197,198$, $199,200,201,202,203,222$

Physicalism 36, 45, 47, 195, 205, 221

Planck, Max 90, 93, 96

Plato 39, 45, 46, 51, 75, 76, 77

Polanyi, Karl 177, 181

Policy advice 31, 136, 151, 156, 176, 177

Policy interdependence 165

Political authority 27, 29, 187

Political relevance 195, 219

Political theory $18,21,68,82,100,126,142$

Politics of interdependence 151, 152

Popper, Karl 39, 61, 66

Positivism 37, 40, 42, 43, 44, 45, 46, 47, 48, $49,52,53,58,59,60,61,62,63,64,72$, $73,77,85,87,139,147,176,191,197$, 200, 203, 204, 205, 214

Positivist science $36,44,45,47,48,49,50$, $52,53,55,56,58,59,60,62,73,84$, 117,178

Postmodern theories 198

Post-positivism 62, 197, 200

Prebisch, Raúl 177, 185

Prediction 36, 58, 60, 116, 136, 146, 158, 167,218

Pre-Socratics 75

Ptolemaic model 70

Ptolemy 69, 75

Putnam, Robert 57, 66, 159, 160, 169, 170, 172,173

Quantum entanglement 95, 96

Quantum mechanics 90, 93, 94, 95, 96, 97

Quantum technology 96

Quantum teleportation 95

Quantum theory 89, 90, 93, 198

Question-driven approach 195, 213, 220

Rational actors $110,147,152,153,167$

Rational choice institutionalism 144

Rational choice 152

Rationalism 44, 76

Rationality assumption $137,147,154,171$

Realism 37, 52, 62, 65, 124, 125, 130, 139, $141,144,145,146,147,149,150,198$, 202, 203, 204, 205, 207, 210, 214, 216, 217,220

Realpolitik 135, 138, 149

Reductionism 36, 55, 56, 57, 58, 84, 102, 105
Regime theory 144, 153, 197

Regional integration 143, 160

Renaissance $67,78,79,82$

Republican liberalism 160

Ricardo, David 19

Risse, Thomas 64, 65, 66, 160, 161, 173, 174,223

Roman empire 16

Rosenau, James 61, 64, 66, 160

Royal Institute of International Affairs 22

Russell, Bertrand 52, 55

Russett, Bruce 160

Rutherford, Ernest 92

Schlick, Moritz 55

Scholasticism 51, 78

Schroedinger equation 93

Schroedinger, Erwin 93, 96, 103

Science and religion 75,86

Scientific knowledge 226

Scientific method $45,57,74,81$

Scientific realism 52, 202, 203, 204, 207

Scientific revolution $66,67,80$

Secular trends 189

Security 19, 21, 26, 29, 31, 32, 33, 62, 125, $128,129,134,136,138,145,149,151$, 155,167

Security dilemma 128, 129, 134, 136, 138

Self-help system 129,149

Smith, Adam 19, 44, 159

Social construction of "anarchy" 197

Social constructivist theory $116,176,197$, 198

Social kinds 204, 205, 206, 207, 208, 209, $212,215,217,219$

Social world $57,58,60,114,176,191,192$, $205,206,207,208,211,215$

Societal actors 111, 161, 162, 164, 167, 169

Sociological institutionalism 144

Sociological liberalism 160

Sovereign state $13,18,19,20,24,25,32$, $132,179,187$

Sovereignty 19, 25, 26, 142, 149, 186, 199, $209,212,213,219$

Spacetime 91

Special theory of relativity 90,91

Spinoza, Baruch de 45

State as a representative institution 163

State individualism 110

State of war 18, 21

State preferences $162,163,165,166,167$, 169,170 
State-society relations $159,161,164,166$, 170

Structural context 111, 112, 128, 211

Structural explanation 150, 195, 215, 218

Structural realism 130, 144, 145, 146, 147, 149,150

Structural times 182

Structural-historical analysis 195, 218, 221

Structuralism 54, 113, 130, 200, 202, 211, 212

Structuration theory 202, 210, 211, 212, 213, $215,217,218$

Structures of knowledge 178

Subject-object distinction 207

Subsumption theory 60

System theory 127, 130, 133, 135, 193

System-level analysis 117

Territorial state 20, 25, 32, 142

The Hague Peace Conferences 20

Theories of foreign policy 126

Theory and praxis $180,190,192$

Theory of forms $46,51,77$

Theory of ideas 46, 77

Theory of rational action 54

Third Debate 197, 200

Thirty Years War 18, 188

Thucydides 17, 34, 124

Time and space 46, 52, 90, 182, 211

TimeSpace 182

Transformation of anarchy 155

Two-level games 169, 170, 172, 173

"Types" of states 25

Understanding 5, 6, 13, 14, 23, 28, 32, 36, $37,38,39,40,42,45,47,54,57,58,60$, $62,63,65,68,72,73,74,80,81,83,87$, $89,100,107,108,115,116,117,123$, $137,141,144,149,154,158,160,171$, $175,178,182,187,191,196,197,203$, $207,210,213,214,219,220,222,225$

Unidisciplinary 179

United Nations 21, 143, 188
Unity of science 36,57

Universals 46, 50, 51, 52, 53, 56

Universals controversy 53

Universe as a machine 82

Unobservable 195, 200, 201, 202, 203, 204, 207, 208, 213, 216, 217, 219

US's Carnegie Endowment for International Peace 20

Utilitarianism 85, 223

Utility-maximization 110

Value-neutral 48

Variables 48, 49, 51, 56, 59, 126, 131, 149, $163,180,215$

Verschränkung 95

Vienna Circle 39, 52, 55

Wallerstein, Immanuel 176, 177, 178, 179 , $180,181,182,183,184,185,186,187$, $188,189,190,192,193,194,197$

Waltz, Kenneth 116, 119, 124, 125, 126, $127,128,129,130,131,132,133,134$, $135,136,138,139,140,144,146,159$, $169,201,208$

Weber, Max 54, 57, 60, 66

Welfare 19, 21, 25, 26, 27, 29, 31, 32, 33, $145,151,155,162,177,189$

Wendt, Alexander 57, 65, 105, 116, 119 , 197, 198, 199, 200, 201, 202, 203, 204, 205, 206, 207, 208, 209, 210, 211, 212, $213,214,215,216,217,218,219,220$, $222,223,224$

Westphalian order 25,142

Wolfers, Arnold 125

World government 28, 142

World view 46, 69, 70, 71, 72, 74, 76, 77, $78,79,80,82,85,87,88,89,95,97,98$, $99,100,102,103,104,107$

World War I 14, 20, 21, 22, 32

World-economy 184, 185, 186, 187, 188

World-system analysis 179

Young's double slit experiment 93 